\title{
Concentration and Size Distributions of Nanoparticle Emissions during Low Temperature Combustion using Fuels for Advanced Combustion Engines (FACE)
}

\author{
Peter Bonsack \\ West Virginia University
}

Follow this and additional works at: https://researchrepository.wvu.edu/etd

\footnotetext{
Recommended Citation

Bonsack, Peter, "Concentration and Size Distributions of Nanoparticle Emissions during Low Temperature Combustion using Fuels for Advanced Combustion Engines (FACE)" (2012). Graduate Theses, Dissertations, and Problem Reports. 4834.

https://researchrepository.wvu.edu/etd/4834

This Thesis is protected by copyright and/or related rights. It has been brought to you by the The Research Repository @ WVU with permission from the rights-holder(s). You are free to use this Thesis in any way that is permitted by the copyright and related rights legislation that applies to your use. For other uses you must obtain permission from the rights-holder(s) directly, unless additional rights are indicated by a Creative Commons license in the record and/ or on the work itself. This Thesis has been accepted for inclusion in WVU Graduate Theses, Dissertations, and Problem Reports collection by an authorized administrator of The Research Repository @ WVU. For more information, please contact researchrepository@mail.wvu.edu.
} 


\title{
Concentration and Size Distributions of Nanoparticle Emissions during Low Temperature Combustion using Fuels for Advanced Combustion Engines (FACE)
}

\section{Peter Bonsack}

\author{
Thesis submitted to the \\ College of Engineering and Mineral Resources \\ at West Virginia University \\ in partial fulfillment of the requirements \\ for the degree of
}

\begin{abstract}
Master of Science
in

Mechanical Engineering

Committee Members:

Mridul Gautam, Ph.D., Chair

Gregory J. Thompson, Ph.D.

Jan Czerwinski, Dr. techn.
\end{abstract}

Department of Mechanical and Aerospace Engineering

Morgantown, West Virginia

2012

Keywords: Nanoparticles; Diesel; Low Temperature Combustion; FACE Diesel Fuels Copyright 2012 Peter Bonsack 


\section{ABSTRACT \\ Concentration and Size Distributions of Nanoparticle Emissions during Low Temperature Combustion using Fuels for Advanced Combustion Engines (FACE)}

\section{Peter Bonsack}

Due to tightening emission legislations, both within the US and Europe, including concerns regarding greenhouse gases, next-generation combustion strategies for internal combustion (IC) diesel engines that simultaneously reduce exhaust emissions while improving thermal efficiency have drawn increasing attention during recent years. In-cylinder combustion temperature plays a critical role in the formation of pollutants as well as in thermal efficiency of the propulsion system. One way to minimize both soot and $\mathrm{NO}_{\mathrm{x}}$ emissions, is to limit the incylinder temperature during the combustion process by means of high levels of dilution via exhaust gas recirculation (EGR) combined with flexible fuel injection strategies. However, fuel chemistry plays a significant role in the ignition delay; hence, influencing the overall combustion characteristics and the resulting emissions. The Advanced Vehicles, Fuels, and Lubricants (AVFL) committee of the Coordinating Research Council (CRC) specified and formulated a matrix of nine test fuels for advanced combustion engines (FACE) based on the variation of three properties: cetane number, aromatic content, and 90 percent distillation temperature.

The primary objective of this study was to study the effects of various FACE diesel fuels on the nanoparticle formation during low temperature combustion processes. An experimental study was performed at West Virginia University's Engine and Emission Research Laboratory (EERL) to determine the FACE property effects on the low temperature combustion (LTC) process in a turbo-charged GM 1.9L light-duty compression ignition engine under steady-state operating conditions (2100rpm/3.5bar BMEP). A comprehensive test matrix was developed including intake oxygen $\left(\mathrm{O}_{2}\right)$, as a surrogate for EGR fractions, and rail-pressure parameter variations during single injection timing settings. Furthermore, the influence of varying injection 
timing and fuel fraction during split injection strategy onto nanoparticles was investigated as well.

Diluted exhaust gas emissions extracted from the CVS tunnel were measured continuously using a Horiba MEXA-7200D gaseous emissions analyzer and included total hydrocarbons (THC), carbon monoxide (CO) as well as carbon dioxide $\left(\mathrm{CO}_{2}\right)$ and oxides of nitrogen $\left(\mathrm{NO}_{\mathrm{x}}\right) . \mathrm{NO}_{\mathrm{x}}$ and $\mathrm{O}_{2}$ concentrations were measured in the raw exhaust and intake manifold using Horiba MEXA-720 $\mathrm{NO}_{\mathrm{x}}$ analyzers, respectively.

Furthermore, the AVL Micro Soot Sensor, consisting of a measuring unit and an exhaust conditioning unit, was used to measure the soot concentration in the raw exhaust based on the photoacoustic measurement method.

Nanoparticle concentration and size distributions were determined using the Exhaust Emissions Particle Sizer (EEPS ${ }^{\mathrm{TM}}$ ) spectrometer from TSI Inc. (model 3090) as well as the Differential Mobility Spectrometer (DMS) from Cambustion (model DMS500). Continuous exhaust gas samples were extracted from the CVS tunnel (dilution ratio DR $\approx 10$ ) and routed through a double stage dilution system using ejector type dilutors. The first stage was maintained at $140^{\circ} \mathrm{C}(\mathrm{DR} \approx 6)$ in order to suppress condensation and particle nucleation phenomena, while the second stage utilized dilution air at ambient temperatures $\left(\sim 25^{\circ} \mathrm{C}, \mathrm{DR} \approx 11\right)$.

Particle number concentration increased with a simultaneous increase in particle diameter for both single and split injection strategies in case of FACE diesel fuels with increasing $\mathrm{CN}$ for the low $\mathrm{NO}_{\mathrm{x}}$, low soot and highest BTE tests. Advancing the start of injection timing led to a decrease in particle number concentration, but a simultaneous increase in nanoparticle emissions was observed for low $\mathrm{CN}$ fuels. 
Opportunity is missed by most people because it is dressed in overalls and looks like work.

- Thomas Edison 


\section{ACKNOWLEDGEMENTS}

First, I would like to thank my parents for their support and encouragement to make the step over the pond to the United States after I told them about my plans to get a Master's degree. I appreciate a lot what you taught me during my childhood about life and work that still benefits me today.

Next, many thanks to Dr. Mridul Gautam: you've been an excellent advisor and I am deeply grateful that you gave me the opportunity to work with you and your dedicated group. I will always keep in mind that there is a way to write down groundbreaking ideas even without any real paper at hand - thanks to napkins.

I would also like to thank the remainder of my committee - Dr. Gregory Thompson and Dr. Jan Czerwinski for their critical review of this document. Special thank goes to Dr. Jan Czerwinski for his support and encouragement to join "Team Gautam" in Morgantown.

I next like to thank the chief engineer for advanced engine operation, Ross Ryskamp, who was a dedicated fellow during uncountable and long laboratory hours, and supported me with the important task of brewing coffee during night-shifts. Thanks to him, I can assure everybody that the lab even looks nice at night and during sunrise. Further, I would also like to thank Brad Ralston, Pragalath (aka Paul) Thiruvengadam and Prabash Abeyratne for their help in the test campaign, so I could also go to my classes.

A special thank also goes to Marc Besch. I greatly appreciated your support along the stony path towards my Master's degree, from the application process and class assistance to instrument troubleshooting and even long Matlab lessons encouraging me to code it the "right" way. Thanks also for being a challenging squash opponent and for lots of good discussions over nice dinners.

Thanks are additionally directed to Oscar Delgado: you made our own office coffee brewery reality and always kept an eye on the coffee powder supply.

Last, but not least, I like to thank all the other people that were also responsible for the great atmosphere in "Team Gautam": Dan Carder - for consistently pushing me into interesting topics to review; Arvind Thiruvengadam - for your support whenever I had a question about particles; Hemanth Kappanna - for showing me the Wild and Wonderful West Virginia in your 
Camry (aka Abhi); Alessandro Cozzolini, Daniele Littera, Mario Velardi, and Gennaro Campitelli - for awesome Italian dinners at Easter and many other occasions; Greg Yoder - for finally washing the Broncos jersey; and Adam Sayres - for teaching me the Appalachian accent. 


\section{TABLE OF CONTENTS}

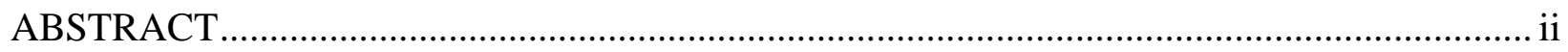

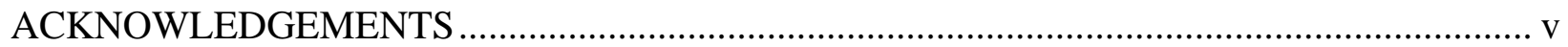

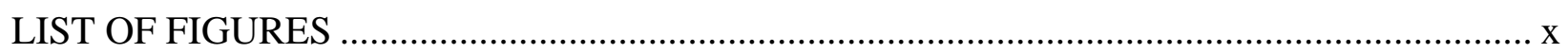

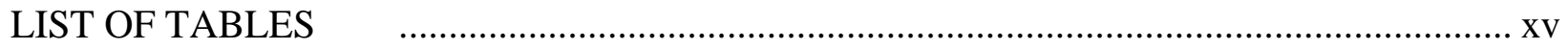

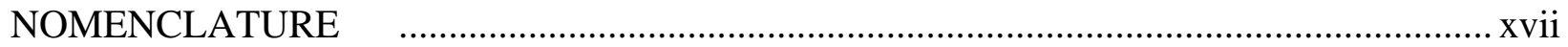

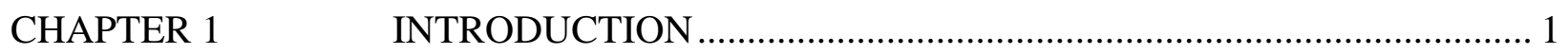

$1.1 \quad$ Objectives ..................................................................................... 2

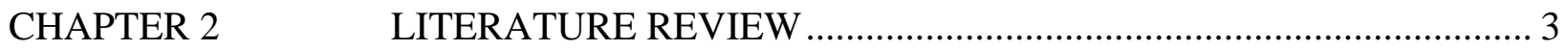

2.1 Advanced Compression-Ignition Combustion Modes ............................... 3

2.1.1 Homogenous Charged Compression Ignition (HCCI) ............................... 4

2.1.2 Premixed Charge Compression Ignition (PCCI) ……............................... 6

2.1.3 Low Temperature Combustion (LTC)................................................. 6

2.2 Initiating and Controlling Advanced Combustion Strategies................... 7

2.2.1 Engine Control System....................................................................... 8

2.2.2 Engine Hardware Modifications.......................................................... 16

2.3 Analysis of Physical and Chemical Properties for FACE Diesel Fuels . 20

2.3.1 Cetane Number / Index...................................................................... 20

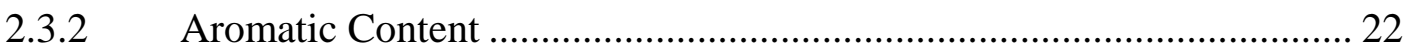

2.3.3 90 Percent Distillation Temperature (T90).......................................... 23

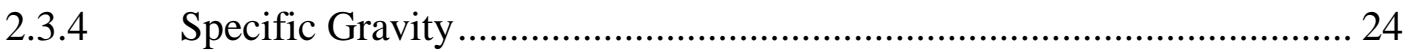

2.3.5 Net Heat of Combustion ..................................................................... 24

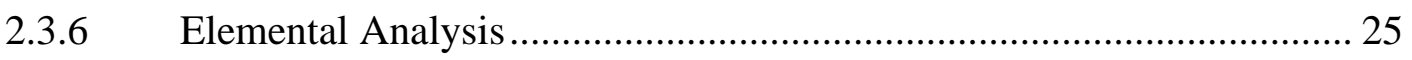

2.3.7 Further ASTM Standard Test Methods used for FACE Diesel Fuels .... 25

2.4 Effect of Fuel Properties on Advanced Combustion Strategies ............. 26

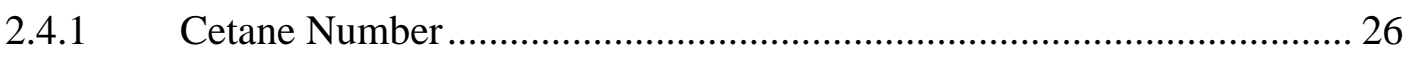

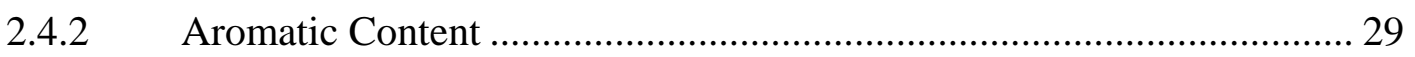

2.4.3 90 Percent Distillation Temperature ....................................................... 30

2.5 Diesel Particulate Matter …………………….................................... 30 
2.5.1 Formation of Diesel Particulate Matter ............................................ 31

2.5.2 Particle Size Distribution................................................................. 32

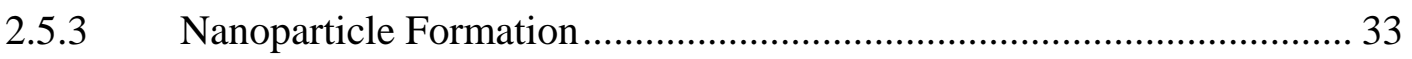

2.6 Particulate Matter Number Concentration and Size Distribution in Advanced Combustion Modes ............................................................. 35

CHAPTER 3

EXPERIMENTAL SETUP ....................................................... 38

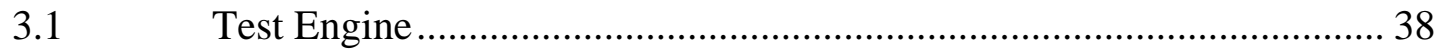

Laboratory Instrumentation .......................................................... 40

3.2.1 Constant Volume Sampling (CVS) Dilution Tunnel............................ 40

3.2.2 Gaseous Emissions Measurement ................................................... 40

3.2.3 Particulate Matter Sampling Setup ................................................... 45

3.2.4 In-Cylinder Pressure Measurement .................................................. 51

3.2.5 Control of Engine Operating Parameters .......................................... 52

3.2.6 Laboratory and Dynamometer Control ........................................... 52

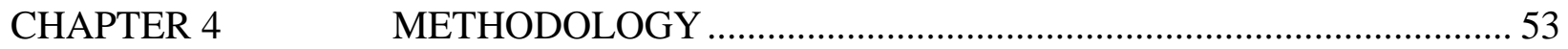

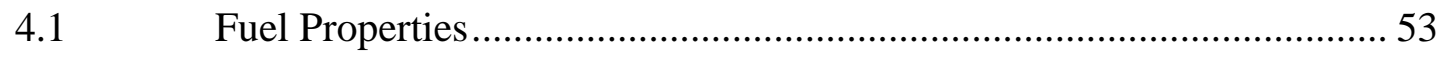

4.2 Particle Concentrations and Size Distributions ................................. 55

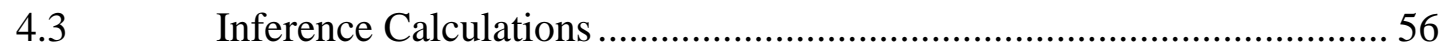

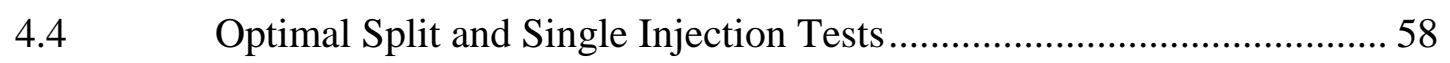

4.4.1 Split Injection Control Strategy ...................................................... 59

4.4.2 Single Injection Control Strategy ................................................. 59

4.5 Low, Medium and High Cetane Fuel Comparison............................... 60

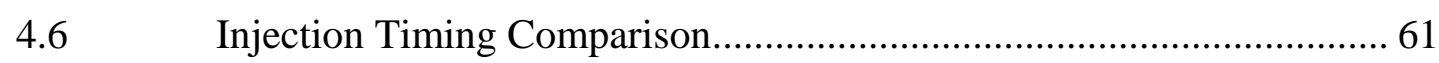

4.7 Rail Pressure and Intake Oxygen Concentration during Single Injection

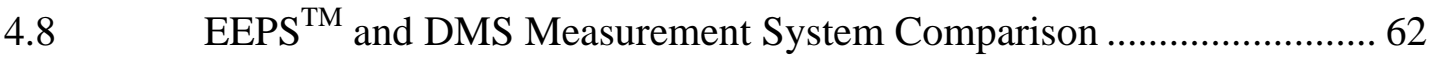

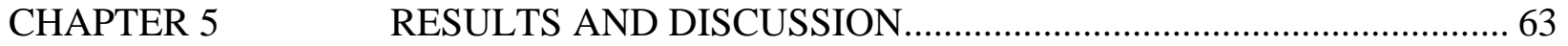

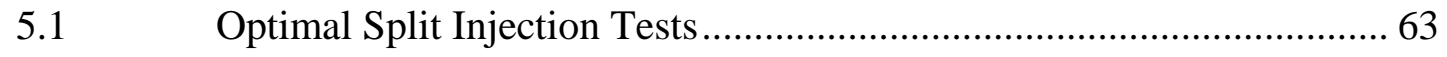

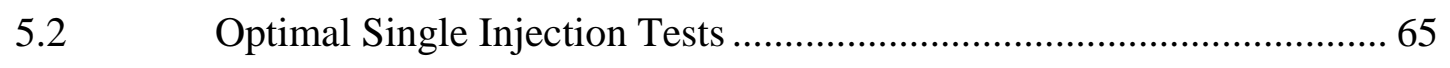

5.3 Low, Medium and High Cetane Fuel Comparison............................... 67

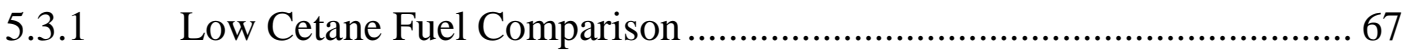


5.3.2 Medium Cetane Fuel Comparison ................................................. 69

5.3.3 High Cetane Fuel Comparison ....................................................... 71

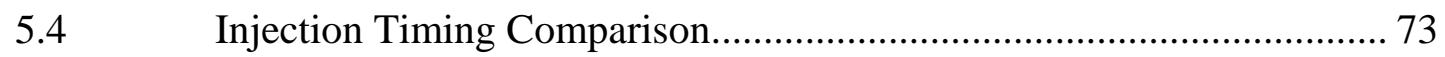

5.5 Rail Pressure and Intake Oxygen Concentration during Single Injection

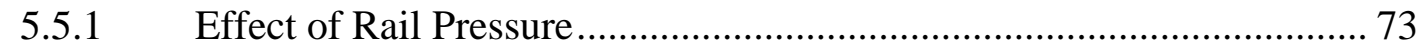

5.5.2 Effect of Intake Oxygen Concentration............................................ 76

CHAPTER 6 CONCLUSIONS AND RECOMMANDATIONS …........................ 78

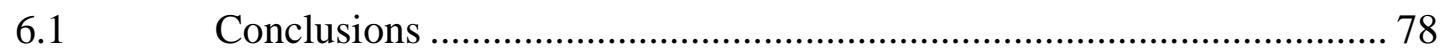

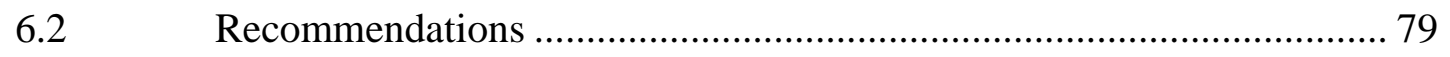

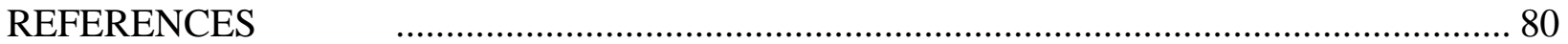

APPENDIX A $\quad$ SPLIT \& SINGLE INJECTION TEST MATRICES .......................... 85

APPENDIX B $\quad$ EEPS $^{\mathrm{TM}}$ AND DMS MEASUREMENT SYSTEM COMPARISON .... 89

APPENDIX C ADDITIONAL PARTICLE SIZE DISTRIBUTIONS ....................... 92 


\section{LIST OF FIGURES}

Figure 1 Local Temperature and Equivalence Ratio for Advanced Combustion Modes [11] ...... 4 Figure 2 Typical Heat Release Rate (HRR) from HCCI Combustion of n-Heptane Fuel 5

Figure 3 Comparison of Conceptual Model for Conventional Combustion with LTC [22] .......... 7

Figure 4 Cylinder Pressure (a) and HRR (b) for Retarded SOI Timing [24] ............................... 8

Figure 5 Exhaust Emissions and Fuel Consumption vs. Injection Timing [27] ............................ 9

Figure 6 UNIBUS Comparison with Conventional Diesel Injection Strategy [8]........................ 11

Figure 7 Effect of Injection Pressure on $\mathrm{NO}_{\mathrm{x}}$ and Soot Emissions [29] ...................................... 12

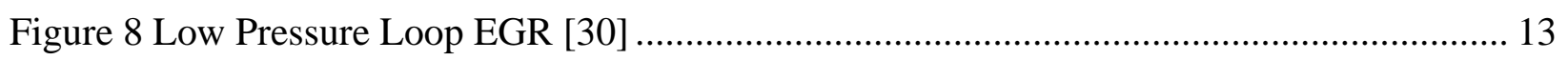

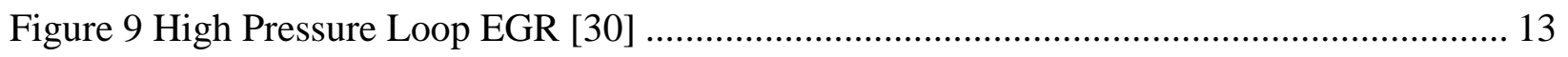

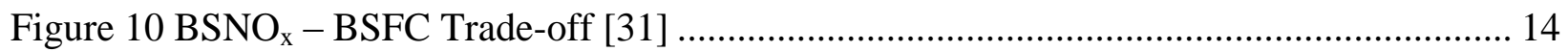

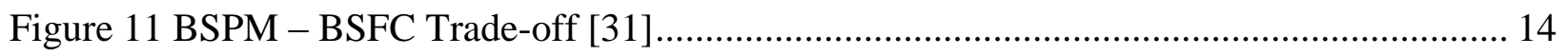

Figure 12 Ignition Delay vs. Additional Intake Valve Opening with Varying EGR Rate

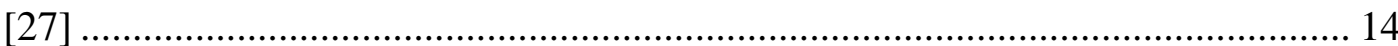

Figure 13 Maximum PRR vs. Additional Intake Valve Opening with Varying EGR Rate

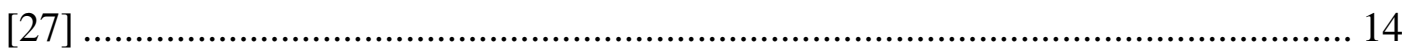

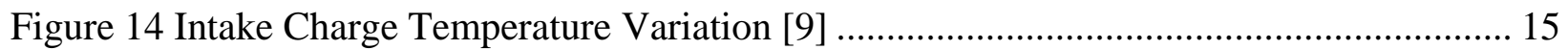

Figure $15 \mathrm{NO}_{\mathrm{x}}$ vs. Intake Pressure Varying IVC Timing and EGR [10]...................................... 16

Figure 16 PM vs. Intake Pressure Varying IVC Timing and EGR [10] ..................................... 16

Figure 17 Compression Ratio Variation [9]......................................................................... 17

Figure 18 Impact of Various Piston Bowl Designs on Fuel Consumption, Soot and $\mathrm{NO}_{\mathrm{x}}$

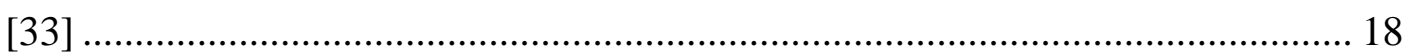

Figure 19 Variation of Valve Lift for Each Additional Intake Valve Opening [27] ................... 18

Figure 20 Exhaust Emissions and Fuel Consumption for Additional Intake Valve Opening

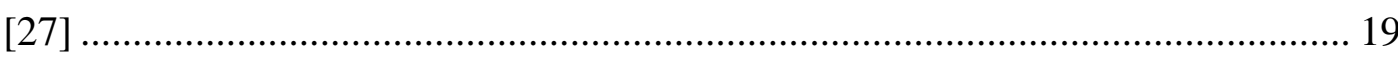

Figure $21 \mathrm{NO}_{\mathrm{x}}$ Emissions for Different Spray Cone Angles [34] ................................................ 20

Figure 22 HC Emissions for Different Spray Cone Angles [34] ................................................ 20

Figure 23 Cetane Method Test Engine Assembly [36]............................................................. 21 
Figure 24 Pictorial Aid for Identification of Chromatographic Boundaries [41] ..................... 23

Figure 25 Apparatus Assembly using a Gas Burner [39] .................................................... 24

Figure 26 Ignition Delay (a) and Combustion Noise (b) vs. SOI Timing for FACE Diesel

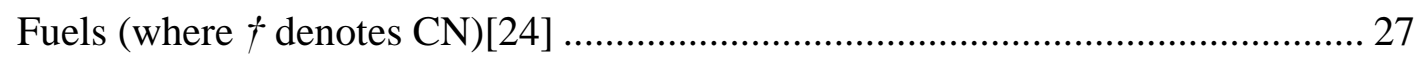

Figure $27 \mathrm{NO}_{\mathrm{x}}, \mathrm{PM}$ and $\mathrm{CO}$ Emissions vs. SOI Timing for FACE Diesel Fuels [24] ............... 28

Figure 28 HC Emissions and BSFC vs. SOI Timing for FACE Diesel Fuels [24] ................... 28

Figure 29 Aromatic Effect at Low T90 on Ignition Delay and Soot Emissions at Medium

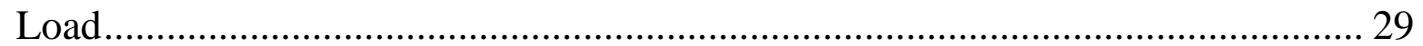

Figure 30 Aromatic Effect on Ignition Delay and Soot Emissions at High Load [49]............... 29

Figure $31 \mathrm{CN}$ and T90 Effects on Ignition Delay and Soot Emissions at Medium Load [49].... 30

Figure 32 Distillation Curves for FACE Diesel Fuels [24] ................................................... 30

Figure 33 Typical Composition and Structure of Engine Exhaust Particles [57] ...................... 32

Figure 34 Typical Particle Composition for a HDDE Tested in a HD Transient Cycle

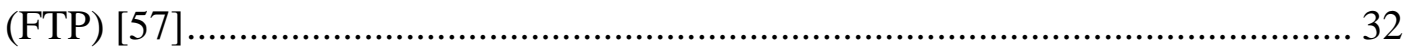

Figure 35 Typical Engine Exhaust Particle Size Distribution (Mass and Number

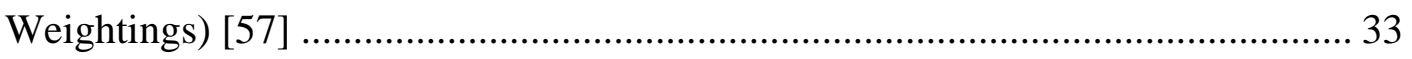

Figure 36 Influence of Dilution Ratio on Particle Size Distribution [59]................................. 34

Figure 37 Influence of Dilution Temperature on Particle Size Distribution [58]...................... 34

Figure 38 Influence of Residence Time in Primary Dilution Stage on Particle Size

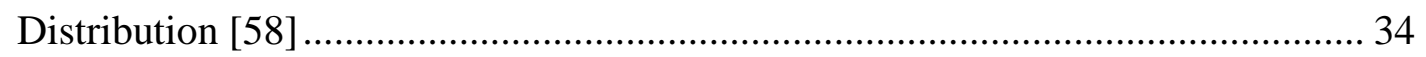

Figure 39 SOF (soluble) and Soot (insoluble) Emission Indices for Conventional and PCCI

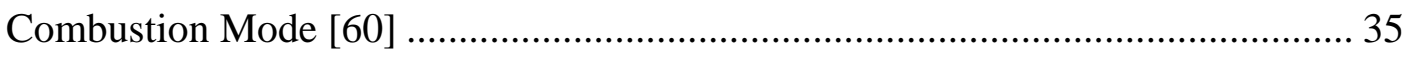

Figure 40 Comparison of Particle Size Distribution for Conventional and PCCI

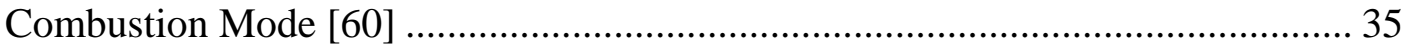

Figure 41 Particle Size Distribution for PCCI and HCCI Combustion Mode [60] .................... 36

Figure 42 Particle Size Distribution for Varying TD Temperatures and SOI Timings during

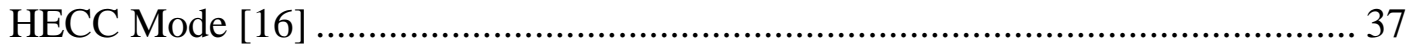

Figure 43 Particle Size Distribution with Varying Injection Pressure [62] .............................. 37

Figure 44 Schematic Overview of EERL's Measurement Capabilities.................................... 38

Figure 45 Test Engine GM Z19DTH in the EERL ............................................................. 39

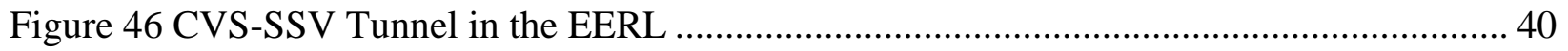


Figure 47 MEXA-7200D with Oven Unit (left) in the EERL .............................................. 41

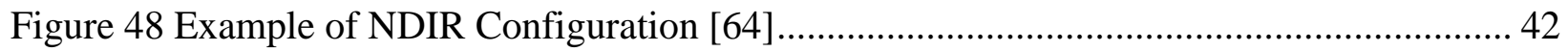

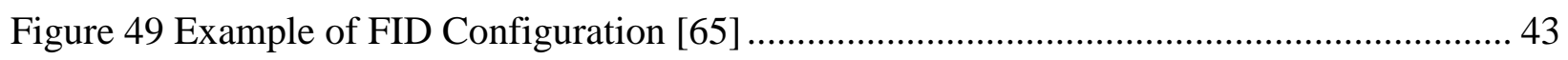

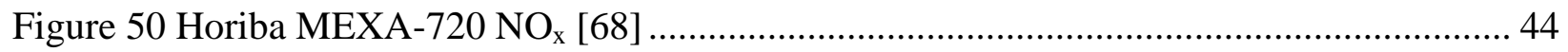

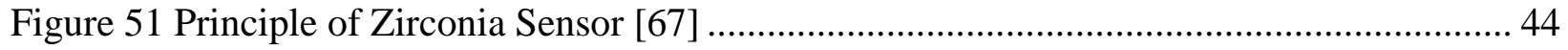

Figure 52 Experimental Setup for Nanoparticle Sampling ................................................ 45

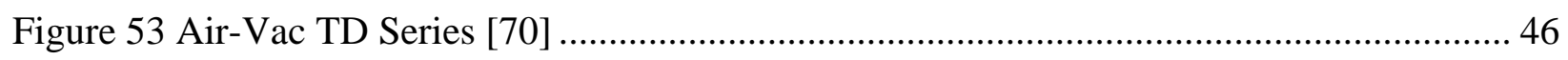

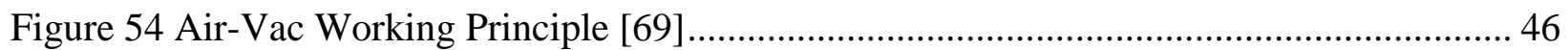

Figure 55 Schematic Diagram of the Model 3090 EEPS $^{\mathrm{TM}}$ Spectrometer [71] ........................ 48

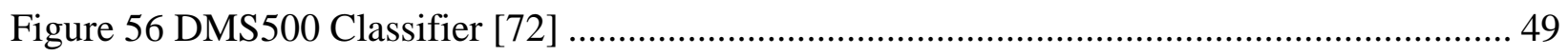

Figure 57 Exhaust Conditioning Unit ............................................................................. 50

Figure 58 Functional Diagram of AVL Micro Soot Sensor [73] ........................................... 50

Figure 59 Principle of Photoacoustic Measurement [73] ................................................... 50

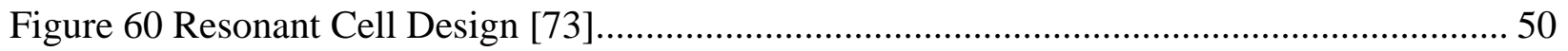

Figure 61 Kistler High Temperature Pressure Sensor Type 6058A1 [74].............................. 51

Figure 62 Kistler Glow Plug Adapter Type 6544Q with Pressure Sensor [75]........................ 51

Figure 63 Kistler Pressure Sensor on GM Z19DTH....................................................... 51

Figure 64 BEI Model H25 Shaft Encoder on GM Z19DTH ............................................. 51

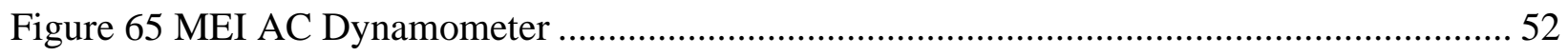

Figure 66 FACE Diesel Fuels Design Matrix: Target (Blue) vs. Actual Values (Red).............. 53

Figure 67 Example Linear Scale Aerosol Size Distribution [78] .......................................... 55

Figure 68 Example Log Scale Aerosol Size Distribution [78] ............................................ 55

Figure 69 Normal Probability Plot for Mode Particle Concentration of FACE 1 (Test 19)........ 58

Figure 70 Box plot for Mode Particle Concentration of FACE 3 and FACE 1 (Test 19) ........... 58

Figure 71 Particle Size Distribution for Optimal Split Injection Tests for Low $\mathrm{NO}_{\mathrm{x}}-$ Filled

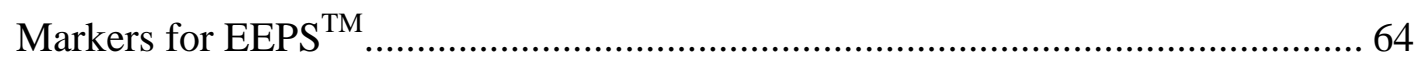

Figure 72 Particle Size Distribution for Optimal Split Injection Tests for Low $\mathrm{NO}_{\mathrm{x}}-$ Low

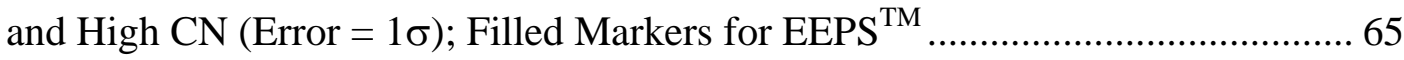

Figure 73 Particle Size Distribution for Optimal Single Injection Tests for Low $\mathrm{NO}_{\mathrm{x}}-$ Filled Markers for EEPS ${ }^{\mathrm{TM}}$ 
Figure 74 NP Size Distribution for Optimal Single Injection Tests for Low $\mathrm{NO}_{\mathrm{x}}-$ Low and

High CN $($ Error $=1 \sigma) ;$ Filled Markers for EEPS ${ }^{\mathrm{TM}}$ 67

Figure 75 Particle Size Distribution for Low Cetane Fuels - Filled Markers for EEPS ${ }^{\mathrm{TM}}$.......... 68

Figure 76 Particle Size Distribution for Medium Cetane Fuels ........................................... 70

Figure 77 Particle Size Distribution for High Cetane Fuels ................................................. 71

Figure 78 Particle Size Distribution for Low and High CN and Varying SOI Timing .............. 73

Figure 79 Particle Size Distribution for Low and High CN and Varying Rail Pressure ............. 74

Figure 80 Particle Size Distribution for Low and High T90 and Varying Rail Pressure ............ 75

Figure 81 Particle Size Distribution for Low and High CN and Varying Intake- $\mathrm{O}_{2} \ldots \ldots \ldots \ldots \ldots . . . . . . .76$

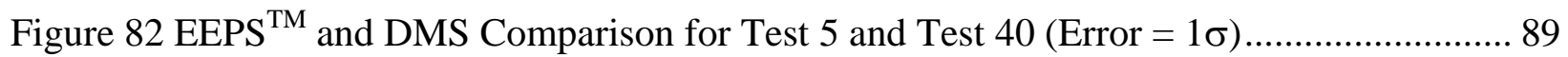

Figure 83 EEPS $^{\mathrm{TM}}$ and DMS Comparison for 6 Consecutive Runs of Test $5($ Error $=1 \sigma) \ldots \ldots . .90$

Figure 84 EEPS $^{\mathrm{TM}}$ vs. DMS Total Particle Concentration with Linear Least Square Fit

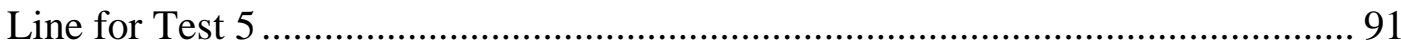

Figure 85 Particle Size Distribution for Optimal Split Injection Tests for Low $\mathrm{NO}_{\mathrm{x}}-$ Filled

Markers for EEPS ${ }^{\mathrm{TM}}$

Figure 86 Particle Size Distribution for Optimal Split Injection Tests for Low $\mathrm{NO}_{\mathrm{x}}($ Error $=$

$1 \sigma)$ - Filled Markers for EEPS ${ }^{\mathrm{TM}}$

Figure 87 Particle Size Distribution for Optimal Split Injection Tests for Low Soot - Filled

Markers for EEPS ${ }^{\mathrm{TM}}$

Figure 88 Particle Size Distribution for Optimal Split Injection Tests for Low Soot (Error =

$1 \sigma)$ - Filled Markers for EEPS ${ }^{\mathrm{TM}}$

Figure 89 Particle Size Distribution for Optimal Split Injection Tests for Highest BTE -

Filled Markers for EEPS ${ }^{\mathrm{TM}}$

Figure 90 Particle Size Distribution for Optimal Split Injection Tests for Highest BTE

$($ Error $=1 \sigma)-$ Filled Markers for EEPS ${ }^{\mathrm{TM}}$

Figure 91 Particle Size Distribution for Optimal Single Injection Tests for Low $\mathrm{NO}_{\mathrm{x}}-$

Filled Markers for EEPS ${ }^{\mathrm{TM}}$ 95

Figure 92 Particle Size Distribution for Optimal Single Injection Tests for Low $\mathrm{NO}_{\mathrm{x}}$ (Error $=1 \sigma)-$ Filled Markers for EEPS ${ }^{\mathrm{TM}}$ 95

Figure 93 Particle Size Distribution for Optimal Single Injection Tests for Low Soot -

Filled Markers for EEPS ${ }^{\mathrm{TM}}$ 96 
Figure 94 Particle Size Distribution for Optimal Single Injection Tests for Low Soot (Error

$$
=1 \sigma)- \text { Filled Markers for EEPS }{ }^{\mathrm{TM}}
$$

Figure 95 Particle Size Distribution for Optimal Single Injection Tests for Highest BTE Filled Markers for EEPS ${ }^{\mathrm{TM}}$...... 97

Figure 96 Particle Size Distribution for Optimal Single Injection Tests for Highest BTE

$$
(\text { Error }=1 \sigma)-\text { Filled Markers for EEPS }{ }^{\mathrm{TM}} \text {.... }
$$

Figure 97 Particle Size Distribution for Low Cetane Fuels (Error $=1 \sigma)$ - Filled Markers

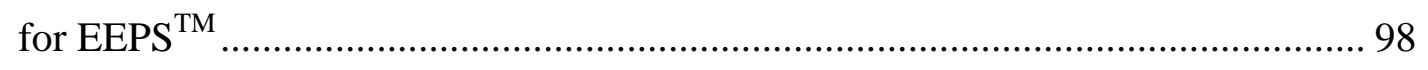

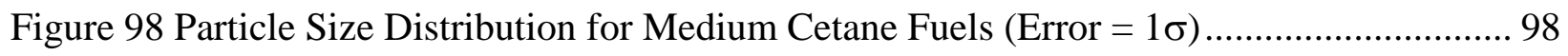

Figure 99 Particle Size Distribution for High Cetane Fuels $($ Error $=1 \sigma)$............................... 99

Figure 100 Particle Size Distribution for Low and High CN and Varying SOI Timing

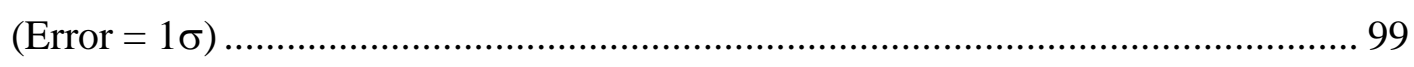

Figure 101 Particle Size Distribution for Low and High CN and Varying Rail Pressure

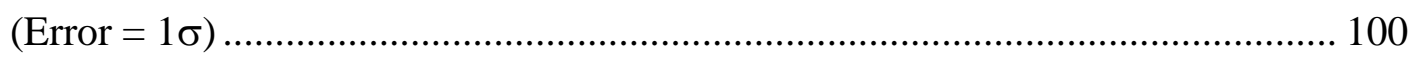

Figure 102 Particle Size Distribution for Low and High T90 and Varying Rail Pressure

$$
(\text { Error }=1 \sigma)
$$

Figure 103 Particle Size Distribution for Low and High CN and Varying Intake- $\mathrm{O}_{2}$ (Error

$$
=1 \sigma)
$$




\section{LIST OF TABLES}

Table 1 Comparison of Traditional Combustion Modes and HCCI Combustion [7].................... 5

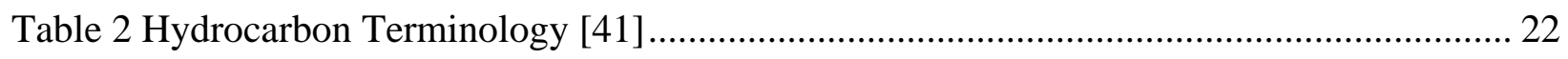

Table 3 Further ASTM Standard Test Methods used for FACE Diesel Fuels .......................... 25

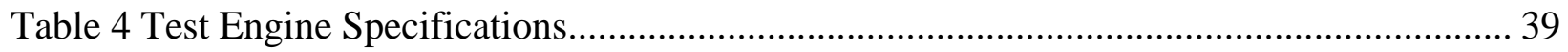

Table 5 Conditions and Parameters for Dilution with Air-Vac Model TD110H ...................... 46

Table 6 Residence Times for Dilution System Components ............................................... 47

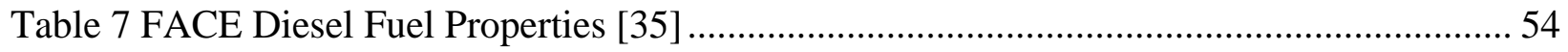

Table 8 Engine Operating Conditions for Split Injection Strategy ........................................ 59

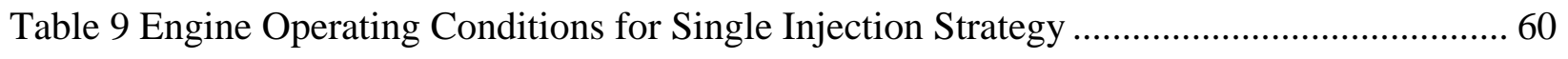

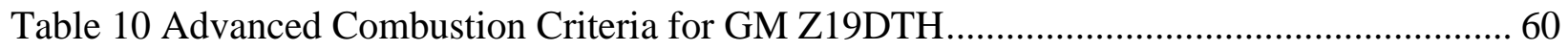

Table 11 Selected Test Runs for Low, Medium and High Cetane Fuel Comparison.................. 61

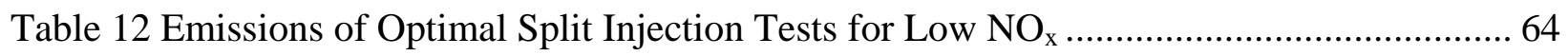

Table 13 Emissions Comparison of Optimal Split and Single Injection Tests for Low $\mathrm{NO}_{\mathrm{x}} \ldots \ldots . . .66$

Table 14 Two-Sample t-Test with Unequal Variances, One-Sided, 5\% Significance Level:

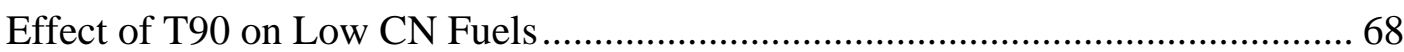

Table 15 Two-Sample t-Test with Unequal Variances, One-Sided, 5\% Significance Level:

Effect of Aromatic Content on Low CN Fuels .................................................... 69

Table 16 Two-Sample t-Test with Unequal Variances, One-Sided, 5\% Significance Level:

Effect of T90 on Medium CN Fuels............................................................... 70

Table 17 Two-Sample t-Test with Unequal Variances, One-Sided, 5\% Significance Level:

Effect of T90 on High CN Fuels ..................................................................... 72

Table 18 Two-Sample t-Test with Unequal Variances, One-Sided, 5\% Significance Level:

Effect of Aromatic Content on High CN Fuels ................................................. 72

Table 19 Emissions Comparison for Low and High CN and Varying Rail Pressure ................. 74

Table 20 Emissions Comparison for Low and High T90 and Varying Rail Pressure ................. 75

Table 21 Emissions Comparison for Low and High CN and Varying Intake- $\mathrm{O}_{2} \ldots \ldots \ldots \ldots \ldots \ldots \ldots . . . . . . . . .77$

Table 22 Low Cetane (FACE 4, FACE 1, FACE 3) Split Injection Matrix .............................. 85

Table 23 Medium Cetane (ULSD, FACE 7, FACE 9) Split Injection Test Matrix..................... 86 
Table 24 High Cetane (FACE 8, FACE 6, FACE 5) Split Injection Test Matrix ...................... 87

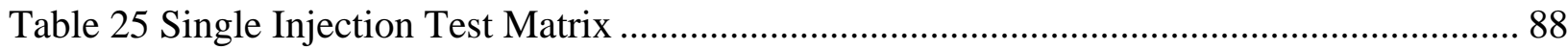




\section{NOMENCLATURE}

\begin{tabular}{|c|c|}
\hline $\mathrm{AC}$ & Alternate Current \\
\hline $\mathrm{AF}$ & Air-to-Fuel Ratio \\
\hline API & American Petroleum Institute \\
\hline ASTM & American Society for Testing and Materials \\
\hline ATDC & After Top Death Center \\
\hline AVFL & Advanced Vehicles, Fuels, and Lubricants Committee \\
\hline BMEP & Brake Mean Effective Pressure \\
\hline BSFC & Brake Specific Fuel Consumption \\
\hline $\mathrm{BSNO}_{\mathrm{x}}$ & Brake Specific Oxides of Nitrogen \\
\hline BSPM & Brake Specific Particulate Matter \\
\hline BTDC & Before Top Death Center \\
\hline BTE & Brake Thermal Efficiency \\
\hline $\mathrm{CA}$ & Crank Angle \\
\hline CAFEE & Center for Alternative Fuels, Engines and Emissions \\
\hline CARB & California Air Resource Board \\
\hline CFR & Code of Federal Regulations \\
\hline $\mathrm{CH}_{4}$ & Methane \\
\hline $\mathrm{CI}$ & Cetane Index / Compression Ignition \\
\hline CLD & Chemiluminescence Detector \\
\hline $\mathrm{CN}$ & Cetane Number \\
\hline $\mathrm{CO}$ & Carbon Monoxide \\
\hline $\mathrm{CO}_{2}$ & Carbon Dioxide \\
\hline $\mathrm{CPC}$ & Condensation Particle Counter \\
\hline $\mathrm{CR}$ & Compression Ratio \\
\hline $\mathrm{CRC}$ & Coordinating Research Council \\
\hline CVS & Constant Volume Sampling \\
\hline DAQ & Data Acquisition \\
\hline DC & Direct Current \\
\hline
\end{tabular}


DCN Derived Cetane Number

DDC Detroit Diesel Corporation

DI

Direct Injection

DICI

Direct Injection Compression Ignition

DMS

Differential Mobility Spectrometer

dN

Particle Number Concentration

$\mathrm{dN} / \mathrm{d} \log \mathrm{D}_{\mathrm{p}}$

Normalized Particle Number Concentration

$\mathrm{D}_{\mathrm{p}}$

Midpoint Particle Diameter

$\mathrm{D}_{\mathrm{p}, 1}$

Lower Channel Diameter

$\mathrm{D}_{\mathrm{p}, \mathrm{u}}$

Upper Channel Diameter

DR

Dilution Ratio

$\mathrm{d}_{50}$

$50 \%$ Cutoff Point for Particles based on Aerodynamic Diameter

EC

Elemental Carbon

EEPS $^{\mathrm{TM}}$

Engine Exhaust Particle Sizer ${ }^{\mathrm{TM}}$ Spectrometer

EERL

Engine and Emission Research Laboratory

EGR

Exhaust Gas Recirculation

EPA

Environmental Protection Agency

F/A

Fuel-to-Air Ratio

FACE

Fuels for Advanced Combustion Engines

FTP

Federal Test Procedure

GDI

Gasoline Direct Injection

GM

General Motors

$\mathrm{H}_{2}$

Hydrogen

HCCI

Homogenous Charged Compression Ignition

HD

Heavy-Duty

HDDE

Heavy-Duty Diesel Engine

HMN

Heptamethylnonane

HRR

Heat Release Rate

IARC

International Agency for Research on Cancer

IC

Internal Combustion

IMEP

Indicated Mean Effective Pressure 


\begin{tabular}{|c|c|}
\hline IQR & Interquartile Range \\
\hline IVC & Intake Valve Closing \\
\hline$\lambda$ & Excess Ratio \\
\hline LTC & Low Temperature Combustion \\
\hline MEI & Medsker Electric Inc. \\
\hline MFB & Mass Fraction Burned \\
\hline MFC & Mass Flow Controller \\
\hline MS & Mass Spectrometry \\
\hline MTBE & Methyl Tertiary-Butyl Ether \\
\hline NAAQS & National Ambient Air Quality Standards \\
\hline NDIR & Non-Dispersive Infrared \\
\hline NI & National Instruments \\
\hline NIOSH & National Institute for Occupational Safety and Health \\
\hline NO & Nitric Oxide \\
\hline $\mathrm{NO}_{2}$ & Nitrogen Dioxide \\
\hline $\mathrm{NO}_{\mathrm{x}}$ & Oxides of Nitrogen \\
\hline NTC & Negative Temperature Coefficient \\
\hline $\mathrm{O}_{2}$ & Oxygen \\
\hline $\mathrm{O}_{3}$ & Ozone \\
\hline $\mathrm{OC}$ & Organic Carbon \\
\hline OEM & Original Equipment Manufacturer \\
\hline PCCI & Premixed Charge Compression Ignition \\
\hline PFI & Port Fuel Injection \\
\hline$\Phi$ & Equivalence Ratio \\
\hline PID & Proportional-Integral-Derivative \\
\hline PM & Particulate Matter \\
\hline PRF & Primary Reference Fuel \\
\hline PRR & Pressure Rise Rate \\
\hline PUF/XAD & Polyurethane Foam Ion Exchange and Adsorbent Resin \\
\hline $\mathrm{Q}_{1}$ & First Quartile \\
\hline $\mathrm{Q}_{3}$ & Third Quartile \\
\hline
\end{tabular}


SAE Society of Automotive Engineers

$\sigma_{\mathrm{pmi}}$

SMPS

SSV

SOF

SOP

T90

THC

TNC

ULSD

UNIBUS

VGT

WVU

$\mathrm{ZrO}_{2}$
Standard Deviation of Mean Indicated Pressure

Scanning Mobility Particle Sizer

Sub-Sonic Venturi

Soluble Organic Fraction

Start of Pulse

T90 Distillation Temperature

Total Hydrocarbons

Total Number Concentration

Ultra Low Sulfur Diesel

Uniform Bulky Combustion System

Variable Geometry Turbocharger

West Virginia University

Zirconium Oxide 


\section{CHAPTER 1 INTRODUCTION}

Internal combustion engines are the primary power source for numerous applications, where the traditional direct injected compression ignition engine employing a heterogeneous airfuel mixture is preferred due to its excellent thermal efficiency. However, the disadvantages are relatively high emissions of oxides of nitrogen $\left(\mathrm{NO}_{\mathrm{x}}\right)$ and particulate matter $(\mathrm{PM})$. Diesel exhaust gases were identified in the past to be a serious threat to human health and the environment, leading to increased morbidity and mortality, and regarded as the main source of air pollution. The National Institute for Occupational Safety and Health (NIOSH), for example, determined in 1988 that the whole diesel exhaust is a potential human carcinogen based on chemical, genotoxicity and carcinogenicity data [1]. The World Health Organization's International Agency for Research on Cancer (IARC) also concluded in 1989 that diesel engine exhaust is probably carcinogenic to humans [2]. Therefore, legislative authorities around the world mandated tighter emissions regulations in recent years, which lead to special attention by researchers on next-generation combustion strategies for internal combustion diesel engines that simultaneously reduce exhaust emissions while improving thermal efficiency. In-cylinder combustion temperature plays an essential role in the formation of emissions as well as thermal efficiency of the engine. One way to minimize both soot and $\mathrm{NO}_{\mathrm{x}}$ emissions is to limit the incylinder temperature during the combustion process in order to avoid $\mathrm{NO}_{\mathrm{x}}$ and soot formation zones by means of high levels of dilution via exhaust gas recirculation (EGR) combined with flexible fuel injection strategies. However, fuel chemistry plays a significant role in the ignition delay; hence, influencing the overall combustion characteristics and the resulting emissions. The Advanced Vehicles, Fuels, and Lubricants (AVFL) committee of the Coordinating Research Council (CRC) specified and formulated a matrix of nine test fuels for advanced combustion engines (FACE) based on the variation of three properties: cetane number, aromatic content, and 90 percent distillation temperature.

Due to the increased attention by researchers on particle size in recent years and evidence

found that several health effects may be associated with ultrafine particles [3-6], the exhaust emissions from a turbo-charged GM 1.9L light-duty compression ignition engine were 
characterized in terms of particle concentrations and size distributions during low temperature combustion mode using different FACE diesel fuels.

\subsection{Objectives}

The global objective of this study was to investigate a matrix of FACE diesel fuels and study their effects on diesel engine emissions during advanced combustion mode. The primary objective was to study the effects of various FACE diesel fuels on the nanoparticle formation during low temperature combustion processes. The specific objectives were (1) to assess the influence of the three main properties of FACE diesel fuel, cetane number, 90 percent distillation temperature and aromatic content on particle concentration and size distributions during low temperature combustion, (2) to investigate single and split injection strategies, and (3) to explore variations in rail pressure and intake oxygen concentration during single injection. 


\section{CHAPTER 2 LITERATURE REVIEW}

This section introduces the principles of advanced combustion strategies and describes how they could be initiated and controlled. A review of relevant physical and chemical properties for FACE diesel fuels is followed by a discussion of the effects of these properties on advanced combustion modes. An overview of particulate matter formation, and PM number concentration and size distributions in the advanced combustion modes completes this section.

\subsection{Advanced Compression-Ignition Combustion Modes}

A considerable body of published literature attests to the fact that the engine and automotive industry has made major strides in the past few decades to lower engine out emissions as well as achieve higher fuel efficiency. Due to tightening emission standards the research and development focus on emission reduction technologies resulted in an improvement in engine-out emissions at the expense of lower fuel economy in previous years [7]. Therefore, new combustion modes, such as Homogeneous Charged Compression Ignition (HCCI), Premixed Charge Compressed Ignition (PCCI) and Low Temperature Combustion (LTC) have been explored [8-13]. Various names have been assigned to these new combustion modes, but they all have the requirement of creating a homogeneous or stratified air-fuel (AF) mixture prior to ignition in common. In order to extend the mixing and ignition chemistry time frame, early injection timing is used in conjunction with a lean air-fuel mixture and/or high levels of exhaust gas recirculation (EGR) [7]. Figure 1 shows the distribution of the soot and nitric oxide (NO) formation regions as a function of local temperature and equivalence ratio $(\Phi)$ for conventional and advanced diesel combustion modes [11]. Such so-called $\Phi-T$ maps were first used in 2001 to explain local temperature and equivalence ratio effects on soot and $\mathrm{NO}_{\mathrm{x}}$ formation by applying chemical kinetics models [14]. 


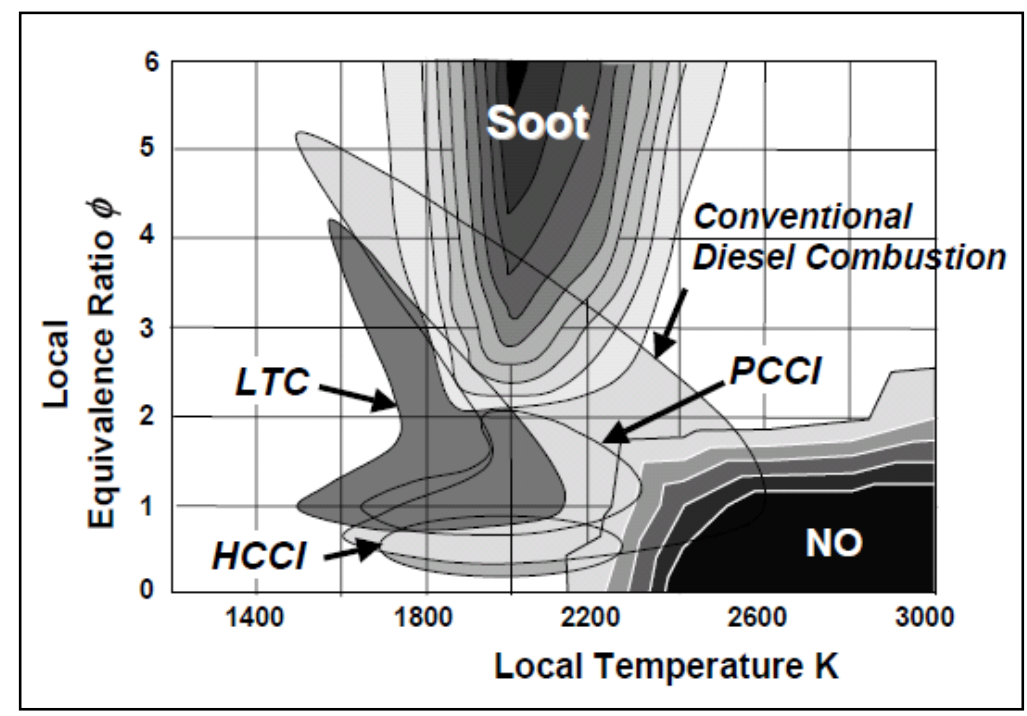

Figure 1 Local Temperature and Equivalence Ratio for Advanced Combustion Modes [11]

\subsubsection{Homogenous Charged Compression Ignition (HCCI)}

HCCI combustion was proposed as a combination of the advantages of conventional spark ignition (SI) and direct injection compression ignition (DICI) engines simultaneously avoiding their inherent disadvantages. As a result, HCCI combustion employs a homogeneous air-fuel mixture leading to low soot emissions and high compression ratio generating higher efficiency. The air-fuel are mixed before start of combustion and the mixture is self-ignited due to the compression stroke. The combustion is controlled by means of the temperature, pressure and compositions of the lean homogeneous air-fuel mixture leading to multipoint auto-ignition. In an optimal HCCI mode, the heat release reaction occurs throughout the cylinder without flame propagation and zones of high temperature or rich fuel-to-air (F/A) ratios. The homogeneous mixture and relatively low average temperatures lead to minimization of the levels of the $\mathrm{NO}_{\mathrm{x}}$ and soot trade-off relationship [7]. A comparison of some key parameters for traditional combustion modes with HCCI combustion is given in Table 1. 
Table 1 Comparison of Traditional Combustion Modes and HCCI Combustion [7]

\begin{tabular}{|l|l|l|l|}
\hline & SI & DICI & HCCI \\
\hline Fuel & Gasoline-like fuels & Diesel-like fuels & Flexible fuel \\
\hline Excess Ratio $\lambda$ & $\approx 1.0$ & $=1.2^{*}-2.2$ & $>1.0$ \\
\hline Mixture Preparation & PFI, GDI & DI & DI, PFI and DI + PFI \\
\hline Ignition & Spark ignition & Auto-ignition & Auto-ignition \\
\hline Combustion Form & Premixed & Diffusion & $\begin{array}{l}\text { Premixed but dominated } \\
\text { by chemical kinetics }\end{array}$ \\
\hline $\begin{array}{l}\text { Combustion Rate } \\
\text { Limitation }\end{array}$ & Flame propagation & Mixing rate & Multipoint or spontaneous \\
\hline Flame Front & Yes & Yes & w/o [without] \\
\hline Combustion Temperature & High & Partially high & Relatively low \\
\hline
\end{tabular}

*Note: older engines with high smoke emissions

Despite promising advantages, some obstacles have kept HCCI combustion from succeeding in original equipment manufacturer (OEM) applications: ignition timing control over wide engine speed and load ranges, combustion rate control at high loads, cold start capacity, higher levels of carbon monoxide $(\mathrm{CO})$ and hydrocarbons $(\mathrm{HC})$, real-time rapid-response in transient cycle operation, increased engine control capacity, cylinder-to-cylinder variation and higher pressure-rise rate as well as higher combustion noise [7].

A typical heat release rate (HRR) curve for HCCI combustion is depicted in Figure 2, which shows a noticeable two-stage heat release. The time delay between the first stage, associated with low temperature kinetic reactions, and the main heat release, the high temperature regime, is the so-called negative temperature coefficient (NTC) regime. In this NTC regime, the in-cylinder temperature increases even though the overall reaction rate decreases leading to a lower reactivity of the system [15].

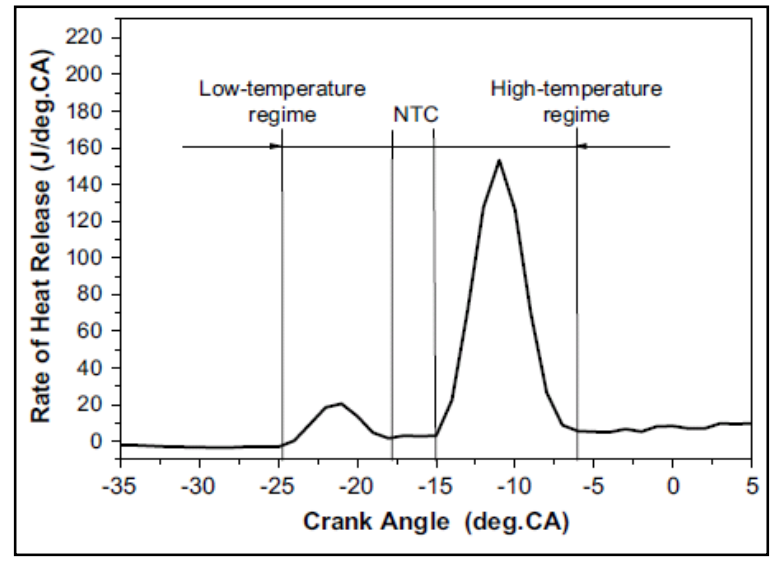

Figure 2 Typical Heat Release Rate (HRR) from HCCI Combustion of n-Heptane Fuel [15] 


\subsubsection{Premixed Charge Compression Ignition (PCCI)}

The acronym PCCI has been used with multiple meanings in advanced combustion literature, as Premixed Controlled Compression Ignition (increased and advanced pilot injection with retarded main injection), Premixed Charge Compression Ignition (early injection of diesel fuel), or partially Premixed Charge Compression Ignition [16]. Independent of the definition, PCCI refers to an advanced combustion mode that allows for a large premixed burn. Fuel is injected early into the cylinder and an ignition delay occurs creating a locally fuel-lean mixture until auto-ignition. Further injection of diesel fuel after auto-ignition leads to a transition from premixed burn to diffusion burn, thereby increasing particle formation. Combustion phasing can be controlled via EGR in order to achieve more time for mixing. In contrast to HCCI, where the air-fuel mixture homogeneously enters the cylinder, the early injection in PCCI leads to a large premixed combustion phase. The charge in PCCI is not mixed enough; hence, leading to more hot spots and the fuel injected tends to impinge on the cylinder walls due to the extended ignition delay resulting in incomplete combustion. $\mathrm{HC}$ and $\mathrm{CO}$ emissions are elevated as well, similar to HCCI $[16,17]$.

\subsubsection{Low Temperature Combustion (LTC)}

In 2000, a new diesel combustion concept named "low temperature oxidation," essentially smokeless combustion at near stoichiometric and locally rich air-to-fuel ratios was presented by Toyota Motor Corporation at the $9^{\text {th }}$ annual "Automobile and Engine Technology" Colloquium in Aachen, Germany. To achieve a simultaneous reduction in $\mathrm{NO}_{\mathrm{x}}$ and soot formation, the combustion temperature was kept very low by using a large amount of cooled EGR [18]. The NO and soot formation zones shown in Figure 1 (Section 2.1) can be avoided regardless of the equivalence ratio by keeping the temperature during combustion below around 1650K. LTC is also known as "dilution-controlled combustion" and compared to HCCI, high levels of dilution (EGR) are used and moderate inhomogeneity of the in-cylinder mixture occurs. In addition to dilution, the overall combustion temperature is controlled by combining fuel injection strategies with strong in-cylinder turbulence and mixing [7]. Dilution leads to a reduction in the overall combustion temperature and lengthens the ignition delay providing more time for fuel evaporation and reduction of inhomogeneities in the mixture. This reduces " $\mathrm{NO}_{\mathrm{x}}$ formation from local temperature spikes and soot formation from locally rich mixtures" [12]. 
However, exploring the limits, dilution can significantly increase $\mathrm{HC}$ and $\mathrm{CO}$ emissions $[12,19$, $20]$.

Due to advances in the 1990's in visualization techniques on research engines with optical access into the combustion chamber, conceptual models for conventional combustion were built explaining the phases of combustion [21, 22]. These models were adapted for earlyinjection low temperature combustion based on experiments using an optical single-cylinder diesel engine operating with $12.7 \%$ intake oxygen, as a surrogate for EGR, and early single injection strategy [23]. A comparison of the conceptual model for conventional combustion with LTC is shown in Figure 3. Longer liquid jet penetration due to the low ambient temperature and density during early-injection conditions may lead to in-cylinder wall wetting increasing emissions and decreasing combustion efficiencies [22].

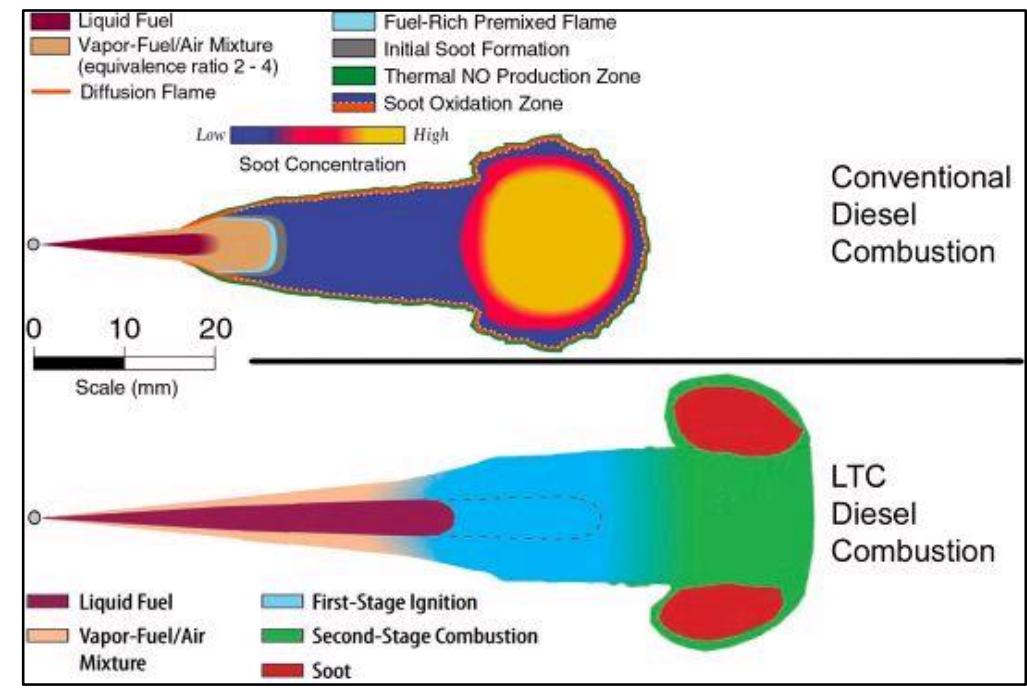

Figure 3 Comparison of Conceptual Model for Conventional Combustion with LTC [22]

\subsection{Initiating and Controlling Advanced Combustion Strategies}

Initiating and controlling of an advanced combustion strategy needs modifications to the conventional compression ignition engine. Several changes in engine control strategy as well as engine hardware may be needed to achieve advanced combustion regimes. The following sections address possible modifications and their influence on engine performance and emissions. 


\subsubsection{Engine Control System}

\subsubsection{Start of Injection Timing}

Better mixing of the air and fuel charge can be achieved through advancement of start of injection timing (SOI) providing more time for homogenization. Figure 4 shows an example of (a) in-cylinder pressure, and (b) heat release rate for a start of injection (SOI) timing sweep. Retarding SOI timing results in a reduction of peak heat release rate (HRR) and in-cylinder pressure as well as retarded combustion phasing [24].

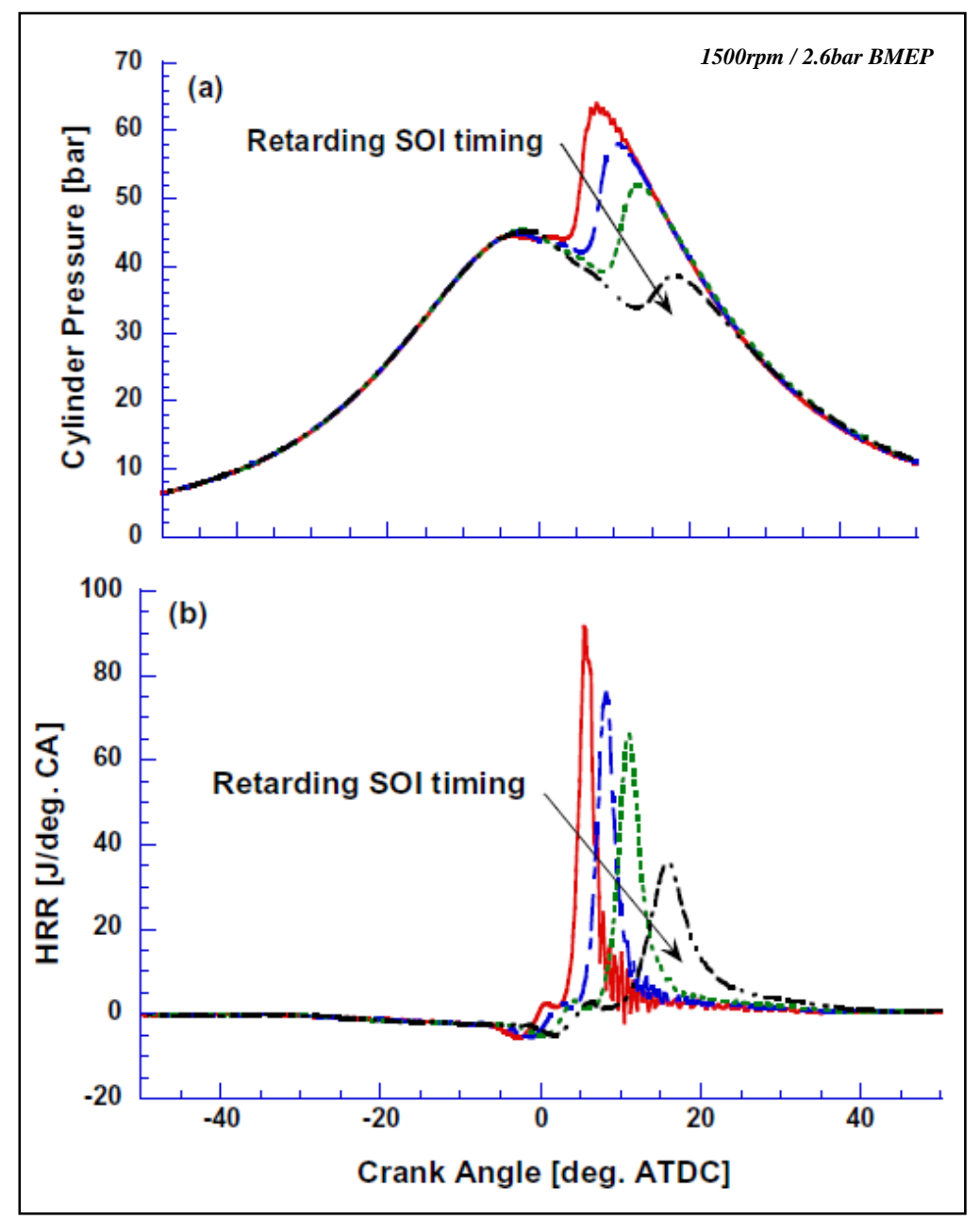

Figure 4 Cylinder Pressure (a) and HRR (b) for Retarded SOI Timing [24]

For conventional diesel combustion advancing the SOI timing results in increased $\mathrm{NO}_{\mathrm{x}}$ emissions [25]. Nevertheless, a study performed on a direct injection single cylinder research engine operating in $\mathrm{HCCI}$ combustion mode showed that $\mathrm{NO}_{\mathrm{x}}$ emissions can be reduced for early SOI timing paired with increased injection pressure, (see Figure 5). At the same time $\mathrm{HC}$ and $\mathrm{CO}$ 
emissions were increased as HCCI combustion regimes were reached [26]. It is likely that this is due to in-cylinder wall wetting as a result of early-injection conditions (see Section 2.1).

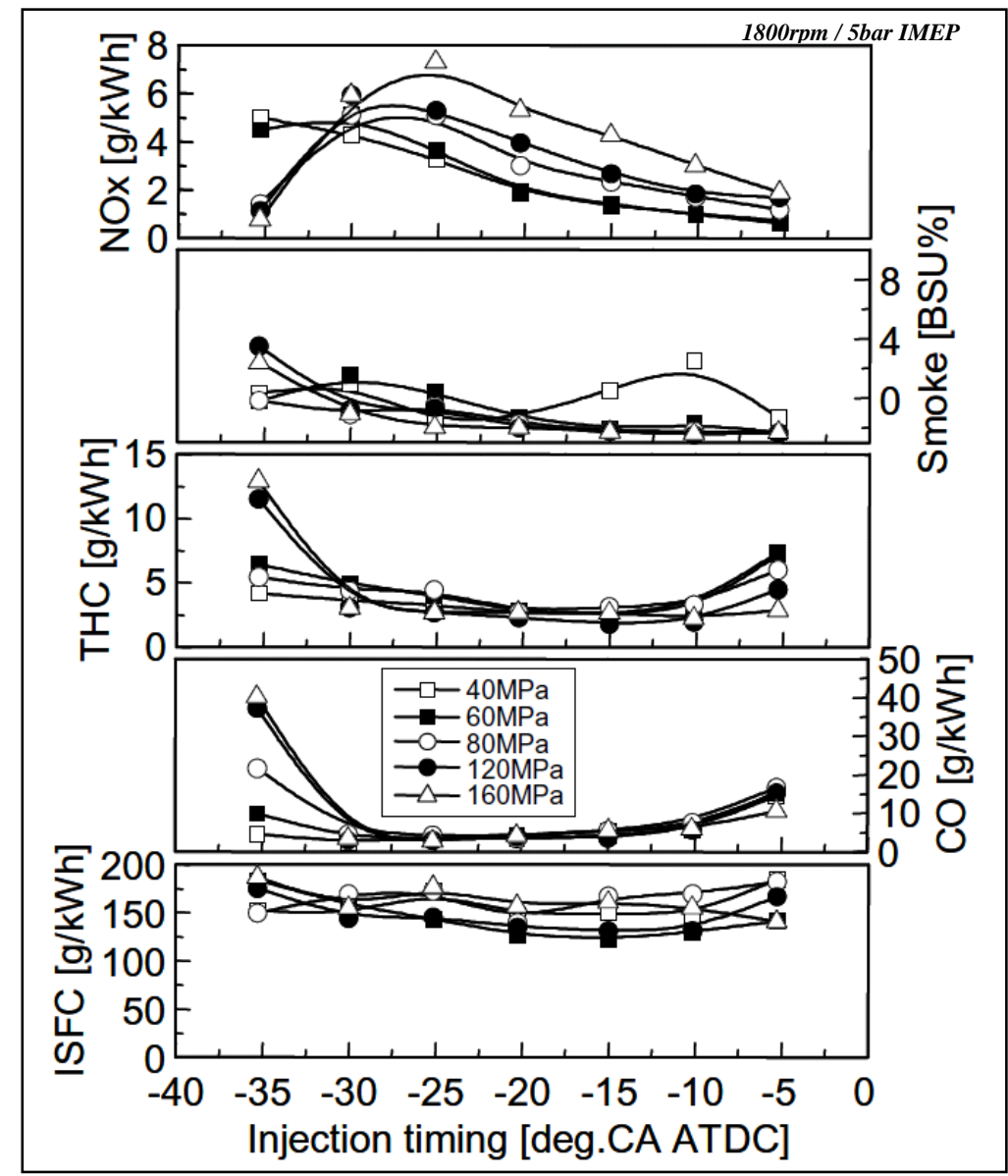

Figure 5 Exhaust Emissions and Fuel Consumption vs. Injection Timing [27]

An increase in pressure and pressure rise rate (PRR) is common when advancing SOI timing (see Figure 4); therefore, dilution with EGR and/or split injection strategies is used to control high pressure rise rates.

\subsubsection{Fuel Split Strategy}

Due to advances in electronically controlled fuel injection systems, multiple injections have become a common strategy to improve combustion in modern compression ignition (CI) engines. Pilot injection accelerates chemical and physical phenomena allowing the main injection to self-ignite; thus, a decrease in ignition delay and fuel quantity burnt in the premixed phase leads to a reduction in PRR [28].

In 2003, researchers studied the effects of a multiple injection strategy termed Uniform Bulky Combustion System (UNIBUS) on a four cylinder dual overhead camshaft common rail 
diesel engine with 3L displacement, variable geometry turbocharger (VGT) and intercooled EGR [8]. The UNIBUS injection strategy to achieve high efficiency and low emissions is depicted in Figure 6. Brake mean effective pressure (BMEP), concentration of $\mathrm{NO}_{\mathrm{x}}$ emissions, soot and the rate of effective injection quantity $\left(\mathrm{Q}_{\mathrm{f}} / \mathrm{Q}_{\mathrm{fe}}\right)$ are shown at various injection timings. $\mathrm{Q}_{\mathrm{f}}$ is the input injection quantity, whereas $\mathrm{Q}_{\mathrm{fe}}$ is defined as injection quantity calculated by the carbon balance method from exhaust gas measurements. Injection timing was varied with constant injection quantity $\left(15 \mathrm{~mm}^{3} / \mathrm{st}\right.$.). For the double injection, where the pilot injection was varied with constant main injection timing $\left(13^{\circ} \mathrm{ATDC}\right)$, BMEP stayed almost constant while $\mathrm{NO}_{\mathrm{x}}$ and soot could be reduced showing the features of HCCI. However, the rate of effective injection quantity decreased by further advancing the pilot injection timing for the UNIBUS double injection strategy due to spray impingement on the cylinder wall [8]. 

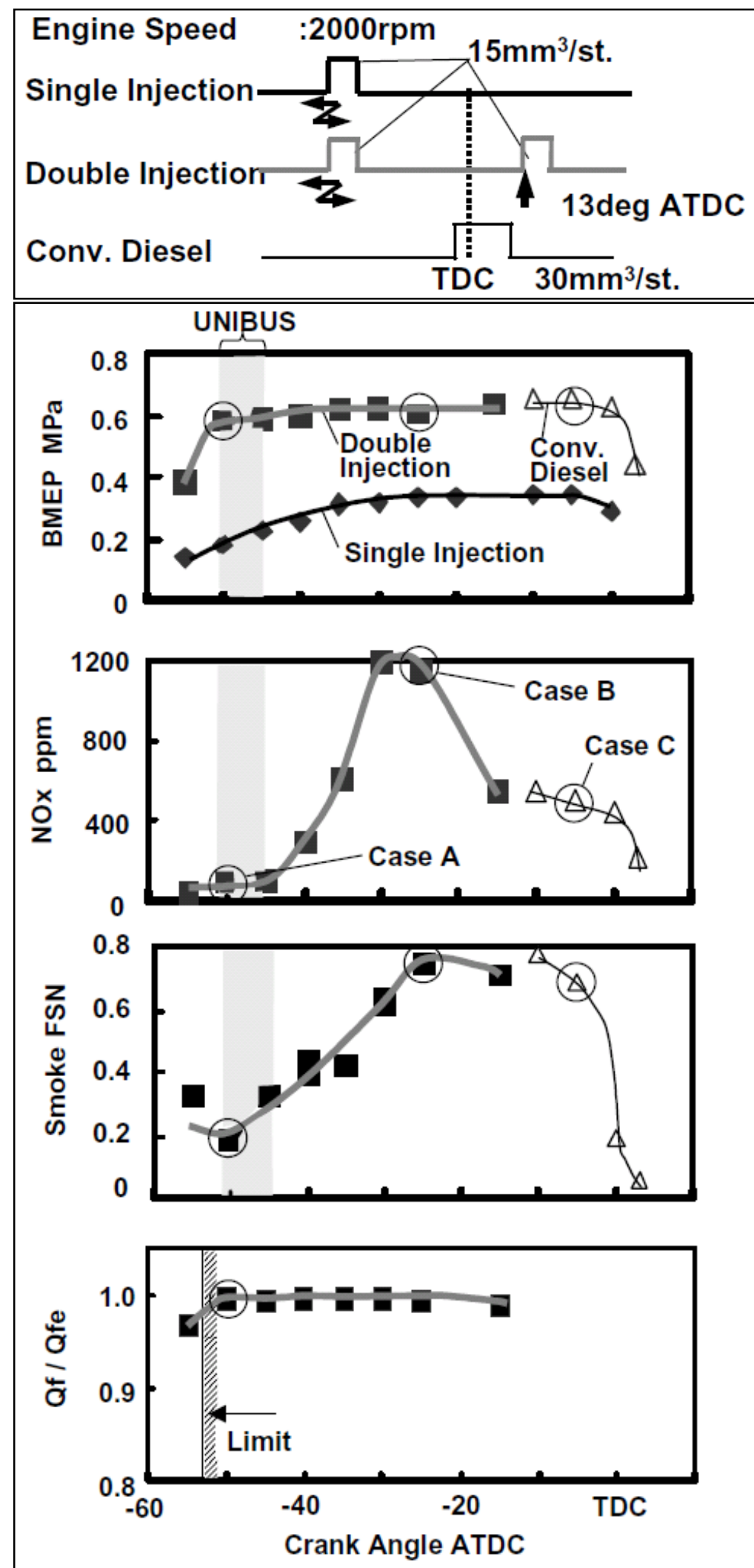

Figure 6 UNIBUS Comparison with Conventional Diesel Injection Strategy [8] 


\subsubsection{Rail Pressure}

Better fuel atomization through higher injection pressure can be achieved by an increase in rail pressure for common rail injection system equipped CI engines. This can lead to a more homogeneous air-fuel mixture affecting combustion phasing and emissions formation. The effect of increased rail pressure on $\mathrm{NO}_{\mathrm{x}}$ and soot formation for different levels of dilution with EGR, as a surrogate for excess air $(\lambda)$, is shown in Figure 7. A $2 \mathrm{~L}$ turbocharged (with VGT) DI diesel engine with cooled EGR was used in this study to demonstrate low load HCCI like combustion [29]. A reduction in soot formation with increased injection pressure was achieved with the highest effect near stoichiometric conditions due to better fuel atomization and more homogeneous air-fuel mixture, whereas $\mathrm{NO}_{\mathrm{x}}$ emissions were increased, especially at higher excess air levels due to higher in-cylinder temperature with lower EGR rates [29].

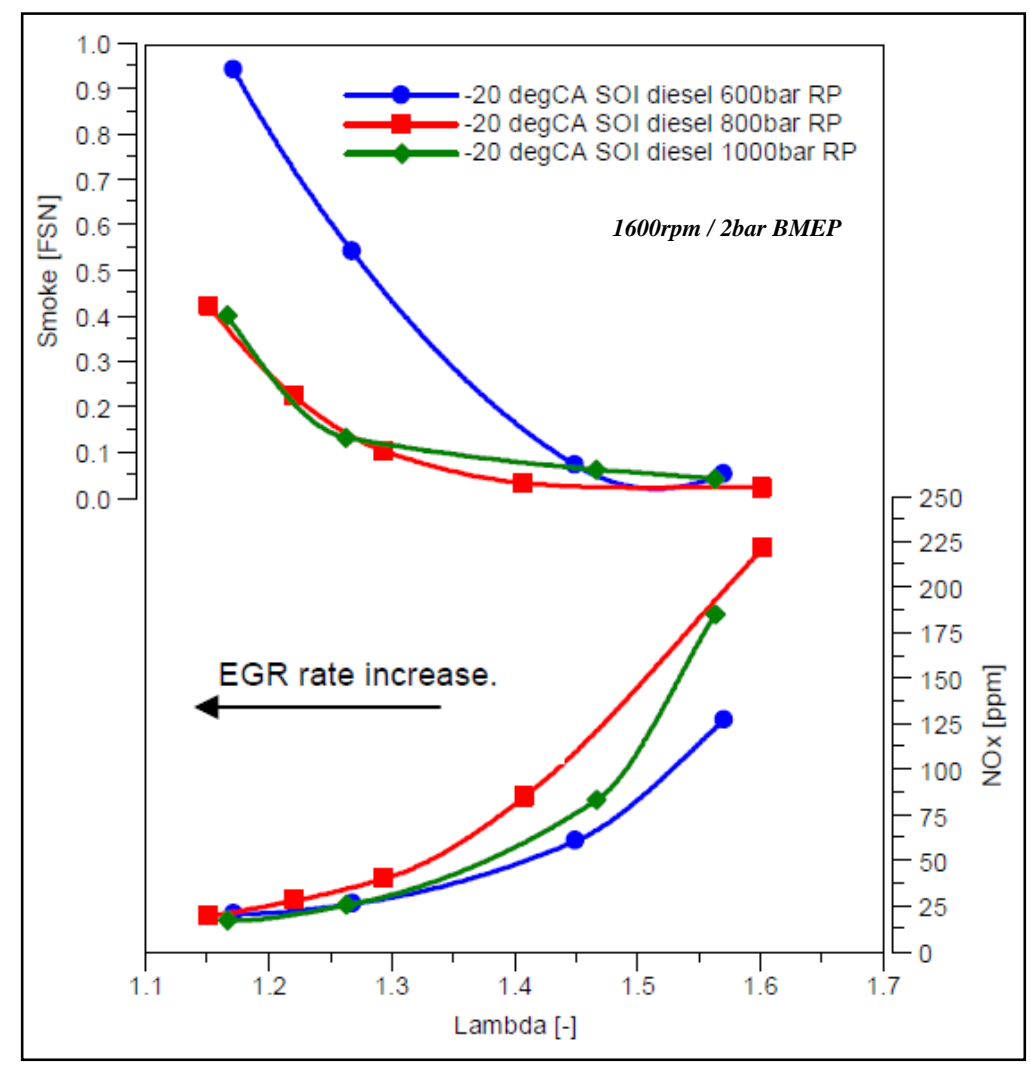

Figure 7 Effect of Injection Pressure on $\mathrm{NO}_{\mathrm{x}}$ and Soot Emissions [29]

A study performed on a single-cylinder research engine with optical access running in LTC mode showed greatly reduced soot emissions at increasing injection pressure, as well. To some extent, injection pressure may be lowered to reduce the combustion temperature, hence $\mathrm{NO}_{\mathrm{x}}$ formation [13]. Therefore, at higher loads, lower injection pressure may be preferred [7]. 


\subsubsection{Exhaust Gas Recirculation (EGR)}

Exhaust gas recirculation (EGR) is largely used in diesel engines to reduce oxides of nitrogen by lowering the adiabatic flame temperature and oxygen concentration in the combustion chamber. Inherent to the lower oxygen concentration, an increase in particulate matter is observed [30]. This $\mathrm{NO}_{\mathrm{x}}$ and PM trade-off can be observed in Figure 7 as well.

EGR in modern diesel engines is achieved by a low or high pressure loop or by a combination of both. Low pressure loop EGR uses the positive differential pressure between turbine outlet and compressor inlet, as shown in Figure 8. Due to temperature and fouling issues, recycling of exhaust gas from upstream of the turbine to downstream of the compressor is preferred as depicted in Figure 9 (high pressure loop EGR). In combination with VGT, the desired pressure difference to drive EGR can be closely controlled via vane position [30].

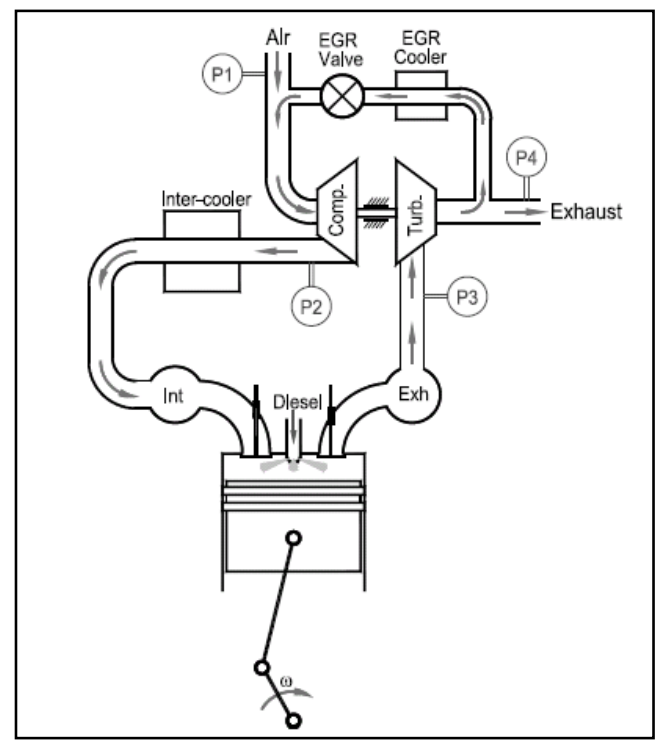

Figure 8 Low Pressure Loop EGR [30]

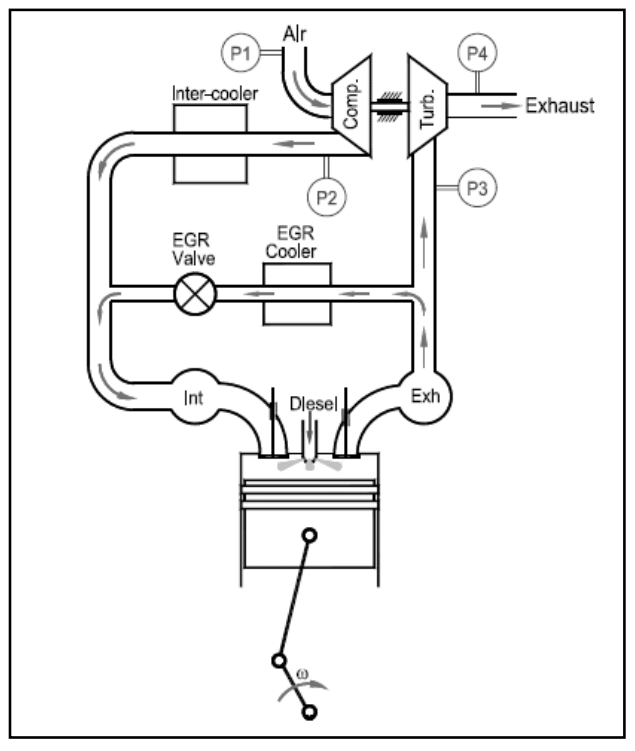

Figure 9 High Pressure Loop EGR [30]

An experimental investigation of the effects of EGR temperature was conducted on a 12L heavy-duty diesel engine with high pressure loop EGR during PCCI combustion mode. Tradeoffs between brake specific mass $\mathrm{NO}_{\mathrm{x}}\left(\mathrm{BSNO}_{\mathrm{x}}\right)$ and brake specific mass fuel consumption (BSFC) as well as brake specific mass PM (BSPM) and BSFC averaged over the AVL 8-Mode test cycle for cooled and un-cooled EGR at varying injection timing are displayed in Figure 10 and Figure 11, respectively. Cooled EGR was observed to reduce $\mathrm{NO}_{\mathrm{x}}$ emissions and improve fuel consumption, while un-cooled EGR tended to result in slightly higher PM emissions with simultaneous higher fuel consumption. No data was provided to compare the baseline timing of 
un-cooled EGR without port fuel injection (PFI) with the case of retarded timing with cooled EGR. Conclusions about cooled and un-cooled EGR for $20 \%$ PFI can neither be drawn from the data provided. On the other hand, $\mathrm{HC}$ and $\mathrm{CO}$ emissions increased by a factor of 8 and 10, respectively, for cooled EGR compared to the baseline settings. It was further noticed, that PM emissions were increased by the addition of PFI which was explained by significantly higher HC emissions associated with PFI mainly due to poor diesel fuel atomization in the air assisted PFI system [31].

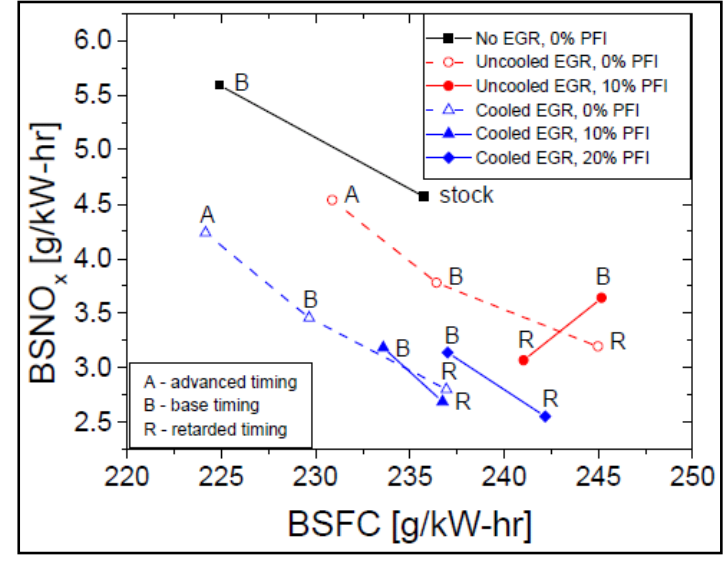

Figure $10 \mathrm{BSNO}_{\mathrm{x}}-\mathrm{BSFC}$ Trade-off [31]

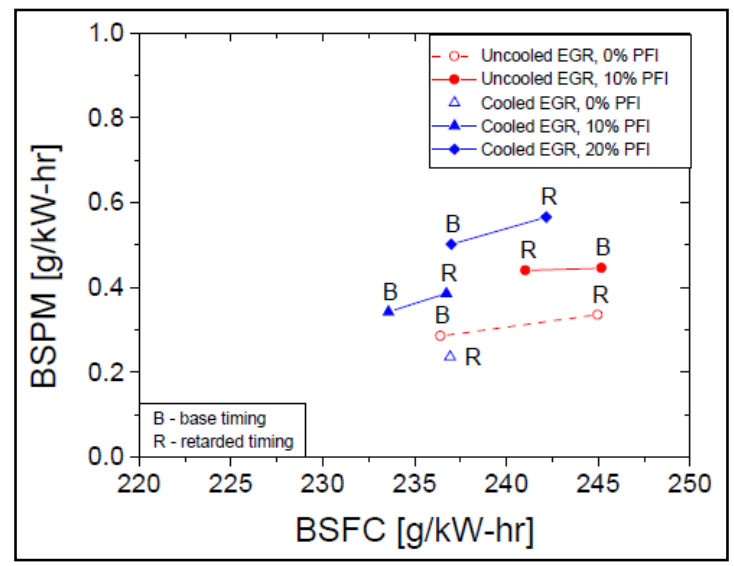

Figure 11 BSPM - BSFC Trade-off [31]

Besides reducing $\mathrm{NO}_{\mathrm{x}}$ by lowering the flame temperature, which is referred to the adiabatic flame temperature in literature, and oxygen concentration in the combustion chamber, EGR is used to control combustion phasing and limit pressure rise rates especially for advanced combustion modes. The effect on ignition delay and maximum PRR in case of HCCI combustion is demonstrated in Figure 12 and Figure 13. PRR is reduced with increased EGR rate due to the decrease in oxygen concentration (slow combustion) [27].

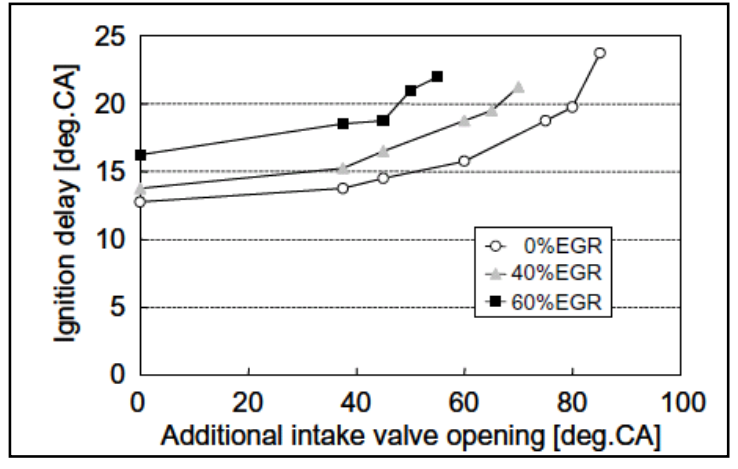

Figure 12 Ignition Delay vs. Additional Intake Valve Opening with Varying EGR Rate [27]

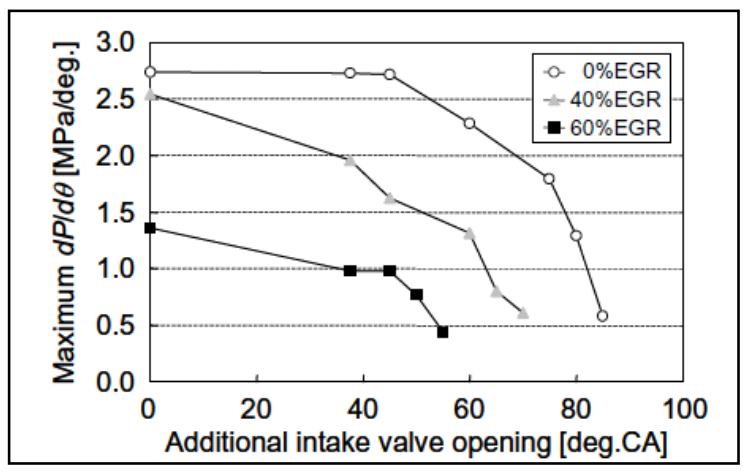

Figure 13 Maximum PRR vs. Additional Intake Valve Opening with Varying EGR Rate [27] 


\subsubsection{Intake Air Temperature}

The influence of varying the intake air temperature on in-cylinder pressure on a singlecylinder engine using fuel with a cetane number of 56.2 is depicted in Figure 14. Increasing the intake air temperature advanced the start of main combustion due to better air-fuel mixing and higher temperatures during compression. External EGR deteriorated the combustion conditions leading to lower HRR and retarded start of main combustion for the 20 and $40^{\circ} \mathrm{C}$ intake air temperature cases, but helped improving the mixture formation reaching higher temperature levels, thus earlier start of combustion could be observed for $60^{\circ} \mathrm{C}$ intake air temperature with $10 \%$ external EGR [9]. Highest in-cylinder pressure and steepest PRR was reached with $60^{\circ} \mathrm{C}$ intake air temperature without EGR which could be beneficial for HCCI engine start up as well as for the use of lower $\mathrm{CN}$ fuels. The effects of different injection pressures and load conditions were not investigated in this study.

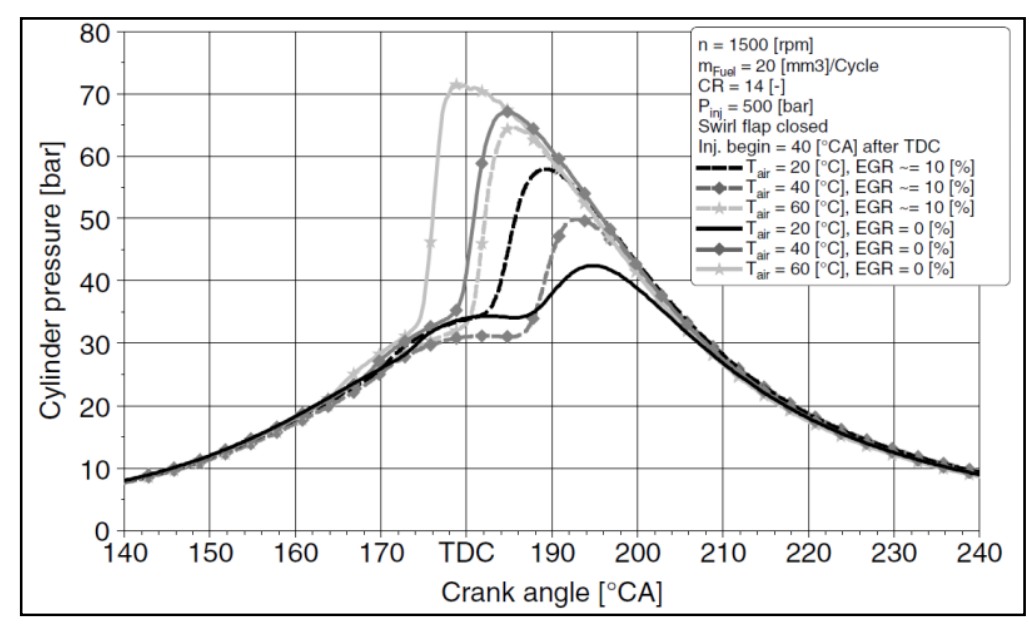

Figure 14 Intake Charge Temperature Variation [9]

\subsubsection{Intake Manifold Pressure}

One way to increase the load range of advanced combustion modes is to increase the intake manifold pressure, also known as intake boost pressure. Under boosted conditions, controlling the combustion phasing is especially important because the autoignition reactivity of the fuel is enhanced under increased pressure and the additional charge mass leads to an increase in PRR [32]. Therefore, use of intake boost pressure for advanced combustion modes is mostly paired with other technologies such as variable valve timing and EGR. The effects of increased intake manifold pressure on $\mathrm{NO}_{\mathrm{x}}$ and $\mathrm{PM}$ emissions as well as intake valve closing (IVC) and 
EGR influences are shown in Figure 15 and Figure 16, respectively. Experimental work performed on a single cylinder research diesel engine with $2.5 \mathrm{~L}$ displacement equipped with artificial boost and variable valve timing capabilities showed increased $\mathrm{NO}_{\mathrm{x}}$ emissions for elevated intake air pressures, whereas PM emissions could be reduced, while the engine was running at 58\% load and 1737rpm (SOI was $30^{\circ} \mathrm{BTDC}$ ). Late intake valve closing conditions (values in ${ }^{\circ} \mathrm{BTDC}$ ) resulted in low $\mathrm{NO}_{\mathrm{x}}$ emissions even for lower EGR fractions, but increased the PM formation. A nearly linear decrease in exhaust temperature while elevating the intake manifold pressure resulted in higher $\mathrm{CO}$ and $\mathrm{HC}$ emissions as well as BSFC values [10].

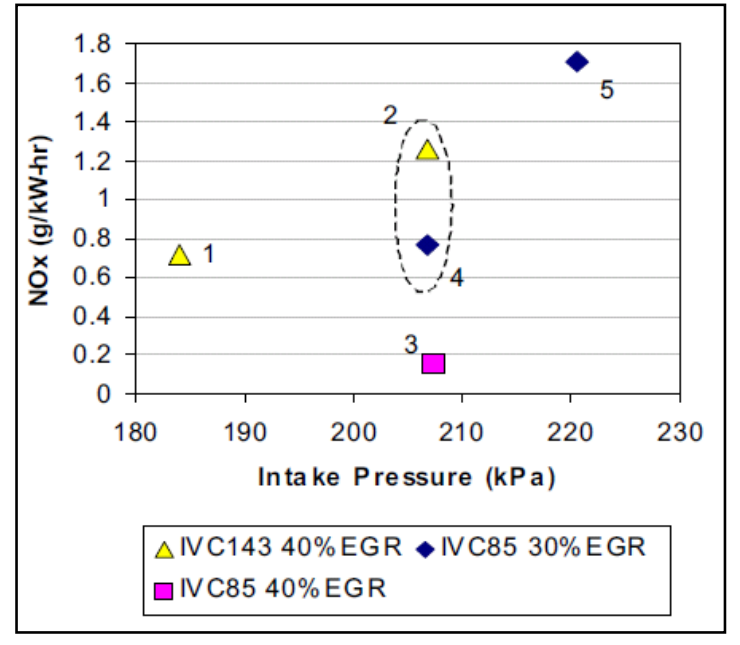

Figure $15 \mathrm{NO}_{\mathrm{x}}$ vs. Intake Pressure Varying IVC Timing and EGR [10]

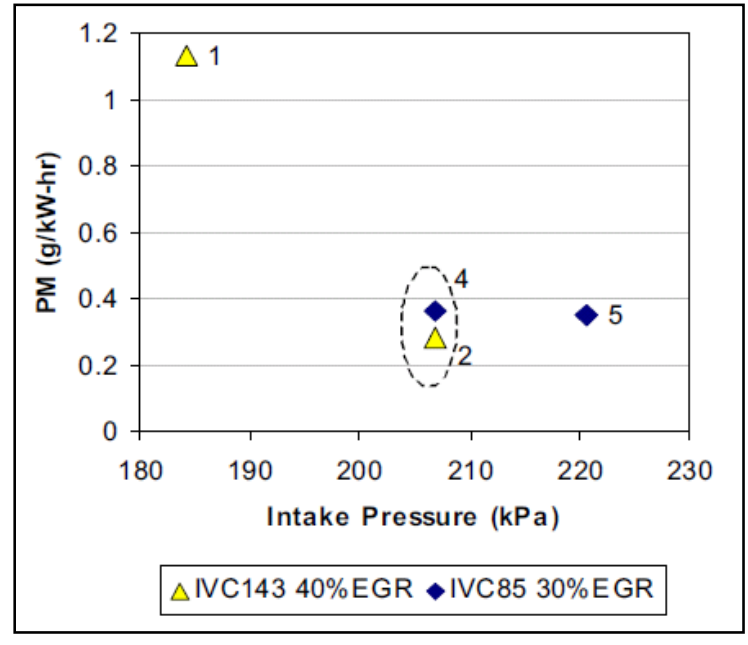

Figure 16 PM vs. Intake Pressure Varying IVC Timing and EGR [10]

\subsubsection{Engine Hardware Modifications}

\subsubsection{Compression Ratio}

The variation of compression ratio (CR) influences the combustion behavior and therefore the in-cylinder pressure as can be seen in Figure 17, where a single-cylinder engine using fuel with a cetane number of 56.2 was employed. As a result of increased compression ratio, the in-cylinder pressure increased and main start of combustion occurred earlier with steep PRR leading to partly knocking. With the use of EGR, HRR and PRR could be controlled: at a CR of 14 with 10\% EGR retarded combustion was obtained compared with no EGR, whereas with CR of 16 and 18, steep PRR and knocking could be prevented with the use of 10\% EGR leading to retardation of the combustion, especially significant for a CR of 18 [9]. 


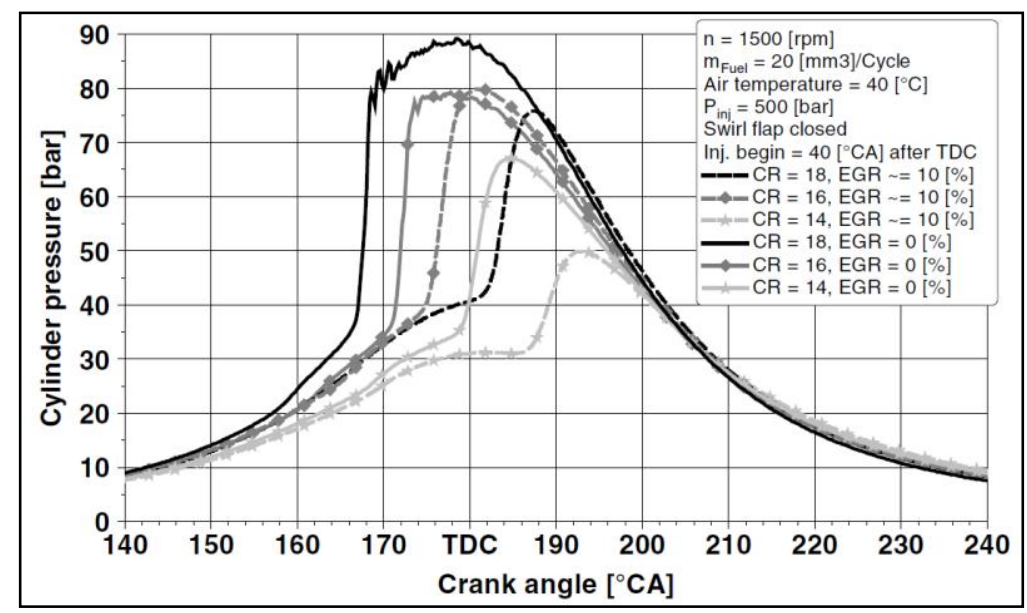

Figure 17 Compression Ratio Variation [9]

\subsubsection{Piston Design}

There are different piston designs for compression ignition engines and it is known that adaptations of piston design with the injection system can improve combustion characteristics and emissions. A piston bowl type design is used in compression ignition engines due to its swirl evocating effect, since swirl in the combustion chamber enhances homogeneous air-fuel mixture. Different piston bowl designs along with nozzle angle variations (wide and narrow) were investigated on a 1.8L heavy-duty single cylinder diesel engine showing PM and fuel consumption versus $\mathrm{NO}_{\mathrm{x}}$ trade-offs. The open bowl design resulted in significant drawbacks, presumably due to slower air movement. Straight bowl design with narrow angle nozzle provided reduced $\mathrm{NO}_{\mathrm{x}}$ emissions with slight penalty in soot emissions and fuel consumption compared to straight bowl design with a wide angle nozzle [33]. 

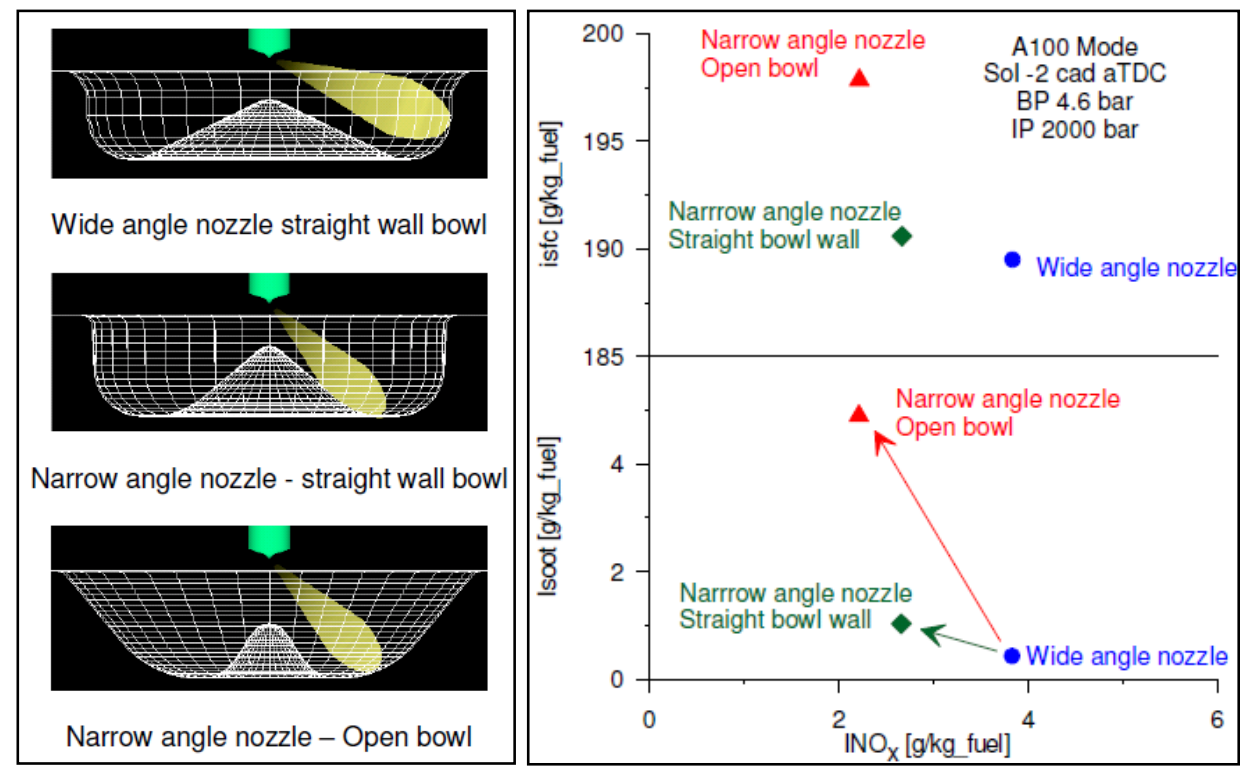

Figure 18 Impact of Various Piston Bowl Designs on Fuel Consumption, Soot and $\mathrm{NO}_{\mathrm{x}}$ [33]

\subsubsection{Variable Valve Actuation}

Variable valve actuation, primarily used for intake valve timing during the compression stroke, has a direct impact on the engines effective compression ratio; thus, affecting combustion behavior in the form of in-cylinder pressure and temperature as well as ignition control of diesel fuel [27]. Electro-hydraulic valve actuation was used to control additional valve openings after mechanically actuated intake valve closing, shown in Figure 19, on a single cylinder test engine to realize HCCI combustion mode using conventional diesel fuel. Additional intake valve opening duration helped reducing $\mathrm{NO}_{\mathrm{x}}$ emissions while $\mathrm{HC}$ and $\mathrm{CO}$ formation increased. Fuel consumption remained almost constant while soot formation increased for extended valve opening without EGR [27].

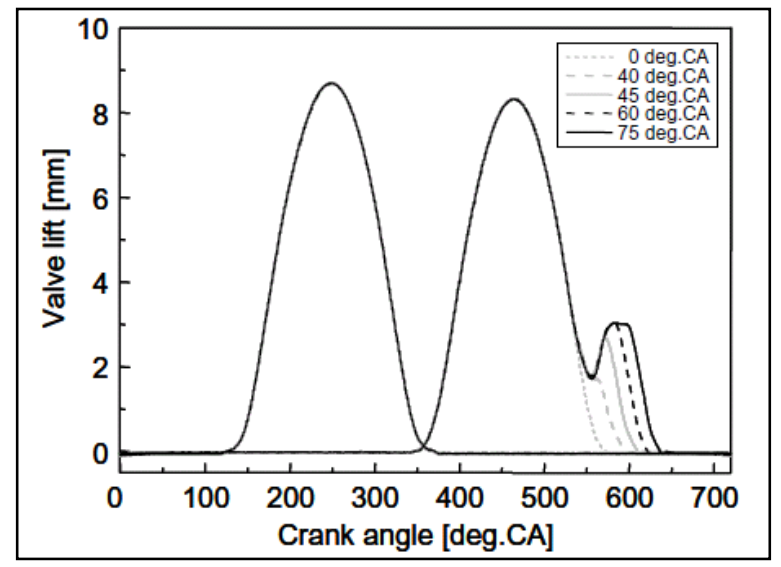

Figure 19 Variation of Valve Lift for Each Additional Intake Valve Opening [27] 


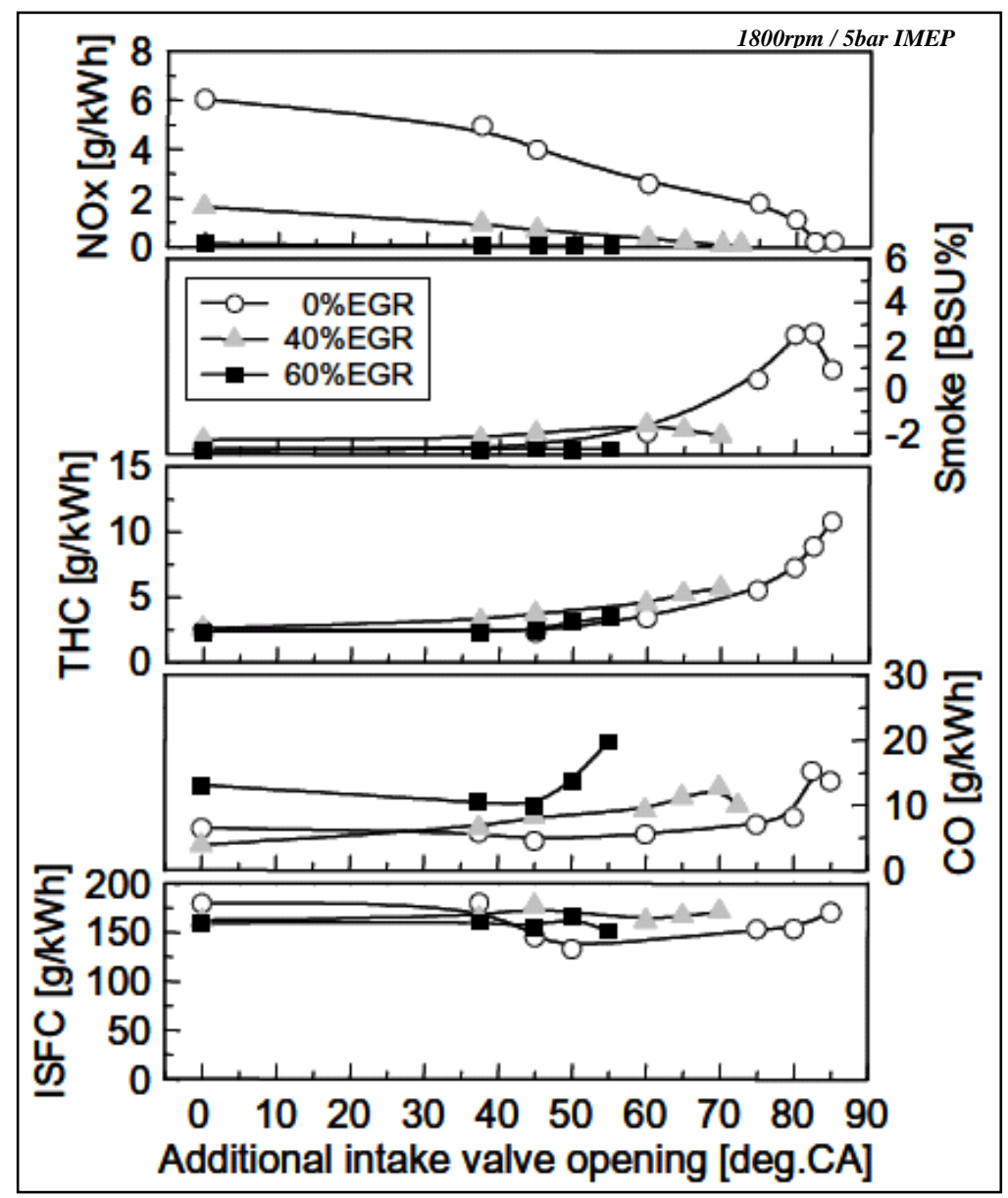

Figure 20 Exhaust Emissions and Fuel Consumption for Additional Intake Valve Opening [27]

Further benefits for additional intake valve opening include control of ignition delay and maximum pressure rise rate, as shown in Figure 12 and Figure 13 (see Section 2.2.1.4).

\subsubsection{Injection Spray Angle}

In-cylinder wall impingement due to longer liquid jet penetration inherent to earlyinjection conditions in advanced combustion regimes may lead to an increase in emissions and decrease in combustion efficiencies [22]. By widening or shortening the injection angle, preferably adapted for the in-cylinder dimensions, charge flow paths and piston bowl design as well as early injection strategy, significant reduction in in-cylinder wall wetting can be achieved. Experiments with three different spray cone angles using a 1.9L DI diesel engine with common rail fuel injection system and VGT showed increased $\mathrm{NO}_{\mathrm{x}}$ emissions with narrow spray cone angle for PCCI combustion modes as depicted in Figure 21 [34]. Better mixture formation conditions were present due to enhanced swirl and turbulence factors for the spray impinging 
close to the piston bowl. Fuel consumption was found to be highest with largest injection angle while HC emissions are slightly lower for narrow angle configuration, but overall high for PCCI combustion mode (advanced SOI timing) regardless of the spray cone angle [34].

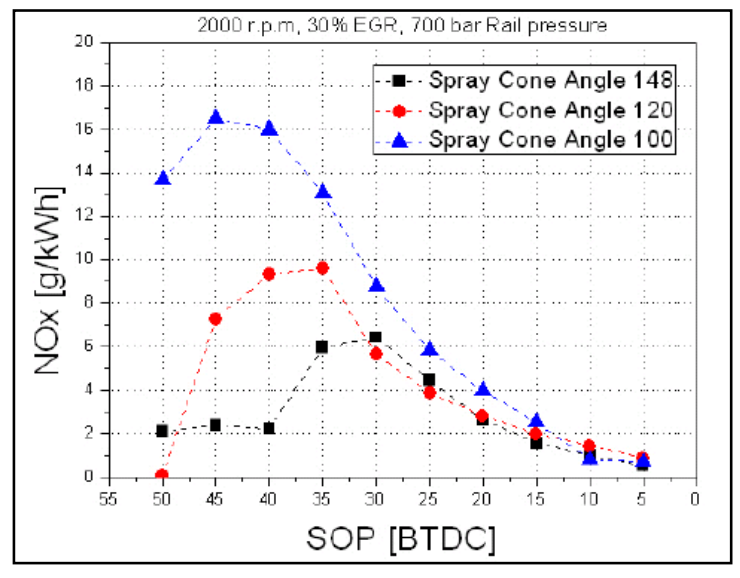

Figure $21 \mathrm{NO}_{\mathrm{x}}$ Emissions for Different Spray Cone Angles [34]

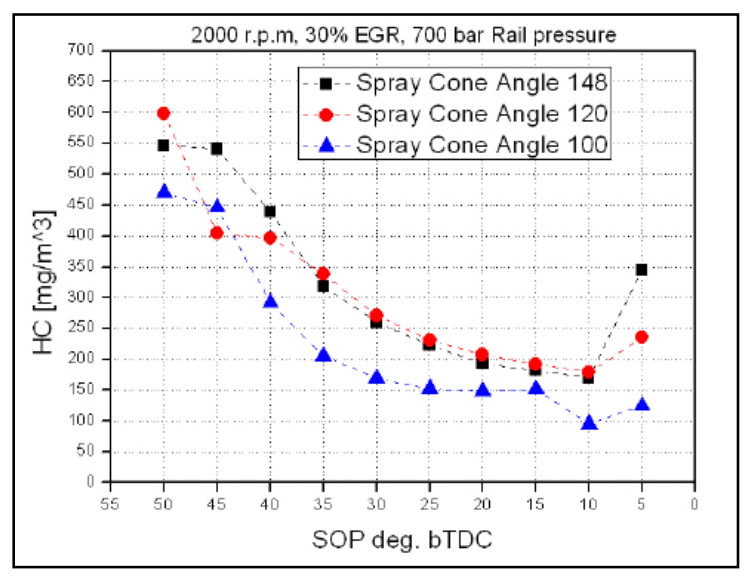

Figure 22 HC Emissions for Different Spray Cone Angles [34]

\subsection{Analysis of Physical and Chemical Properties for FACE Diesel Fuels}

In this section the most important methods of ASTM analyses used to measure the chemical and physical properties of the designed Fuels for Advanced Combustion Engines (FACE) are described. It should be noted that the formulation of the FACE diesel fuels in some cases differ from the fuel properties for which the ASTM tests were originally designed, leading to variation in the results obtained in comparison with conventional fuel measurements [35]. A more detailed description of the FACE diesel fuels including their design is given in Section 4.1 ('Fuel Properties").

\subsubsection{Cetane Number / Index}

The ASTM D613 "Standard Test Method for Cetane Number of Diesel Fuel Oil" describes the test method to rate diesel fuel oil on a scale of cetane numbers $(\mathrm{CN})$ ranging from zero to 100 using a standard four-stroke single cylinder indirect injected diesel engine with variable compression ratio (CR) [36]. The cetane number is, by definition, "a measure of the ignition performance of a diesel fuel oil obtained by comparing it to reference fuels in a standardized engine test" [36]. The ignition performance is the ignition delay of the fuel under controlled conditions of fuel flow rate, injection timing and compression ratio. As primary reference fuels (PRF) with known $\mathrm{CN}$, n-cetane (n-hexadecane) and heptamethylnonane (HMN) 
with assigned values of 100 and 15, respectively, are used, as well as volumetrically proportioned blends. The $\mathrm{CN}$ of a sample diesel fuel is then determined by comparing its combustion characteristics with the blended fuels with known $\mathrm{CN}$ under standard engine operating conditions using a handwheel procedure, which allows an interpolation of $\mathrm{CN}$ with the specific ignition delays obtained [36]. Figure 23 shows a test engine assembly used for the cetane method by the petroleum industry, as well as governmental and independent laboratories.

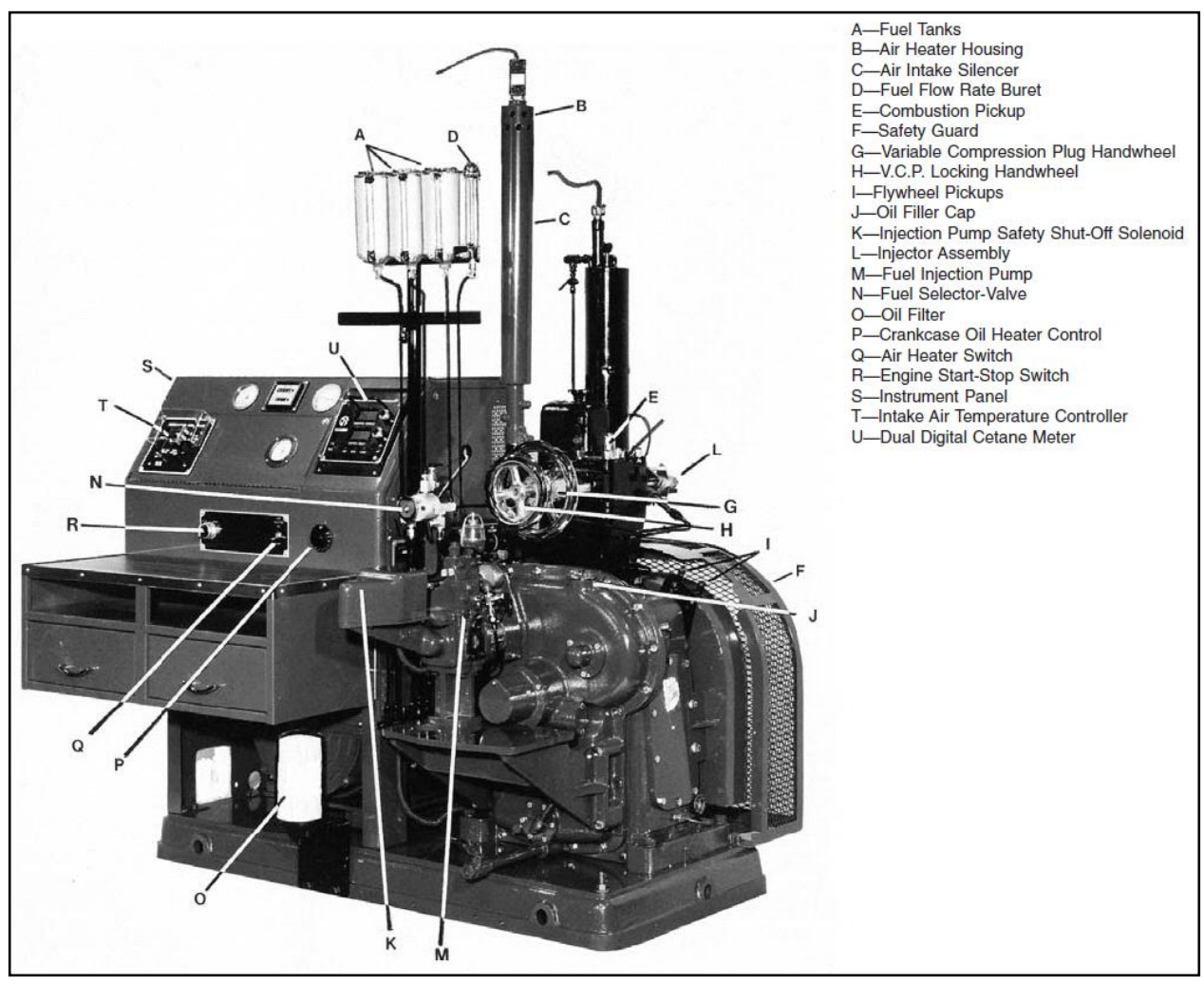

Figure 23 Cetane Method Test Engine Assembly [36]

If no test engine is available to determine $\mathrm{CN}$ or the sample quantity is too small for an engine rating, the ASTM cetane number can be approximated by the calculated cetane index (CI) formula, described in ASTM D976, including API gravity, determined by ASTM D4052, and mid-boiling point by ASTM D86, outlined in [37], [38] and [39], respectively. Applying this method to FACE diesel fuels results in significant differences compared to CN's determined by the ASTM D613 test method, since it is particularly applicable to straight-run fuels, catalytically cracked stocks and blends of the two, not for fuels with unusual chemistry as the FACE diesel fuels [40]. 


\subsubsection{Aromatic Content}

The volumetric percentage of the hydrocarbon types aromatics, olefins and saturates in petroleum fractions that distill below $315^{\circ} \mathrm{C}$ can be determined per ASTM D1319 "Standard Test Method for Hydrocarbon Types in Liquid Petroleum Products by Fluorescent Indicator Adsorption." Table 2 lists the definitions for the different hydrocarbon types.

Table 2 Hydrocarbon Terminology [41]

\begin{tabular}{|l|l|}
\hline Hydrocarbon Type & Definition \\
\hline Aromatics & $\begin{array}{l}\text { Monocyclic and polycyclic } \\
\text { aromatics, plus aromatic olefins, } \\
\text { some dienes, compounds } \\
\text { containing sulfur and nitrogen, } \\
\text { or higher boiling oxygenated } \\
\text { compounds }\end{array}$ \\
\hline Olefins & $\begin{array}{l}\text { Alkenes, plus cycloalkenes, } \\
\text { some dienes }\end{array}$ \\
\hline Saturates & Alkanes, plus cycloalkanes \\
\hline
\end{tabular}

For this method, the sample is introduced into a glass adsorption column that is tapered in the filling section on top and packed with an activated silica gel to a certain level. A small layer of the silica gel contains a mixture of fluorescent dyes and after adsorption of the sample on the gel, alcohol is added desorbing the sample down the column. This separates the hydrocarbons into aromatics, olefins and saturates. Under ultraviolet light, the boundaries of the zones are visible, because the dyes are also separated selectively with the hydrocarbon types; see Figure 24. The volumetric percentage is then calculated from the length of each zone in the column. 


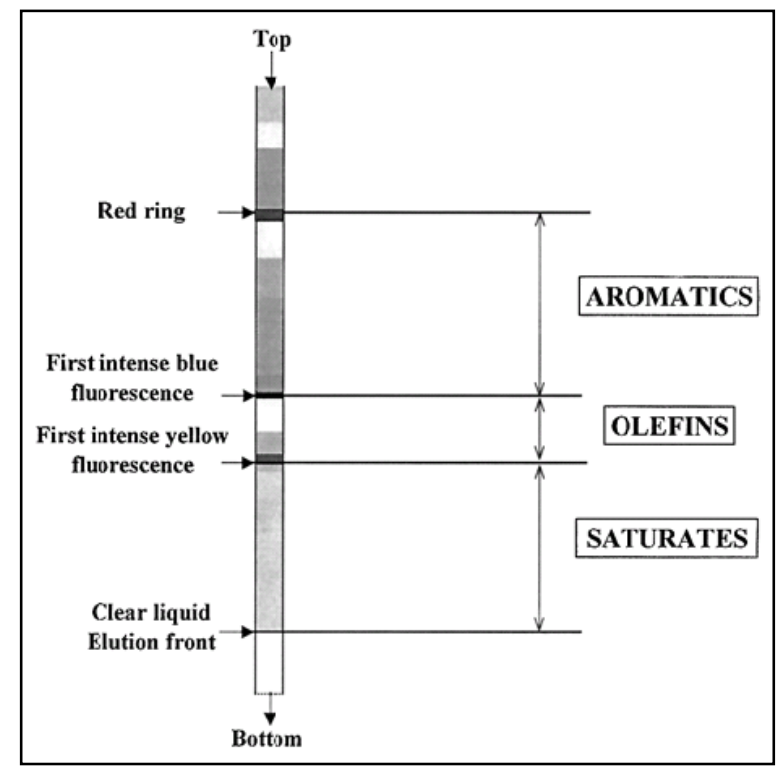

Figure 24 Pictorial Aid for Identification of Chromatographic Boundaries [41]

Two other test methods to determine aromatic content are ASTM D5186 and ASTM D2425, which were also conducted for the FACE diesel fuels [40]. The test method ASTM D1319 excludes hydrocarbon types in petroleum fractions that distill above $315^{\circ} \mathrm{C}$; thus, the ASTM D5186 test method is often used giving the monoaromatic, polynuclear aromatic and nonaromatic components on a percent mass basis in the boiling range of diesel fuels. ASTM D2425, outlined in [42], has shown higher precision determining total aromatics and polynuclear aromatic hydrocarbons in diesel fuels using mass spectrometry (MS), but is more expensive and time-consuming than the two aforementioned test methods [43].

\subsubsection{Percent Distillation Temperature (T90)}

The ASTM standard test method D86 describes the distillation (volatility) of petroleum products using a laboratory distillation unit at atmospheric pressure. A sample of known quantity is distilled under prescribed conditions in a distilling flask, whereas systematic observations of temperature readings and volumes of condensate are made either manually or automated. The test results are reported in percent evaporated sample versus the corresponding temperature. Therefore, a T90 distillation temperature value of a fuel declares that $90 \%$ of the fuel was evaporated at the indicated temperature. A typical apparatus used for this test method is shown in Figure 25. 


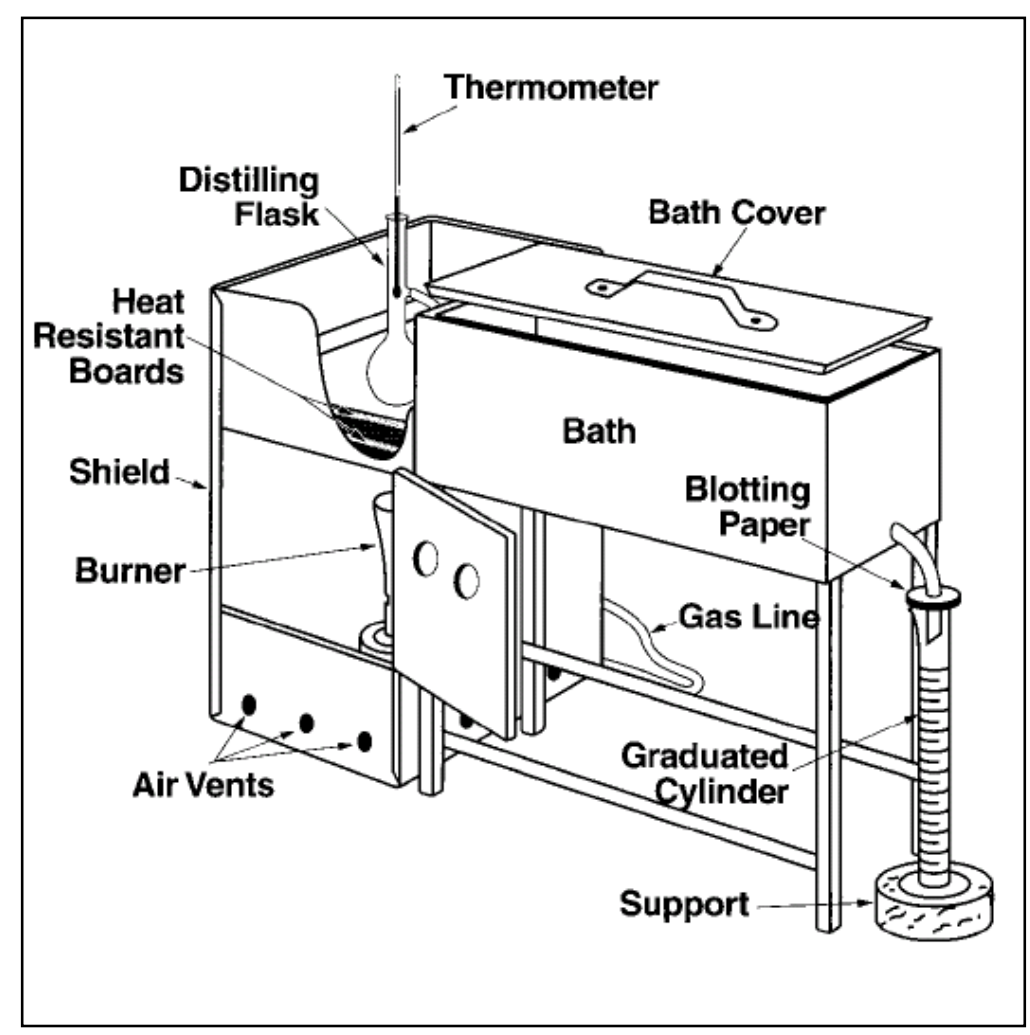

Figure 25 Apparatus Assembly using a Gas Burner [39]

Distillation temperatures can also be simulated by the use of gas chromatography, as outlined in ASTM D2887 [44]. Distillation curves for all FACE diesel fuels are included in the final report of the Coordinating Research Council (CRC) and can be found in [35].

\subsubsection{Specific Gravity}

The determination of the density, relative density (often referred to as specific gravity) and API gravity of petroleum distillates and viscous oils is covered in the standard test method ASTM D4052. A small sample is filled into an oscillating sample tube. The change in mass of the tube changes the oscillating frequency. Together with calibration data, the density, relative density and API gravity of the sample can be determined [38].

\subsubsection{Net Heat of Combustion}

In test method ASTM D240 the determination of the heat of combustion of liquid hydrocarbon fuels is described. The heat of combustion is a measure of the energy available from a fuel and is computed from temperature observations before, during and after combustion of a weighed sample in an oxygen bomb calorimeter. The net heat of combustion is "the quantity of 
energy released when a unit mass of fuel is burned at constant pressure, with all of the products, including water, being gaseous" [45].

\subsubsection{Elemental Analysis}

The "Instrumental Determination of Carbon, Hydrogen and Nitrogen in Petroleum Products and Lubricants" outlined in ASTM standard method D5291 delivers total carbon, total hydrogen and total nitrogen values in percent of mass. There are four different test methods outlined in the standard, which can vary from type of instrument used. The general principle for all of them is burning a sample in a combustion reactor where it is being entirely converted to carbon dioxide, water vapor and elemental nitrogen. The gases are subsequently determined by isolating the desired gaseous products in an appropriate gas stream [46].

\subsubsection{Further ASTM Standard Test Methods used for FACE Diesel Fuels}

Numerous analyses were performed for the FACE diesel fuels by different laboratories to thoroughly characterize their physical and chemical properties. An overview of the standard test methods performed, but not described here, is given in Table 3.

Table 3 Further ASTM Standard Test Methods used for FACE Diesel Fuels

\begin{tabular}{|l|l|l|}
\hline $\begin{array}{l}\text { ASTM Standard } \\
\text { Test Method }\end{array}$ & Physical or Chemical Property & Standard Test Method for \\
\hline ASTM D445 & Kinematic Viscosity & $\begin{array}{l}\text { Kinematic Viscosity of Transparent and Opaque Liquids } \\
\text { (and Calculation of Dynamic Viscosity) }\end{array}$ \\
\hline ASTM D2500 & Cloud Point & Cloud Point of Petroleum Products \\
\hline ASTM D93 & Flash Point & Flash Point by Pensky-Martens Closed Cup Tester \\
\hline ASTM D6079 & Lubricity & $\begin{array}{l}\text { Evaluating Lubricity of Diesel Fuels by the High- } \\
\text { Frequency Reciprocating Rig (HFRR) }\end{array}$ \\
\hline ASTM D6890 & Derived Cetane Number (DCN) & $\begin{array}{l}\text { Determination of Ignition Delay and Derived Cetane } \\
\text { Number (DCN) of Diesel Fuel Oils by Combustion in a } \\
\text { Constant Volume Chamber }\end{array}$ \\
\hline ASTM D1159 & Bromine Number & $\begin{array}{l}\text { Bromine Numbers of Petroleum Distillates and } \\
\text { Commercial Aliphatic Olefins by Electrometric Titration }\end{array}$ \\
\hline ASTM D5453 & Sulfur Content & $\begin{array}{l}\text { Determination of Total Sulfur in Light Hydrocarbons, } \\
\text { Spark Ignition Engine Fuel, Diesel Engine Fuel and } \\
\text { Engine Oil by Ultraviolet Fluorescence }\end{array}$ \\
\hline ASTM D5623 & Sulfur Content & $\begin{array}{l}\text { Sulfur Compounds in Light Petroleum Liquids by Gas } \\
\text { Chromatography and Sulfur Selective Detection }\end{array}$ \\
\hline ASTM D4629 & Nitrogen Content & $\begin{array}{l}\text { Trace Nitrogen in Liquid Petroleum Hydrocarbons by } \\
\text { Syringe/Inlet Oxidative Combustion and } \\
\text { Chemiluminescence Detection }\end{array}$ \\
\hline
\end{tabular}




\subsection{Effect of Fuel Properties on Advanced Combustion Strategies}

Fuel properties have a significant impact on the ignition and combustion process; hence, achievement of advanced combustion modes with their impact on resulting emissions and engine performance by fuel design in conjunction with engine control strategy, and engine hardware modification (see subsection 2.2) has become a common approach [7]. Therefore, the AVFL committee of the CRC specified and formulated a matrix of nine test fuels for advanced combustion engines (FACE) based on the variation of the following three properties [35]:

1. Cetane number

2. Aromatic content

3. 90 percent distillation temperature.

Other researchers blended conventional diesel fuel with iso-octane, iso-paraffins, toluene and methyl tertiary-butyl ether (MTBE) to study fuel property effects on combustion and exhaust emissions of a 2.15L single cylinder diesel engine operating in HCCI mode [26]. The following subsections discuss the effects of the fuel properties cetane number, aromatic content and 90 percent distillation temperature on advanced combustion strategies.

\subsubsection{Cetane Number}

Cetane number is a key measure of diesel fuel combustion quality and is inversely related to ignition delay time; thus, longer ignition delay for low $\mathrm{CN}$ and shorter ignition delay for high $\mathrm{CN}$ fuels, respectively. A lower $\mathrm{CN}$ fuel tends to ignite slower creating longer ignition delay than a high $\mathrm{CN}$ fuel. This results in longer mixing time for air and fuel, hence homogeneity of the incylinder charge is related to cetane number, as well $[47,48]$. The strong resistance to autoignition can cause difficulties in certain combustion conditions, for example cold start [49]. An experimental investigation on a 1.9L DI light-duty diesel engine with VGT and high pressure loop EGR was performed to better understand FACE diesel fuel property effects [24]. CN showed to be the main factor in determining acceptable injection timing ranges for each fuel for low temperature combustion regimes [24]. Other researchers who have used FACE diesel fuels have reported that $\mathrm{CN}$ significantly affected the combustion phasing [50]. Figure 26(a) shows the aforementioned longer ignition delay for the low CN FACE diesel fuels (fuels 1 through 4, straight lines) allowing for more mixing time; hence, reduced local fuel rich regions and thus 
lower PM formation. Combustion noise was increased for both, low and high CN fuels, while advancing SOI timing, see Figure 26(b) [24].

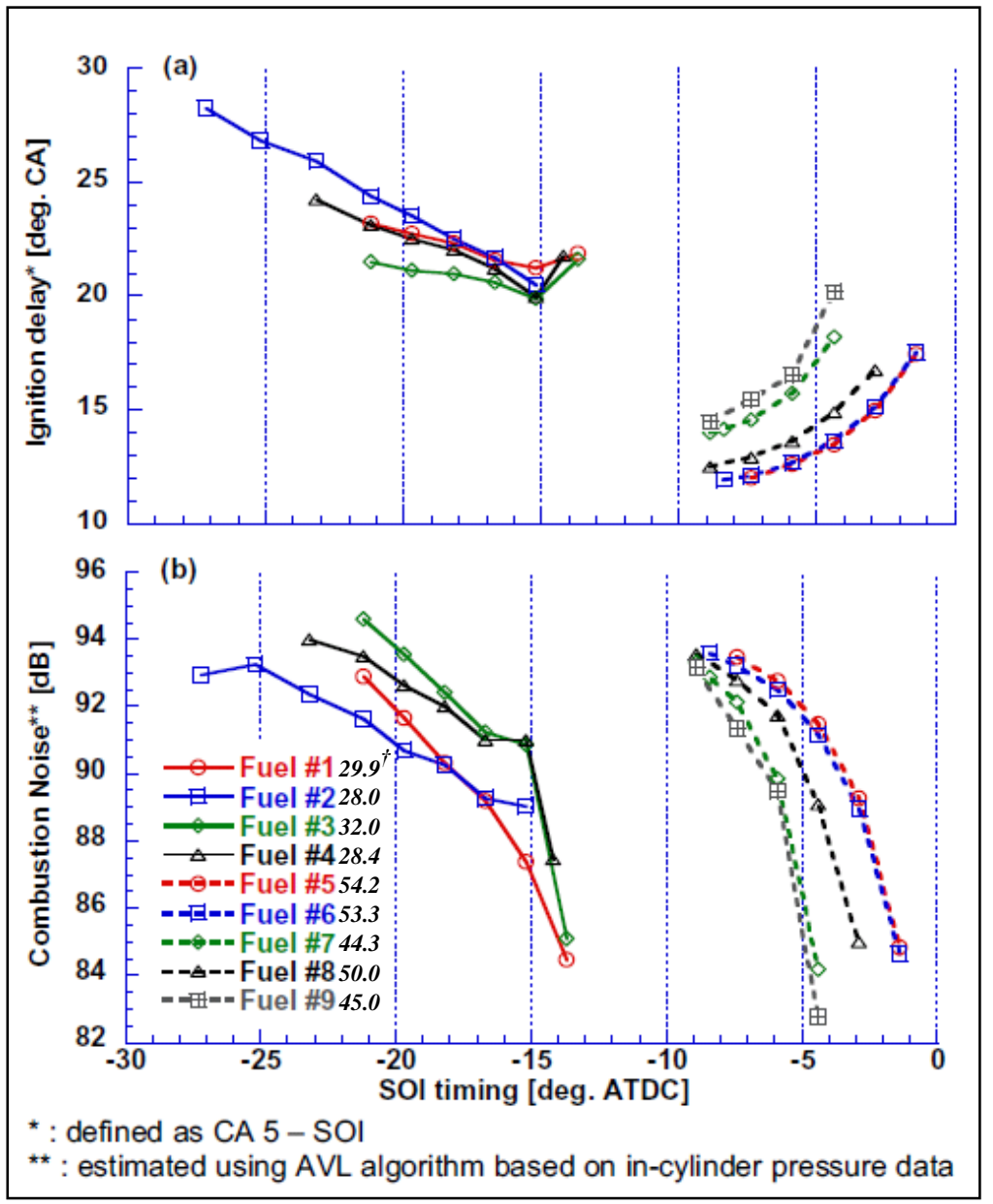

Figure 26 Ignition Delay (a) and Combustion Noise (b) vs. SOI Timing for FACE Diesel Fuels (where $\%$ denotes CN)[24]

For higher $\mathrm{CN}$ fuels a small decrease in $\mathrm{NO}_{\mathrm{x}}$ emissions can usually be observed. For $\mathrm{CN}$ ranging from 40 to 55 around $5 \%$ reduction in $\mathrm{NO}_{\mathrm{x}}$ formation per $10 \mathrm{CN}$ increments was found in a fuel property study [51]. Results from a single cylinder HCCI engine showed the same trend in $\mathrm{NO}_{\mathrm{x}}$ reduction for fuels with higher $\mathrm{CN}$, presumably "due to lower intake air temperatures required for higher cetane fuels, which results in lower peak combustion temperatures" and an increase in $\mathrm{CO}$ emissions [52].

Figure 27 shows higher $\mathrm{NO}_{\mathrm{x}}$ and $\mathrm{CO}$ emissions as well, with very low PM emissions for low CN fuels performing a SOI timing sweep compared to the high $\mathrm{CN}$ fuels (fuels 5 through 9 , dashed lines). The longer ignition delay with the low $\mathrm{CN}$ fuels resulted in the higher $\mathrm{NO}_{\mathrm{x}}$ emissions. In general, much more advanced SOI timings were possible for low $\mathrm{CN}$ fuels and an 
increase in $\mathrm{NO}_{\mathrm{x}}$ emissions for low and high $\mathrm{CN}$ fuels advancing $\mathrm{SOI}$ timings was obtained, as expected. Furthermore, slightly lower $\mathrm{HC}$ emissions resulted from high $\mathrm{CN}$ fuels compared to low CN fuels, while BSFC was comparable, as depicted in Figure 28. These results agreed with other investigations using FACE diesel fuels on a $0.75 \mathrm{~L}$ single cylinder test engine during low temperature combustion modes (low, medium and high loads), where low $\mathrm{CN}$ fuels showed higher $\mathrm{HC}$ and $\mathrm{CO}$ emissions and lower fuel efficiency compared to higher $\mathrm{CN}$ fuels, due to the "considerable amount of fuel energy" contained in these elevated emissions [49]. Lesser resistance to auto-ignition helped reducing $\mathrm{HC}$ and $\mathrm{CO}$ emissions from incomplete combustion for high $\mathrm{CN}$ fuels. Additionally, low $\mathrm{CN}$ fuels improved the trade-off between $\mathrm{NO}_{\mathrm{x}}$ and $\mathrm{PM}$ emissions for low and medium loads (5.5 and 10.6bar IMEP), whereas no difference could be detected for high load (14.6bar IMEP) [49].

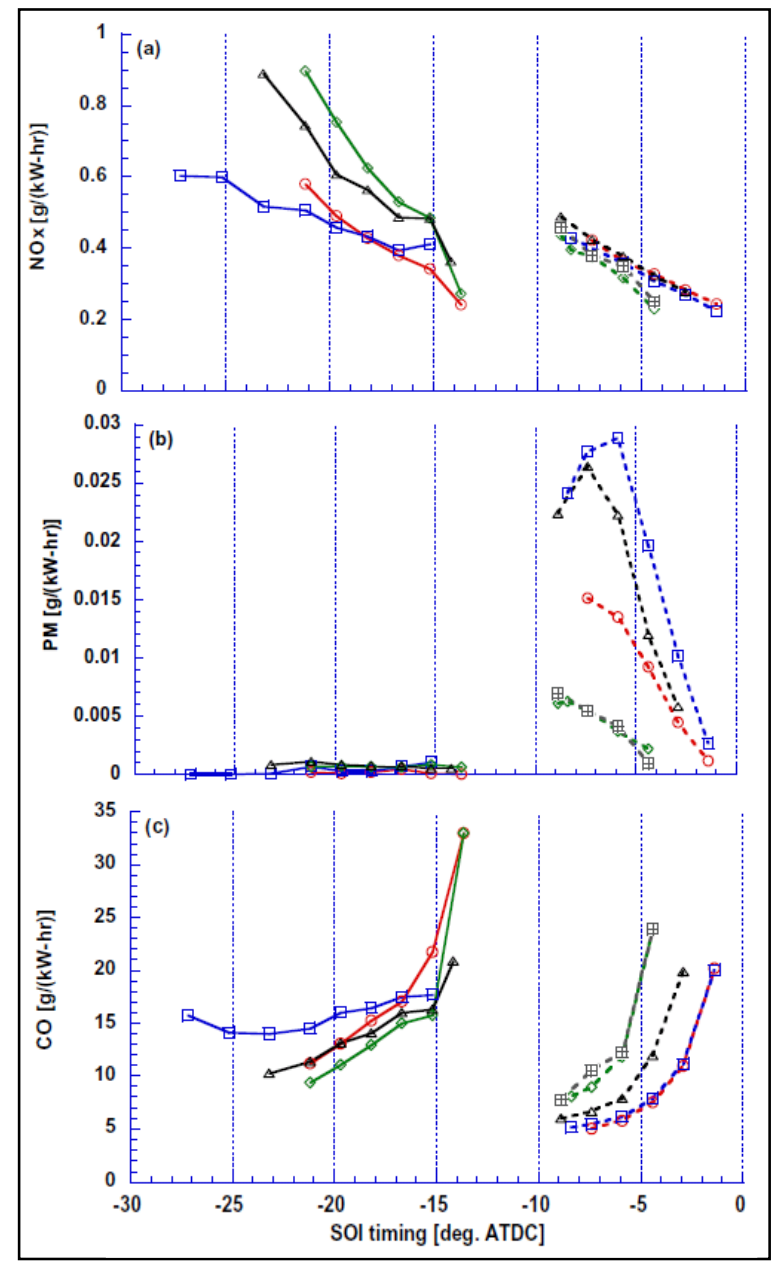

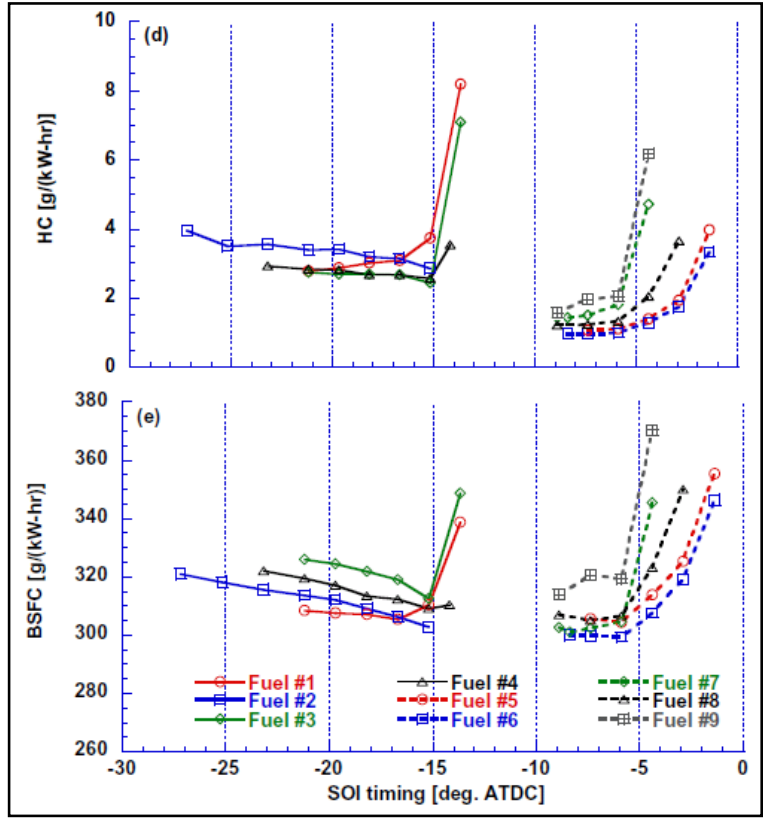

Figure $28 \mathrm{HC}$ Emissions and BSFC vs. SOI Timing for FACE Diesel Fuels [24]

Figure $27 \mathrm{NO}_{\mathrm{x}}, \mathrm{PM}$ and $\mathrm{CO}$ Emissions vs. SOI Timing for FACE Diesel Fuels [24] 


\subsubsection{Aromatic Content}

Aromatic content and $\mathrm{CN}$ are not completely independent of each other; hence, aromatic content can affect $\mathrm{CN}$ and exhaust emissions [43]. Aromatic compounds are usually very low $\mathrm{CN}$ compounds, therefore fuels with high aromatic content tend to be low CN fuels [49]. It has been reported that aromatics are precursors of PM formation, and therefore, greatly affect PM emissions [24]. This effect is shown in Figure 29, where two FACE diesel fuels are compared with blocked CN (low) and T90 (high) from results on a single cylinder 0.75L diesel engine using single injection for LTC regimes. At medium load (10.6bar IMEP), the higher soot emissions from fuel 3 could be attributed to the higher aromatic contents, since the ignition delay was even slightly longer [49]. On the other hand, a comparison of low $\mathrm{CN}$ fuels with high and low aromatic contents at high load (14.6bar IMEP) showed very minor impact on PM formation. The effect on prolonged ignition delay seemed to compete with the PM formation propensity of the aromatic fuel molecules [49].

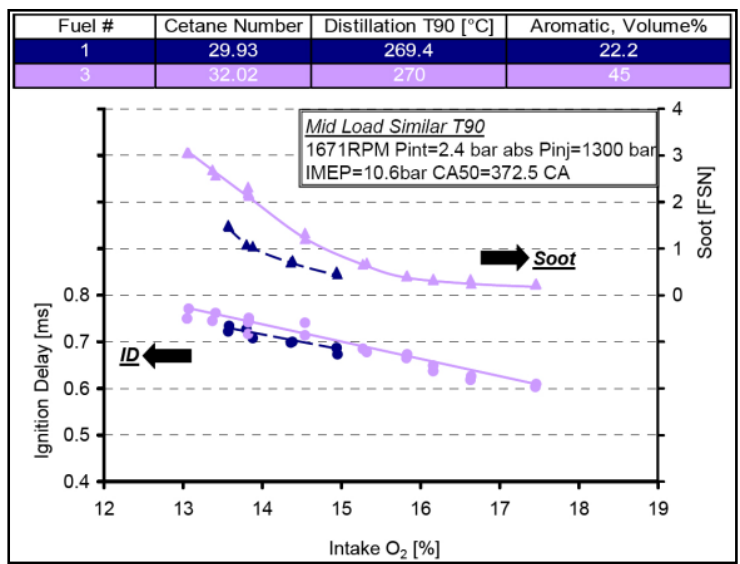

Figure 29 Aromatic Effect at Low T90 on Ignition Delay and Soot Emissions at Medium Load

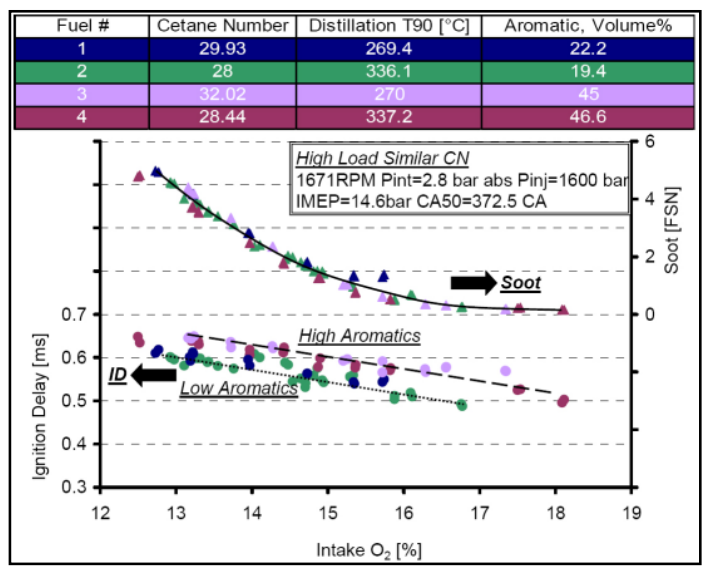

Figure 30 Aromatic Effect on Ignition Delay and Soot Emissions at High Load [49]

Furthermore, insignificant impact was reported on $\mathrm{NO}_{\mathrm{x}}$ emissions, albeit in disagreement with Figure 27, which shows lower $\mathrm{NO}_{\mathrm{x}}$ emissions for fuels 1 and 2 (low aromatic contents) compared to fuels 3 and 4 (high aromatic contents) during SOI timing sweeps [24]. For low CN fuels with higher aromatic contents, the highest $\mathrm{HC}$ and $\mathrm{CO}$ emissions resulted at low load conditions (5.5bar IMEP) indicating that aromatics also contribute to the products of incomplete combustion [49]. 


\subsubsection{Percent Distillation Temperature}

The T90 distillation temperature value of a fuel, an indication that $90 \%$ of the fuel was evaporated at the indicated temperature, is often used to draw conclusions about the volatility of the fuel. A lower distillation temperature indicates higher volatility, and therefore, evaporation, which improves the air-fuel mixing rate and enhances the potential to form homogeneous mixtures. This eliminates local fuel zones and reduces the maximum combustion temperature; hence, $\mathrm{NO}_{\mathrm{x}}$ and PM emissions [7]. The effect of low T90 (fuels 1 and 5) on PM formation is shown in Figure 31, which corresponds to results presented for high CN fuels in Figure 27 (fuels 5 and 7) for SOI timing sweeps. Even though ignition delay is more dependent on $\mathrm{CN}$, minor but noticeable differences were found for high and low T90 [49].

A drawback of using T90 as a fuel parameter can be seen in Figure 32, where the T90 distillation temperature values for fuels 1 and 2 were clearly separated $\left(284\right.$ vs. $\left.346^{\circ} \mathrm{C}\right)$, but the T10 and T50 distillation temperatures were similar [24].

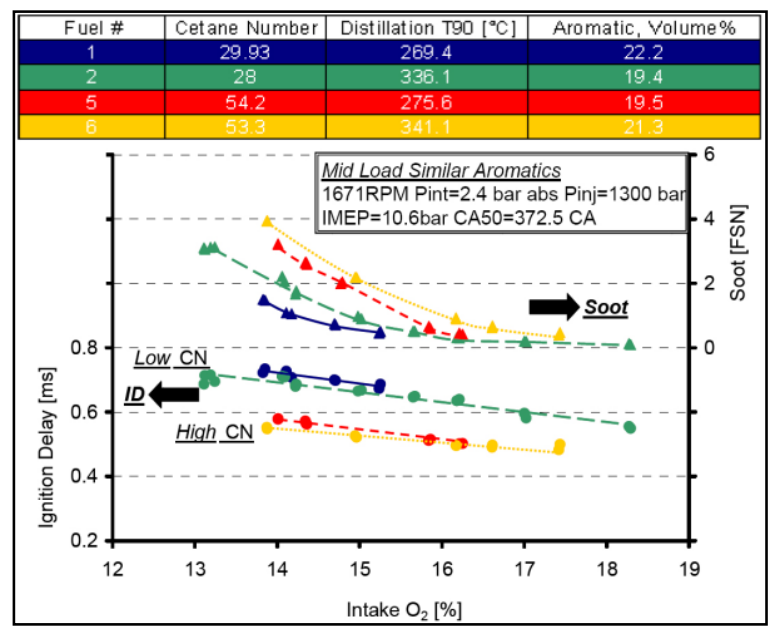

Figure $31 \mathrm{CN}$ and T90 Effects on Ignition Delay and Soot Emissions at Medium Load [49]

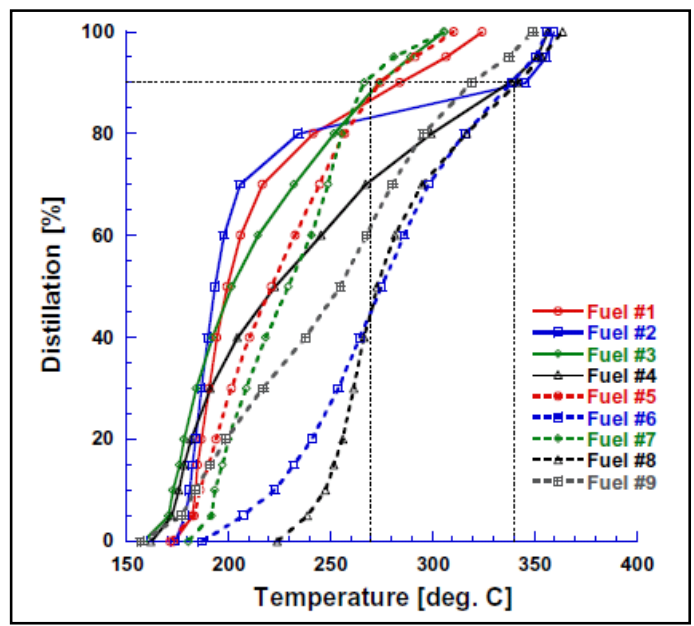

Figure 32 Distillation Curves for FACE Diesel Fuels [24]

\subsection{Diesel Particulate Matter}

Due to environmental concerns about particles, namely adverse health effects, decreased visibility and soiling of buildings, that are mainly produced by diesel and spark-ignited GDI engines, the US Environmental Protection Agency (EPA) set National Ambient Air Quality Standards (NAAQS) for particle pollution maintaining the allowed levels of PM10 (particles with a $\mathrm{d}_{50}$ of smaller than $10 \mu \mathrm{m}$ aerodynamic diameter) at $150 \mu \mathrm{g} / \mathrm{m}^{3}$ average concentration, not 
to be exceeded more than once per year on average over 3 years, and PM2.5 at $15 \mu \mathrm{g} / \mathrm{m}^{3}$ annual arithmetic mean, averaged over 3 years [53]. These standards are the result of many studies in the field of toxicology and epidemiology that have established adverse health effects due to particulate matter, namely cardiopulmonary and lung cancer mortality [54, 55].

\subsubsection{Formation of Diesel Particulate Matter}

The US Environmental Protection Agency defines diesel particulate matter as the mass collected on a filter placed in the exhaust sample stream that has been diluted and cooled down to a temperature of $47^{\circ} \mathrm{C} \pm 5^{\circ} \mathrm{C}$ [56]. Diesel particulate matter in the exhaust before dilution consists mainly of solid carbonaceous agglomerates, originating from combustion in locally rich regions, and a small amount of metallic ash from metal compounds in the fuel and lube oil [57]. Volatile or soluble organic compounds, mostly described as soluble organic fraction (SOF) and originating from partially burned and unburned fractions of fuel and lube oil, appear in the exhaust as well. A schematically illustration is given in Figure 33. However, due to dilution and cooling of the exhaust, a significant quantity of the volatile organic and sulfur compounds, being in gas phase at exhaust temperatures, is transformed to diesel PM by nucleation, adsorption and condensation. Most of it is adsorbed onto the surface of the existing carbonaceous agglomerates (heterogeneous nucleation), but a certain amount may also undergo "homogeneous nucleation to form new particles in the nanometer diameter range" [58]. The formation of these nucleation particles may be favored when solid carbon emissions are relatively low compared to emissions of volatile organic and sulfur compounds. Depending on temperature, dilution rate, humidity and relative concentrations of carbon and volatile matter, the volatile fraction may remain in the gas phase, condense on existing solid particles or nucleate and form new particles [3]. An example of typical particulate matter composition from a heavy-duty diesel engine (HDDE) tested over a heavy-duty (HD) transient cycle (FTP) on an engine test bench is depicted in Figure 34. The fraction associated with unburned fuel and lube oil (SOF) can vary from less than 10\% to more than $90 \%$ depending on engine design and operating condition, but is highest for low exhaust temperatures during light engine load conditions [57]. 

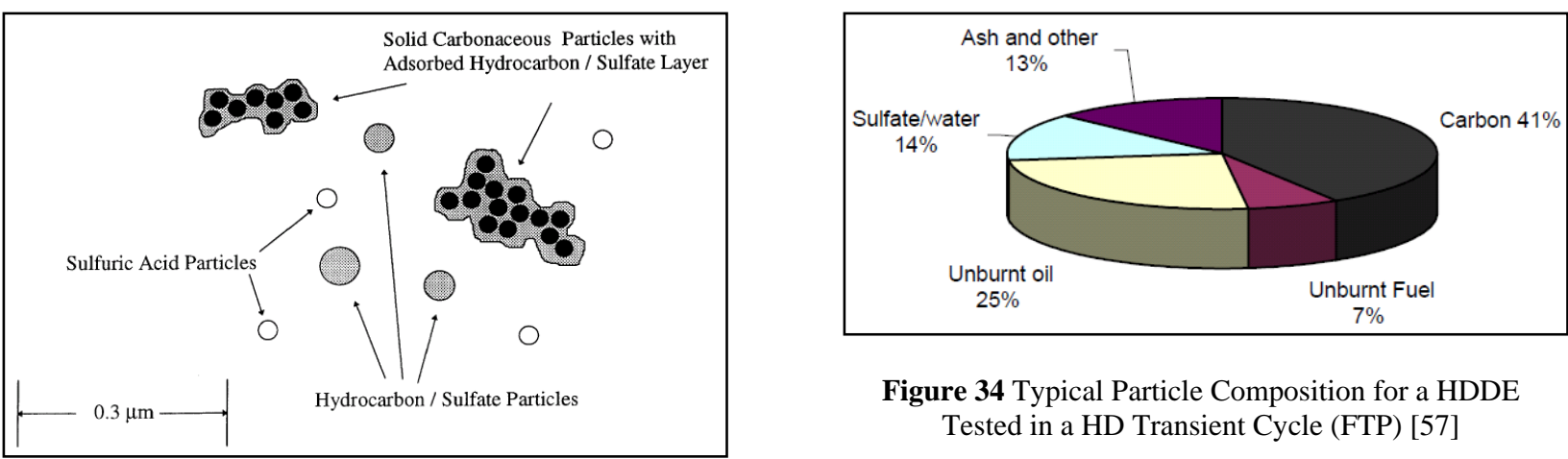

Figure 34 Typical Particle Composition for a HDDE Tested in a HD Transient Cycle (FTP) [57]

Figure 33 Typical Composition and Structure of Engine Exhaust Particles [57]

\subsubsection{Particle Size Distribution}

Particle size earned increasing attention by researchers in recent years and evidence was found that several health effects may be associated with particles having a diameter smaller than $100 \mathrm{~nm}$ that can penetrate cell membranes, enter into the blood and even reach the brain $[3,4]$.

Figure 35 shows a typical (idealized) diesel engine exhaust particle size distribution with distinction between mass and number weighting. Most of the particle mass exists in the so-called accumulation mode, which ranges from 100 to $300 \mathrm{~nm}$, consisting of the aforementioned carbonaceous agglomerates and associated adsorbed materials [57]. The nucleation mode, typically consisting of particles in the 5 to $50 \mathrm{~nm}$ range, contains more than $90 \%$ of the particle number (1 to 20\% mass). These particles are mainly formed from the volatile organic and sulfur compounds during exhaust dilution and cooling, but may also contain solid carbon and metal compounds. Accumulation mode particles that have been deposited on cylinder and exhaust system surfaces and/or the particulate sampling system and subsequently re-entrained are represented in the so-called coarse mode, containing 5 to $20 \%$ of the total PM mass [57]. Some size definitions for atmospheric particles based on their aerodynamic diameter, defined as the diameter of a $1 \mathrm{~g} / \mathrm{cm}^{3}$ density sphere of the same settling velocity in air as the measured particle, are also shown in Figure 35, namely PM10 consisting of particles with a $d_{50}$ of $10 \mu \mathrm{m}$, fine particles of diameters below $2.5 \mu \mathrm{m}$, ultrafine particles of diameters less than $100 \mathrm{~nm}$ and nanoparticles, characterized by diameters less than $50 \mathrm{~nm}$. Based on number weightings, almost all of the particles emitted by a diesel engine are nanoparticles [57]. 


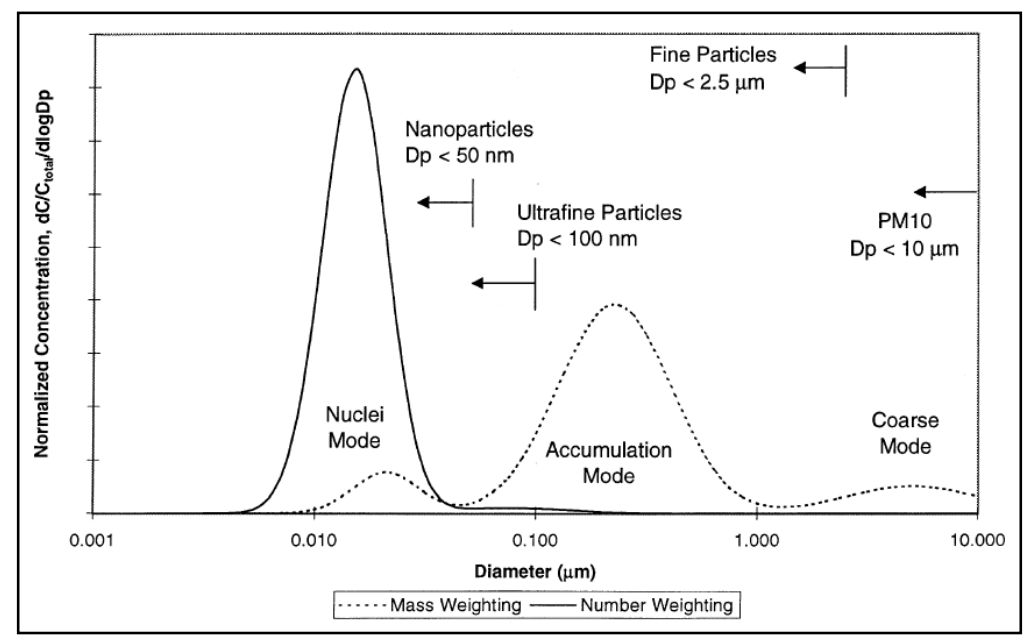

Figure 35 Typical Engine Exhaust Particle Size Distribution (Mass and Number Weightings) [57]

\subsubsection{Nanoparticle Formation}

Due to the importance of nanoparticles for size and number characterization of diesel engine exhaust, laboratory experiments were performed exploring factors affecting the nanoparticle formation, namely dilution ratio and temperature as well as residence time and humidity.

\subsubsection{Dilution Ratio and Temperature}

In order to simulate real-world atmospheric dilution processes, and condition the particles in the raw exhaust in a way, such that the exhaust sample can be handled by the measurement system in terms of concentration and temperature, raw engine exhaust is diluted prior to measurement. Cooling the exhaust with low to moderate dilution ratios in the range of about 5 to 50 results most likely in high saturation ratios (the ratio of partial pressure to vapor pressure of condensable species), thus nucleation, as shown in Figure 36, where raw exhaust was diluted using an ejector type dilutor [58, 59]. An investigation on the influence of dilution temperature on particle size distribution was performed using a medium-duty MY95 compliant diesel engine running on standard number 2 diesel fuel (0.03\% sulfur content) at $50 \%$ load at $1600 \mathrm{rpm}$. Particle size distributions were measured using a scanning mobility particle sizer (SMPS) in conjunction with a condensation particle counter (CPC) to quantify the size resolved number concentrations. The variation in primary dilution stage temperature at fixed residence time of $400 \mathrm{~ms}$, fixed dilution ratios (first stage $\mathrm{DR}=12$, second stage $\mathrm{DR}=60$ ) and a dew point of $1^{\circ} \mathrm{C}$ 
is illustrated in Figure 37. An increase in up to more than one order of magnitude for particles in the nanoparticle size range was observed by reducing the temperature from 65 to $32^{\circ} \mathrm{C}$ [58].

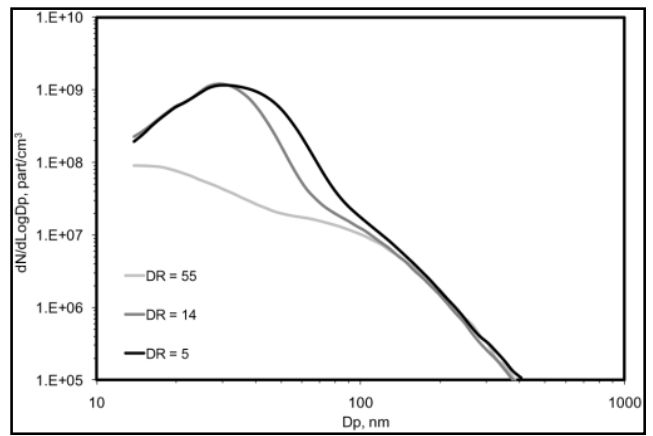

Figure 36 Influence of Dilution Ratio on Particle Size Distribution [59]

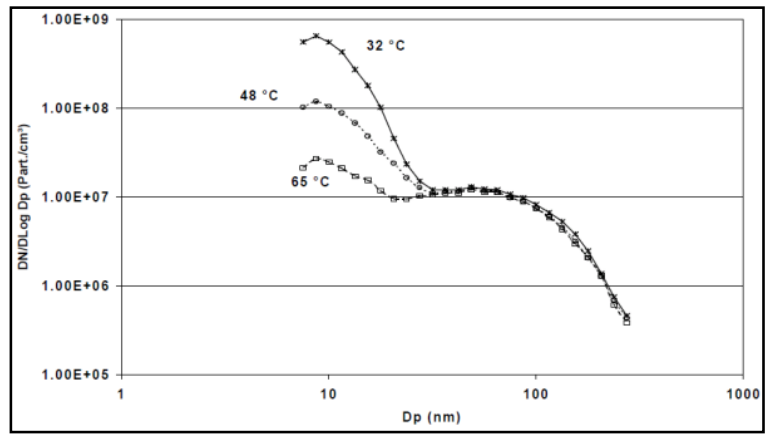

Figure 37 Influence of Dilution Temperature on Particle Size Distribution [58]

\subsubsection{Residence Time and Humidity}

Using the same aforementioned diesel particle source at 50\% load and 1600rpm, the influence of residence time in the primary dilution stage on particle size distribution at fixed dilution ratios (first stage $\mathrm{DR}=12$, second stage $\mathrm{DR}=60$ ), fixed primary dilution temperature of $48^{\circ} \mathrm{C}$ and dew point of $1^{\circ} \mathrm{C}$ were investigated, see Figure 38. Particles in the nanoparticle size range were increased by almost two orders of magnitude for a change in residence time from 90 to $900 \mathrm{~ms}$. However, for particles larger than about $50 \mathrm{~nm}$ almost no changes were observed, indicating that they may consist of carbonaceous agglomerates [58].

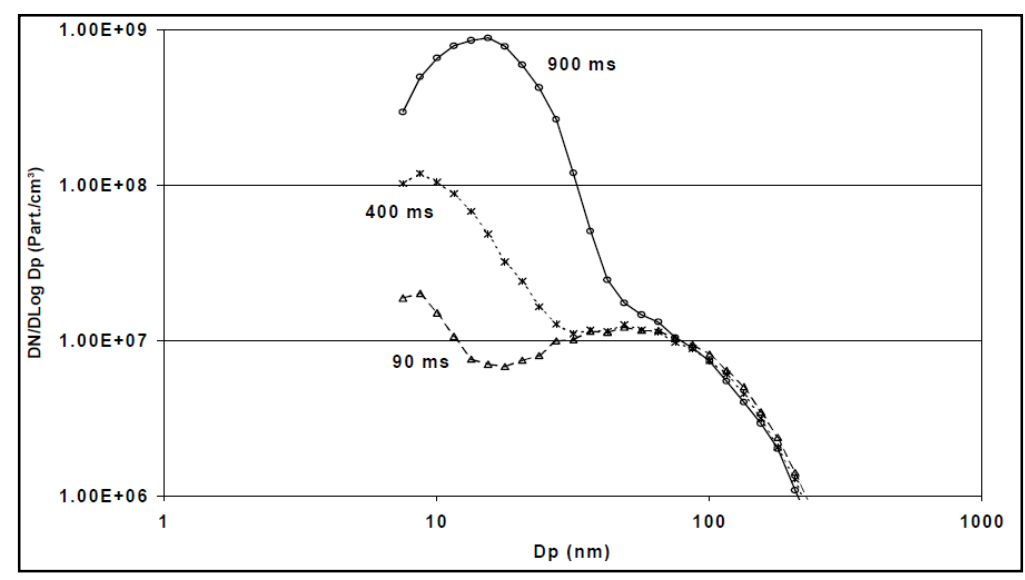

Figure 38 Influence of Residence Time in Primary Dilution Stage on Particle Size Distribution [58]

Rising the relative humidity from 15 to $50 \%$ with a dilution temperature of $30^{\circ} \mathrm{C}$ and fixed residence time of $300 \mathrm{~ms}$ showed a modest increase in total number concentration of 10 to $20 \%[58]$. 


\subsection{Particulate Matter Number Concentration and Size Distribution in Advanced Combustion Modes}

Particulates from advanced combustion modes are different compared to conventional diesel combustion. A study on a 1.7L common-rail diesel engine with high pressure loop EGR exploring PCCI and HCCI combustion modes during steady state engine operation showed significantly higher soluble organic fractions (SOF) compared to the insoluble fractions at an operating point of $0.8 \mathrm{bar}$ BMEP and 1500rpm in PCCI combustion mode compared to the conventional combustion mode (see Figure 39). It is evident from Figure 39 that even for the higher PM emissions index (defined as fuel-specific PM mass emissions in $\mathrm{g}$ of $\mathrm{PM} / \mathrm{kg}$ of fuel) in the PCCI mode the carbonaceous agglomerates fraction was clearly lower. The same trend was found for higher loads and speeds (2.6bar, 1500rpm and 2.2bar, 2000rpm) as well [60]. It was also reported, that the HCCI engine out SOF was greater than $95 \%$. The same study further investigated particle size concentrations and distributions and revealed that most particles in PCCI mode have smaller diameters compared to conventional diesel operation, depicted in Figure 40. The geometric mean diameter for particles emitted during PCCI mode was half of that for particles from conventional operation, while the total number concentration was slightly lower as well [60]. However, it should be noted that it is difficult to draw conclusions from semilog particle size distribution graphs, since small differences appear to be significant. Therefore, $\log -\log$ scales are more convenient.

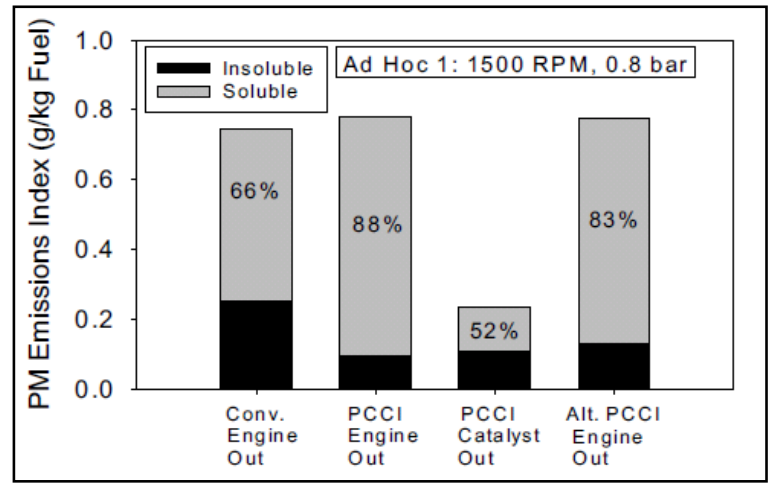

Figure 39 SOF (soluble) and Soot (insoluble) Emission Indices for Conventional and PCCI Combustion Mode [60]

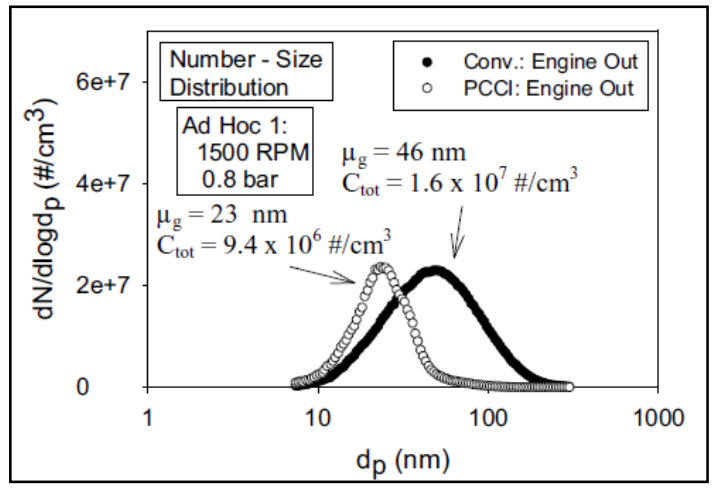

Figure 40 Comparison of Particle Size Distribution for Conventional and PCCI Combustion Mode [60]

A comparison by the same authors between PCCI and HCCI combustion modes with comparable IMEP values showed even smaller particle diameters as well as total number concentration values for the HCCI mode, presumably due to enhanced fuel and air mixing in 
HCCI mode that resulted in less particle formation than in PCCI mode, as shown in Figure 41 [60].

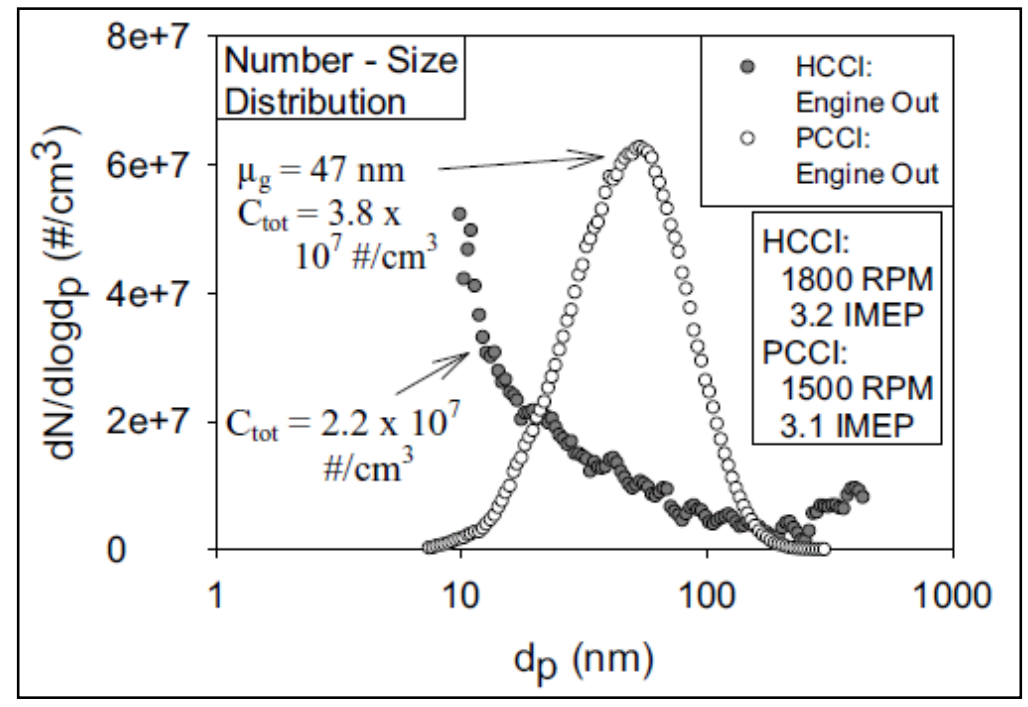

Figure 41 Particle Size Distribution for PCCI and HCCI

Combustion Mode [60]

Similar results concerning SOF of engine out PM emissions as well as the shift in particle diameter towards nanoparticles during advanced combustion were obtained in an investigation on a GM 1.7L common-rail diesel engine comparing conventional diesel operation with partially premixed early and late injection LTC strategies [61].

The effect of a thermal denuder removing the organic fraction of the particles emitted by a DDC/VM Motori 2.5L common-rail diesel engine running in a so-called high efficiency clean combustion (HECC) mode at 4.2bar BMEP and 1800rpm is shown in Figure 42. With constant rail pressure at 490bar and about 50\% EGR, the thermal denuder (TD) temperature and start of single injection timing (SOI) was varied as follows: (०) TD at $30^{\circ} \mathrm{C}$, SOI at $2^{\circ} \mathrm{BTDC}$; ( $\square$ ) TD at $300^{\circ} \mathrm{C}$, SOI at $2^{\circ} \mathrm{BTDC}$; (•) TD at $30^{\circ} \mathrm{C}$, SOI at $4^{\circ} \mathrm{BTDC}$; and (匹) $\mathrm{TD}$ at $300^{\circ} \mathrm{C}$, SOI at $4^{\circ}$ BTDC. Advancing the single injection timing with low thermal denuder temperature lead to an increase in nanoparticle formation composed of organic fraction, which was shown to be significantly reduced with a TD temperature at $300^{\circ} \mathrm{C}[16]$. 


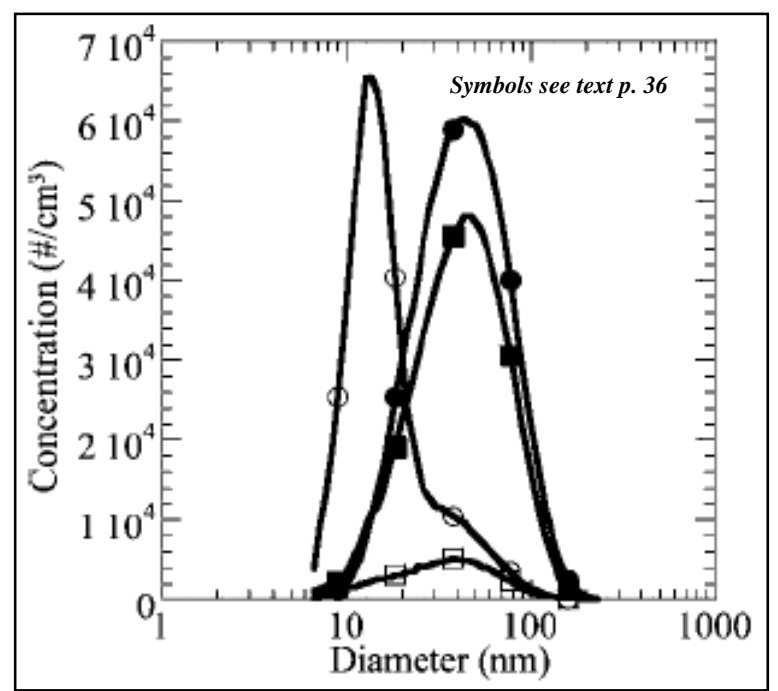

Figure 42 Particle Size Distribution for Varying TD Temperatures and SOI Timings during HECC Mode [16]

An experimental investigation on a 4.2L single cylinder research diesel engine running in LTC combustion mode with $60 \%$ EGR further showed a shift in particle size distributions towards nanoparticles for increased rail pressures, due to better fuel atomization, as shown in Figure 43 [62].

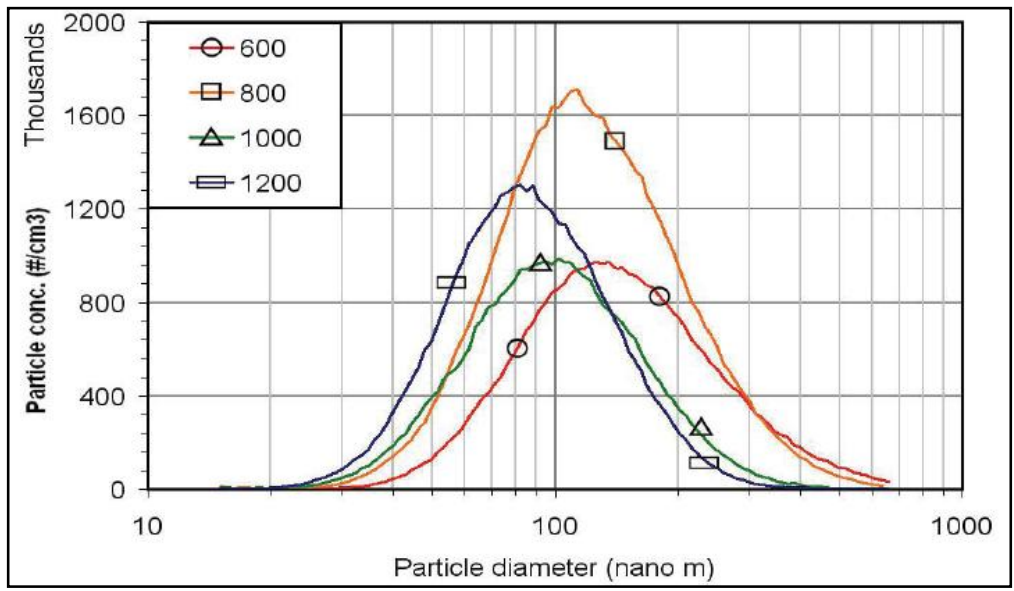

Figure 43 Particle Size Distribution with Varying Injection Pressure [62] 


\section{CHAPTER 3 EXPERIMENTAL SETUP}

All measurements in this study were conducted at the Engine and Emission Research Laboratory (EERL) at West Virginia University. The EERL is part of West Virginia University's Center for Alternative Fuels, Engines and Emissions (CAFEE) and the transient heavy-duty engine test cell follows the recommendations outlined in the Code of Federal Regulations (CFR), Title 40, Part 1065 [56]. A schematic overview of the EERL's measurement capabilities, for regulated and (some) unregulated engine exhaust emissions, is given in Figure 44.

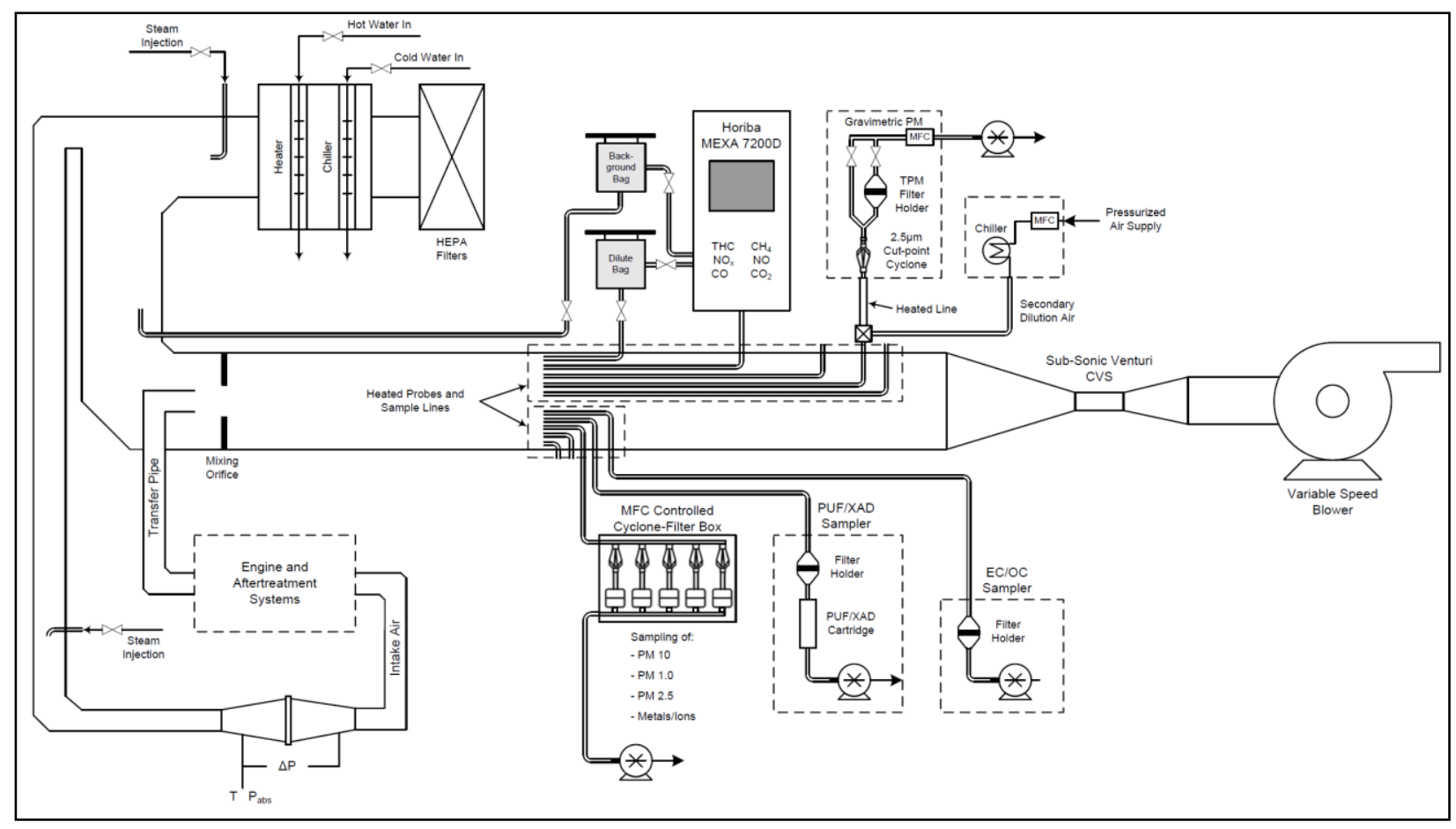

Figure 44 Schematic Overview of EERL's Measurement Capabilities

\subsection{Test Engine}

The test engine used for this study was an in-line 4-cylinder common rail diesel engine model Z19DTH from General Motors, depicted in Figure 45. The intake air pressure was controlled via a variable turbine geometry (VTG) turbocharger. The engine was instrumented with thermocouples measuring engine lubricant, coolant, intake manifold and exhaust manifold temperatures. Inlet depression, intake manifold pressure and exhaust backpressure were measured as well by pressure transducers. 


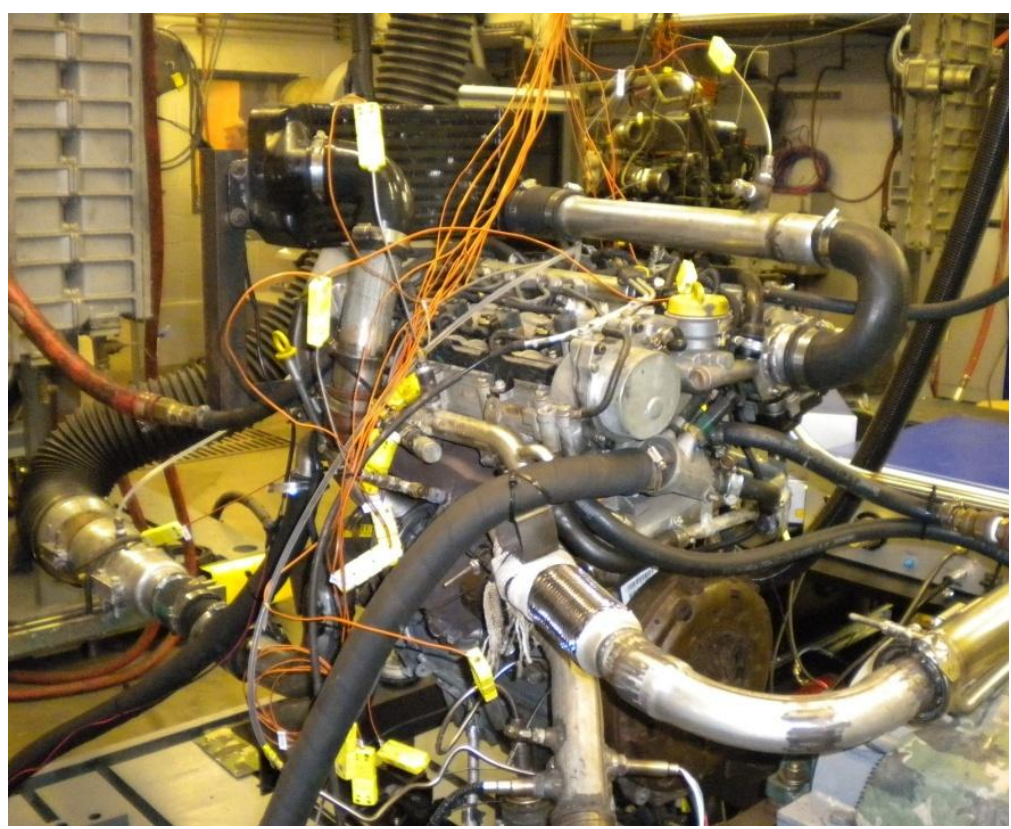

Figure 45 Test Engine GM Z19DTH in the EERL

Since EGR rates that were adopted for the advanced combustion research on this engine were higher than the original equipment manufacturer (OEM) specifications, a larger EGR cooler was fitted to the engine in order to reduce inherent higher intake manifold temperatures. An overview of the test engine specifications are shown in Table 4.

Table 4 Test Engine Specifications

\begin{tabular}{|l|l|}
\hline Type & CDTi Diesel Engine \\
\hline Manufacturer & General Motors \\
\hline Model & Z19DTH \\
\hline Valve Configuration & 4 Valves per Cylinder \\
\hline Year & 2005 \\
\hline Configuration & In-Line 4 Cylinder \\
\hline Displacement & $1.9 \mathrm{~L}$ \\
\hline Bore & $82 \mathrm{~mm}$ \\
\hline Stroke & $90.4 \mathrm{~mm}$ \\
\hline Compression Ratio & $17.5: 1$ \\
\hline Turbocharger & Garret VGT \\
\hline Injection System & Common Rail \\
\hline EGR & Cooled, External \\
\hline Rated Power & $110 \mathrm{~kW}$ @ 4000rpm \\
\hline
\end{tabular}




\subsection{Laboratory Instrumentation}

This section describes the laboratory instrumentation in the EERL that was used for this study. The exhaust dilution system, gaseous emissions measurement instrumentation and particulate matter sampling system and technique, as well as in-cylinder pressure measurement and the engine and dynamometer control system are presented.

\subsubsection{Constant Volume Sampling (CVS) Dilution Tunnel}

A total-exhaust dilution, constant-volume sampling (CVS) tunnel, designed to simulate the mixing of exhaust gas with ambient air conditions, maintains a nominally constant total molar flow rate of the diluted exhaust, as outlined in the Code of Federal Regulations (CFR), Title 40, Part 1065, Subpart 140 [56]. To accurately measure and actively control the flow rate maintaining proportional sampling of the exhaust constituents, a subsonic venturi (SSV) flow meter is used, see Figure 46. The SSV was calibrated for a Reynolds number at the throat greater than the maximum Reynolds number expected during testing and used only between the minimum and maximum calibrated flow rates.

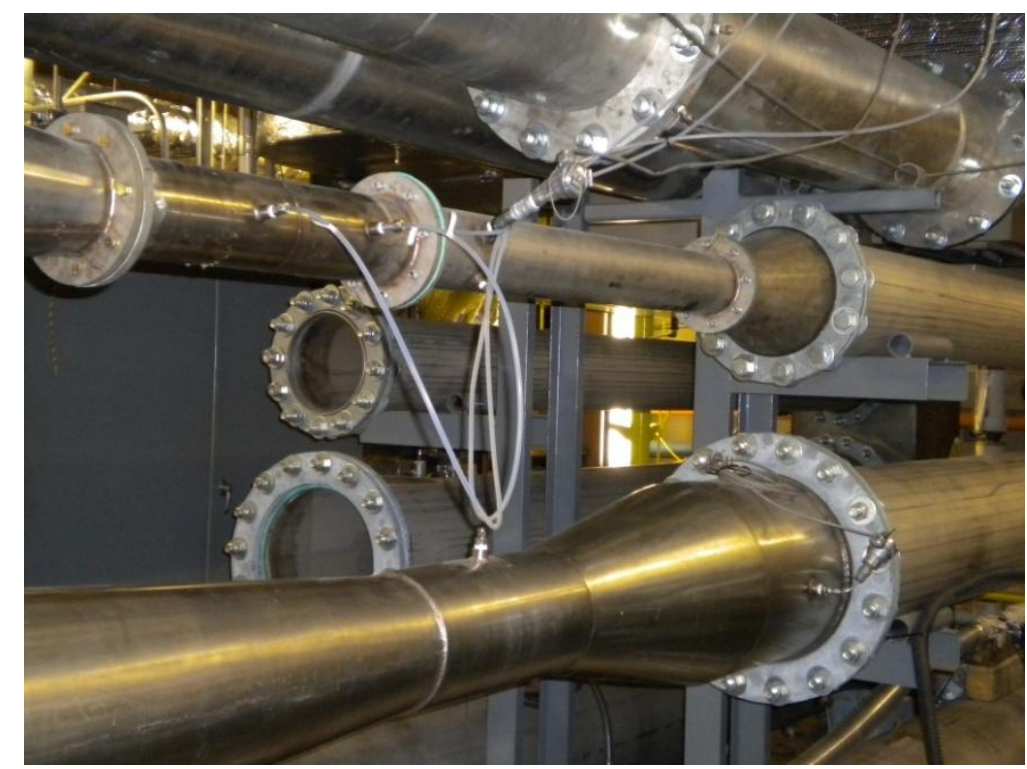

Figure 46 CVS-SSV Tunnel in the EERL

\subsubsection{Gaseous Emissions Measurement}

Diluted exhaust gas emissions extracted from the CVS tunnel were measured continuously using a Horiba MEXA-7200D gaseous emissions analyzer and included total hydrocarbons, carbon monoxide as well as carbon dioxide and oxides of nitrogen. $\mathrm{NO}_{\mathrm{x}}$ and 
oxygen concentrations were measured in the raw exhaust and intake manifold using Horiba MEXA-720 $\mathrm{NO}_{\mathrm{x}}$ analyzers, respectively.

\subsubsection{Horiba Automotive Emission Analyzer System MEXA-7200D}

The Horiba automotive emission analyzer system MEXA-7200D is a modular components system consisting of a main control unit, an interface controller (provides communications between the modules and the main control unit), an analyzer rack with up to five analyzer modules, a heated analyzer module for $\mathrm{THC}, \mathrm{THC} / \mathrm{CH}_{4}, \mathrm{NO}_{\mathrm{x}}$ and $\mathrm{NO} / \mathrm{NO}_{\mathrm{x}}$ analyzers, a power supply unit, as well as a solenoid valve selector, which routes zero, span and sample gas to the analyzer modules, and a sample handling system dehumidifying the sample gas and directing it to the analyzers. A separate heated oven unit cart contains up to three heated analyzers $\left(\mathrm{THC}, \mathrm{NO}_{\mathrm{x}}\right.$ and $\left.\mathrm{CH}_{4}\right)$ with heated lines, pumps and solenoid valves [63]. The analyzer system is shown in Figure 47 below.

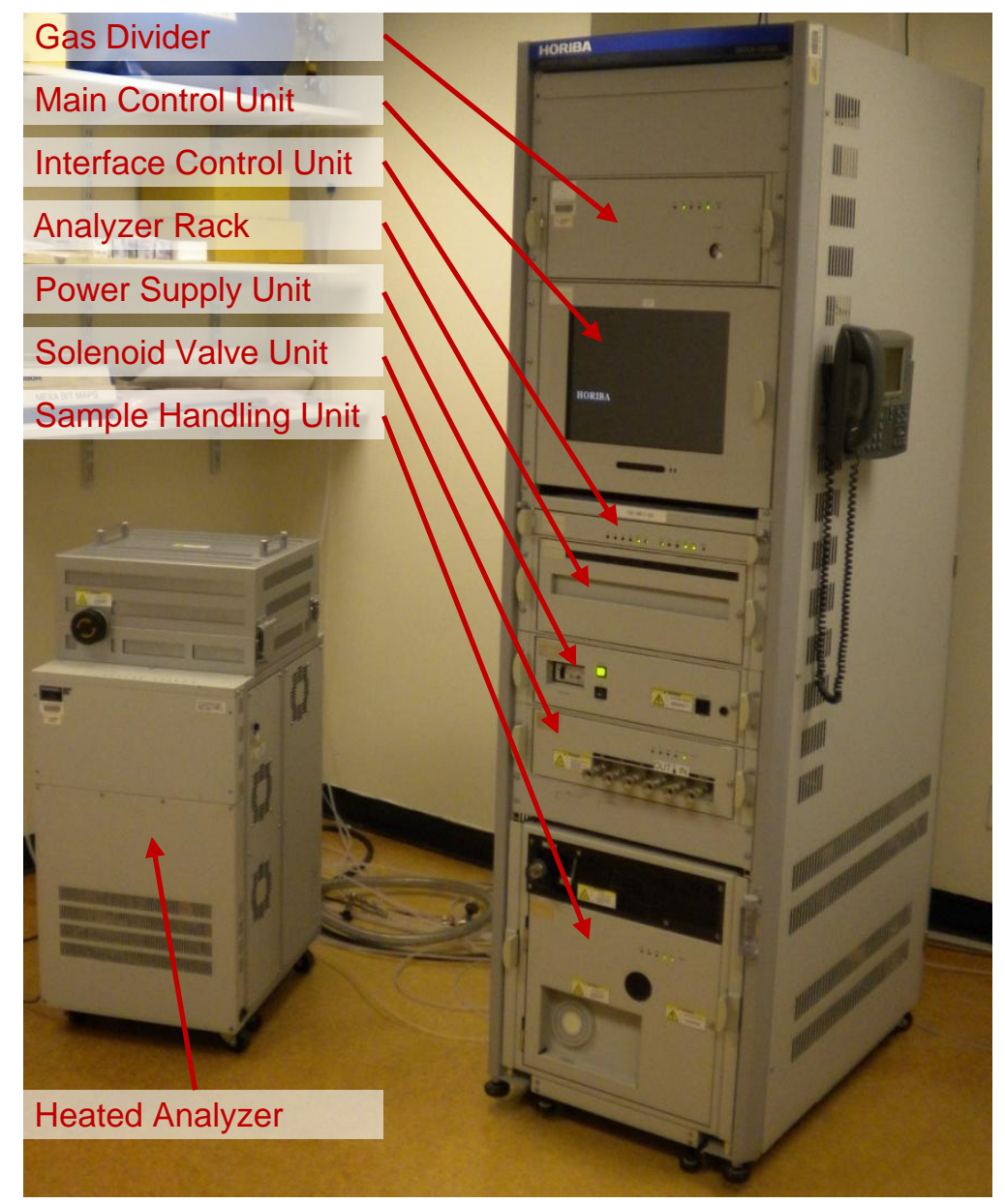

Figure 47 MEXA-7200D with Oven Unit (left) in the EERL 
The analyzer modules measuring the concentration of $\mathrm{CO}$ and $\mathrm{CO}_{2}$ (cold dry sample) use the non-dispersive infrared (NDIR) principle. Infrared energy at specific wavelengths is absorbed by a molecule consisting of different atoms and the degree of absorption is proportional to the concentration at constant pressure [64]. In a NDIR analyzer, an infrared beam is passed through a sample and a comparison cell by a light source. The comparison cell is filled with a gas nonabsorbent to infrared radiation (such as nitrogen). Figure 48 shows an example of an NDIR configuration.

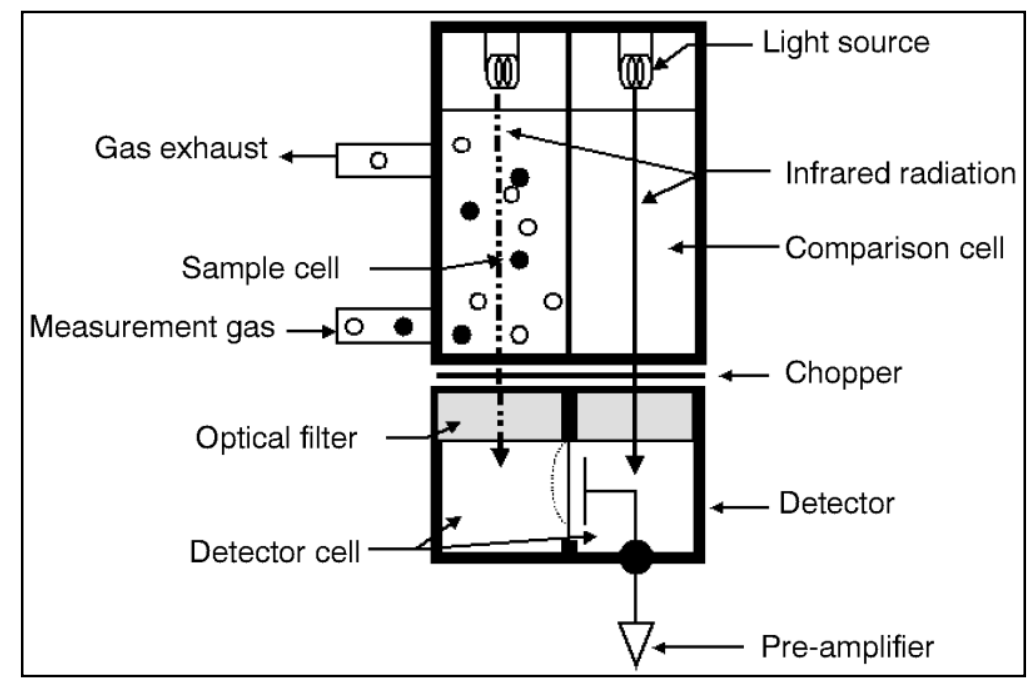

Figure 48 Example of NDIR Configuration [64]

A sealed capacitor type detector, consisting of two cells separated by a movable membrane and filled with the gas to be measured, transforms the displacement of the membrane, which moves as a result of the differential pressure generated by the difference in quantity of radiation each gas received and therefore heated up and expanded, into an electrical output signal. To prevent interference with another gas component absorbing infrared radiation in the same wavelength range, an optical filter in front of the detector is used to eliminate the absorption area of the interfering component [64].

The concentration of total hydrocarbons is measured employing hydrogen $\left(\mathrm{H}_{2}\right)$ flame ionization detection (FID) (heated wet sample). Hydrocarbons introduced into a hydrogen flame generate ions, which are proportional to the number of carbon atoms in the sample. This measurement principle is sensitive to almost all hydrocarbon compounds [65]. Figure 49 shows a possible FID configuration. 


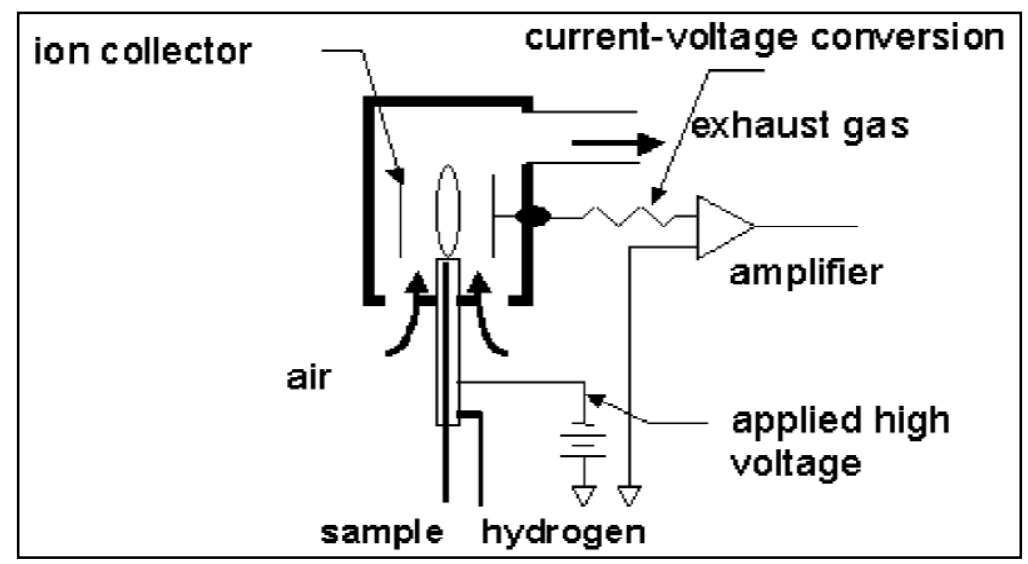

Figure 49 Example of FID Configuration [65]

The sample gas is mixed with $\mathrm{H}_{2}$ and directed into the $\mathrm{H}_{2}$ flame. Ions in the hightemperature area are generated following the reaction in Equation 1:

$$
\mathrm{CH}^{*}+\mathrm{O}^{*} \rightarrow \mathrm{CHO}^{+}+e^{-}
$$

where the stars $(*)$ denote radicals. A DC voltage is applied on two electrodes in the ion collector which causes a migration of ions towards them and a current can be measured and amplified. Due to the proportionality of the current to the number of carbon atoms, this is a measure of the total hydrocarbons (THC), but no information of different hydrocarbon components can be obtained by this method [65].

The analyzer module measuring $\mathrm{NO}$ and $\mathrm{NO}_{\mathrm{x}}$ concentration (heated dry atmospheric sample) uses a chemiluminescence detector (CLD). Sample gas containing NO is mixed with ozone gas $\left(\mathrm{O}_{3}\right)$ in a reactor to be oxidized into nitrogen dioxide $\left(\mathrm{NO}_{2}\right)$, whereas part of the $\mathrm{NO}_{2}$ is in excited state, releasing excited energy as light (radiation) when returning to the ground state, as shown in Equations 3 and 4:

$$
\begin{aligned}
& \mathrm{NO}+\mathrm{O}_{3} \rightarrow \mathrm{NO}_{2}^{*}+\mathrm{O}_{2} \\
& \mathrm{NO}_{2}^{*} \rightarrow \mathrm{NO}_{2}+h v
\end{aligned}
$$

where the star $\left(^{*}\right)$ denotes the $\mathrm{NO}_{2}$ molecules in excited state. The light released is directly proportional to the NO molecule quantity before the reaction and therefore a measure of the NO concentration. This chemiluminescence signal is detected photo-electrically. Excited $\mathrm{NO}_{2}$ molecules can also return to ground state without radiation emission due to collision with other molecules $\left(\mathrm{H}_{2} \mathrm{O}, \mathrm{CO}_{2}, \mathrm{~N}_{2}\right.$ or $\left.\mathrm{O}_{2}\right)$. This interference can be reduced by reducing the pressure in 
the reaction chamber. Since there is also $\mathrm{NO}_{2}$ in the initial sample that does not have chemiluminescence, it has to be converted to $\mathrm{NO}$ by means of a $\mathrm{NO}_{\mathrm{x}}$ converter. The measurement of the converted $\mathrm{NO}_{2}$ and the aforementioned $\mathrm{NO}$ measurement can therefore be added up to yield the $\mathrm{NO}_{\mathrm{x}}$ concentration.

\subsubsection{Horiba MEXA-720 NO Analyzer}

Two heated zirconia-ceramic $\left(\mathrm{ZrO}_{2}\right)$ sensors were installed in the intake manifold and exhaust pipe directly as parts of MEXA-720 $\mathrm{NO}_{\mathrm{x}}$ analyzer units (see Figure 50), which are capable of measuring $\mathrm{NO}_{\mathrm{x}}$ concentrations, air/fuel ratio, excess air ratio (lambda) and $\mathrm{O}_{2}$ concentrations simultaneously. The measurement principle of a zirconia sensor is depicted in Figure 51. It is based on the oxygen conducting properties of zirconia [66]. Zirconia is used as an ion pump lowering the oxygen concentration from the sample gas to approximately 10ppm in the first internal cavity, where nitrogen dioxide is reduced to nitric oxide and oxygen. The pump current, depending on the amount of oxygen pumped, is measured and used to calculate the oxygen concentration in the sample gas. Further lowering the oxygen concentration to nearly zero ppm (1ppb) is achieved by an auxiliary oxygen pump (not showed in schema). Nitric oxide is further split into nitrogen and oxygen. A measure of the oxygen generated is the current created by the zirconia ion pump and can be used to calculate the NO concentration, which is an indicator of the $\mathrm{NO}_{\mathrm{x}}$ concentration in the exhaust stream, since $\mathrm{NO}_{2}$ is reduced to $\mathrm{NO}$ in the first internal cavity [67].

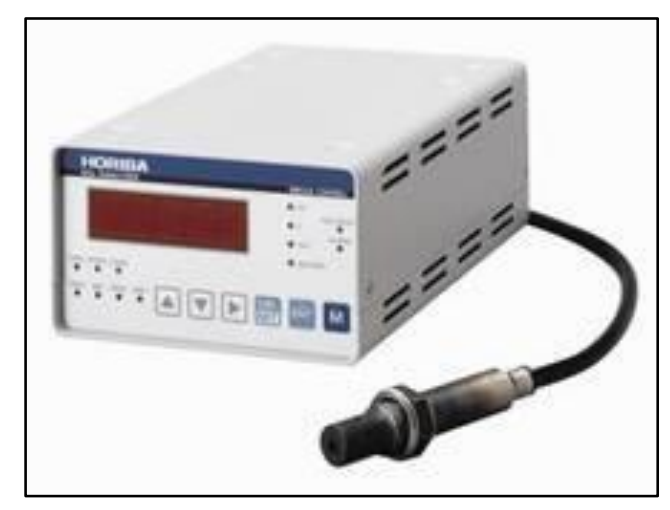

Figure 50 Horiba MEXA-720 $\mathrm{NO}_{\mathrm{x}}[68]$

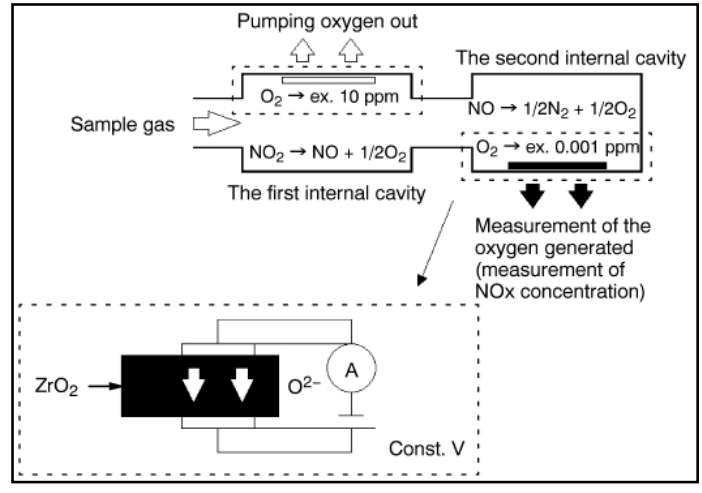

Figure 51 Principle of Zirconia Sensor [67] 
Intake oxygen concentration was one of the primary controlled operating parameters in this study and raw exhaust $\mathrm{O}_{2}$ concentration was used along with intake $\mathrm{O}_{2}$ concentration to determine actual EGR fractions.

\subsubsection{Particulate Matter Sampling Setup}

Nanoparticle number concentration and size distributions were determined using the Exhaust Emissions Particle Sizer (EEPS ${ }^{\mathrm{TM}}$ ) spectrometer from TSI Inc. (model 3090) as well as the Differential Mobility Spectrometer (DMS) from Cambustion (model DMS500). Continuous exhaust gas samples were extracted from the CVS tunnel (dilution ratio DR $\approx 10$ ) and routed through a double stage dilution system using ejector type dilutors, see Figure 52. The first stage was maintained at $140^{\circ} \mathrm{C}(\mathrm{DR} \approx 6)$ in order to suppress condensation and particle nucleation phenomena, while the second stage utilized dilution air at ambient temperatures $\left(\sim 25^{\circ} \mathrm{C}\right.$, $\mathrm{DR} \approx 11)$.

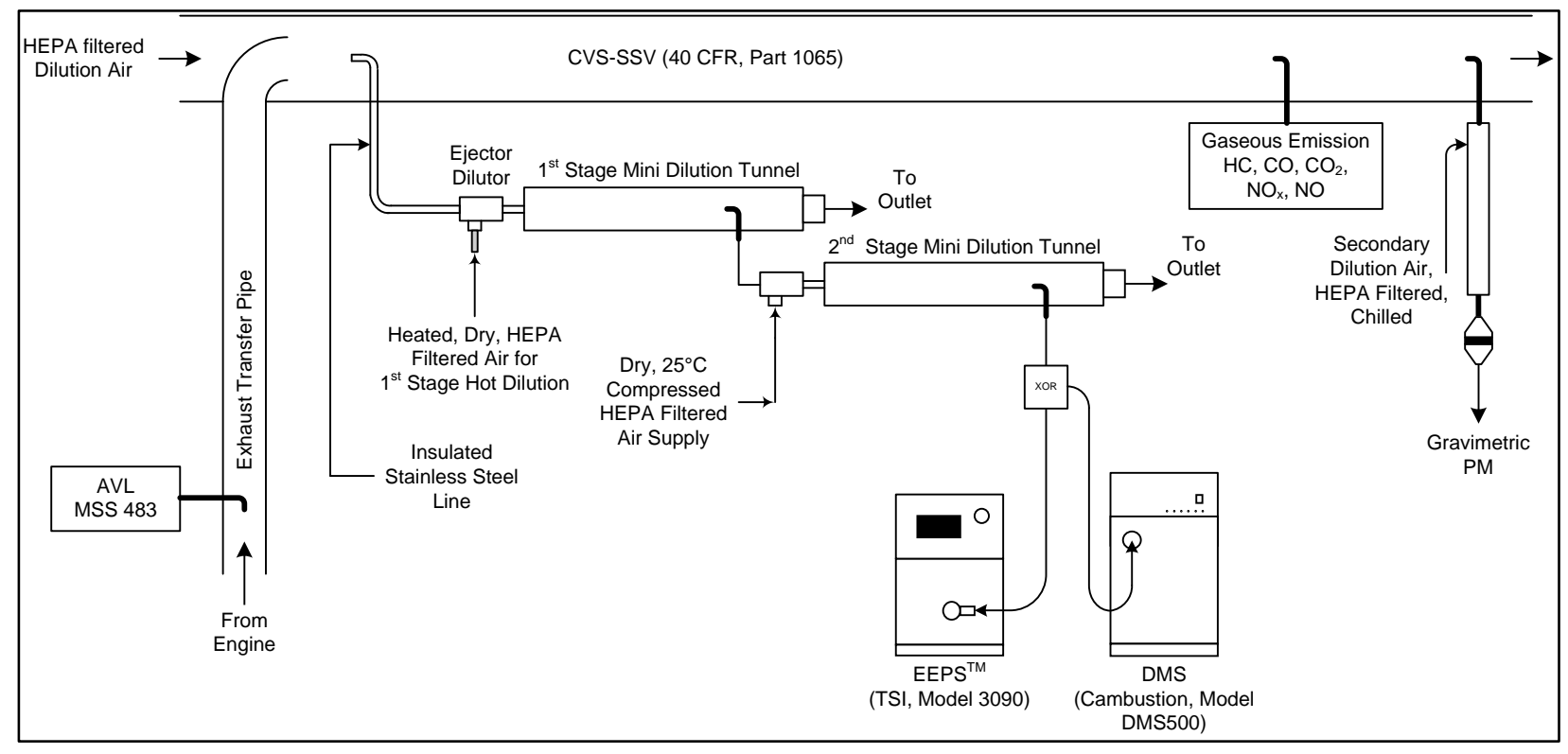

Figure 52 Experimental Setup for Nanoparticle Sampling

\subsubsection{Single Stage Air-Operated Vacuum Generator (Air-Vac)}

For the hot and cold stage dilution of the particulate sample, two single stage air-operated vacuum generators, depicted in Figure 53, were used, along with a $1^{\text {st }}$ and $2^{\text {nd }}$ stage mini-dilution tunnel, shown in Figure 52. Compressed air, filtered with a High-Efficiency Particulate Air (HEPA) filter and dried with a desiccant air line dryer, was supplied to the model TD110H ejector diluter. The compressed air thereby created a high velocity through expansion into an 
open vacuum passage, as shown in Figure 54. This method allows solid material to flow from either the CVS dilution tunnel or $1^{\text {st }}$ stage mini dilution tunnel through the pump without any decrease in the vacuum flow rate [69].

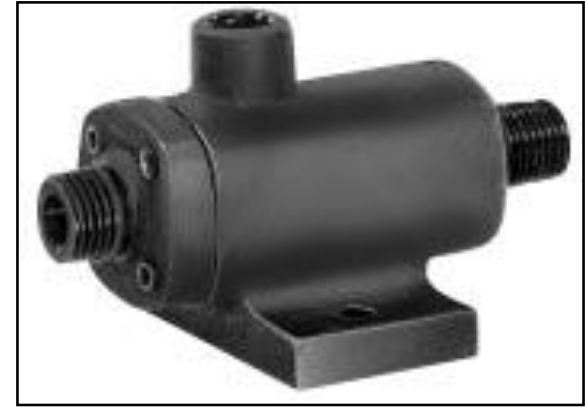

Figure 53 Air-Vac TD Series [70]

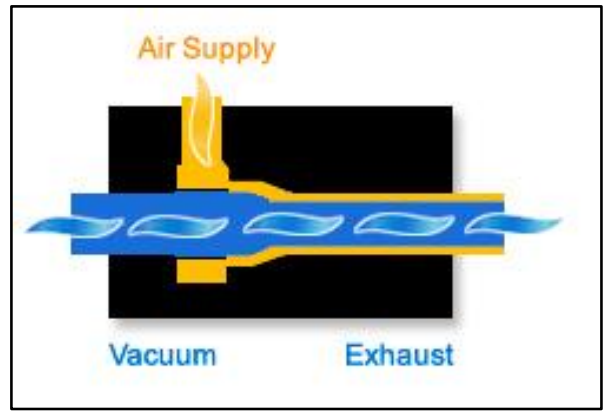

Figure 54 Air-Vac Working Principle [69]

Two different orifices were employed to restrict the sample flows for the $1^{\text {st }}$ and $2^{\text {nd }}$ stage dilution creating fixed dilution ratios. Table 5 lists the parameters and conditions set throughout this study. In order to achieve a hot $1^{\text {st }}$ stage dilution, a heated line (about 4 meters long) for the dilution air in conjunction with a flexible heating tape for the mini-dilution tunnel was installed and controlled via Omega temperature controllers (CNi32 Series).

Table 5 Conditions and Parameters for Dilution with Air-Vac Model TD110H

\begin{tabular}{|c|c|c|c|c|c|c|}
\hline & $\begin{array}{c}\text { Temperature } \\
{\left[{ }^{\circ} \mathbf{C}\right]}\end{array}$ & $\begin{array}{c}\text { Flow Rate } \\
(\varnothing \text { Orifice) } \\
{[\mathbf{l p m}]}\end{array}$ & $\begin{array}{c}\text { Dilution Air } \\
\text { Pressure } \\
{[\mathbf{p s i g}]}\end{array}$ & $\begin{array}{c}\text { Mass Flow } \\
\text { Dilution Air } \\
{[\mathbf{l p m}]}\end{array}$ & $\begin{array}{c}\text { Total Flow } \\
{[\mathbf{l p m}]}\end{array}$ & $\begin{array}{c}\text { Dilution } \\
\text { Ratio (DR) } \\
{[-]}\end{array}$ \\
\hline $\begin{array}{c}\mathbf{1}^{\text {st }} \text { stage hot } \\
\text { dilution }\end{array}$ & $140 \pm 5$ & 22 & 60 & 113 & 135 & 6.1 \\
\hline $\begin{array}{c}\mathbf{2}^{\text {nd }} \text { stage cold } \\
\text { dilution }\end{array}$ & $25 \pm 5$ & 11 & 60 & 113 & 124 & 11.3 \\
\hline
\end{tabular}

\subsubsection{Residence Time}

Residence times for the CVS tunnel as well as $1^{\text {st }}$ and $2^{\text {nd }}$ stage mini-dilution tunnels were calculated from the dilution system dimensions and the mass flow rates set during the tests and are presented in Table 6. 
Table 6 Residence Times for Dilution System Components

\begin{tabular}{|l|c|c|c|}
\hline & $\begin{array}{c}\text { Temperature } \\
{\left[{ }^{\circ} \mathbf{C}\right]}\end{array}$ & $\begin{array}{c}\text { Mass Flow } \\
{[\mathbf{l p m}]}\end{array}$ & $\begin{array}{c}\text { Residence Time } \\
{[\mathbf{m s}]}\end{array}$ \\
\hline CVS Tunnel & $31 \pm 2$ & 10874 & 6935 \\
\hline $\begin{array}{l}\mathbf{1}^{\text {st }} \text { stage hot } \\
\text { dilution }\end{array}$ & $140 \pm 5$ & 135 & 519 \\
\hline $\begin{array}{l}\mathbf{2}^{\text {nd }} \text { stage cold } \\
\text { dilution }\end{array}$ & $25 \pm 5$ & 124 & 373 \\
\hline
\end{tabular}

\subsubsection{Exhaust Emissions Particle Sizer ${ }^{T M}$ Spectrometer $\left(\right.$ EEPS $\left.^{T M}\right)$}

The TSI model 3090 EEPS $^{\mathrm{TM}}$ spectrometer measures the particle size based on differential electrical mobility classification. The sample aerosol entering the measurement column is first charged by a negative diffusion charger in order to reduce the number of highly positive charged particles and prevent particle overcharging in the second charger. A predictable net positive charge is then applied to the particles before they enter the measuring section. The charged particles are then deflected radially outwards toward the outer cylinder wall by means of a positive high-voltage center-electrode and collected on electrically isolated electrode rings, depicted in Figure 55. Small particles, which have high electrical mobility, are deflected to the electrode rings near the top, whereas larger particles are deflected further downstream as flow moves from the top to the bottom of the measurement column. Particles, which land on the sensing electrodes, transfer their charge. The particle number concentration is then determined by measuring the electrical current at the electrode rings with electrometers, see Figure 55. Conceptually, the EEPS ${ }^{\mathrm{TM}}$ spectrometer works similarly to a Differential Mobility Analyzer (DMA), with the difference that particles are deflected towards the outer cylinder wall, rather than to the center, as in a DMA. 


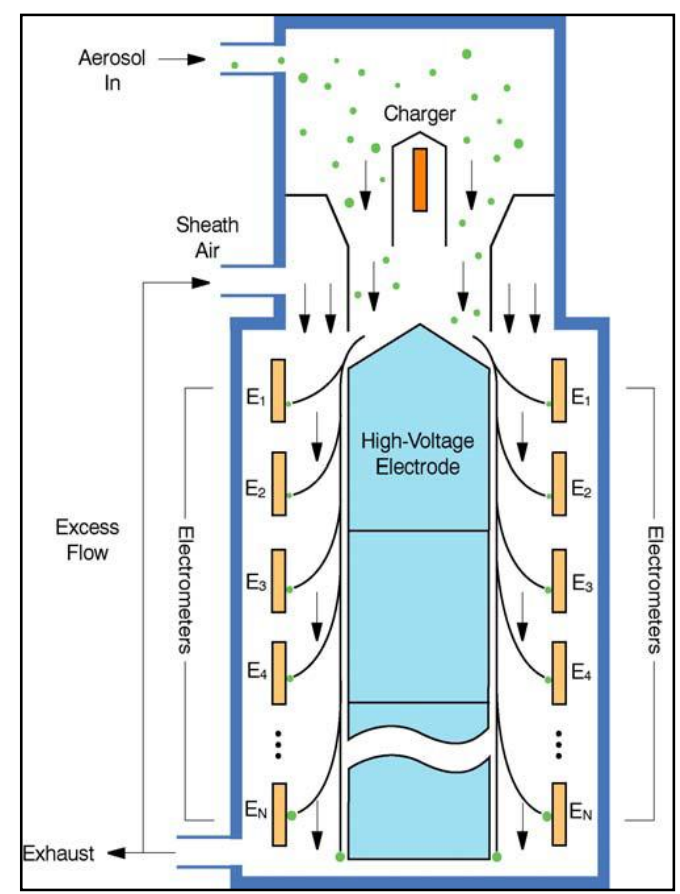

Figure 55 Schematic Diagram of the Model 3090 EEPS $^{\mathrm{TM}}$ Spectrometer [71]

The EEPS ${ }^{\mathrm{TM}}$ spectrometer can measure a particle size range of 5.6 to $560 \mathrm{~nm}$, has a particle size resolution of 16 channels per decade (32 in total) and incorporates 22 electrometer channels. An inlet cyclone with a cut point of $1 \mu \mathrm{m}$ removes large particles that are above the instrument's size range. The maximum data rate allows up to 10 size distributions per second.

\subsubsection{Differential Mobility Spectrometer (DMS)}

The DMS500 measures particle size spectra very similar to the EEPS ${ }^{\mathrm{TM}}$. The aerosol sample passes through a corona discharge charger, which produces positive ions, to charge the particles and flows into the classifier column, see Figure 56. Particles are then deflected towards the electrode rings by means of a central high-voltage rod according to their electrical mobility. The small currents (fA) are measured by the electrometer amplifiers and the particle number concentration can be determined from each electrode ring. 


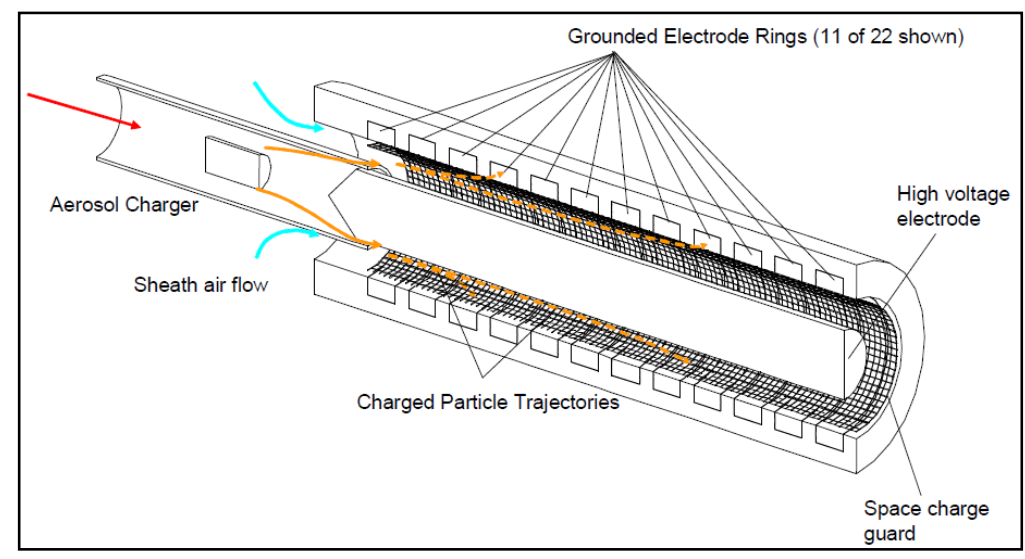

Figure 56 DMS500 Classifier [72]

The particle size range of the DMS500 is 5 to $1000 \mathrm{~nm}$ with the specified sample flow of 8slpm. Its particle size resolution is 16 channels per decade, 16 between 10 and 100 and 16 between 100 and 1000 (32 in total) and incorporates 22 electrometer channels. An inlet cyclone with a cut point of $1 \mu \mathrm{m}$ removes large particles that are above the instrument's size range. The maximum data rate also allows up to 10 size distributions per second. The DMS500 uses an external vacuum pump.

\subsubsection{AVL 483 Micro Soot Sensor}

The AVL Micro Soot Sensor, consisting of a measuring unit and an exhaust conditioning unit, is capable in measuring the soot concentration in the raw exhaust based on the photoacoustic measurement method. The exhaust conditioning unit itself consists of a dilution unit and a pressure reducing unit with dilution cell. The dilution ratio (DR) can be set from 2 to 20. The exhaust conditioning unit with sample probe is depicted in Figure 57. The sampling probe has a $45^{\circ}$ incline in exhaust gas line axis looking into the direction of the flow. Figure 58 shows how the three basic units operate and interact. 


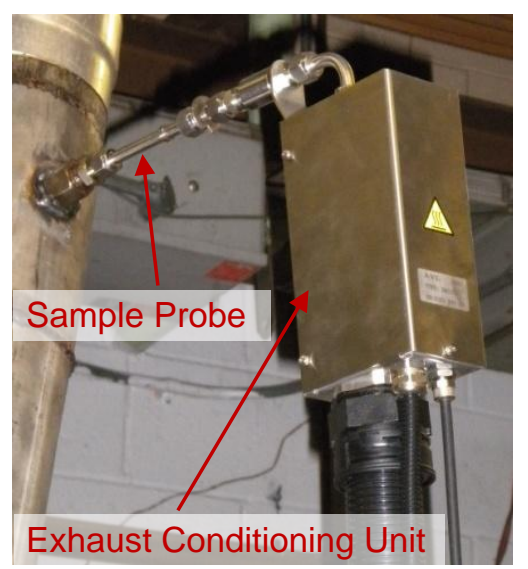

Figure 57 Exhaust Conditioning Unit

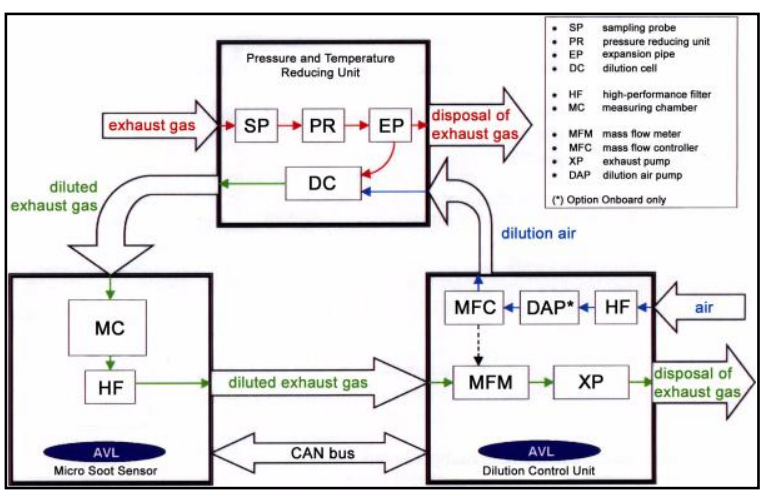

Figure 58 Functional Diagram of AVL Micro Soot Sensor [73]

The principle of the photoacoustic measurement method can be seen in Figure 59, where a strongly absorbing ("black") soot particle is exposed to modulated light from a laser beam. The modulated heating and cooling result in an expansion and contraction of the carrier gas producing a sound wave which can be detected by a microphone. The signal is proportional to the concentration of soot in the measurement volume, where clean air produces no signal. A soot concentration up to $50 \mathrm{mg} / \mathrm{m}^{3}$ can be detected by the measurement cell, while the resolution of the measurement value is $\leq 0.01 \mathrm{mg} / \mathrm{m}^{3}$ (defined as $3 \sigma$ of the zero signal measurement variation). In order to achieve a good sensitivity, an "open-pipe" resonance cell design is used, where a standing acoustic wave with pressure wave amplitude maximum in the middle is formed by means of acoustic notch filters (expanded cells at both ends), as depicted in Figure 60.

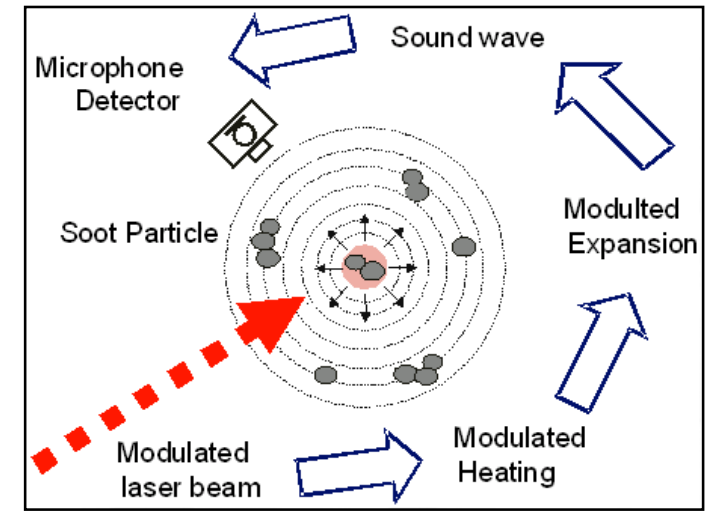

Figure 59 Principle of Photoacoustic Measurement [73]

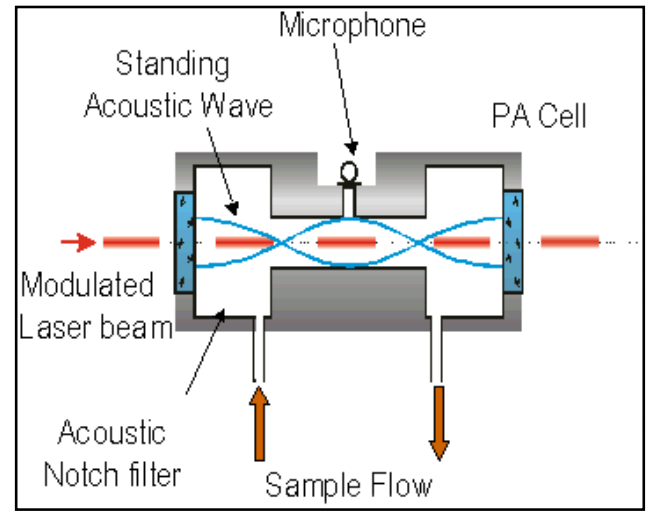

Figure 60 Resonant Cell Design [73]

Since the windows of the measurement cell can become contaminated by this measurement principle increasing the zero signal, this zero signal was determined between each measurement and the measurement cell was periodically cleaned. 


\subsubsection{In-Cylinder Pressure Measurement}

A piezoelectric crystal high temperature pressure sensor type 6058A1 (Figure 61) with a measuring range of 0 to $250 \mathrm{bar}$ from Kistler was installed with a type $6544 \mathrm{Q}$ glow plug adapter (Figure 62), replacing the OEM glow plug for cylinder number 3.

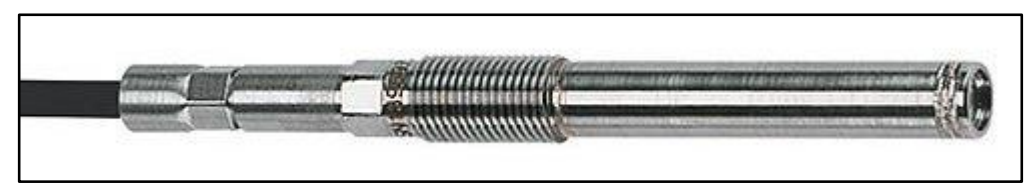

Figure 61 Kistler High Temperature Pressure Sensor Type 6058A1 [74]

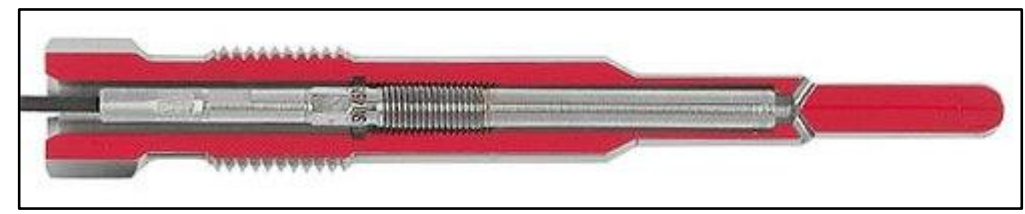

Figure 62 Kistler Glow Plug Adapter Type 6544Q with Pressure Sensor [75]

Instantaneous in-cylinder pressure, as well as intake temperature, exhaust temperature and engine speed, were measured and numerous combustion parameters were calculated by means of a custom combustion analysis software, which allowed for real-time pressure, temperature, heat release rate (HRR) and mass fraction burned (MFB) plots to overview engine operation in general and misfiring or high pressure variation $\left(\sigma_{\mathrm{pmi}}\right)$ in particular. The charge signals were converted to an output voltage using a Kistler type 5010B charge amplifier and a model H25 shaft encoder from BEI Sensors with a resolution of 720 counts per revolution provided accurate piston position needed for pressure recording.

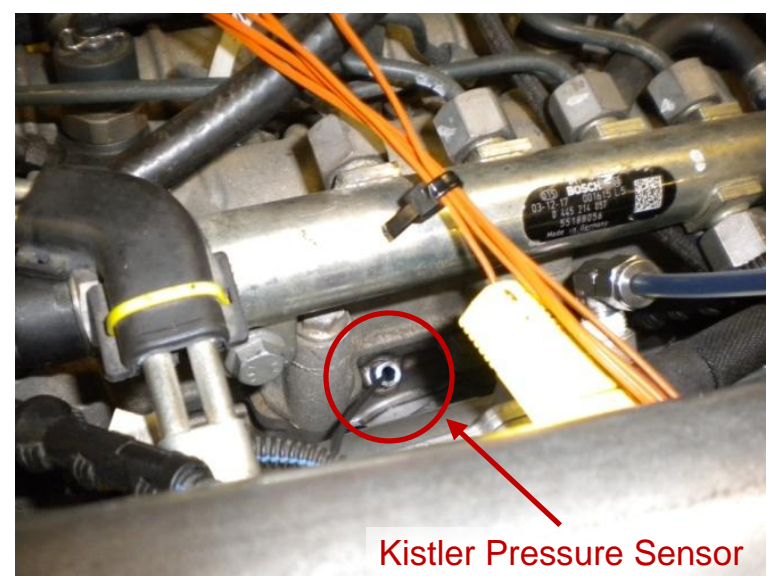

Figure 63 Kistler Pressure Sensor on GM Z19DTH

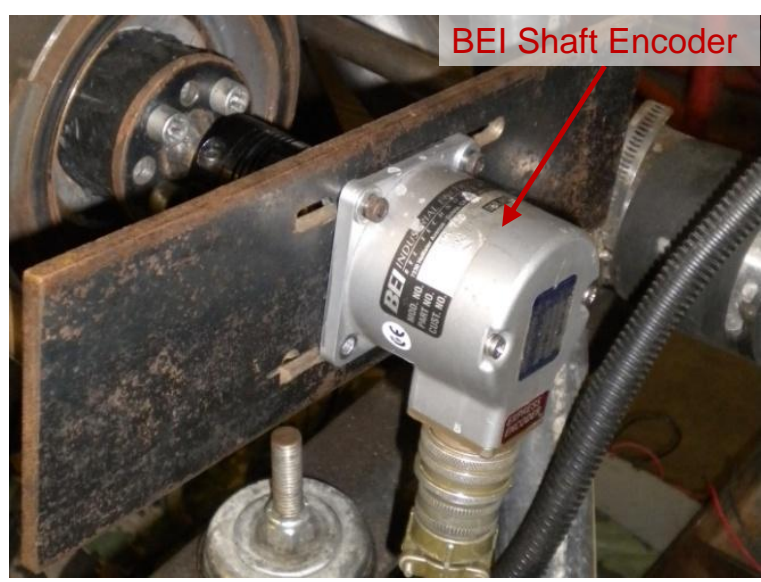

Figure 64 BEI Model H25 Shaft Encoder on GM Z19DTH 


\subsubsection{Control of Engine Operating Parameters}

In order to have full control on the engine operating parameters, an open engine controller from Drivven Inc. was used. The controller is based on National Instruments (NI) hardware. Operating parameters such as main start of injection (SOI), number and duration of fuel injection events, turbocharger boost (by controlling VGT vane position), EGR rate, rail pressure, throttle, and more, were accessed and controlled to obtain advanced combustion regimes.

\subsubsection{Laboratory and Dynamometer Control}

The GM Z19DTH engine was coupled to a Medsker Electric Inc. (MEI) alternate current (AC) dynamometer operated in speed mode (see Figure 65). Engine torque was controlled by means of a proportional-integral-derivative (PID) throttle controller integrated into the laboratory's data acquisition system (DAQ). The EERL's DAQ system is an in-house solution using National Instruments (NI) hardware and software developed by CAFEE with high-grade automation capabilities for engine testing as well as calibration and quality control. The DAQ system follows the recommendations outlined in 40 CFR, Part 1065 [56].

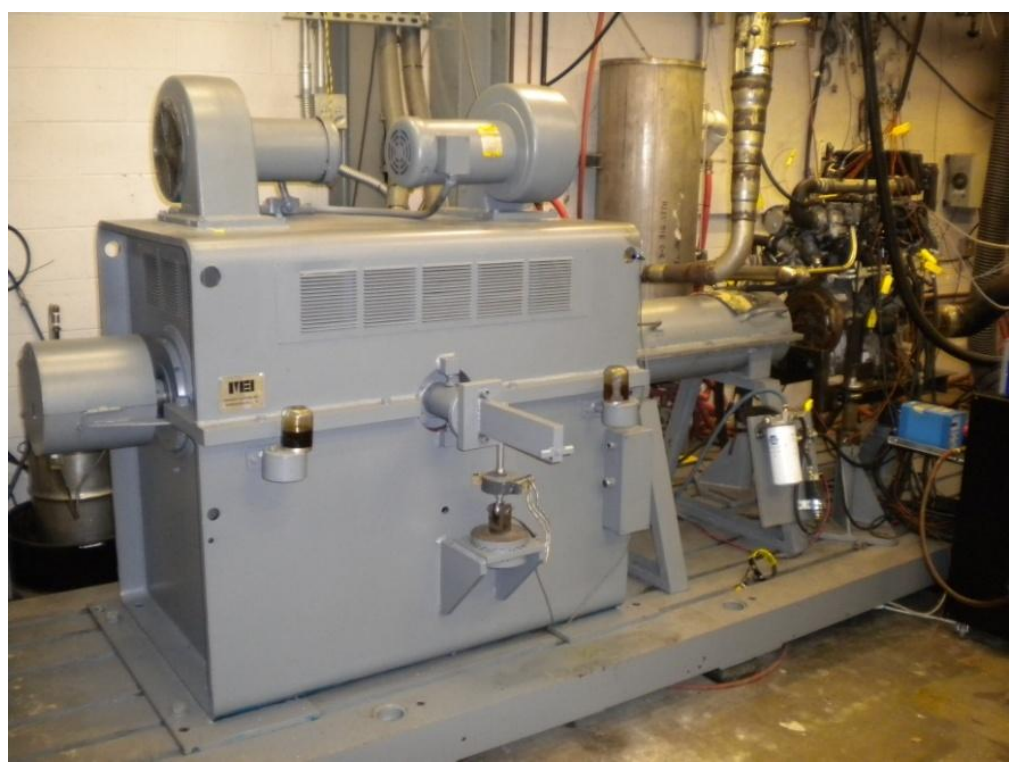

Figure 65 MEI AC Dynamometer 


\section{CHAPTER 4 METHODOLOGY}

\subsection{Fuel Properties}

The Advanced Vehicles, Fuels, and Lubricants committee of the Coordinating Research Council specified and formulated a matrix of nine test fuels for advanced combustion engines (FACE) based on the variation of three properties:

1. Cetane number $(\mathrm{CN})$, a measure of ignition quality;

2. Aromatic content, a measure of chemistry; and

3. The 90 percent distillation temperature (T90), a measure of volatility.

These properties were obtained by fuel blending and determined to be of primary importance to the performance of advanced combustion engines [35]. The target values build up a $2^{3}$ full factorial statistical design with a center run representing average marketplace values of the design variables [76]. This design theoretically allows investigation of $\mathrm{CN}$-aromatic content, CN-T90, aromatic content-T90, as well as CN-T90-aromatic content interactions. A graphical representation of the design matrix is shown in Figure 66, where target values (in blue) of the three factors at two levels build a design cube. The actual values of the formulated fuels are represented, as well (in red).

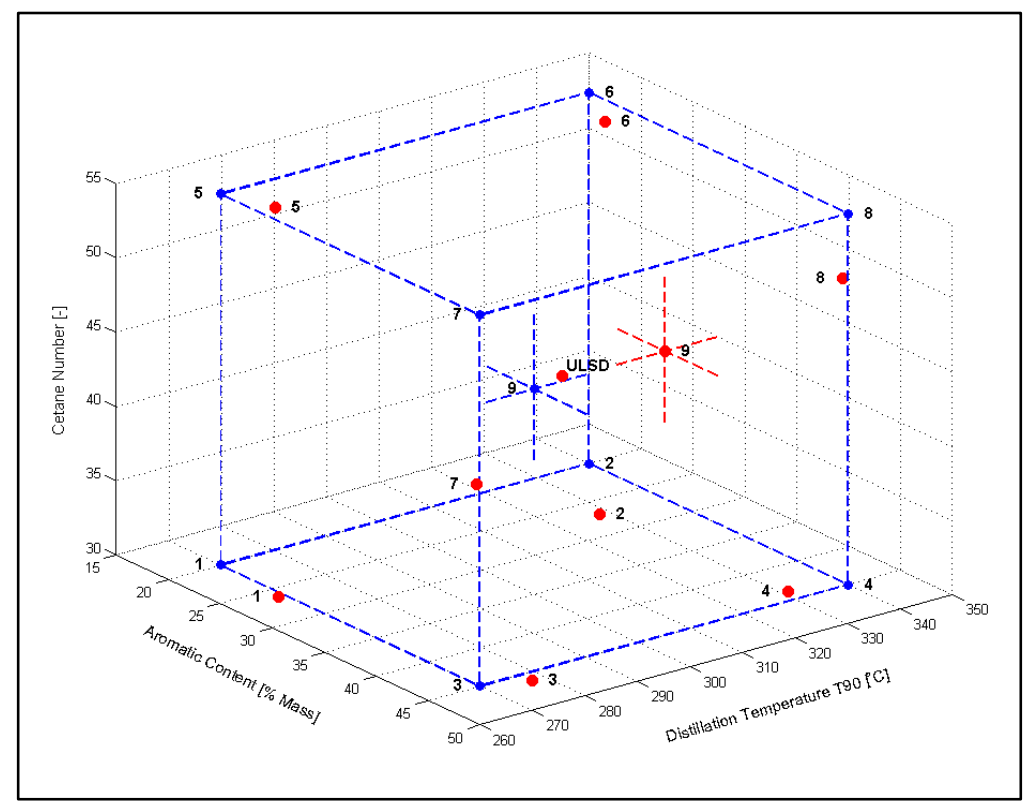

Figure 66 FACE Diesel Fuels Design Matrix: Target (Blue) vs. Actual Values (Red) 
The target values selected were:

- $\mathrm{CN}: 30$ and 55

- T90: 270 and $340^{\circ} \mathrm{C}$

- Aromatic content: 20 and $45 \%$ (mass)

Table 7 lists these target values together with actual values resulting from ASTM International standard analyses. Close matches could be achieved for most of the fuels; however, greater differences had to be accepted for FACE 7 and FACE 8, since difficulties in achieving the desired CN simultaneously targeting aromatic content occurred [35]. This is due to the dependence of $\mathrm{CN}$ and aromatic content as high aromatic content in diesel fuels tends to be accompanied by low CN [49].

The hydrogen-to-carbon ratio was determined by converting the mass fractions from the elemental analysis into molar fractions in order to get the values used to adapt the carbon balance calculations for each fuel. The net heat of combustion for each fuel is in vicinity of the other values for the fuels in the designed set with a coefficient of variance (COV) of $0.78 \%$.

Table 7 FACE Diesel Fuel Properties [35]

\begin{tabular}{|l|c|c|c|c|c|c|c|c|c|}
\hline Fuel & \multicolumn{2}{|c|}{$\begin{array}{c}\text { Cetane } \\
\text { Number } \\
{[-]}\end{array}$} & \multicolumn{2}{c|}{$\begin{array}{c}\text { Aromatic } \\
\text { Content } \\
{[\text { Mass \%] }}\end{array}$} & \multicolumn{2}{c|}{$\begin{array}{c}\mathbf{9 0 \%} \text { Distill. } \\
\text { Temperature } \\
{\left[{ }^{\circ} \mathbf{C}\right]}\end{array}$} & $\begin{array}{c}\text { Specific } \\
\text { Gravity } \\
{[-]}\end{array}$ & $\begin{array}{c}\text { H/C Ratio } \\
{[-]}\end{array}$ & $\begin{array}{c}\text { Net Heat of } \\
\text { Combustion } \\
{[\mathbf{M J} / \mathbf{k g}]}\end{array}$ \\
\cline { 2 - 10 } & Tgt. & Act. & Tgt. & Act. & Tgt. & Act. & Actual & Actual & Actual \\
\hline FACE 1 & 30 & 29.93 & 20 & 26.1 & 270 & 269 & 0.8084 & 1.956 & 42.803 \\
\hline FACE 2 & 30 & 28.00 & 20 & 23.1 & 340 & 336 & 0.8037 & 1.988 & 43.155 \\
\hline FACE 3 & 30 & 32.02 & 45 & 50.0 & 270 & 270 & 0.8401 & 1.749 & 42.147 \\
\hline FACE 4 & 30 & 28.44 & 45 & 40.7 & 340 & 337 & 0.8355 & 1.819 & 42.495 \\
\hline FACE 5 & 55 & 54.20 & 20 & 22.2 & 270 & 276 & 0.8086 & 1.967 & 42.897 \\
\hline FACE 6 & 55 & 53.30 & 20 & 21.1 & 340 & 341 & 0.8411 & 1.871 & 42.797 \\
\hline FACE 7 & 55 & 44.30 & 45 & 46.2 & 270 & 267 & 0.8375 & 1.773 & 42.359 \\
\hline FACE 8 & 55 & 50.00 & 45 & 43.5 & 340 & 342 & 0.8682 & 1.704 & 42.196 \\
\hline FACE 9 & 42.5 & 44.95 & 32.5 & 37.0 & 305 & 321 & 0.8465 & 1.788 & 42.465 \\
\hline ULSD & - & 44.00 & - & 34.7 & - & 306 & 0.8496 & 1.796 & 42.857 \\
\hline
\end{tabular}

Note: Tgt. $=$ Target Value; Act. $=$ Actual Value

During this study, eight out of the nine test fuels were used and FACE 2 was replaced by an ultra low sulfur diesel (ULSD) 2007 certification fuel as a "check fuel." The reason for this is the rather "odd" fuel property behavior of FACE 2, namely the distillation temperature values, as discussed in subsection 2.4.3 and shown in Figure 32. 


\subsection{Particle Concentrations and Size Distributions}

Most aerosol size distributions are skewed to the right, as shown in Figure 67. For such a distribution the relation between the mode (most frequent size or the diameter of the highest particle concentration), the median (diameter for which half of the total number of particles are smaller and half larger) and the mean (arithmetic average) is as follows [77]:

mode $<$ median $<$ mean

A logarithmic transformation of the size data has been extensively used due to the empirically best fit of the observed size distributions. Statistical analysis of particle size distributions is therefore routinely based on lognormal distributions, shown in Figure 68.

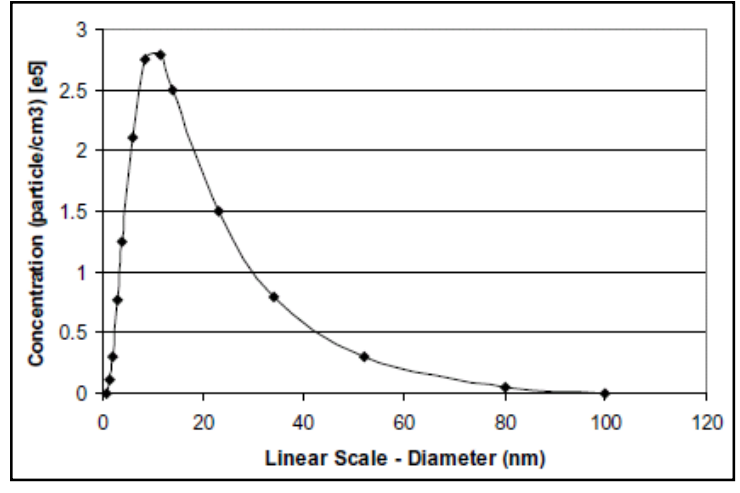

Figure 67 Example Linear Scale Aerosol Size Distribution [78]

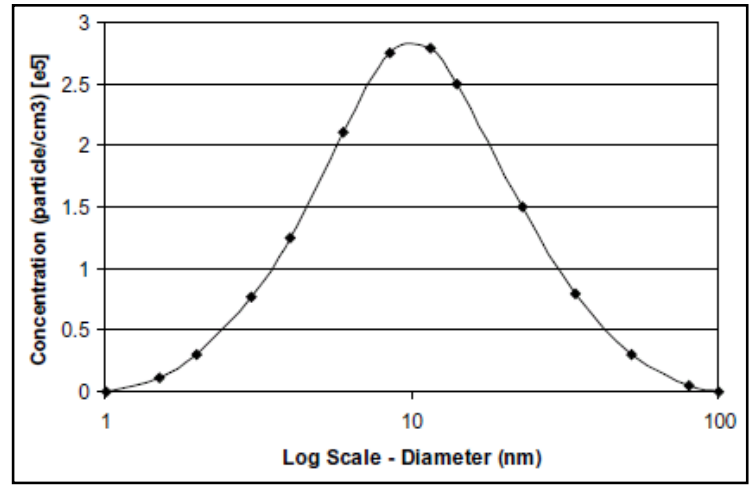

Figure 68 Example Log Scale Aerosol Size Distribution [78]

Particle size data can be plotted on a log scale as a function of the particle concentration (dN) for each particle size bin, as depicted in Figure 68. The mode concentration is then defined by the concentration in the peak bin. The midpoint particle diameter $\left(D_{p}\right)$ of this peak bin is the so-called count mode diameter. A problem can occur by using the particle concentration (dN) and comparing data taken from different instruments with different channel resolutions. As an example, same data taken with a particle sizing instrument with a channel resolution of 32 compared with another with 64 channel resolution leads to a nearly doubled particle mode concentration because the width of the bins is twice as large. In order to get comparable data, normalized particle concentration is used $\left(\mathrm{dN} / \mathrm{d} \log \mathrm{D}_{\mathrm{p}}\right)$. The particle concentration is thereby divided by the bin width, as indicated in Equation 8:

$$
\frac{d N}{d \log D_{p}}=\frac{d N}{\log D_{p, u}-\log D_{p, l}}
$$


where $D_{p, u}$ is the upper channel diameter and $D_{p, l}$ is the lower channel diameter. The advantage of plotting particle number distributions using normalized particle concentration is that the number of particles in any size range is proportional to the area under the distribution curve within that range [79].

The TSI EEPS ${ }^{\mathrm{TM}}$ model 3090 and the Cambustion DMS500 have equally spaced size channels on a log scale. The difference between every upper and lower channel is therefore (approximately) the same. Both instruments have 16 channels per decade resolution; therefore the logarithmic difference between each size class is $1 / 16$. This means, to calculate the normalized particle concentration, the concentration value for each bin is divided by $1 / 16$, hence multiplied by 16 .

In order to calculate a total number concentration (TNC) of the particle size distribution, the normalized particle concentration values have to be summed up followed by a division by the channels per decade resolution, in this case by 16, as described with Equation 10:

$$
T N C=\frac{1}{16} \sum_{i=1}^{n} \frac{d N}{\operatorname{dlog} D_{p, i}}
$$

Due to the difference in particle number concentration of several orders of magnitude over the diameter range, diesel engine exhaust is therefore often depicted on a log-log scale. In this way, significant changes and trends can be examined for two to four orders of magnitude change.

\subsection{Inference Calculations}

The purpose of statistical inference is to draw conclusions from data by probability calculations. Probability calculations help distinguish between patterns that are consistent or inconsistent [80]. In this study, the idea of significance testing was applied. A significance test is a procedure for comparing observed data with a hypothesis, which is a statement about the population parameters. The results are represented in terms of a probability measuring how well the data and the hypothesis agree. The statement tested in a test of significance is called the null hypothesis $\left(\mathrm{H}_{0}\right)$ and the strength of the evidence against the null hypothesis, which is a statement of "no effect," is evaluated. The statement one suspects to be true instead of the null hypothesis is the so-called alternative hypothesis $\left(\mathrm{H}_{\mathrm{a}}\right)$. The probability, assuming $\mathrm{H}_{0}$ is true, that the test statistic would take a value as extreme or more extreme than the actually observed is called the 
$\mathrm{P}$-value of the test. The smaller the $\mathrm{P}$-value, the stronger the evidence against $\mathrm{H}_{0}$ provided by the data [80]. If the P-value is as small as or smaller than a value called the significance level, the data are statistically significant at that level. The standard significance level is 0.05 or $5 \%$, which is used throughout this study.

In this study, t-Tests of the null hypothesis that the data from two independent random samples from normal distributions with equal means but unequal and unknown variances, against the alternative hypothesis that the means are not equal were performed using the MATLAB ${ }^{\circledR}$ function "ttest2." After stating the $\mathrm{H}_{0}$ and $\mathrm{H}_{\mathrm{a}}$, a test statistic is calculated on which the t-Test is based. Significance tests for $\mathrm{H}_{0}: \mu_{1}=\mu_{2}$ use the following two-sample t statistic:

$$
t=\frac{\bar{x}_{1}-\bar{x}_{2}}{\sqrt{\frac{s_{1}^{2}}{n_{1}}+\frac{s_{2}^{2}}{n_{2}}}}
$$

where $\bar{x}_{i}$ is the sample mean, $\mathrm{s}_{\mathrm{i}}$ is the sample standard deviation and $\mathrm{n}_{\mathrm{i}}$ the sample size. The $\mathrm{P}$ value is then approximated using a t-distribution and together with the significance level a conclusion about the evidence against $\mathrm{H}_{0}$ can be stated. The t-Test assumes that the data are independently sampled from a normal distribution. Therefore, the data to be tested were assessed by testing this assumption that the samples come from normal distributions with normal probability plots. Figure 69 shows an example of a normal probability for mode particle concentration. The scatter follows well the straight line through the first and third quartile of the sample, indicating approximate normal distribution of the data. Other data examination was performed using box plots. A box plot displaying the distribution of two samples around their median is depicted in Figure 70 . The central box spans the first $\left(\mathrm{Q}_{1}\right)$ and third $\left(\mathrm{Q}_{3}\right)$ quartiles, whereas the lines extended from the box indicate the smallest and largest observation. Observations that are suspected as outliers falling more than 1.5 times the interquartile range $\left(\mathrm{IQR}=\mathrm{Q}_{3}-\mathrm{Q}_{1}\right)$ above the third or below the first quartile are listed separately, as shown in Figure 70 [80]. This approach provides a visual check about the quality of the data and may indicate presumably rejection of a null hypothesis. 


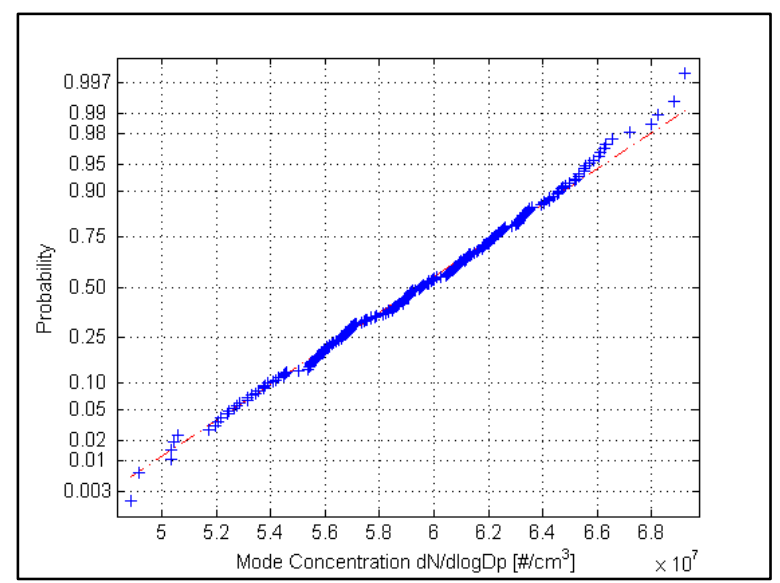

Figure 69 Normal Probability Plot for Mode Particle Concentration of FACE 1 (Test 19)

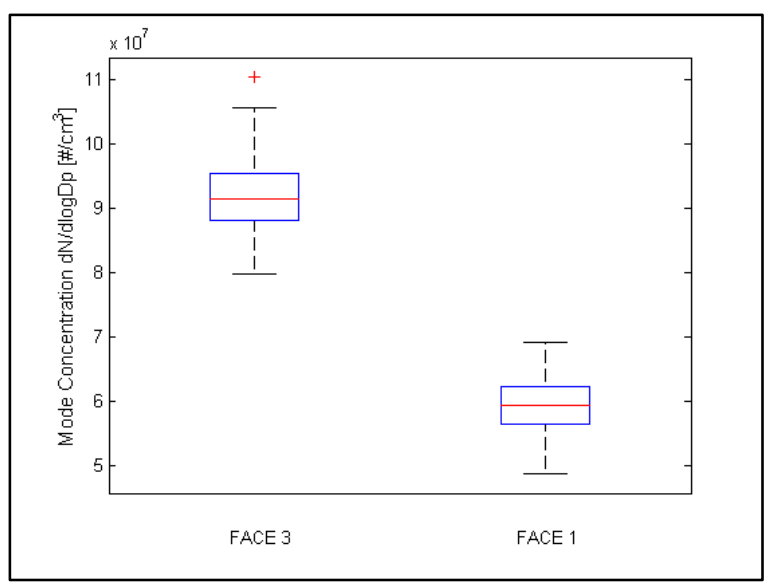

Figure 70 Box plot for Mode Particle Concentration of FACE 3 and FACE 1 (Test 19)

T-tests are relatively robust against the aforementioned test assumption if the sample size, in this study 200 s of measurement time at $1 \mathrm{~Hz}$ sample frequency, is large enough. The calculated sample means $\bar{x}_{i}$ have approximately normal sampling distribution with mean equal to the population mean $\mu$ for increasing sample sizes [80].

\subsection{Optimal Split and Single Injection Tests}

In order to get a first comparison of the particle size distributions for different FACE diesel fuels during low temperature combustion and due to the large number of tests performed for each fuel, optimal split injection tests were selected by isolating the ten tests with the highest brake thermal efficiency (BTE). Out of these ten tests, the test with the highest BTE, the test with the lowest soot emissions and the test with the lowest $\mathrm{NO}_{\mathrm{x}}$ emissions were selected. The three optimal single injection tests were selected similar to the split injection tests out of all single injection tests performed.

The set order for the selected optimal tests was sorted according to the fuel's cetane number in order to show the increase in $\mathrm{CN}$ in the graphs. The test set FACE 4 was measured with the Engine Exhaust Particle Sizer ${ }^{\mathrm{TM}}$ Spectrometer from TSI (model 3090 EEPS $^{\mathrm{TM}}$ ), whereas the remaining eight sets were measured with the Differential Mobility Spectrometer (DMS) from Cambustion (model DMS500). The EEPS ${ }^{\mathrm{TM}}$ cut-off limit, which is the instrument detection limit corrected for DR, was plotted in the corresponding graphs to show the relation between measured values and instrument restriction. The values of each channel were averaged over the sampling time similar to the other emissions measured during this project. 


\subsubsection{Split Injection Control Strategy}

Based on the concept of the UNIBUS control strategy (see Section 2.2.1.2), a split injection control strategy was refined for use with the GM Z19DTH engine and the FACE diesel fuels to be used during the study. The fuel injection parameters, namely main SOI timing, pilot SOI timing and fuel split in percent of pilot injection quantity, were varied while holding the intake oxygen concentration at $16 \%$ as a surrogate for EGR fraction. The exhaust gas recirculation fraction can be quantified on the basis of the volume percent of $\mathrm{CO}_{2}$ in the ambient air, intake air and exhaust [16]. However, an alternative is calculating the EGR fraction based on the oxygen concentration, as given in Equation 13 and used in this study:

$$
E G R \%_{O_{2}}=\frac{O_{2 \text { intake }}(\text { vol } \%)-O_{2 \text { ambient }}(\text { vol } \%)}{O_{2 \text { exhaust }}(\text { vol } \%)-O_{2 \text { ambient }}(\text { vol } \%)}
$$

The engine operating conditions for the split injection strategy are listed in Table 8 . Significantly different fuel properties required a grouping by $\mathrm{CN}$ to form three different split injection matrices with accordingly adjusted fuel injection parameters based on CN. For low CN fuels, more advanced range of SOI timing was selected to limit the presence of misfiring at retarded main SOI timing, due to the longer ignition delay inherent to these fuels. In order to limit heat release before the main injection event, pilot SOI timings were adjusted as well. These low, medium and high cetane split injection test matrices are listed in Table 22 to Table 24 in APPENDIX A.

Table 8 Engine Operating Conditions for Split Injection Strategy

\begin{tabular}{|c|c|}
\hline Engine Speed & $2100 \mathrm{rpm}$ \\
\hline BMEP & $3.5 \mathrm{bar}$ \\
\hline Intake Oxygen Concentration & $16 \%$ \\
\hline Rail Pressure & $1600 \mathrm{bar}$ \\
\hline Fuel Temperature & $31^{\circ} \mathrm{C}$ \\
\hline Coolant Temperature & $86^{\circ} \mathrm{C}$ \\
\hline
\end{tabular}

\subsubsection{Single Injection Control Strategy}

For each of the FACE diesel fuels, a single injection strategy was also explored. Intake oxygen concentration, as a surrogate for EGR fraction, and rail pressure were varied while 
holding the location of 50 percent mass fraction burned (CA50) constant at $7^{\circ}$ ATDC by adjusting SOI timing for each test and fuel in order to achieve the most advanced combustion phasing while still retaining "safe" pressure rise rates (below $10 \mathrm{bar} /{ }^{\circ} \mathrm{CA}$ ). Table 9 gives an overview of the engine operating conditions for this single injection strategy.

Table 9 Engine Operating Conditions for Single Injection Strategy

\begin{tabular}{|c|c|}
\hline Engine Speed & $2100 \mathrm{rpm}$ \\
\hline BMEP & $3.5 \mathrm{bar}$ \\
\hline CA50 & $7^{\circ} \mathrm{ATDC}$ \\
\hline Fuel Temperature & $32^{\circ} \mathrm{C}$ \\
\hline Coolant Temperature & $84^{\circ} \mathrm{C}$ \\
\hline
\end{tabular}

For an overview of the single injection test matrix, refer to Table 25 in APPENDIX A.

\subsection{Low, Medium and High Cetane Fuel Comparison}

In order to block out the predominant effects of the cetane number, the fuels were grouped into "low", "medium" and "high" cetane fuels for comparison purposes. The test runs showed in the corresponding graphs were selected in a way to show a maximum of tests meeting four of the five criteria for advanced combustion defined for this specific GM Z19DTH engine. Table 10 gives an overview of the criteria to be met for advanced combustion by the GM Z19DTH engine.

Table 10 Advanced Combustion Criteria for GM Z19DTH

\begin{tabular}{|c|c|c|c|c|}
\hline $\begin{array}{c}\text { HC } \\
{[\mathbf{p p m}]}\end{array}$ & $\begin{array}{c}\mathbf{N O}_{\mathbf{x}} \\
{[\mathbf{p p m}]}\end{array}$ & $\begin{array}{c}\text { CO } \\
{[\mathbf{p p m}]}\end{array}$ & $\begin{array}{c}\text { Soot } \\
{\left[\mathbf{m g} / \mathbf{m}^{3}\right]}\end{array}$ & $\begin{array}{c}\text { BTE } \\
{[\%]}\end{array}$ \\
\hline$<1000$ & $<50$ & $<3000$ & $<10$ & $>30$ \\
\hline
\end{tabular}

These specific criteria were defined based on data from other projects on this engine combined with the intrinsic experience of FACE fuel project committee members ${ }^{1}$. However, a drawback of these definitions is its basis on concentration rather than brake specific, which makes it flow rate dependent and impossible to compare with other engine platforms.

1 AVFL-16 Technical Panel: Tennant, C., Coordinating Research Council, Inc.; Cannella, B., Chevron Energy Technology Co.; Sluder, S., and Wagner, R., Oak Ridge National Laboratories. 
Nevertheless, these criteria are used as a measure of advanced combustion regime in this study. Table 11 lists the selected test runs with highlighted runs meeting four out of the five criteria.

Table 11 Selected Test Runs for Low, Medium and High Cetane Fuel Comparison

\begin{tabular}{|l|l|l|l|}
\hline Fuel & CN Group & \multicolumn{2}{l|}{ Test \# Showed in Graphs } \\
\hline FACE 4 & low & 19 & 28 \\
\hline FACE 1 & low & 19 & 28 \\
\hline FACE 3 & low & 19 & 28 \\
\hline ULSD & medium & 19 & 28 \\
\hline FACE 7 & medium & 19 & 28 \\
\hline FACE 9 & medium & 19 & 28 \\
\hline FACE 8 & high & 19 & 28 \\
\hline FACE 6 & high & 19 & 28 \\
\hline FACE 5 & high & 19 & 28 \\
\hline \multicolumn{2}{|l|}{ Note: highlighted test \# meet four out of five criteria in Table 10 }
\end{tabular}

For the low cetane group, the EEPS ${ }^{\mathrm{TM}}$ cut-off limit, which is the instrument detection limit corrected for DR, was again plotted to show the relation between measured values and instrument restriction. The EEPS ${ }^{\mathrm{TM}}$ was used for FACE 4 only, whereas FACE 1 and 3 were measured using the DMS500.

To show similar information as the EEPS ${ }^{\mathrm{TM}}$ cut-off limit for runs measured with DMS500 only, a total background average was plotted for medium and high cetane fuels.

\subsection{Injection Timing Comparison}

For a low and high CN fuel, namely FACE 4 and 8, trends of start of injection (SOI) timing variation during split injection strategy at a selected pilot SOI and fuel split in percent of pilot injection quantity $\left(40^{\circ} \mathrm{BTDC}\right.$ and $\left.35 \%\right)$ were studied as an additional comparison.

\subsection{Rail Pressure and Intake Oxygen Concentration during Single Injection}

The effect of varying rail pressure was evaluated for a low and high CN fuel (FACE 1 and 5) as well as for two high $\mathrm{CN}$ fuels with low and high 90 percent distillation temperature. The consequences of varying intake oxygen concentration as a surrogate for EGR fraction was then examined again for a low and high CN fuel (FACE 4 and 8) during single injection strategy. 


\section{8 $\operatorname{EEPS}^{\mathrm{TM}}$ and DMS Measurement System Comparison}

Due to unavailability of the EEPS ${ }^{\mathrm{TM}}$ measurement system after the first measurement set (FACE4), the DMS500 was set up under the same conditions for the subsequent 8 measurement sets. In a study performed by the Californian Air Resource Board (CARB), the EEPS ${ }^{\mathrm{TM}}$ and DMS showed "relatively good agreement" even though a slight offset in accumulation mode was detected [81]. Nevertheless, an opportunity was taken after completing this study to examine simultaneous sampling from the $2^{\text {nd }}$ stage mini dilution tunnel with the EEPS ${ }^{\mathrm{TM}}$ and DMS for direct comparison purposes. The results of this measurement system comparison are presented in APPENDIX B. 


\section{CHAPTER 5 RESULTS AND DISCUSSION}

In this section, concentration and size distributions of PM emissions from the optimal split and single injection tests are presented, followed by a comparison of low, medium and high cetane fuels. Further, effects of varying injection timing during split injection strategy as well as rail pressure and intake oxygen concentration during single injection strategy for selected FACE diesel fuels are discussed.

\subsection{Optimal Split Injection Tests}

The particle size distribution for the optimal split injection test for low $\mathrm{NO}_{\mathrm{x}}$, depicted on a $\log -\log$ scale, is shown Figure 71 . The particle diameter $D_{p}$ in nanometers is plotted versus the normalized particle concentration, which is integrated over each bin (instrument channel), in number of particles per volume $\left(\mathrm{cm}^{3}\right)$. In general, there is an increase in particle number concentration with simultaneous increase in particle diameter as the fuel $\mathrm{CN}$ increases for the low $\mathrm{NO}_{\mathrm{x}}$ tests, as indicated with an arrow in Figure 71. The shorter ignition delay for higher $\mathrm{CN}$ fuels leads to a greater inhomogeneity of the cylinder charge and therefore increased particle emissions due to higher fuel fractions allocated to the diffusion burning, compared to lower CN fuels. Similar trends could be seen for low soot and highest BTE tests (shown in APPENDIX C). These additional graphs in APPENDIX C are presented as a version with and without error bars on one page for comparison purposes. The cut-off limit of the EEPS ${ }^{\mathrm{TM}}$, which is the instrument's detection limit corrected for DR, was plotted to show the relation between measured values and instrument limitation. The legend shows the engine control parameters, such as main start of injection, pilot start of injection (both in BTDC) and the fuel split of pilot (in \%) as a number code, as well as the fuel used for the individual tests. In the upper left, the dilution ratio as an average value used to correct the measured values is shown. 


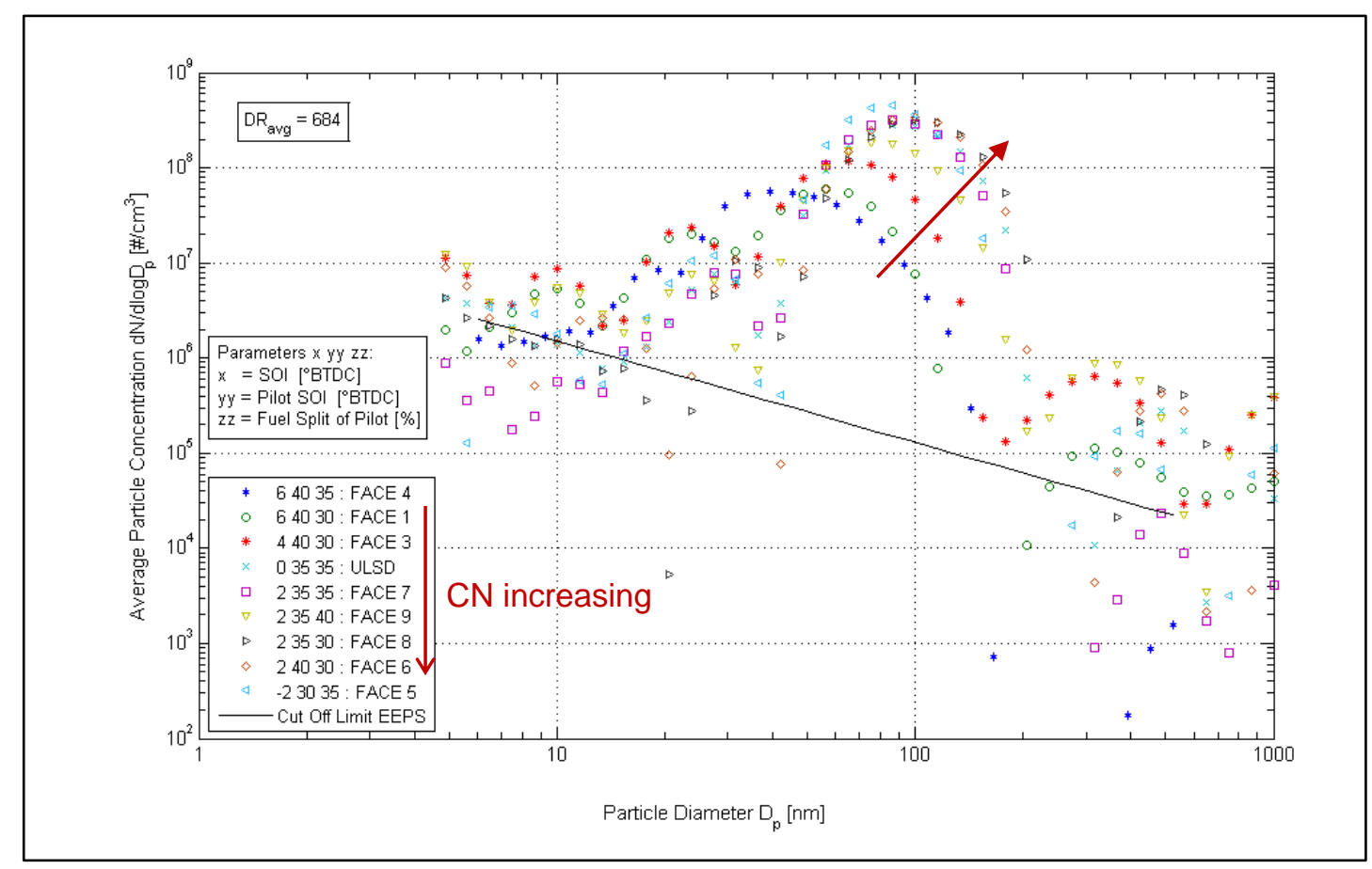

Figure 71 Particle Size Distribution for Optimal Split Injection Tests for Low $\mathrm{NO}_{\mathrm{x}}-$ Filled Markers for EEPS ${ }^{\mathrm{TM}}$

Emissions of the optimal split injection tests for low $\mathrm{NO}_{\mathrm{x}}$ are listed in Table 12, where highlighted cells meet the criteria in Table 10. With the exception of FACE 4 all the other fuels reach a brake thermal efficiency of more than $30 \%$.

Table 12 Emissions of Optimal Split Injection Tests for Low $\mathrm{NO}_{\mathrm{x}}$

\begin{tabular}{|c|c|c|c|c|c|c|}
\hline Fuel & Test \# & $\begin{array}{c}\text { HC } \\
{[\mathbf{g} / \mathbf{k W h}]}\end{array}$ & $\begin{array}{c}\mathbf{N O} \\
{[\mathbf{g} / \mathbf{k W h}]}\end{array}$ & $\begin{array}{c}\mathbf{C O} \\
{[\mathbf{g} / \mathbf{k W h}]}\end{array}$ & $\begin{array}{c}\text { Soot } \\
{[\mathbf{m g} / \mathbf{k W h}]}\end{array}$ & $\begin{array}{c}\text { BTE } \\
{[\%]}\end{array}$ \\
\hline FACE 4 & 20 & 7.35 & 0.476 & 19.72 & 6.6 & 29.4 \\
\hline FACE 1 & 19 & 4.36 & 0.549 & 16.45 & 9.1 & 30.4 \\
\hline FACE 3 & 28 & 4.59 & 0.485 & 17.64 & 30.4 & 30.2 \\
\hline ULSD & 29 & 1.90 & 0.438 & 10.18 & 138.6 & 31.4 \\
\hline FACE 7 & 20 & 1.77 & 0.501 & 10.11 & 161.8 & 31.1 \\
\hline FACE 9 & 21 & 1.86 & 0.599 & 9.72 & 128.6 & 31.7 \\
\hline FACE 8 & 13 & 1.38 & 0.575 & 7.37 & 314.0 & 31.8 \\
\hline FACE 6 & 16 & 1.82 & 0.460 & 11.56 & 264.2 & 31.8 \\
\hline FACE 5 & 29 & 1.09 & 0.384 & 6.63 & 131.8 & 31.5 \\
\hline
\end{tabular}

Note: highlighted cells meet criteria in Table 10

Figure 72 shows a comparison of FACE 4 (low $\mathrm{CN}$ ) and 5 (high $\mathrm{CN}$ ). It can be seen that the particle diameter at the highest particle number concentration, the count mode diameter (CMD), is shifted towards lower numbers with decreasing CN. The PM size distribution for 
FACE 5 (high $\mathrm{CN}$ ) shows distinctive accumulation and nucleation modes. Figure 72 also includes error bars for each mean value as one standard deviation, indicating that conclusions regarding nanoparticles size distribution and concentrations have to be carefully drawn.

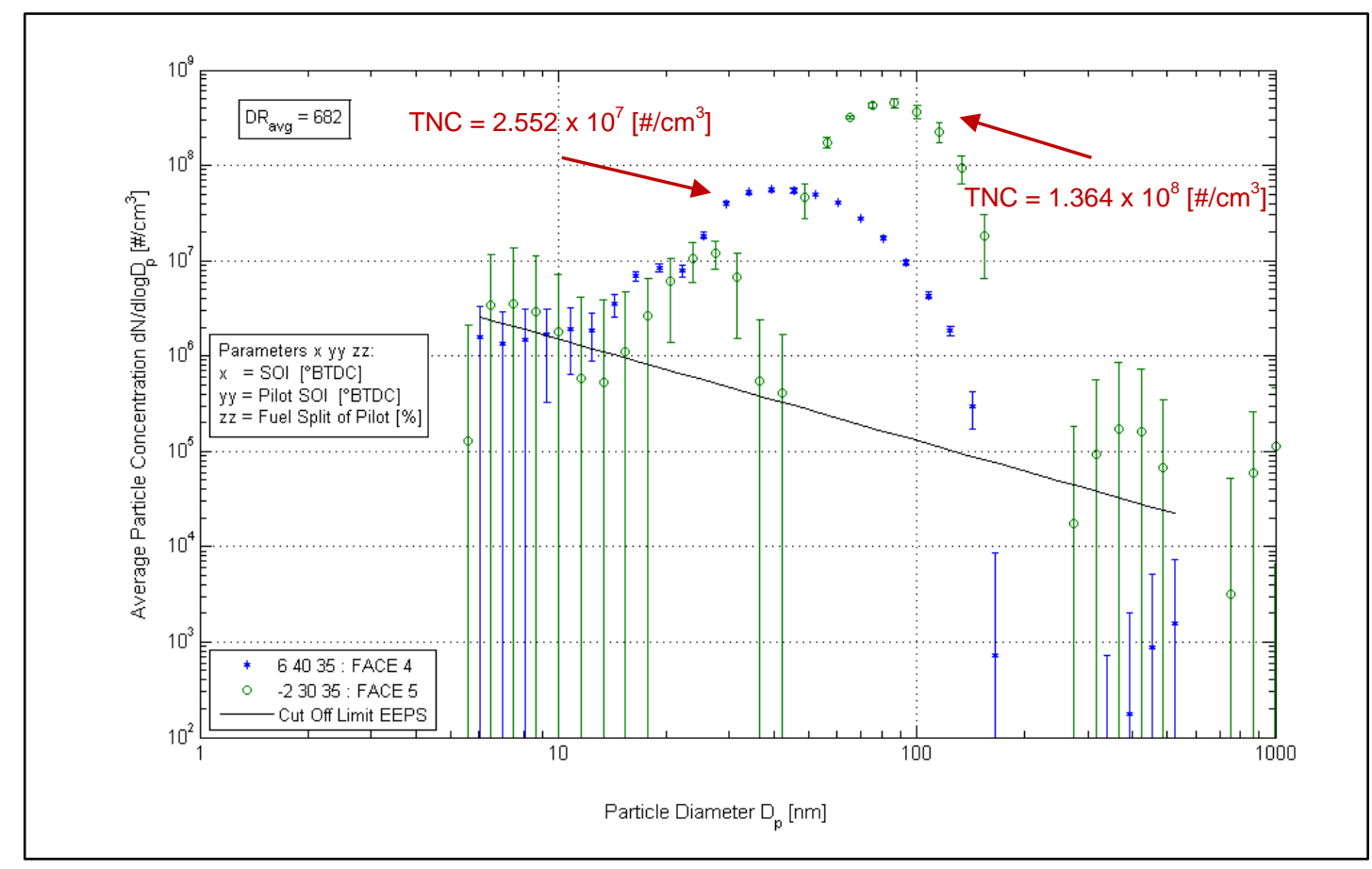

Figure 72 Particle Size Distribution for Optimal Split Injection Tests for Low $\mathrm{NO}_{\mathrm{x}}-$ Low and High CN $($ Error $=1 \sigma)$; Filled Markers for EEPS ${ }^{\mathrm{TM}}$

\subsection{Optimal Single Injection Tests}

Trends for the optimal low $\mathrm{NO}_{\mathrm{x}}$ single injection tests can be seen in Figure 73 (see arrow). Higher particle number concentrations were found for higher cetane numbers. Similar trends can be seen for low soot and highest BTE tests as well (see APPENDIX C). These additional graphs in APPENDIX $\mathrm{C}$ are again presented with and without the error bars on one page for comparison purposes. The legend shows the engine control parameters, such as intake $\mathrm{O}_{2}$ (in \%) and rail pressure (in bar) as a number code, as well as the fuel used for this test. 


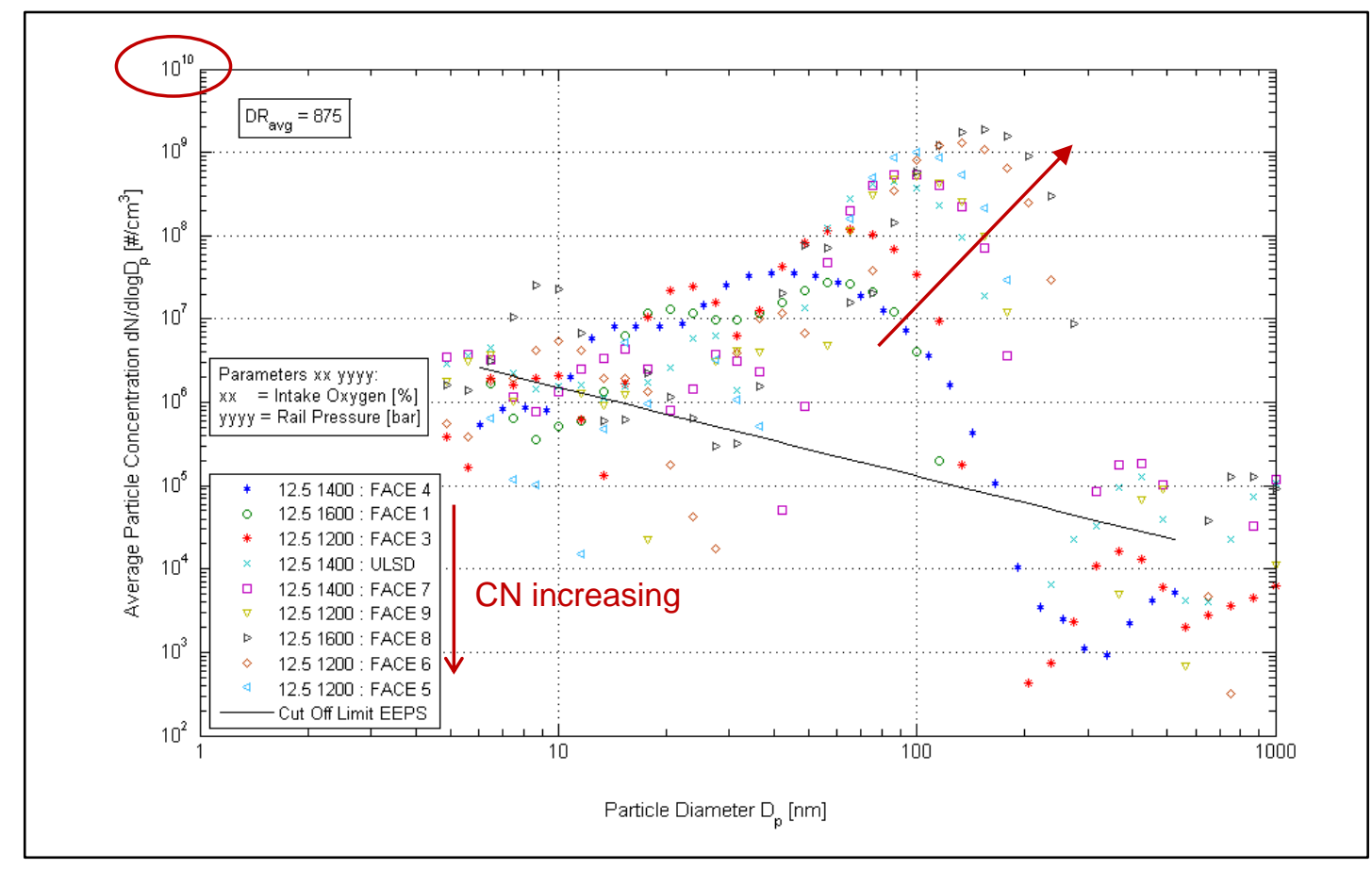

Figure 73 Particle Size Distribution for Optimal Single Injection Tests for Low $\mathrm{NO}_{\mathrm{x}}-$ Filled Markers for EEPS ${ }^{\mathrm{TM}}$

An emissions comparison between the optimal split and single injection tests for low $\mathrm{NO}_{\mathrm{x}}$ is given in Table 13. $\mathrm{NO}_{\mathrm{x}}$ emissions are significantly lower for the single injection strategy while brake thermal efficiency is slightly higher compared to the split injection strategy. Soot emission values confirm the trend seen for the particle size distributions in Figure 73 with significantly higher values for the single injection strategy with FACE 9, 5, 6 and 8, increasing in this order. Intake oxygen concentration was held at $16 \%$ for split and $12.5 \%$ for single injection strategy.

Table 13 Emissions Comparison of Optimal Split and Single Injection Tests for Low $\mathrm{NO}_{\mathrm{x}}$

\begin{tabular}{|l|c|c|c|c|c|c|c|c|c|c|c|c|}
\hline \multirow{2}{*}{ Fuel } & \multicolumn{2}{|c|}{ Test \# } & \multicolumn{2}{c|}{$\begin{array}{c}\text { HC } \\
{[\mathbf{g} / \mathbf{k W h}]}\end{array}$} & \multicolumn{2}{c|}{$\begin{array}{c}\text { NO } \\
{[\mathbf{g} / \mathbf{k} \mathbf{W h}]}\end{array}$} & \multicolumn{2}{c|}{$\begin{array}{c}\text { CO } \\
\mathbf{[ g / k W h}]\end{array}$} & \multicolumn{2}{c|}{$\begin{array}{c}\text { Soot } \\
{[\mathbf{m g} / \mathbf{k W h}]}\end{array}$} & \multicolumn{2}{c|}{$\begin{array}{c}\text { BTE } \\
{[\%]}\end{array}$} \\
\cline { 2 - 13 } & Split & Single & Split & Single & Split & Single & Split & Single & Split & Single & Split & Single \\
\hline FACE 4 & 20 & 50 & 7.35 & 6.91 & 0.476 & 0.083 & 19.72 & 19.10 & 6.6 & 2.0 & 29.4 & 30.5 \\
\hline FACE 1 & 19 & 51 & 4.36 & 3.58 & 0.549 & 0.107 & 16.45 & 12.65 & 9.1 & 2.0 & 30.4 & 32.7 \\
\hline FACE 3 & 28 & 49 & 4.59 & 2.94 & 0.485 & 0.119 & 17.64 & 17.09 & 30.4 & 20.2 & 30.2 & 32.0 \\
\hline ULSD & 29 & 50 & 1.90 & 1.30 & 0.438 & 0.134 & 10.18 & 10.93 & 138.6 & 103.3 & 31.4 & 33.4 \\
\hline FACE 7 & 20 & 50 & 1.77 & 1.38 & 0.501 & 0.137 & 10.11 & 13.73 & 161.8 & 168.7 & 31.1 & 32.1 \\
\hline FACE 9 & 21 & 49 & 1.86 & 1.12 & 0.599 & 0.182 & 9.72 & 10.37 & 128.6 & 266.8 & 31.7 & 33.7 \\
\hline FACE 8 & 13 & 51 & 1.38 & 1.11 & 0.575 & 0.186 & 7.37 & 15.02 & 314.0 & 924.9 & 31.8 & 32.2 \\
\hline FACE 6 & 16 & 49 & 1.82 & 1.02 & 0.460 & 0.159 & 11.56 & 15.54 & 264.2 & 749.4 & 31.8 & 33.0 \\
\hline FACE 5 & 29 & 49 & 1.09 & 1.12 & 0.384 & 0.122 & 6.63 & 13.83 & 131.8 & 271.9 & 31.5 & 33.5 \\
\hline
\end{tabular}

Note: Split / Single = Split / Single Injection Strategy; highlighted cells meet criteria in Table 10 
In Figure 74, FACE 4 (low $\mathrm{CN}$ ) shows a wide particle number distribution with good statistical significance, whereas the accumulation mode for FACE 5 is especially narrow. There is also increased variability in the measurements towards nanoparticles.

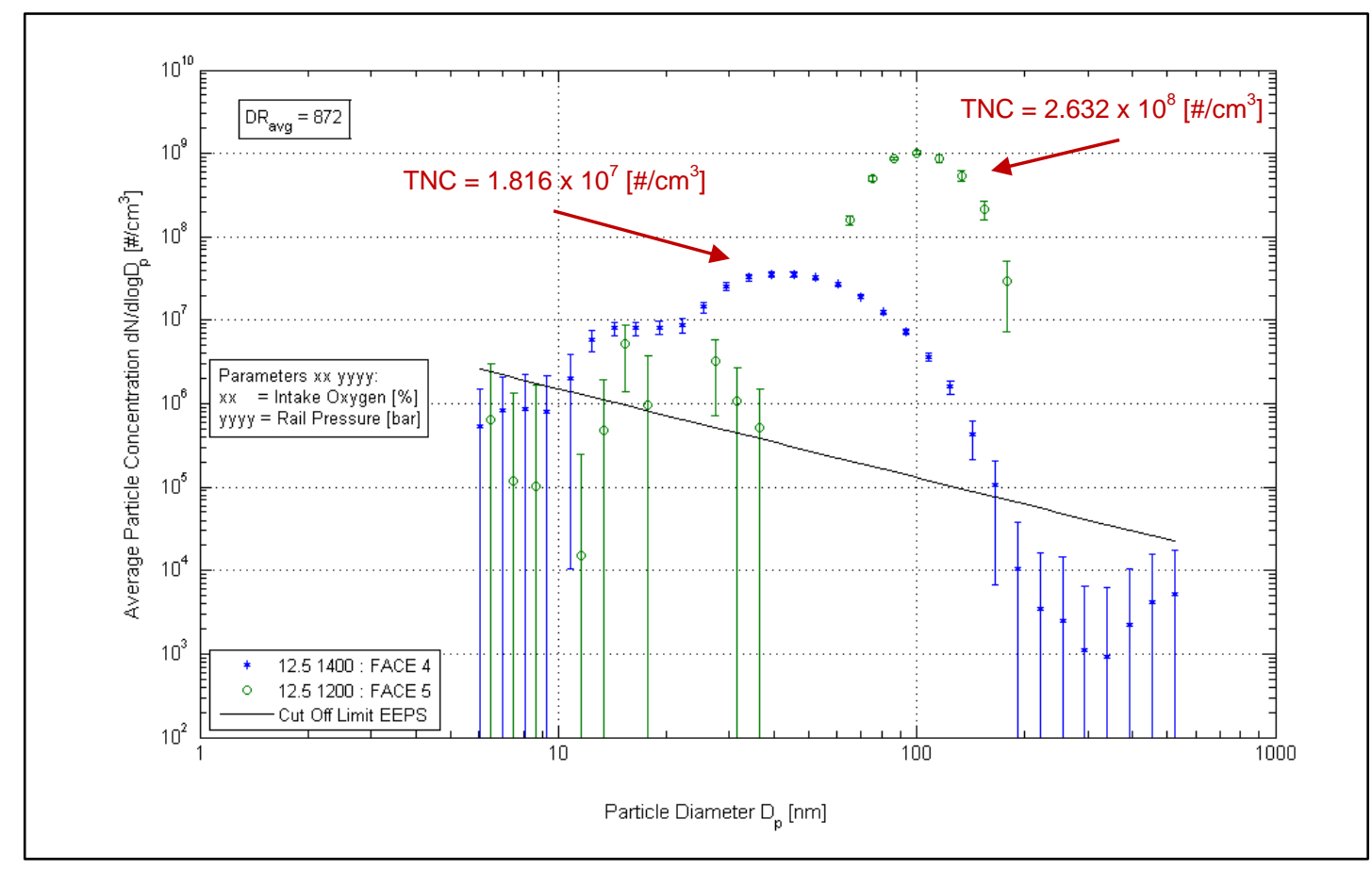

Figure 74 NP Size Distribution for Optimal Single Injection Tests for Low $\mathrm{NO}_{\mathrm{x}}-$ Low and High CN $($ Error $=1 \sigma)$; Filled Markers for EEPS ${ }^{\mathrm{TM}}$

\subsection{Low, Medium and High Cetane Fuel Comparison}

\subsubsection{Low Cetane Fuel Comparison}

In Figure 75, the selected runs for the low cetane group are shown. There is a trend towards a more pronounced bimodal distribution when comparing FACE 4 (high T90 / high aromatics) with FACE 1 (low T90 / low aromatics) and FACE 3 (low T90 / high aromatics), which could be explained by the difference in distillation temperature (T90) between FACE 4 and FACE 1 and FACE 3. Comparing the two fuels with low 90 percent distillation temperature, FACE 1 (low T90 / low aromatics) and FACE 3 (low T90 / high aromatics), a slightly increased number concentration can be seen for the fuel with high aromatic content (FACE 3). De Ojeda et al. [49] have attributed the greater inclination to form particles to the higher aromatic fuels. A version of Figure 75 showing the error as one standard deviation is presented in APPENDIX C. 


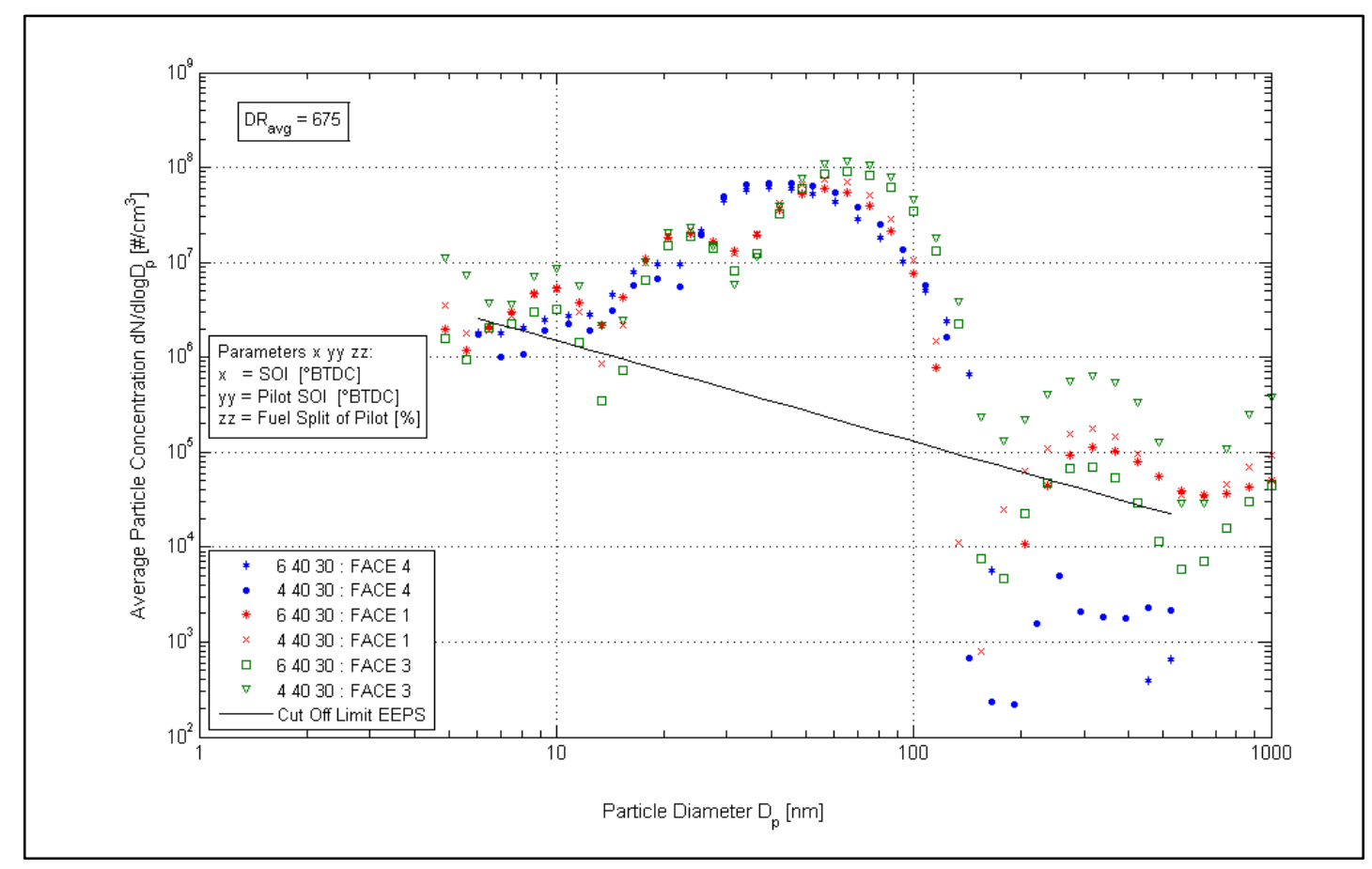

Figure 75 Particle Size Distribution for Low Cetane Fuels - Filled Markers for EEPS ${ }^{\mathrm{TM}}$

In Table 14 the results of the two-sample t-test for FACE 4 (high T90 / high aromatics) and FACE 3 (low T90 / high aromatics) are presented. As the P-values indicate the shift towards lower count mode diameters as well as lower mode particle number concentrations for the higher T90 distillation temperature of FACE 4 are statistically significant at 5\% significance level for both tests selected. These results confirm the trends observed in Figure 75.

Table 14 Two-Sample t-Test with Unequal Variances, One-Sided, 5\% Significance Level: Effect of T90 on Low CN Fuels

\begin{tabular}{|c|c|c|c|c|c|}
\hline Hypothesis & \multicolumn{4}{|c|}{90 Percent Distillation Temperature } & \\
\hline $\mathrm{H}_{0}: \mu_{\mathrm{FACE} 4}=\mu_{\mathrm{FACE} 3}$ & \multicolumn{2}{|c|}{ Count Mode Diameter } & \multicolumn{2}{|c|}{ Mode $\mathbf{d N} / \mathbf{d} \log D_{p}$} & \\
\hline $\mathrm{H}_{\mathrm{a}}: \mu_{\mathrm{FACE} 4}<\mu_{\mathrm{FACE} 3}$ & FACE 4 & FACE 3 & FACE 4 & FACE 3 & \\
\hline Mean value & $39.2 \mathrm{~nm}$ & $64.9 \mathrm{~nm}$ & $6.17 \times 10^{7} \# / \mathrm{cm}^{3}$ & $9.21 \times 10^{7} \# / \mathrm{cm}^{3}$ & \multirow{5}{*}{$\begin{array}{l}\text { Test } 19 \\
64030^{*}\end{array}$} \\
\hline Sample Std & $0 \mathrm{~nm}^{\dagger}$ & $0 \mathrm{~nm}^{\dagger}$ & $2.72 \times 10^{6} \# / \mathrm{cm}^{3}$ & $5.19 \times 10^{6} \# / \mathrm{cm}^{3}$ & \\
\hline t Statstic & \multicolumn{2}{|c|}{$-2.13 \times 10^{15}$} & \multicolumn{2}{|c|}{-72.62} & \\
\hline P-value & \multicolumn{2}{|c|}{$<0.0001$} & \multicolumn{2}{|c|}{$<0.0001$} & \\
\hline Rejecting $\mathrm{H}_{0}$ & \multicolumn{2}{|c|}{ Yes } & \multicolumn{2}{|c|}{ Yes } & \\
\hline Mean value & $39.2 \mathrm{~nm}$ & $64.9 \mathrm{~nm}$ & $6.90 \times 10^{7} \# / \mathrm{cm}^{3}$ & $1.20 \times 10^{7} \# / \mathrm{cm}^{3}$ & \\
\hline Sample Std & $2.52 \mathrm{~nm}$ & $5.50 \mathrm{~nm}$ & $3.53 \times 10^{6} \# / \mathrm{cm}^{3}$ & $9.04 \times 10^{6} \# / \mathrm{cm}^{3}$ & \\
\hline t Statstic & \multicolumn{2}{|c|}{-56.37} & \multicolumn{2}{|c|}{-76.04} & $\begin{array}{l}\text { Test } 28 \\
44030^{*}\end{array}$ \\
\hline P-value & \multicolumn{2}{|c|}{$<0.0001$} & \multicolumn{2}{|c|}{$<0.0001$} & \\
\hline Rejecting $\mathrm{H}_{0}$ & \multicolumn{2}{|c|}{ Yes } & \multicolumn{2}{|c|}{ Yes } & \\
\hline
\end{tabular}

Note: Parameters $x$ yy $z z: x=$ SOI $\left[{ }^{\circ}\right.$ BTDC]; yy = Pilot SOI [ ${ }^{\circ}$ BTDC]; $z z=$ Fuel Split of Pilot [\%]

${ }^{\dagger}$ Recall: mean value from 200s data@1Hz sample frequency; CMD based on normal distribution within the bin 
The effects on aromatic content for FACE 1 (low T90 / low aromatics) and FACE 3 (low T90 / high aromatics) are statistically significant at 5\% significance level. The decrease in mode particle number concentrations for the fuel with lower aromatic content (FACE1) is therefore accompanied by a slight lower count mode diameter of the particle distribution compared to FACE 3 with higher aromatic content for both tests selected.

Table 15 Two-Sample t-Test with Unequal Variances, One-Sided, 5\% Significance Level: Effect of Aromatic Content on Low CN Fuels

\begin{tabular}{|c|c|c|c|c|c|}
\hline Hypothesis & \multicolumn{4}{|c|}{ Aromatic Content } & \\
\hline $\mathrm{H}_{0}: \mu_{\mathrm{FACE} 1}=\mu_{\mathrm{FACE} 3}$ & \multicolumn{2}{|c|}{ Count Mode Diameter } & \multicolumn{2}{|c|}{$\mathrm{dN} / \mathrm{dlog} D_{\mathrm{p}}$} & \\
\hline $\mathrm{H}_{\mathrm{a}}: \mu_{\mathrm{FACE} 1}<\mu_{\mathrm{FACE} 3}$ & FACE 1 & FACE 3 & FACE 1 & FACE 3 & \\
\hline Mean value & $56.2 \mathrm{~nm}$ & $64.9 \mathrm{~nm}$ & $5.94 \times 10^{7} \mathrm{\#} / \mathrm{cm}^{3}$ & $9.21 \times 10^{7} \# / \mathrm{cm}^{3}$ & \multirow{5}{*}{$\begin{array}{l}\text { Test } 19 \\
64030^{*}\end{array}$} \\
\hline Sample Std & $0 \mathrm{~nm}^{\dagger}$ & $0 \mathrm{~nm}^{\dagger}$ & $4.00 \times 10^{6} \# / \mathrm{cm}^{3}$ & $5.19 \times 10^{6} \# / \mathrm{cm}^{3}$ & \\
\hline t Statstic & \multicolumn{2}{|c|}{$-4.06 \times 10^{14}$} & \multicolumn{2}{|c|}{-76.87} & \\
\hline $\mathrm{P}$-value & \multicolumn{2}{|c|}{$<0.0001$} & \multicolumn{2}{|c|}{$<0.0001$} & \\
\hline Rejecting $\mathrm{H}_{0}$ & \multicolumn{2}{|c|}{ Yes } & \multicolumn{2}{|c|}{ Yes } & \\
\hline Mean value & $56.2 \mathrm{~nm}$ & $64.9 \mathrm{~nm}$ & $7.57 \times 10^{7} \# / \mathrm{cm}^{3}$ & $1.20 \times 10^{7} \mathrm{\#} / \mathrm{cm}^{3}$ & \\
\hline Sample Std & $3.33 \mathrm{~nm}$ & $5.50 \mathrm{~nm}$ & $4.89 \times 10^{6} \# / \mathrm{cm}^{3}$ & $9.04 \times 10^{6} \# / \mathrm{cm}^{3}$ & \\
\hline t Statstic & \multicolumn{2}{|c|}{-20.23} & \multicolumn{2}{|c|}{-65.72} & $\begin{array}{l}\text { Test } 28 \\
44030^{*}\end{array}$ \\
\hline $\mathrm{P}$-value & \multicolumn{2}{|c|}{$<0.0001$} & \multicolumn{2}{|c|}{$<0.0001$} & \\
\hline Rejecting $\mathrm{H}_{0}$ & \multicolumn{2}{|c|}{ Yes } & \multicolumn{2}{|c|}{ Yes } & \\
\hline
\end{tabular}

\subsubsection{Medium Cetane Fuel Comparison}

Comparing the medium cetane fuels in Figure 76, FACE 9 tends to produce lower particle number concentrations, presumably due to the highest 90 percent distillation temperature value $\left(321^{\circ} \mathrm{C}\right)$ within this group. No statistical significant conclusion can be drawn from the data for FACE 7 and ULSD, since the size distributions are close together. The higher aromatic content but lower T90 of FACE $7\left(46.2 \% / 267^{\circ} \mathrm{C}\right)$ seems to compete with higher T90 but lower aromatic content of ULSD $\left(34.7 \% / 306^{\circ} \mathrm{C}\right)$. A version of Figure 76 showing the error as one standard deviation is once more presented in APPENDIX B. 


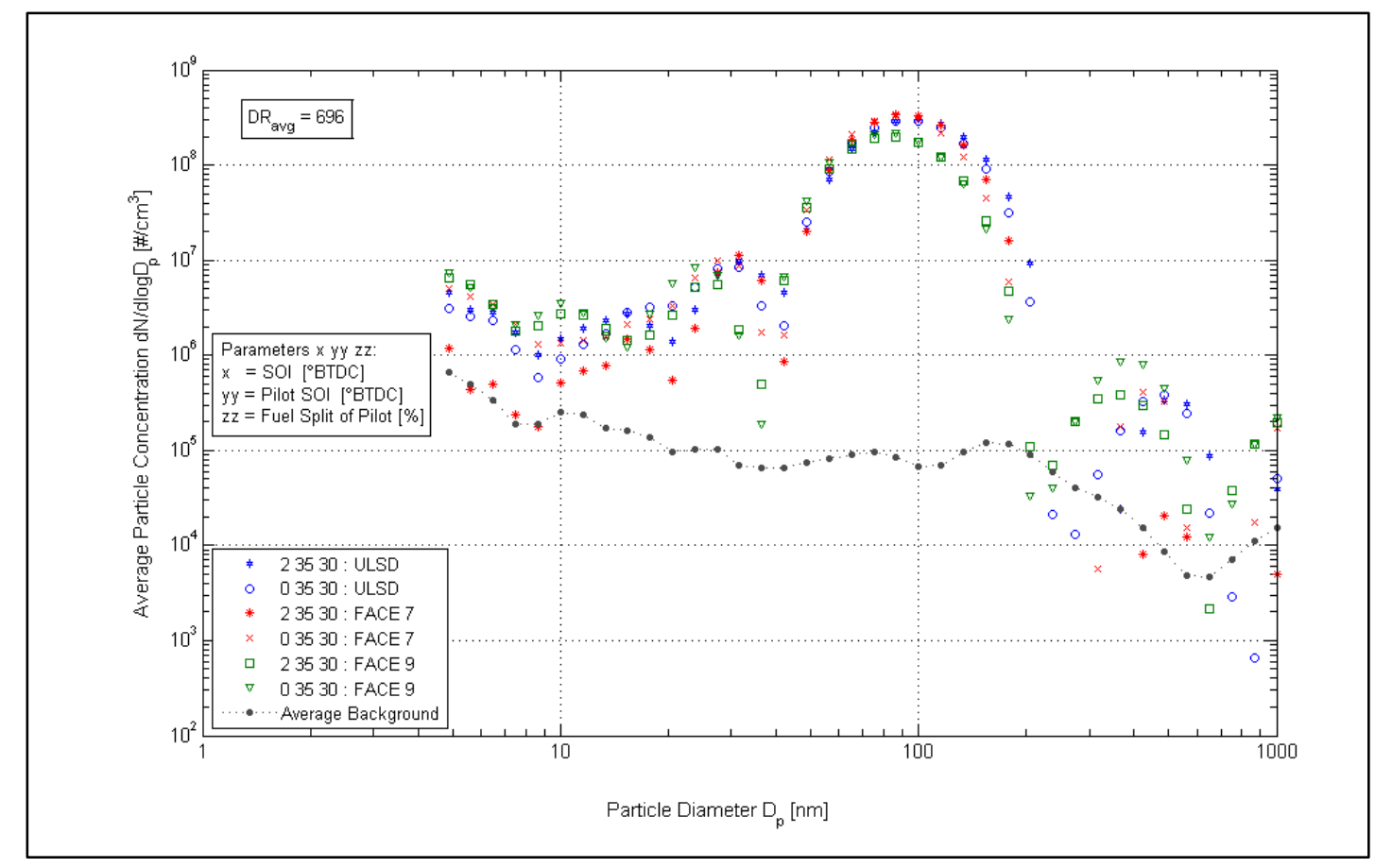

Figure 76 Particle Size Distribution for Medium Cetane Fuels

In order to prove the alternative hypothesis that FACE 9 produces lower particle number concentrations than ULSD or FACE 7, since their cetane numbers (44.00 / 44.95) and aromatic content (34.7 / 37.0) are close together, another two-sample t-test was performed (see Table 16). The null hypothesis was rejected at the 5\% significance level in all cases representing that T90 has a significant influence on lowering particle number concentrations for FACE 9 compared to ULSD by simultaneously lowering the count mode diameter as well.

Table 16 Two-Sample t-Test with Unequal Variances, One-Sided, 5\% Significance Level: Effect of T90 on Medium CN Fuels

\begin{tabular}{|c|c|c|c|c|c|}
\hline Hypothesis & \multicolumn{4}{|c|}{90 Percent Distillation Temperature } & \\
\hline $\mathbf{H}_{0}: \mu_{\mathrm{FACE} 9}=\mu_{\mathrm{ULSD}}$ & \multicolumn{2}{|c|}{ Count Mode Diameter } & \multicolumn{2}{|c|}{ Mode $d N / d \log D_{p}$} & \\
\hline $\mathrm{H}_{\mathrm{a}}: \mu_{\mathrm{FACE}}<\mu_{\mathrm{ULSD}}$ & FACE 9 & ULSD & FACE 9 & ULSD & \\
\hline Mean value & $86.6 \mathrm{~nm}$ & $100 \mathrm{~nm}$ & $1.99 \times 10^{8} \# / \mathrm{cm}^{3}$ & $3.05 \times 10^{8} \# / \mathrm{cm}^{3}$ & \multirow{5}{*}{$\begin{array}{l}\text { Test } 19 \\
23530^{*}\end{array}$} \\
\hline Sample Std & $8.41 \mathrm{~nm}$ & $2.11 \mathrm{~nm}$ & $1.49 \times 10^{7} \# / \mathrm{cm}^{3}$ & $2.18 \times 10^{7} \# / \mathrm{cm}^{3}$ & \\
\hline t Statstic & \multicolumn{2}{|c|}{-27.46} & \multicolumn{2}{|c|}{-61.65} & \\
\hline P-value & \multicolumn{2}{|c|}{$<0.0001$} & \multicolumn{2}{|c|}{$<0.0001$} & \\
\hline Rejecting $\mathrm{H}_{0}$ & \multicolumn{2}{|c|}{ Yes } & \multicolumn{2}{|c|}{ Yes } & \\
\hline Mean value & $86.6 \mathrm{~nm}$ & 100nm & $2.16 \times 10^{8} \# / \mathrm{cm}^{3}$ & $2.94 \times 10^{8} \# / \mathrm{cm}^{3}$ & \\
\hline Sample Std & $5.22 \mathrm{~nm}$ & $6.45 \mathrm{~nm}$ & $1.72 \times 10^{7} \# / \mathrm{cm}^{3}$ & $3.33 \times 10^{7} \# / \mathrm{cm}^{3}$ & \\
\hline t Statstic & \multicolumn{2}{|c|}{-15.01} & \multicolumn{2}{|c|}{-32.36} & $\begin{array}{l}\text { Test } 28 \\
03530^{*}\end{array}$ \\
\hline P-value & \multicolumn{2}{|c|}{$<0.0001$} & \multicolumn{2}{|c|}{$<0.0001$} & \\
\hline Rejecting $\mathrm{H}_{0}$ & \multicolumn{2}{|c|}{ Yes } & \multicolumn{2}{|c|}{ Yes } & \\
\hline
\end{tabular}




\subsubsection{High Cetane Fuel Comparison}

Comparison of FACE 8 (high T90 / high aromatics) and FACE 6 (high T90 / low aromatics) with FACE 5 (low T90 / low aromatics) indicates a stronger influence of distillation temperature on particle emissions than the aromatic content (see Figure 77). The particle size distributions for FACE 5 show lower particle number concentrations and a shift of the count mode diameter towards nanoparticles can be observed. APPENDIX C contains a version of Figure 77 showing the error as one standard deviation for comparison purposes.

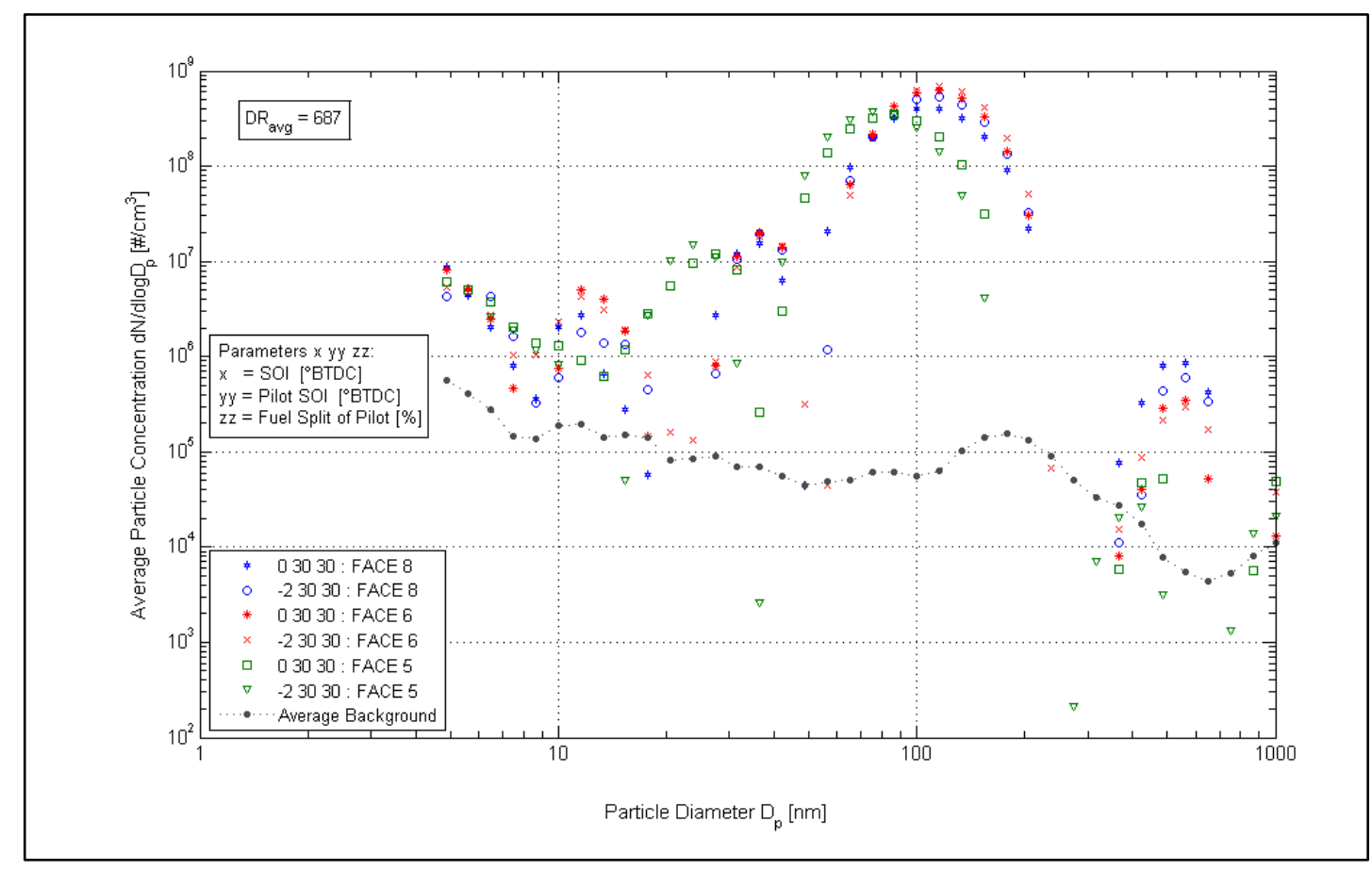

Figure 77 Particle Size Distribution for High Cetane Fuels

A low T90 distillation temperature together with low aromatic content seems to lower both, the count mode diameter of the particle size distribution, and the particle concentration for FACE 5 (low T90 / low aromatics) compared to FACE 6 (high T90 / low aromatics). Table 17 lists the results of the one-sided two-sample t-tests with unequal variances and shows statistical significance at 5\% significance level. 
Table 17 Two-Sample t-Test with Unequal Variances, One-Sided, 5\% Significance Level: Effect of T90 on High CN Fuels

\begin{tabular}{|c|c|c|c|c|c|}
\hline Hypothesis & \multicolumn{4}{|c|}{90 Percent Distillation Temperature } & \\
\hline $\mathrm{H}_{0}: \mu_{\mathrm{FACE} 5}=\mu_{\mathrm{FACE} 6}$ & \multicolumn{2}{|c|}{ Count Mode Diameter } & \multicolumn{2}{|c|}{ Mode $\mathbf{d N} / \mathbf{d} \log D_{p}$} & \\
\hline $\mathrm{H}_{\mathrm{a}}: \mu_{\mathrm{FACE} 5}<\mu_{\mathrm{FACE} 6}$ & FACE 5 & FACE 6 & FACE 5 & FACE 6 & \\
\hline Mean value & $86.6 \mathrm{~nm}$ & $115.5 \mathrm{~nm}$ & $3.46 \times 10^{8} \# / \mathrm{cm}^{3}$ & $6.28 \times 10^{8} \# / \mathrm{cm}^{3}$ & \multirow{5}{*}{$\begin{array}{l}\text { Test } 19 \\
03030^{*}\end{array}$} \\
\hline Sample Std & $0 \mathrm{~nm}^{\dagger}$ & $1.73 \mathrm{~nm}$ & $2.12 \times 10^{7} \# / \mathrm{cm}^{3}$ & $3.80 \times 10^{7} \# / \mathrm{cm}^{3}$ & \\
\hline t Statstic & \multicolumn{2}{|c|}{-254.63} & \multicolumn{2}{|c|}{-99.76} & \\
\hline P-value & \multicolumn{2}{|c|}{$<0.0001$} & \multicolumn{2}{|c|}{$<0.0001$} & \\
\hline Rejecting $\mathrm{H}_{0}$ & \multicolumn{2}{|c|}{ Yes } & \multicolumn{2}{|c|}{ Yes } & \\
\hline Mean value & $75.0 \mathrm{~nm}$ & $115.5 \mathrm{~nm}$ & $3.70 \times 10^{8} \# / \mathrm{cm}^{3}$ & $6.97 \times 10^{8} \# / \mathrm{cm}^{3}$ & \\
\hline Sample Std & $3.50 \mathrm{~nm}$ & $0 \mathrm{~nm}^{\dagger}$ & $3.38 \times 10^{7} \# / \mathrm{cm}^{3}$ & $7.70 \times 10^{7} \mathrm{\#} / \mathrm{cm}^{3}$ & \\
\hline t Statstic & \multicolumn{2}{|c|}{-173.86} & \multicolumn{2}{|c|}{-60.05} & $\begin{array}{l}\text { Test } 28 \\
-23030 *\end{array}$ \\
\hline P-value & \multicolumn{2}{|c|}{$<0.0001$} & \multicolumn{2}{|c|}{$<0.0001$} & \\
\hline Rejecting $\mathrm{H}_{0}$ & \multicolumn{2}{|c|}{ Yes } & \multicolumn{2}{|c|}{ Yes } & \\
\hline
\end{tabular}

Note: Parameters $x$ yy zz: $x=$ SOI $\left[{ }^{\circ} B T D C\right] ; y y=$ Pilot SOI $\left[{ }^{\circ} B T D C\right] ; z z=$ Fuel Split of Pilot [\%]

${ }^{\dagger}$ Recall: mean value from 200s data @ 1Hz sample frequency; CMD based on normal distribution within the bin

Examination of the influence of aromatic content with a null hypothesis of equal sample means for FACE 8 (high T90 / high aromatics) and FACE 6 (high T90 / low aromatics) results in a rejection at 5\% significance level for mode particle number concentration and count mode diameter. However, the change in the latter is small for test run 19 and even smaller for test run 28 as indicated by the P-value. This supports the aforementioned stronger influence of T90 distillation temperature on particle emission characteristics than the aromatic content.

Table 18 Two-Sample t-Test with Unequal Variances, One-Sided, 5\% Significance Level: Effect of Aromatic Content on High CN Fuels

\begin{tabular}{|c|c|c|c|c|c|}
\hline Hypothesis & \multicolumn{4}{|c|}{ Aromatic Content } & \\
\hline $\mathrm{H}_{0}: \mu_{\mathrm{FACE} 8}=\mu_{\mathrm{FACE} 6}$ & \multicolumn{2}{|c|}{ Count Mode Diameter } & \multicolumn{2}{|c|}{ Mode $d N / d \log D_{p}$} & \\
\hline $\mathrm{H}_{\mathrm{a}}: \mu_{\mathrm{FACE} 8}<\mu_{\mathrm{FACE} 6}$ & FACE 8 & FACE 6 & FACE 8 & FACE 6 & \\
\hline Mean value & $100 \mathrm{~nm}$ & $115.5 \mathrm{~nm}$ & $3.97 \times 10^{8} \# / \mathrm{cm}^{3}$ & $6.28 \times 10^{8} \mathrm{\#} / \mathrm{cm}^{3}$ & \multirow{5}{*}{$\begin{array}{c}\text { Test } 19 \\
03030^{*}\end{array}$} \\
\hline Sample Std & $7.49 \mathrm{~nm}$ & $1.73 \mathrm{~nm}$ & $2.09 \times 10^{7} \# / \mathrm{cm}^{3}$ & $3.80 \times 10^{7} \# / \mathrm{cm}^{3}$ & \\
\hline t Statstic & \multicolumn{2}{|c|}{-19.19} & \multicolumn{2}{|c|}{-82.21} & \\
\hline P-value & \multicolumn{2}{|c|}{$<0.0001$} & \multicolumn{2}{|c|}{$<0.0001$} & \\
\hline Rejecting $\mathrm{H}_{0}$ & \multicolumn{2}{|c|}{ Yes } & \multicolumn{2}{|c|}{ Yes } & \\
\hline Mean value & $115.2 \mathrm{~nm}$ & $115.5 \mathrm{~nm}$ & $5.32 \times 10^{8} \# / \mathrm{cm}^{3}$ & $6.97 \times 10^{8} \# / \mathrm{cm}^{3}$ & \\
\hline Sample Std & $1.99 \mathrm{~nm}$ & $0 \mathrm{~nm}^{\dagger}$ & $4.76 \times 10^{7} \# / \mathrm{cm}^{3}$ & $7.70 \times 10^{7} \# / \mathrm{cm}^{3}$ & \\
\hline t Statstic & \multicolumn{2}{|c|}{-2.01} & \multicolumn{2}{|c|}{-28.15} & $\begin{array}{l}\text { Test } 28 \\
-23030^{*}\end{array}$ \\
\hline P-value & \multicolumn{2}{|c|}{0.0226} & \multicolumn{2}{|c|}{$<0.0001$} & \\
\hline Rejecting $\mathrm{H}_{0}$ & \multicolumn{2}{|c|}{ Yes } & \multicolumn{2}{|c|}{ Yes } & \\
\hline
\end{tabular}




\subsection{Injection Timing Comparison}

In general, advancing start of injection (SOI) timing provides more time for homogenization; hence, leading to a decrease in particle concentration. This is shown in Figure 78 for a low and high CN fuel, namely FACE 4 and 8, respectively. Even though this trend is observed for both, high and low $\mathrm{CN}$ fuel, it is somewhat restricted to accumulation mode particles, since a simultaneous increase in nanoparticle emissions was observed for FACE 4 (see arrows). Due to higher variability in the data, this trend in enhanced nanoparticles could not be confirmed for FACE 8, as depicted in Figure 100 in APPENDIX B.

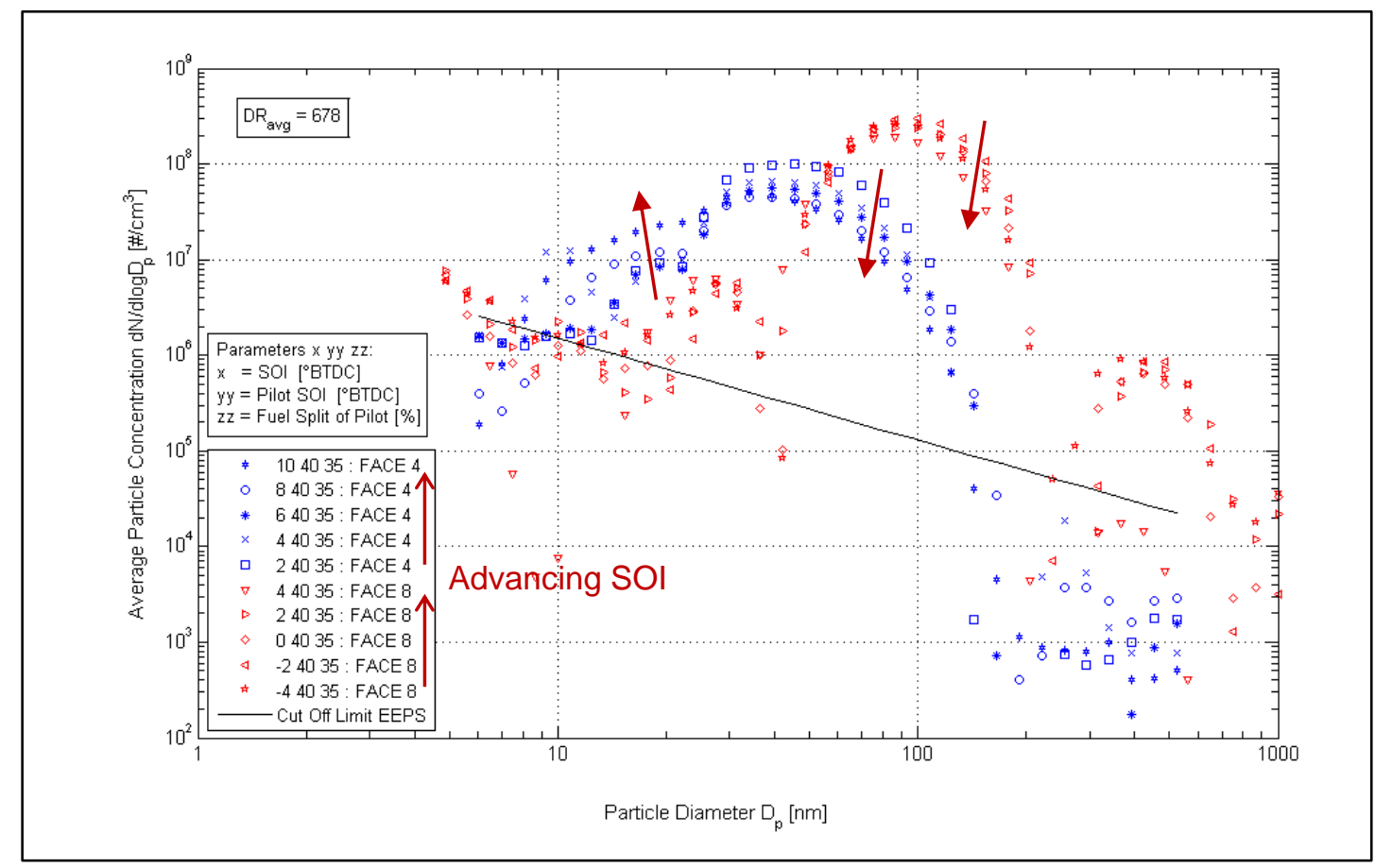

Figure 78 Particle Size Distribution for Low and High CN and Varying SOI Timing

\subsection{Rail Pressure and Intake Oxygen Concentration during Single Injection}

This subsection presents some of the effects for changes in rail pressure and intake oxygen concentration as a surrogate for EGR fraction during the single injection strategy. Results for selected FACE diesel fuels are shown.

\subsubsection{Effect of Rail Pressure}

By increasing the rail pressure during single injection timings, a decrease in particle number concentration was observed for the high CN fuel FACE 5, whereas no significant influence was detected for a low $\mathrm{CN}$ fuel (FACE 1), as depicted in Figure 79. This may be due to 
the lower particle number concentration values of more than one order of magnitude in case of FACE 1 suppressing the measurable effect of better fuel atomization.

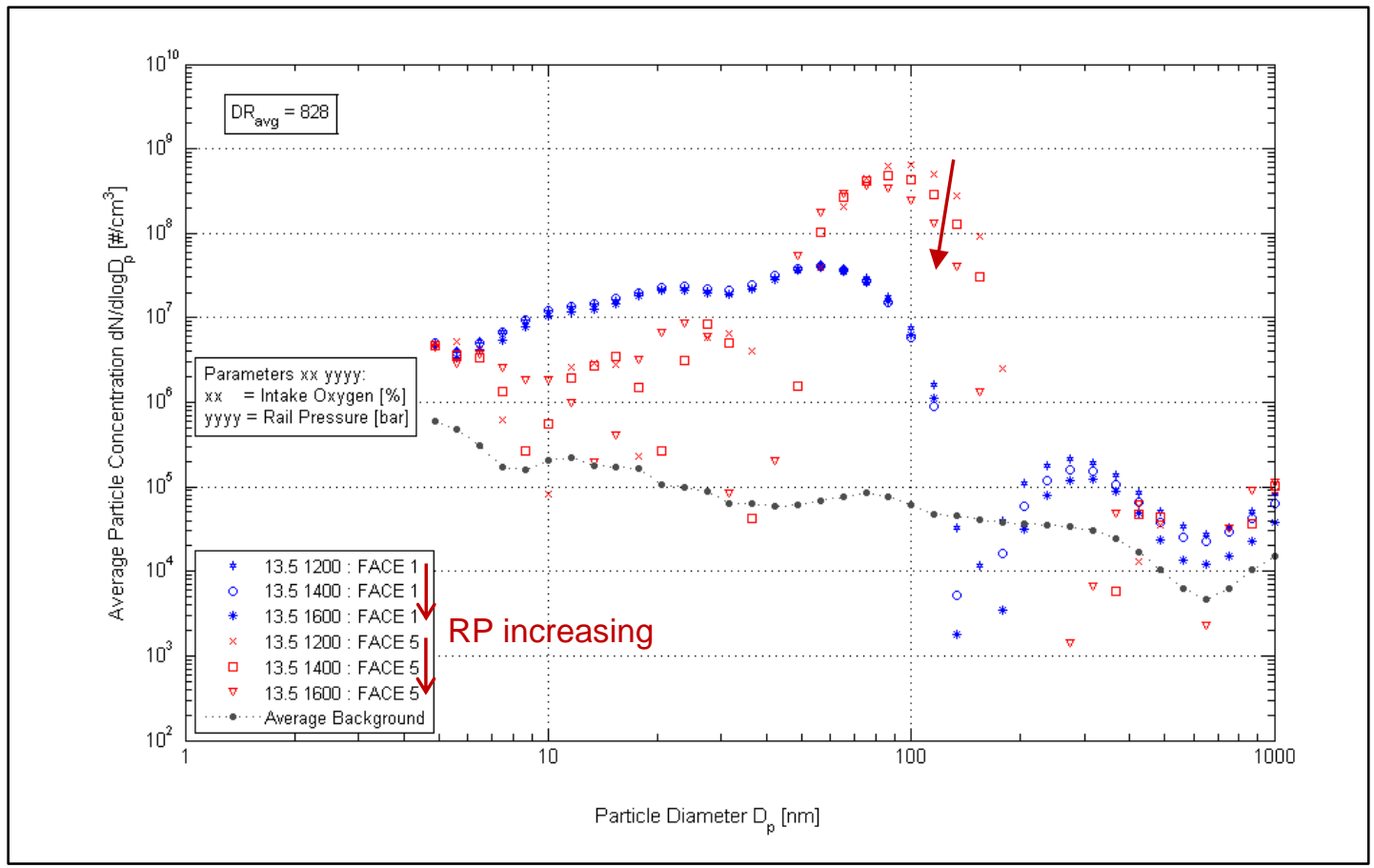

Figure 79 Particle Size Distribution for Low and High CN and Varying Rail Pressure

An emissions comparison between the high CN fuel FACE 5 (54.2) and the low CN fuel FACE 1 (29.93) is given in Table 19. Increasing the rail pressure shows that soot emissions were minimized for FACE 5, while almost no effect was detected for FACE 1. The AVL Micro Soot Sensor confirmed the findings, as shown in Figure 79. HC emissions were significantly higher for FACE 1 compared to FACE 5, which follows the trend found for low CN fuels in this and other studies [24, 49].

Table 19 Emissions Comparison for Low and High CN and Varying Rail Pressure

\begin{tabular}{|c|c|c|c|c|c|c|c|c|c|c|}
\hline \multirow{2}{*}{$\begin{array}{l}\text { Test } \\
\text { Para- } \\
\text { meters }\end{array}$} & \multicolumn{2}{|c|}{$\begin{array}{c}\mathbf{H C} \\
{[\mathrm{g} / \mathbf{k W h}]}\end{array}$} & \multicolumn{2}{|c|}{$\begin{array}{c}\mathbf{N O}_{\mathbf{x}} \\
{[\mathrm{g} / \mathbf{k W h}]}\end{array}$} & \multicolumn{2}{|c|}{$\begin{array}{c}\mathbf{C O} \\
{[\mathrm{g} / \mathbf{k W h}]}\end{array}$} & \multicolumn{2}{|c|}{$\begin{array}{c}\text { Soot } \\
{[\mathrm{mg} / \mathrm{kWh}]}\end{array}$} & \multicolumn{2}{|c|}{$\begin{array}{l}\text { BTE } \\
{[\%]}\end{array}$} \\
\hline & $\begin{array}{c}F A C E \\
1\end{array}$ & $\begin{array}{c}F A C E \\
5\end{array}$ & $\begin{array}{c}F A C E \\
l\end{array}$ & $\begin{array}{c}F A C E \\
5\end{array}$ & $\begin{array}{c}\text { FACE } \\
1\end{array}$ & $\begin{array}{c}F A C E \\
5\end{array}$ & $\begin{array}{c}\text { FACE } \\
1\end{array}$ & $\begin{array}{c}\text { FACE } \\
5\end{array}$ & $\begin{array}{c}F A C E \\
1\end{array}$ & $\begin{array}{c}F A C E \\
5\end{array}$ \\
\hline $\begin{array}{l}13.5 \\
1200^{*}\end{array}$ & 2.60 & 1.00 & 0.221 & 0.178 & 9.25 & 8.19 & 1.4 & 181.2 & 32.8 & 33.4 \\
\hline $\begin{array}{l}13.5 \\
1400^{*}\end{array}$ & 2.77 & 1.00 & 0.207 & 0.185 & 9.42 & 7.62 & 1.4 & 128.4 & 33.0 & 32.9 \\
\hline $\begin{array}{l}13.5 \\
1600^{*}\end{array}$ & 2.68 & 1.01 & 0.239 & 0.178 & 8.57 & 7.02 & 1.8 & 80.4 & 32.2 & 32.8 \\
\hline
\end{tabular}

Note: Parameters $x x$ yyyy: $x x=$ Intake Oxygen [\%]; yyyy = Rail Pressure [bar]; highlighted cells meet criteria in Table 10 
Comparing two high CN fuels (FACE 6 and 5) the effect of better fuel atomization by increasing the rail pressure is visible especially for the right tail of the accumulation mode, as shown in Figure 80. The higher 90 percent distillation temperature of FACE $6\left(341^{\circ} \mathrm{C}\right)$ compared to FACE $5\left(276^{\circ} \mathrm{C}\right)$ with fairly similar aromatic content $(21.1$ and $22.2 \%)$ tends to increase the particle number concentration with simultaneous shift of the count mode diameter towards higher values.

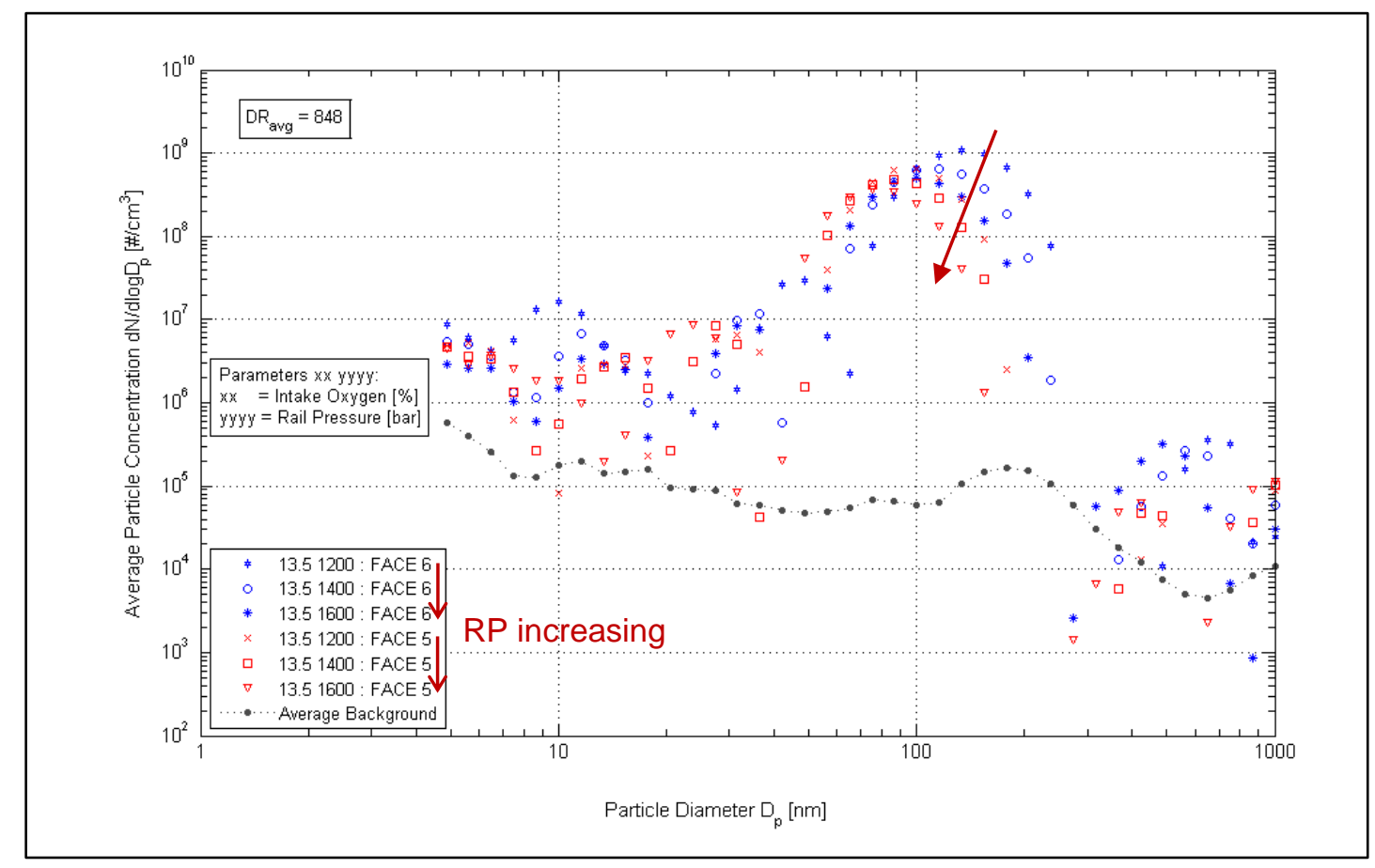

Figure 80 Particle Size Distribution for Low and High T90 and Varying Rail Pressure

The findings regarding particle number concentrations in Figure 80 are confirmed by the soot values in Table 20. Significant higher soot values and higher $\mathrm{NO}_{\mathrm{x}}$ emissions were found for FACE 6 compared with FACE 5.

Table 20 Emissions Comparison for Low and High T90 and Varying Rail Pressure

\begin{tabular}{|c|c|c|c|c|c|c|c|c|c|c|}
\hline \multirow{2}{*}{$\begin{array}{l}\text { Test } \\
\text { Para- } \\
\text { meters }\end{array}$} & \multicolumn{2}{|c|}{$\begin{array}{c}\mathbf{H C} \\
{[\mathrm{g} / \mathrm{kWh}]}\end{array}$} & \multicolumn{2}{|c|}{$\begin{array}{c}\mathrm{NO}_{\mathbf{x}} \\
{[\mathrm{g} / \mathrm{kWh}]}\end{array}$} & \multicolumn{2}{|c|}{$\begin{array}{c}\mathrm{CO} \\
{[\mathrm{g} / \mathrm{kWh}]}\end{array}$} & \multicolumn{2}{|c|}{$\begin{array}{c}\text { Soot } \\
{[\mathrm{mg} / \mathrm{kWh}]}\end{array}$} & \multicolumn{2}{|c|}{$\begin{array}{c}\text { BTE } \\
{[\%]}\end{array}$} \\
\hline & $\begin{array}{c}F A C E \\
6\end{array}$ & $\begin{array}{c}F A C E \\
5\end{array}$ & $\begin{array}{c}\text { FACE } \\
6\end{array}$ & $\begin{array}{c}F A C E \\
5\end{array}$ & $\begin{array}{c}\text { FACE } \\
6\end{array}$ & $\begin{array}{c}\text { FACE } \\
5\end{array}$ & $\begin{array}{c}F A C E \\
6\end{array}$ & $\begin{array}{c}F A C E \\
5\end{array}$ & $\begin{array}{c}\text { FACE } \\
6\end{array}$ & $\begin{array}{c}F A C E \\
5\end{array}$ \\
\hline $\begin{array}{l}13.5 \\
1200^{*}\end{array}$ & 0.89 & 1.00 & 0.323 & 0.178 & 8.14 & 8.19 & 517.0 & 181.2 & 33.3 & 33.4 \\
\hline $\begin{array}{l}13.5 \\
1400^{*}\end{array}$ & 0.88 & 1.00 & 0.239 & 0.185 & 6.76 & 7.62 & 315.9 & 128.4 & 33.3 & 32.9 \\
\hline $\begin{array}{l}13.5 \\
1600^{*}\end{array}$ & 0.91 & 1.01 & 0.288 & 0.178 & 6.20 & 7.02 & 210.5 & 80.4 & 33.2 & 32.8 \\
\hline
\end{tabular}

Note: Parameters $x x$ yyyy: $x x=$ Intake Oxygen [\%]; yyyy = Rail Pressure [bar]; highlighted cells meet criteria in Table 10 


\subsubsection{Effect of Intake Oxygen Concentration}

The effect of varying intake oxygen concentration during single injection strategy with a high CN fuel (FACE 8) compared to a low CN fuel (FACE 4) can be seen in Figure 81. The decrease in intake- $\mathrm{O}_{2}$ leads to an increase in particle number concentration for the high $\mathrm{CN}$ fuel (FACE 8). However, for the same decrease in intake- $\mathrm{O}_{2}$, a slight decrease in particle number concentration was observed for the low $\mathrm{CN}$ fuel (FACE 4) with increased trend towards the lower tail of the particle size distribution.

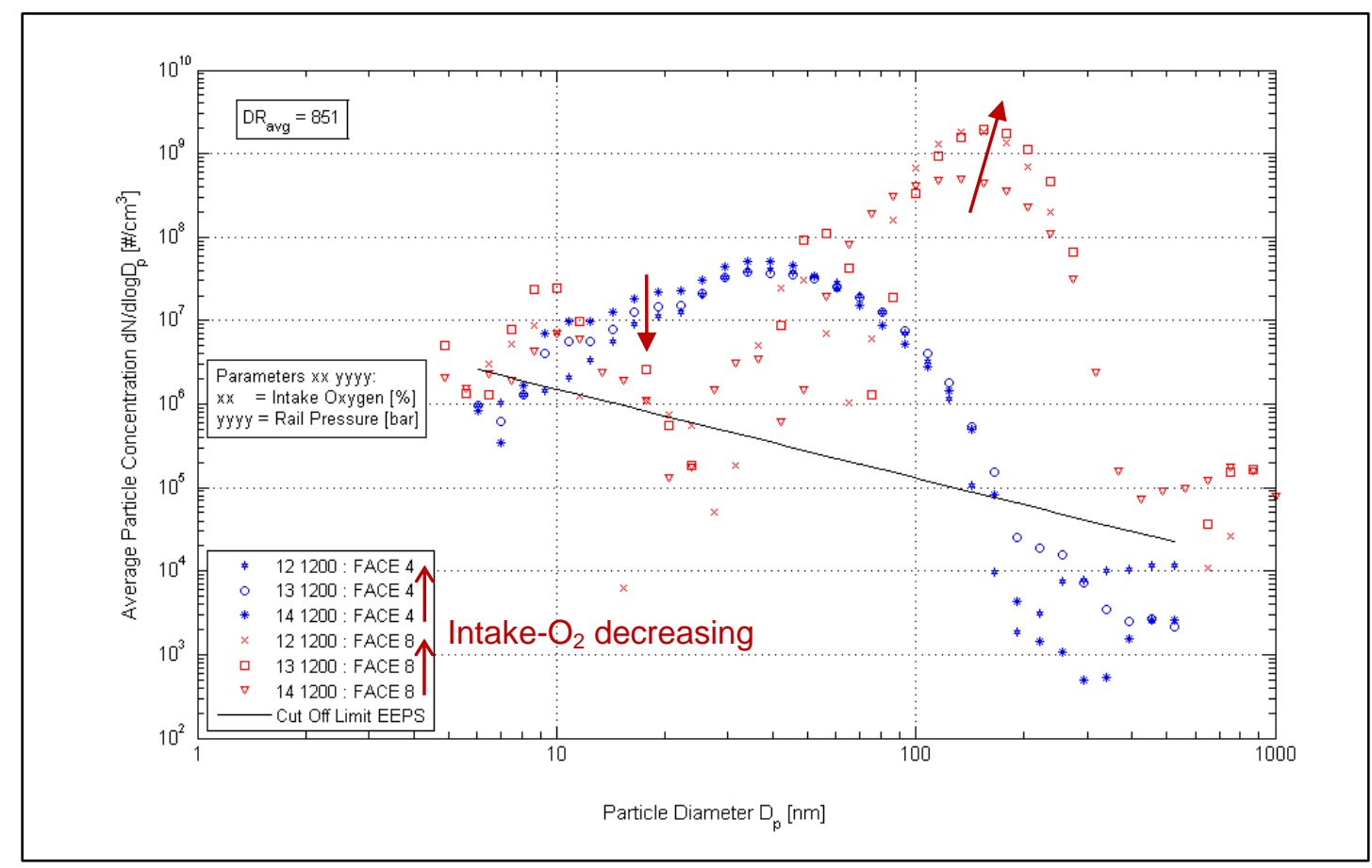

Figure 81 Particle Size Distribution for Low and High CN and Varying Intake- $\mathrm{O}_{2}$

An emissions comparison between the low CN FACE 4 (28.44) and the high CN FACE 8 (50.00) is shown in Table 21. Soot emissions for FACE 8 were almost tripled when the intake oxygen concentration was reduced from 14 to 12\% (43 to 49\% EGR) and slightly increased for FACE 4. However, the decrease in particle number concentration may be explained by lower mass fraction burned by decreasing intake- $\mathrm{O}_{2}$ due to difficulties in maintaining the 50 percent mass fraction burned (CA50) at the same $7^{\circ}$ ATDC level. 
Table 21 Emissions Comparison for Low and High $\mathrm{CN}$ and Varying Intake- $\mathrm{O}_{2}$

\begin{tabular}{|c|c|c|c|c|c|c|c|c|c|c|}
\hline \multirow{2}{*}{$\begin{array}{l}\text { Test } \\
\text { Para- } \\
\text { meters }\end{array}$} & \multicolumn{2}{|c|}{$\begin{array}{c}\mathbf{H C} \\
{[\mathrm{g} / \mathbf{k W h}]}\end{array}$} & \multicolumn{2}{|c|}{$\begin{array}{c}\mathbf{N O}_{\mathbf{x}} \\
{[\mathrm{g} / \mathbf{k W h}]}\end{array}$} & \multicolumn{2}{|c|}{$\begin{array}{c}\mathbf{C O} \\
{[\mathrm{g} / \mathrm{kWh}]}\end{array}$} & \multicolumn{2}{|c|}{$\begin{array}{c}\text { Soot } \\
{[\mathrm{mg} / \mathrm{kWh}]}\end{array}$} & \multicolumn{2}{|c|}{$\begin{array}{l}\text { BTE } \\
{[\%]}\end{array}$} \\
\hline & $\begin{array}{c}F A C E \\
4\end{array}$ & $\begin{array}{c}\text { FACE } \\
8\end{array}$ & $\begin{array}{c}F A C E \\
4\end{array}$ & $\begin{array}{c}\text { FACE } \\
8\end{array}$ & $\begin{array}{c}F A C E \\
4\end{array}$ & $\begin{array}{c}F A C E \\
8\end{array}$ & $\begin{array}{c}F A C E \\
4\end{array}$ & $\begin{array}{c}F A C E \\
8\end{array}$ & $\begin{array}{c}F A C E \\
4\end{array}$ & $\begin{array}{c}F A C E \\
8\end{array}$ \\
\hline $\begin{array}{l}12 \\
1200^{*}\end{array}$ & 5.27 & 1.22 & 0.103 & 0.152 & 19.2 & 21.9 & 3.53 & 1342.2 & 31.2 & 32.8 \\
\hline $\begin{array}{l}13 \\
1200^{*}\end{array}$ & 4.60 & 1.04 & 0.175 & 0.230 & 13.7 & 9.6 & 3.00 & 861.3 & 32.4 & 33.3 \\
\hline $\begin{array}{l}14 \\
1200^{*}\end{array}$ & 3.45 & 1.04 & 0.351 & 0.357 & 9.0 & 5.3 & 2.31 & 473.1 & 31.2 & 33.9 \\
\hline
\end{tabular}

"Note: Parameters $x x$ yyyy: $x x=$ Intake Oxygen [\%]; yyyy = Rail Pressure [bar]; highlighted cells meet criteria in Table 10 


\section{CHAPTER 6 CONCLUSIONS AND RECOMMENDATIONS}

In this section, conclusions of this study about the effects of various FACE diesel fuels on the nanoparticle formation during low temperature combustion processes are presented. Conclusions from the results of the specific objectives, namely the assessment of the influence of the three main properties of FACE diesel fuel, cetane number, 90 percent distillation temperature and aromatic content on particle concentration and size distributions during low temperature combustion, the investigation of single and split injection strategies, and the exploration of variations in rail pressure and intake oxygen concentration during single injection are pointed out as well. Finally, recommendations and ideas for further data analysis are presented.

\subsection{Conclusions}

Particle number concentration increased with a simultaneous increase in particle diameter for both single and split injection strategies in case of FACE diesel fuels with increasing $\mathrm{CN}$ for the low $\mathrm{NO}_{\mathrm{x}}$, low soot and highest BTE tests.

Particle number concentrations were higher for single injection compared to split injection strategy.

Low CN fuels exhibit wide particle number distributions whereas high $\mathrm{CN}$ fuels tend to have especially narrow accumulation modes.

The 90 percent distillation temperature had significant influence on the particle size distribution: the count mode diameter was found to be lower for low $\mathrm{CN}$ and high T90 fuels compared to low CN and low T90 fuels, and also lower for high CN and low T90 fuels compared to high $\mathrm{CN}$ and high $\mathrm{T} 90$ fuels.

Advancing the start of injection timing led to a decrease in particle number concentration, but a simultaneous increase in nanoparticle emissions was observed for a low $\mathrm{CN}$ fuels, whereas this increase could not be confirmed for high $\mathrm{CN}$ fuels due to higher variability in the data in the nanoparticle range (up to 30 to $40 \mathrm{~nm}$ ). 
By increasing the rail pressure during single injection timings, a decrease in particle number concentration was observed for a high CN fuel (FACE 5), whereas no significant influence was detected for a low CN fuel (FACE 1).

A direct comparison between the EEPS ${ }^{\mathrm{TM}}$ model 3090 and the DMS model DMS500 for two different injection timing settings during split injection strategy showed a good agreement between the two measurement systems. However, measurements with the DMS500 showed consistently higher values for accumulation mode particles and a somewhat more pronounced nucleation mode about half of an order of magnitude higher compared with the EEPS ${ }^{\mathrm{TM}}$ model 3090. Consecutive runs of the same test parameters during split injection strategy showed good repeatability of the data measured by both instrument types.

\subsection{Recommendations}

In general, more profound statistical analysis can be performed with this extensive set of data for each fuel tested forming a full factorial fuel design matrix.

Response surface plots for count mode diameter as the response for the variables, pilot start of injection and fuel split at different main start of injection timings can be executed to study their effects on count mode diameter in detail.

Adding information about the total number concentration to the response surface plots would extend the understanding about the hypothesis that advancing start of injection decreases particle number concentration of the accumulation mode but increases nucleation mode particle emissions.

A correlation study can be carried out with the data set comparing the information about particle size distribution with soot measurements obtained with the AVL Micro Soot Sensor.

In order to provide a conversion of the advanced combustion criteria presented in Table 10 from a concentration to a brake specific basis, an evaluation can be performed with these threshold values for the different fuels and engine operating conditions.

The effect of fuel gravity on the particle concentration and size distribution can be further included in an evaluation especially for the "low", "medium" and "high" cetane fuel comparison to provide possible clarification about the phenomena discussed. 


\section{REFERENCES}

1. Niosh, "Carcinogenic Effects of Exposure to Diesel Exhaust," in Current Intelligence Bulletin 50, ed, 1988

2. IARC, "Diesel and Gasoline Engine Exhausts and Some Nitroarenes, Summary of Data Reported and Evaluation," in IARC Monographs on the Evaluation of Carcinogenic Risks to Humans, ed, 1989

3. Burtscher, H., "Physical characterization of particulate emissions from diesel engines: a review," Journal of Aerosol Science, vol. 36, pp. 896-932, 2005.

4. Oberdörster, G., Sharp, Z., Atudorei, V., Elder, A., Gelein, R., Kreyling, W., and Cox, C., "Translocation of Inhaled Ultrafine Particles to the Brain," Inhalation Toxicology, vol. 16, pp. 437-445, 2004.

5. Oberdörster, G., Oberdörster, E., and Oberdörster, J., "Nanotoxicology: An Emerging Discipline Evolving from Studies of Ultrafine Particles," Environmental Health Perspectives, vol. 113, pp. 823-839, 2005.

6. Li, Z., Hulderman, T., Salmen, R., Chapman, R., Leonard, S.S., Young, S.-H., Shvedova, A., Luster, M.I., and Simeonova, P.P., "Cardiovascular Effects of Pulmonary Exposure to Single-Wall Carbon Nanotubes," Environmental Health Perspectives, vol. 115, pp. 377$382,2007$.

7. Lu, X., Han, D., and Huang, Z., "Fuel design and management for the control of advanced compression-ignition combustion modes," Progress in Energy and Combustion Science, vol. 37, pp. 741-783, 2011.

8. Hasegawa, R. and Yanagihara, H., "HCCI Combustion in DI Diesel Engine," in SAE Technical Paper 2003-01-0745, 2003.

9. Wagner, U., Anca, R., Velji, A., and Spicher, U., "An Experimental Study of Homogeneous Charge Compression Ignition (HCCI) with Various Compression Ratios, Intake Air Temperatures and Fuels with Port and Direct Fuel Injection," in SAE Technical Paper 2003-01-2293, 2003.

10. Nevin, R.M., Sun, Y., Gonzalez, M.A., and Reitz, R.D., "PCCI Investigation Using Variable Intake Valve Closing in a Heavy Duty Diesel Engine," in SAE Technical Paper 2007-01-0903, 2007.

11. Neely, G.D., Sasaki, S., Huang, Y., Leet, J.A., and Stewart, D.W., "New Diesel Emission Control Strategy to Meet US Tier 2 Emissions Regulations," in SAE Technical Paper 2005-01-1091, 2005.

12. Opat, R., Ra, Y., Gonzalez D, M.A., Krieger, R., Reitz, R.D., Foster, D.E., Durrett, R.P., and Siewert, R.M., "Investigation of Mixing and Temperature Effects on $\mathrm{HC} / \mathrm{CO}$ Emissions for Highly Dilute Low Temperature Combustion in a Light Duty Diesel Engine," in SAE Technical Paper 2007-01-0193, 2007.

13. Fang, T., Coverdill, R.E., Lee, C.-F.F., and White, R.A., "Combustion and Soot Visualization of Low Temperature Combustion within an HSDI Diesel Engine Using Multiple Injection Strategy," in SAE Technical Paper 2006-01-0078, 2006. 
14. Akihama, K., Takatori, Y., Inagaki, K., Sasaki, S., and Dean, A.M., "Mechanism of the Smokeless Rich Diesel Combustion by Reducing Temperature," in SAE Technical Paper 2001-01-0655, 2001.

15. Yao, M., Zheng, Z., and Liu, H., "Progress and recent trends in homogeneous charge compression ignition (HCCI) engines," Progress in Energy and Combustion Science, vol. 35, pp. 398-437, 2009.

16. Lilik, G.K., Herreros, J.M.N., and Boehman, A.L., "Advanced Combustion Operation in a Compression Ignition Engine," Energy \& Fuels, vol. 23, pp. 143-150, 2009/01/22 2009.

17. Sluder, C.S. and Wagner, R.M., "An Estimate of Diesel High-Efficiency Clean Combustion Impacts on FTP-75 Aftertreatment Requirements," in SAE Technical Paper 2006-01-3311, 2006.

18. Sasaki, S., Ito, T., and Iguchi, S., "Smokeless Rich Combustion by Low Temperature Oxidation in Diesel Engines," in $9^{\text {th }}$ Automobile and Engine Technology Colloquium, Aachen, 2000.

19. Kook, S., Bae, C., Miles, P.C., Choi, D., and Pickett, L.M., "The Influence of Charge Dilution and Injection Timing on Low-Temperature Diesel Combustion and Emissions," in SAE Technical Paper 2005-01-3837, 2005.

20. Kook, S., Bae, C., Miles, P.C., Choi, D., Bergin, M., and Reitz, R.D., "The Effect of Swirl Ratio and Fuel Injection Parameters on CO Emission and Fuel Conversion Efficiency for High-Dilution, Low-Temperature Combustion in an Automotive Diesel Engine," in SAE Technical Paper 2006-01-0197, 2006.

21. Flynn, P.F., Durrett, R.P., Hunter, G.L., Zur Loye, A.O., Akinyemi, O.C., Dec, J.E., and Westbrook, C.K., "Diesel Combustion: An Integrated View Combining Laser Diagnostics, Chemical Kinetics, and Empirical Validation," in SAE Technical Paper 1999-01-0509, 1999.

22. Dieselnet. (2012). DieselNet Technology Guide: Low Temperature Combustion.

23. Musculus, M.P.B., "Multiple Simultaneous Optical Diagnostic Imaging of EarlyInjection Low-Temperature Combustion in a Heavy-Duty Diesel Engine," in SAE Technical Paper 2006-01-0079, 2006.

24. Cho, K., Han, M., Sluder, C.S., Wagner, R.M., and Lilik, G.K., "Experimental Investigation of the Effects of Fuel Characteristics on High Efficiency Clean Combustion in a Light-Duty Diesel Engine," in SAE Technical Paper 2009-01-2669, 2009.

25. Heywood, J.B., InTERnAL COMBUSTION ENGINE FundAMENTALS. New York: McGrawHill, 1988.

26. Kawano, D., Naito, H., Suzuki, H., Ishii, H., Hori, S., Goto, Y., and Odaka, M., "Effects of Fuel Properties on Combustion and Exhaust Emissions of Homogeneous Charge Compression Ignition (HCCI) Engine," in SAE Technical Paper 2004-01-1966, 2004.

27. Kawano, D., Suzuki, H., Ishii, H., Goto, Y., Odaka, M., Murata, Y., Kusaka, J., and Daisho, Y., "Ignition and Combustion Control of Diesel HCCI," in SAE Technical Paper 2005-01-2132, 2005.

28. Carlucci, P., Ficarella, A., and Laforgia, D., "Effects of Pilot Injection Parameters on Combustion for Common Rail Diesel Engines," in SAE Technical Paper 2003-01-0700, 2003.

29. Weall, A. and Collings, N., "Highly Homogeneous Compression Ignition in a Direct Injection Diesel Engine Fuelled with Diesel and Biodiesel," in SAE Technical Paper 2007-01-2020, 2007. 
30. Zheng, M., Reader, G.T., and Hawley, J.G., "Diesel engine exhaust gas recirculation-a review on advanced and novel concepts," Energy Conversion and Management, vol. 45, pp. 883-900, 2004.

31. Simescu, S., Ryan, T.W., Neely, G.D., Matheaus, A.C., and Surampudi, B., "Partial PreMixed Combustion with Cooled and Uncooled EGR in a Heavy-Duty Diesel Engine," in SAE Technical Paper 2002-01-0963, 2002.

32. Silke, E.J., Pitz, W.J., Westbrook, C.K., Sjöberg, M., and Dec, J.E., "Understanding the Chemical Effects of Increased Boost Pressure under HCCI Conditions," SAE Int. J. Fuels Lubr., vol. 1, pp. 12-25, 2008.

33. Benajes, J., Molina, S., Novella, R., and Arthozoul, S., "Advanced Injection Strategies to Attain Partially Premixed Combustion Process in a Heavy Duty Diesel Engine," in SAE Technical Paper 2008-01-0642, 2008.

34. Vanegas, A., Won, H., and Peters, N., "Influence of the Nozzle Spray Angle on Pollutant Formation and Combustion Efficiency for a PCCI Diesel Engine," in SAE Technical Paper 2009-01-1445, 2009.

35. CrC, "Chemical and Physical Properties of the Fuels for Advanced Combustion Engines (FACE) Research Diesel Fuels," Coordinating Research Council, Inc. FACE-1, 2010.

36. ASTM, "D613-10a, Standard Test Method for Cetane Number of Diesel Fuel Oil," ed. West Conshohocken, PA: ASTM International, 2010

37. AstM, "D976-06, Standard Test Method for Calculated Cetane Index of Distillate Fuels," ed. West Conshohocken, PA: ASTM International, 2006

38. AstM, "D4052-09, Standard Test Method for Density, Relative Density, and API Gravity of Liquids by Digital Density Meter," ed. West Conshohocken, PA: ASTM International, 2009

39. AstM, "D86-11a, Standard Test Method for Distillation of Petroleum Products at Atmospheric Pressure," ed. West Conshohocken, PA: ASTM International, 2011

40. Gallant, T., Franz, J.A., Alnajjar, M.S., Storey, J.M.E., Lewis, S.A., Sluder, C.S., Cannella, W.J., Fairbridge, C., Hager, D., Dettman, H., Luecke, J., Ratcliff, M.A., and Zigler, B.T., "Fuels for Advanced Combustion Engines Research Diesel Fuels: Analysis of Physical and Chemical Properties," SAE Int. J. Fuels Lubr., vol. 2, pp. 262-272, 2009.

41. ASTM, "D1319-10, Standard Test Method for Hydrocarbon Types in Liquid Petroleum Products by Fluorescent Indicator Adsorption," ed. West Conshohocken, PA: ASTM International, 2010

42. ASTM, "D2425-04, Standard Test Method for Hydrocarbon Types in Middle Distillates by Mass Spectrometry," ed. West Conshohocken, PA: ASTM International, 2004

43. AstM, "D5186-03, Standard Test Method for Determination of the Aromatic Content and Polynuclear Aromatic Content of Diesel Fuels and Aviation Turbine Fuels by Supercritical Fluid Chromatography," ed. West Conshohocken, PA: ASTM International, 2003

44. AstM, "D2887-08, Standard Test Method for Boiling Range Distribution of Petroleum Fractions by Gas Chromatography," ed. West Conshohocken, PA: ASTM International, 2008

45. AstM, "D240-09, Standard Test Method for Heat of Combustion of Liquid Hydrocarbon Fuels by Bomb Calorimeter," ed. West Conshohocken, PA: ASTM International, 2009 
46. AstM, "D5291-10, Standard Test Method for Instrumental Determination of Carbon, Hydrogen and Nitrogen in Petroleum Products and Lubricants," ed. West Conshohocken, PA: ASTM International, 2010

47. Risberg, P., Kalghatgi, G., Ångstrom, H.-E., and Wåhlin, F., "Auto-ignition quality of Diesel-like fuels in HCCI engines," in SAE Technical Paper 2005-01-2127, 2005.

48. Hildingsson, L., Johansson, B., Kalghatgi, G.T., and Harrison, A.J., "Some Effects of Fuel Autoignition Quality and Volatility in Premixed Compression Ignition Engines," SAE Int. J. Engines, vol. 3, pp. 440-460, 2010.

49. De Ojeda, W., Bulicz, T., Han, X., Zheng, M., and Cornforth, F., "Impact of Fuel Properties on Diesel Low Temperature Combustion," SAE Int. J. Engines, vol. 4, pp. 188-201, 2011.

50. Hosseini, V., Neill, W., Guo, H., Dumitrescu, C.E., Chippior, W., Fairbridge, C., and Mitchell, K., "Effects of Cetane Number, Aromatic Content and 90\% Distillation Temperature on HCCI Combustion of Diesel Fuels," in SAE Technical Paper, 2010-012168, 2010.

51. Tamanouchi, M., Morihisa, H., Yamada, S., Iida, J., Sasaki, T., and Sue, H., "Effects of Fuel Properties on Exhaust Emissions for Diesel Engines With and Without Oxidation Catalyst and High Pressure Injection," in SAE Technical Paper 970758, 1997.

52. Bunting, B.G., Crawford, R.W., Wolf, L.R., and Xu, Y., "The Relationships of Diesel Fuel Properties, Chemistry, and HCCI Engine Performance as Determined by Principal Components Analysis," in SAE Technical Paper 2007-01-4059, 2007.

53. EPA, "Code of Federal Regulations, Title 40, Part 50, National Ambient Air Quality Standards for Particulate Matter."

54. Dockery, D.W., Pope, C.A., Xu, X., Spengler, J.D., Ware, J.H., Fay, M.E., Ferris, B.G., and Speizer, F.E., "An Association between Air Pollution and Mortality in Six U.S. Cities," New England Journal of Medicine, vol. 329, pp. 1753-1759, 1993.

55. Pope III, C.A., Thun, M.J., Namboodiri, M.M., Dockery, D.W., Evans, J.S., Speizer, F.E., and Heath, C.W., "Particulate Air Pollution as a Predictor of Mortality in a Prospective Study of U.S. Adults," American Journal of Respiratory and Critical Care Medicine, vol. 151, pp. 669-674, Mar 1995.

56. $\quad$ EPA, "Code of Federal Regulations, Title 40, Part 1065, Engine-Testing Procedures."

57. Kittelson, D.B., "Engines and nanoparticles: a review," Journal of Aerosol Science, vol. 29, pp. 575-588, 1998.

58. Kittelson, D.B. and Abdul-Khalek, I.S., "Formation of Nanoparticles during Exhaust Dilution," in Fuels, Lubricants, Engines and Emissions Energy Frontiers International Members' Conference, Tucson, Arizona, 1999.

59. Swanson, J.J., Watts Jr, W., and Kittelson, D., "Diesel Exhaust Aerosol Measurements Using Air-Ejector and Porous Wall Dilution Techniques," SAE Int. J. Engines, vol. 4, pp. 667-676, 2011.

60. Storey, J.M.E., Lewis, S.A., Parks, J.E., Szybist, J.P., Barone, T.L., and Prikhodko, V.Y., "Mobile Source Air Toxics (MSATs) from High Efficiency Clean Combustion: Catalytic Exhaust Treatment Effects," SAE Int. J. Engines, vol. 1, pp. 1157-1166, 2008.

61. Northrop, W.F., Madathil, P.V., Bohac, S.V., and Assanis, D.N., "Condensational Growth of Particulate Matter from Partially Premixed Low Temperature Combustion of Biodiesel in a Compression Ignition Engine," Aerosol Science and Technology, vol. 45, pp. 26-36, 2011/01/01 2011. 
62. Natti, K.C., Henein, N.A., Poonawala, Y., and Bryzik, W., "Particulate Matter Characterization Studies in an HSDI Diesel Engine under Conventional and LTC Regime," SAE Int. J. Engines, vol. 1, pp. 735-745, 2008.

63. Horiba, "Automotive Emission Analysis System MEXA-7000, Series 7000 User's Guide," ed, 2007.

64. Horiba, "CO/CO $2\left(\mathrm{HC}, \mathrm{NO}, \mathrm{N}_{2} \mathrm{O}, \mathrm{SO}_{2}\right)$ Analyzer AIA-72X Series, Instruction Manual," ed, 2007.

65. Horiba, "THC Analyzer FIA-725A, Instruction Manual," ed, 2007.

66. Eddy, D.S., "Physical principles of the zirconia exhaust gas sensor," Vehicular Technology, IEEE Transactions on, vol. 23, pp. 125-128, 1974.

67. Horiba, "Non-Sampling Type $\mathrm{NO}_{\mathrm{x}}-\mathrm{A} / \mathrm{F}$ Analyzer MEXA-720NO $\mathrm{N}_{\mathrm{x}}$, User Manual," ed, 2003.

68. Horiba. (2012). MEXA-720 NO . Available: http://www.horiba.com/automotive-testsystems

69. Air-Vac. (2012). TD Single Stage Vacuum Generators. Available: http://www.airvacpumps.com/TDpump.html

70. Air-Vac. (1999). Air-Vac TD Series Data Sheet. Available: http://www.airvacpumps.com/pdfs/td.pdf

71. TSI, "Model 3090 Engine Exhaust Particle Sizer ${ }^{\mathrm{TM}}$ Spectrometer, Operation and Service Manual," ed, 2009.

72. Cambustion, "DMS500 Fast Particulate Spectrometer, User Manual," ed, 2010.

73. AVL, "AVL Micro Soot Sensor, AVL Exhaust Conditioning Unit, Operating Manual, Product Guide," ed, 2008.

74. Kistler. (2012). High Temperature Pressure Sensor Type 6058A, Data Sheet. Available: http://www.kistler.com

75. Kistler. (2012). Glow Plug Adapter Type 6544Q, Data Sheet. Available: http://www.kistler.com

76. Montgomery, D.C., DESIGN AND ANALYSIS OF EXPERIMENTS, $7^{\text {th }}$ ed. New York: John Wiley \& Sons, Inc., 2009.

77. Hinds, W.C., Aerosol Technology, $1^{\text {st }}$ ed. New York: John Wiley \& Sons, Inc., 1982.

78. TSI, "Aerosol Statistics, Lognormal Distributions and dN/dlog $D_{p}$, Application Note PR001," ed, 2010.

79. Eastwood, P., Particulate Emissions From Vehicles. West Sussex: John Wiley \& Sons Ltd, 2008.

80. Moore, D.S., McCabe, G.P., and Craig, B.A., InTRoduction to the Practice of STATISTICS, $6^{\text {th }}$ ed. New York: W. H. Freeman and Company, 2009.

81. Huai, T., "California's Efforts for Advancing Ultrafine Particle Number Measurements for Clean Diesel Exhaust," in Diesel Engine-Efficiency and Emissions Reduction (DEER), Detroit, MI, 2006.

82. Flaim, K.A.C., "Study of the Variations in Continuous Diesel Particulate Matter Size Measurements and Effect of Fuel Properties on DPM Size," Master's Thesis, Mechanical and Aerospace Engineering, West Virginia University, Morgantown, 2008. 


\section{APPENDIX A SPLIT \& SINGLE INJECTION TEST MATRICES}

Table 22 Low Cetane (FACE 4, FACE 1, FACE 3) Split Injection Matrix

\begin{tabular}{|c|c|c|c|}
\hline Test \# & $\begin{array}{c}\text { Main SOI } \\
\left({ }^{\circ} \text { BTDC) }\right.\end{array}$ & $\begin{array}{l}\text { Pilot SOI } \\
\left({ }^{\circ} \text { BTDC) }\right.\end{array}$ & $\begin{array}{c}\text { Fuel Split } \\
(\%)\end{array}$ \\
\hline 1 & 10 & 40 & 30 \\
\hline 2 & 10 & 40 & 35 \\
\hline 3 & 10 & 40 & 40 \\
\hline 4 & 10 & 45 & 30 \\
\hline 5 & 10 & 45 & 35 \\
\hline 6 & 10 & 45 & 40 \\
\hline 7 & 10 & 50 & 30 \\
\hline 8 & 10 & 50 & 35 \\
\hline 9 & 10 & 50 & 40 \\
\hline 10 & 8 & 40 & 30 \\
\hline 11 & 8 & 40 & 35 \\
\hline 12 & 8 & 40 & 40 \\
\hline 13 & 8 & 45 & 30 \\
\hline 14 & 8 & 45 & 35 \\
\hline 15 & 8 & 45 & 40 \\
\hline 16 & 8 & 50 & 30 \\
\hline 17 & 8 & 50 & 35 \\
\hline 18 & 8 & 50 & 40 \\
\hline 19 & 6 & 40 & 30 \\
\hline 20 & 6 & 40 & 35 \\
\hline 21 & 6 & 40 & 40 \\
\hline 22 & 6 & 45 & 30 \\
\hline 23 & 6 & 45 & 35 \\
\hline 24 & 6 & 45 & 40 \\
\hline 25 & 6 & 50 & 30 \\
\hline 26 & 6 & 50 & 35 \\
\hline 27 & 6 & 50 & 40 \\
\hline
\end{tabular}

\begin{tabular}{|c|c|c|c|}
\hline Test \# & $\begin{array}{c}\text { Main SOI } \\
\left({ }^{\circ} \text { B TDC) }\right.\end{array}$ & $\begin{array}{c}\text { Pilot SOI } \\
\left({ }^{\circ} \text { BTDC) }\right.\end{array}$ & $\begin{array}{c}\text { Fuel Split } \\
(\%)\end{array}$ \\
\hline 28 & 4 & 40 & 30 \\
\hline 29 & 4 & 40 & 35 \\
\hline 30 & 4 & 40 & 40 \\
\hline 31 & 4 & 45 & 30 \\
\hline 32 & 4 & 45 & 35 \\
\hline 33 & 4 & 45 & 40 \\
\hline 34 & 4 & 50 & 30 \\
\hline 35 & 4 & 50 & 35 \\
\hline 36 & 4 & 50 & 40 \\
\hline 37 & 2 & 40 & 30 \\
\hline 38 & 2 & 40 & 35 \\
\hline 39 & 2 & 40 & 40 \\
\hline 40 & 2 & 45 & 30 \\
\hline 41 & 2 & 45 & 35 \\
\hline 42 & 2 & 45 & 40 \\
\hline 43 & 2 & 50 & 30 \\
\hline 44 & 2 & 50 & 35 \\
\hline 45 & 2 & 50 & 40 \\
\hline
\end{tabular}


Table 23 Medium Cetane (ULSD, FACE 7, FACE 9) Split Injection Test Matrix

\begin{tabular}{|c|c|c|c|}
\hline Test \# & $\begin{array}{c}\text { Main SOI } \\
\left({ }^{\circ} \text { BTDC) }\right.\end{array}$ & $\begin{array}{l}\text { Pilot SOI } \\
\left({ }^{\circ} \text { BTDC) }\right.\end{array}$ & $\begin{array}{c}\text { Fuel Split } \\
(\%)\end{array}$ \\
\hline 1 & 6 & 35 & 30 \\
\hline 2 & 6 & 35 & 35 \\
\hline 3 & 6 & 35 & 40 \\
\hline 4 & 6 & 40 & 30 \\
\hline 5 & 6 & 40 & 35 \\
\hline 6 & 6 & 40 & 40 \\
\hline 7 & 6 & 45 & 30 \\
\hline 8 & 6 & 45 & 35 \\
\hline 9 & 6 & 45 & 40 \\
\hline 10 & 4 & 35 & 30 \\
\hline 11 & 4 & 35 & 35 \\
\hline 12 & 4 & 35 & 40 \\
\hline 13 & 4 & 40 & 30 \\
\hline 14 & 4 & 40 & 35 \\
\hline 15 & 4 & 40 & 40 \\
\hline 16 & 4 & 45 & 30 \\
\hline 17 & 4 & 45 & 35 \\
\hline 18 & 4 & 45 & 40 \\
\hline 19 & 2 & 35 & 30 \\
\hline 20 & 2 & 35 & 35 \\
\hline 21 & 2 & 35 & 40 \\
\hline 22 & 2 & 40 & 30 \\
\hline 23 & 2 & 40 & 35 \\
\hline 24 & 2 & 40 & 40 \\
\hline 25 & 2 & 45 & 30 \\
\hline 26 & 2 & 45 & 35 \\
\hline 27 & 2 & 45 & 40 \\
\hline
\end{tabular}

\begin{tabular}{|c|c|c|c|}
\hline Test \# & $\begin{array}{c}\text { Main SOI } \\
\left({ }^{\circ} \text { B TDC) }\right.\end{array}$ & $\begin{array}{c}\text { Pilot SOI } \\
\left({ }^{\circ} \text { BTDC) }\right.\end{array}$ & $\begin{array}{c}\text { Fuel Split } \\
(\%)\end{array}$ \\
\hline 28 & 0 & 35 & 30 \\
\hline 29 & 0 & 35 & 35 \\
\hline 30 & 0 & 35 & 40 \\
\hline 31 & 0 & 40 & 30 \\
\hline 32 & 0 & 40 & 35 \\
\hline 33 & 0 & 40 & 40 \\
\hline 34 & 0 & 45 & 30 \\
\hline 35 & 0 & 45 & 35 \\
\hline 36 & 0 & 45 & 40 \\
\hline 37 & -2 & 35 & 30 \\
\hline 38 & -2 & 35 & 35 \\
\hline 39 & -2 & 35 & 40 \\
\hline 40 & -2 & 40 & 30 \\
\hline 41 & -2 & 40 & 35 \\
\hline 42 & -2 & 40 & 40 \\
\hline 43 & -2 & 45 & 30 \\
\hline 44 & -2 & 45 & 35 \\
\hline 45 & -2 & 45 & 40 \\
\hline
\end{tabular}


Table 24 High Cetane (FACE 8, FACE 6, FACE 5) Split Injection Test Matrix

\begin{tabular}{|c|c|c|c|}
\hline Test \# & $\begin{array}{c}\text { Main SOI } \\
\left({ }^{\circ} \text { BTDC) }\right.\end{array}$ & $\begin{array}{l}\text { Pilot SOI } \\
\left({ }^{\circ} \text { BTDC) }\right.\end{array}$ & $\begin{array}{c}\text { Fuel Split } \\
(\%)\end{array}$ \\
\hline 1 & 4 & 30 & 30 \\
\hline 2 & 4 & 30 & 35 \\
\hline 3 & 4 & 30 & 40 \\
\hline 4 & 4 & 35 & 30 \\
\hline 5 & 4 & 35 & 35 \\
\hline 6 & 4 & 35 & 40 \\
\hline 7 & 4 & 40 & 30 \\
\hline 8 & 4 & 40 & 35 \\
\hline 9 & 4 & 40 & 40 \\
\hline 10 & 2 & 30 & 30 \\
\hline 11 & 2 & 30 & 35 \\
\hline 12 & 2 & 30 & 40 \\
\hline 13 & 2 & 35 & 30 \\
\hline 14 & 2 & 35 & 35 \\
\hline 15 & 2 & 35 & 40 \\
\hline 16 & 2 & 40 & 30 \\
\hline 17 & 2 & 40 & 35 \\
\hline 18 & 2 & 40 & 40 \\
\hline 19 & 0 & 30 & 30 \\
\hline 20 & 0 & 30 & 35 \\
\hline 21 & 0 & 30 & 40 \\
\hline 22 & 0 & 35 & 30 \\
\hline 23 & 0 & 35 & 35 \\
\hline 24 & 0 & 35 & 40 \\
\hline 25 & 0 & 40 & 30 \\
\hline 26 & 0 & 40 & 35 \\
\hline 27 & 0 & 40 & 40 \\
\hline
\end{tabular}

\begin{tabular}{|c|c|c|c|}
\hline Test \# & $\begin{array}{c}\text { Main SOI } \\
\left({ }^{\circ} \text { B TDC) }\right.\end{array}$ & $\begin{array}{c}\text { Pilot SOI } \\
\left({ }^{\circ} \text { BTDC) }\right.\end{array}$ & $\begin{array}{c}\text { Fuel Split } \\
(\%)\end{array}$ \\
\hline 28 & -2 & 30 & 30 \\
\hline 29 & -2 & 30 & 35 \\
\hline 30 & -2 & 30 & 40 \\
\hline 31 & -2 & 35 & 30 \\
\hline 32 & -2 & 35 & 35 \\
\hline 33 & -2 & 35 & 40 \\
\hline 34 & -2 & 40 & 30 \\
\hline 35 & -2 & 40 & 35 \\
\hline 36 & -2 & 40 & 40 \\
\hline 37 & -4 & 30 & 30 \\
\hline 38 & -4 & 30 & 35 \\
\hline 39 & -4 & 30 & 40 \\
\hline 40 & -4 & 35 & 30 \\
\hline 41 & -4 & 35 & 35 \\
\hline 42 & -4 & 35 & 40 \\
\hline 43 & -4 & 40 & 30 \\
\hline 44 & -4 & 40 & 35 \\
\hline 45 & -4 & 40 & 40 \\
\hline
\end{tabular}


Table 25 Single Injection Test Matrix

\begin{tabular}{|c|c|c|}
\hline Test \# & Intake $\mathbf{O}_{\mathbf{2}}(\boldsymbol{\%})$ & Rail Pressure (bar) \\
\hline 46 & 12 & 1200 \\
\hline 47 & 12 & 1400 \\
\hline 48 & 12 & 1600 \\
\hline 49 & 12.5 & 1200 \\
\hline 50 & 12.5 & 1400 \\
\hline 51 & 12.5 & 1600 \\
\hline 52 & 13 & 1200 \\
\hline 53 & 13 & 1400 \\
\hline 54 & 13 & 1600 \\
\hline 55 & 13.5 & 1200 \\
\hline 56 & 13.5 & 1400 \\
\hline 57 & 13.5 & 1600 \\
\hline 58 & 14 & 1200 \\
\hline 59 & 14 & 1400 \\
\hline 60 & 14 & 1600 \\
\hline
\end{tabular}




\section{APPENDIX B EEPS ${ }^{\mathrm{TM}}$ AND DMS MEASUREMENT SYSTEM COMPARISON}

A direct comparison between the EEPS ${ }^{\mathrm{TM}}$ model 3090 and the DMS model DMS500 for two different injection timing settings during split injection strategy is presented in Figure 82. The same sample conditioning systems as well as the same operational conditions (e.g. zeroing of the instruments) were used for this evaluation. In general, there is a good agreement between the two measurement systems. However, measurements with the DMS500 showed consistently higher values for accumulation mode particles for both of the injection timings and a somewhat more pronounced nucleation mode of about half of an order of magnitude higher compared with the EEPS ${ }^{\mathrm{TM}}$ model 3090.

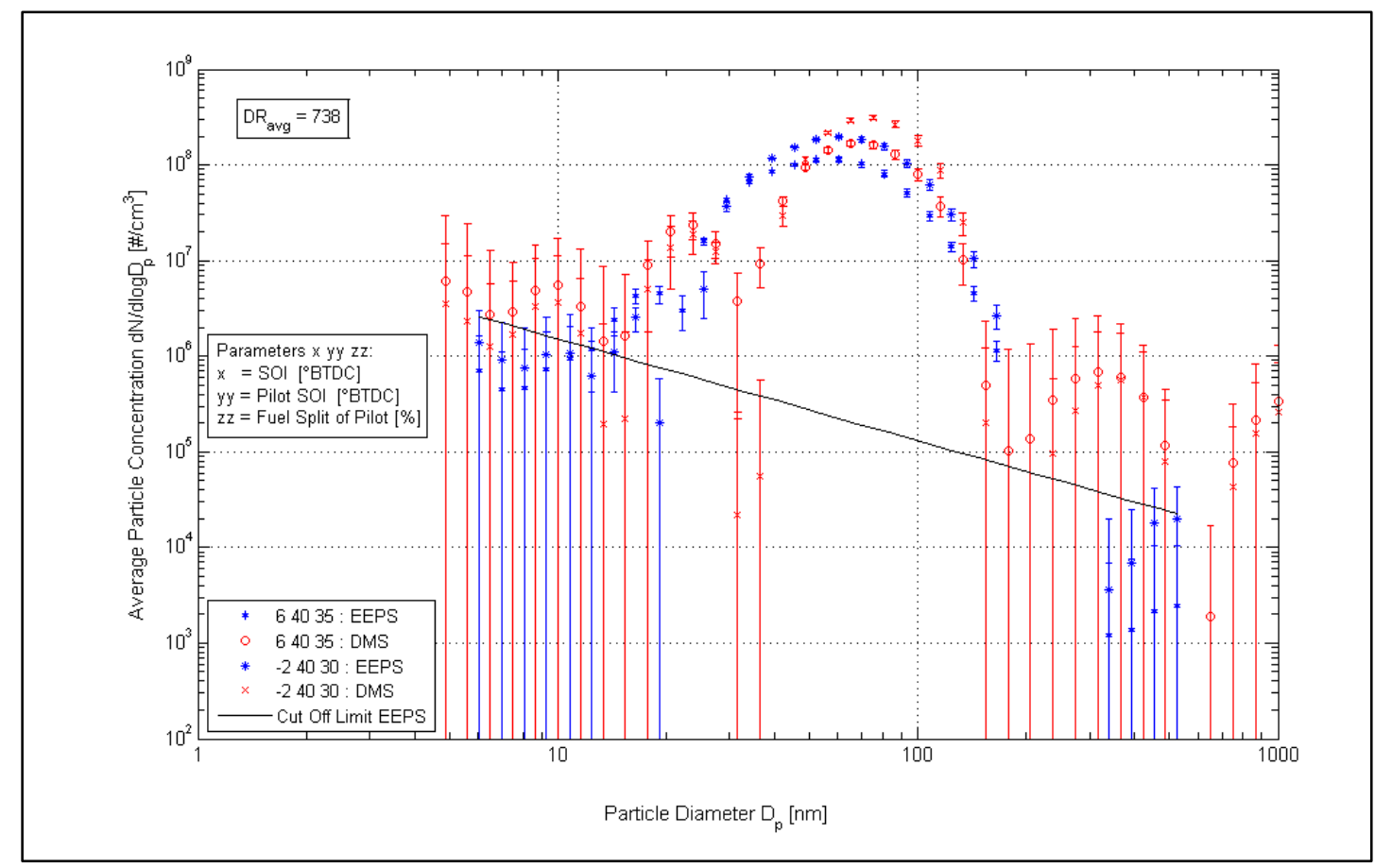

Figure 82 EEPS $^{\mathrm{TM}}$ and DMS Comparison for Test 5 and Test $40($ Error $=1 \sigma)$

Consecutive runs of Test 5 of the split injection strategy confirm the findings from Figure 82 and show good repeatability of the data (see Figure 83). Nevertheless, measured values below particle diameters smaller than $14.3 \mathrm{~nm}$ for $\mathrm{EEPS}^{\mathrm{TM}}$ and smaller than $17.8 \mathrm{~nm}$ for DMS as well as above $143.3 \mathrm{~nm}$ and $133.4 \mathrm{~nm}$, respectively, demonstrate enhanced variability. In a study investigating different parameters affecting particle size distribution on three different heavy- 
duty diesel engines using a DMS500, day-to-day concentration variations of between 3 and 10\% in the 32 to $316 \mathrm{~nm}$ particle diameter range were observed and suspected to be due to changes in barometric pressure variation, since this was the only parameter that was not controlled [82].

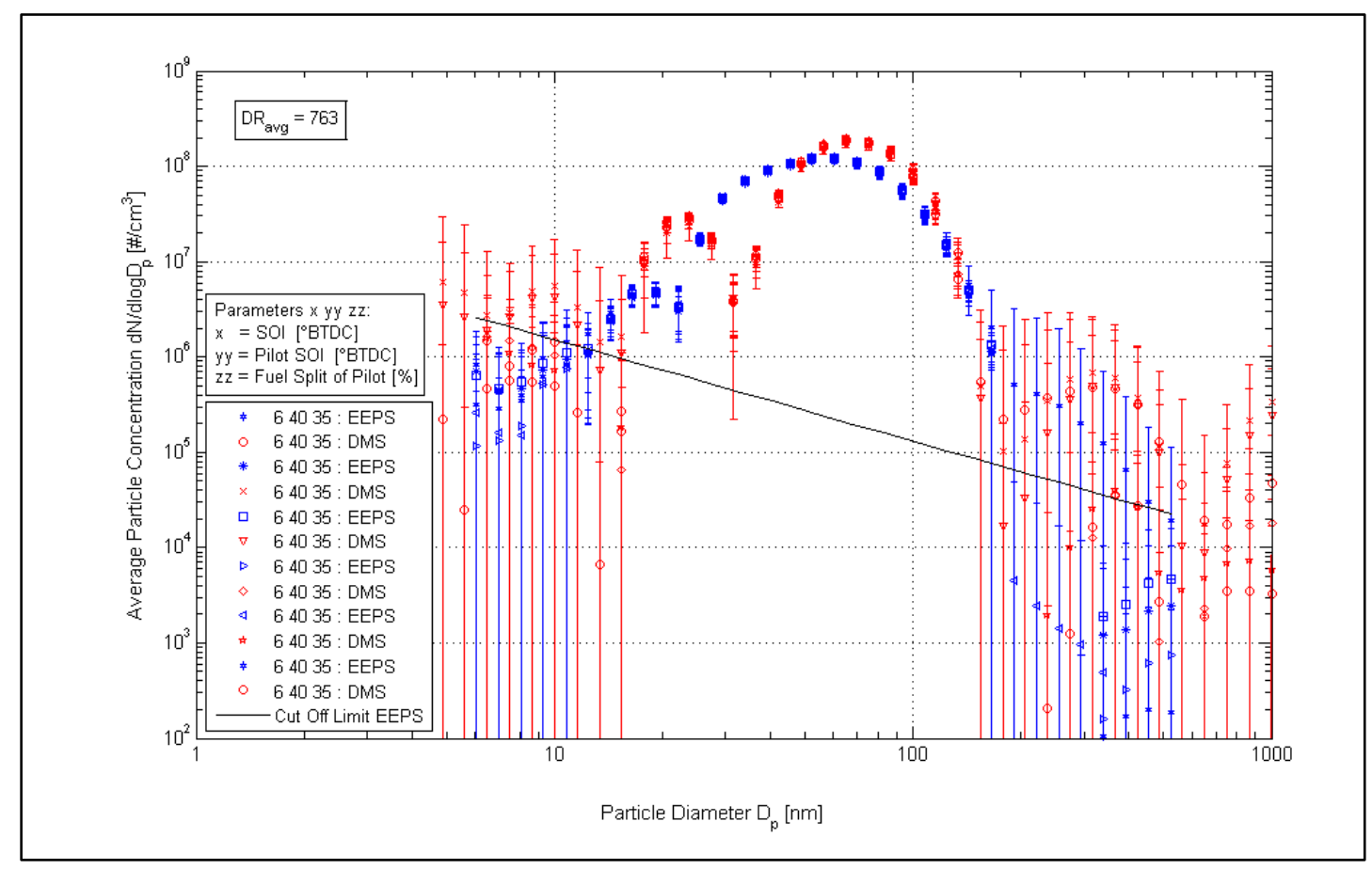

Figure 83 EEPS $^{\mathrm{TM}}$ and DMS Comparison for 6 Consecutive Runs of Test 5 (Error $=1 \sigma$ )

The findings in Figure 82 that measurements with the DMS500 showed consistently higher values were also confirmed by a linear least square regression for EEPS ${ }^{\mathrm{TM}}$ versus DMS for Test 5, where a slope of 1.36 was obtained. The linear regression showed the squared multiple correlation coefficient $\mathrm{R}^{2}$ to be $93 \%$. 


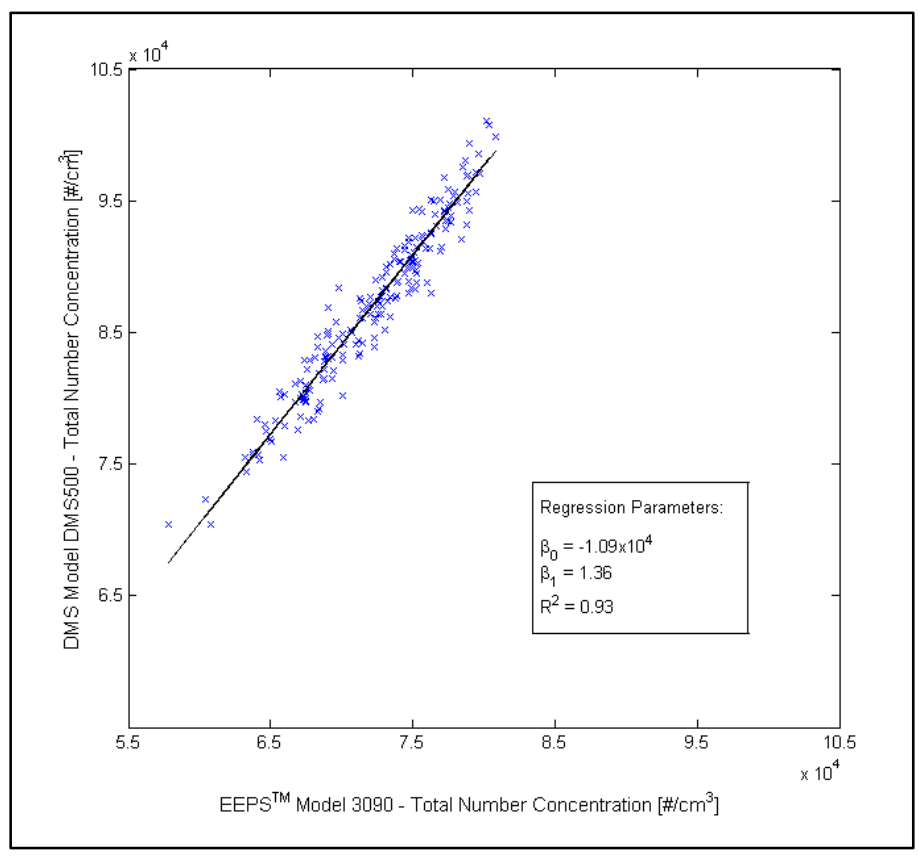

Figure $84 \mathrm{EEPS}^{\mathrm{TM}}$ vs. DMS Total Particle Concentration with Linear Least Square Fit Line for Test 5 


\section{APPENDIX C ADDITIONAL PARTICLE SIZE DISTRIBUTIONS}

\section{Optimal Split Injection Tests - Low $\mathrm{NO}_{\mathrm{x}}$}

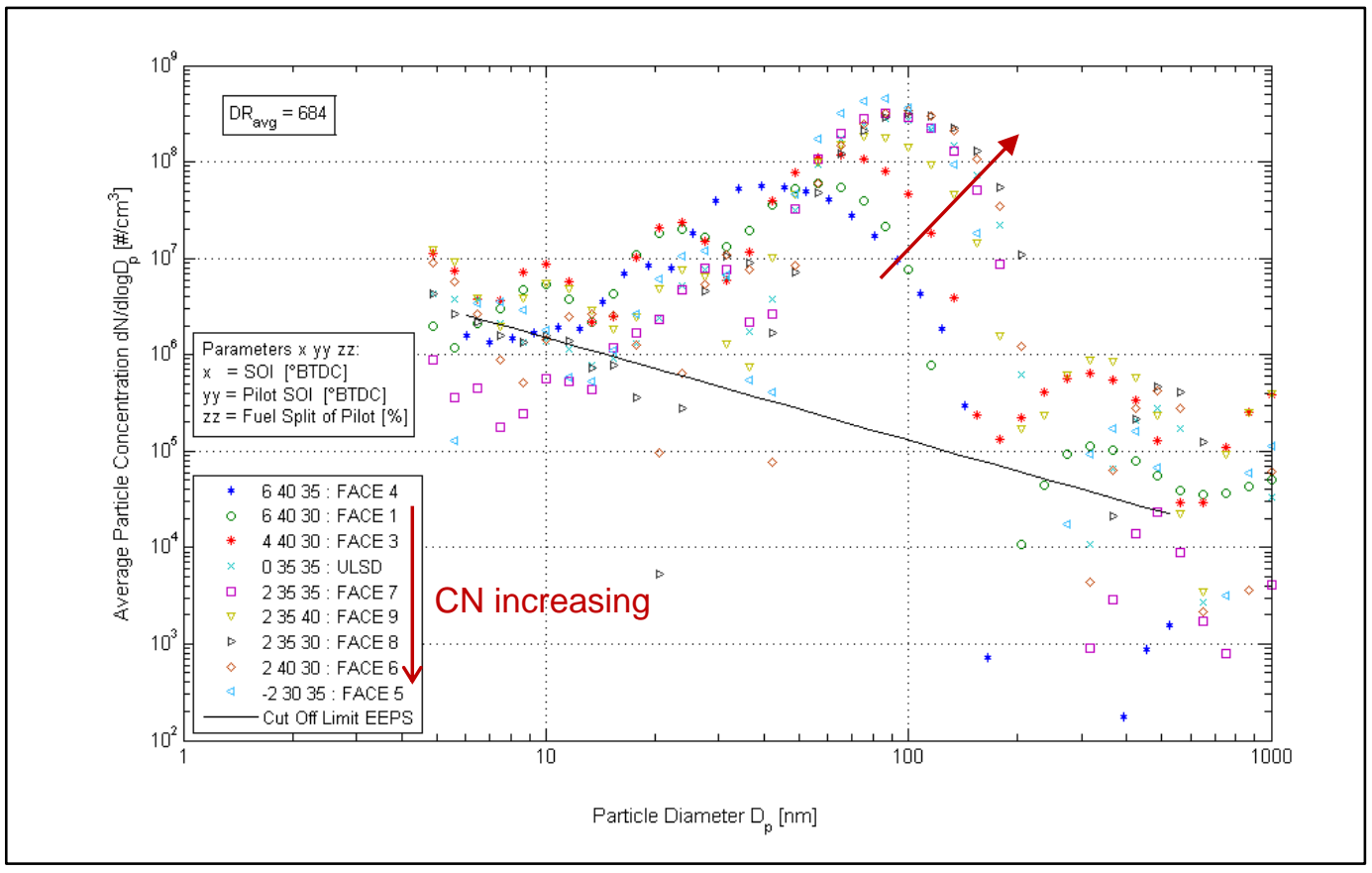

Figure 85 Particle Size Distribution for Optimal Split Injection Tests for Low $\mathrm{NO}_{\mathrm{x}}-$ Filled Markers for EEPS ${ }^{\mathrm{TM}}$

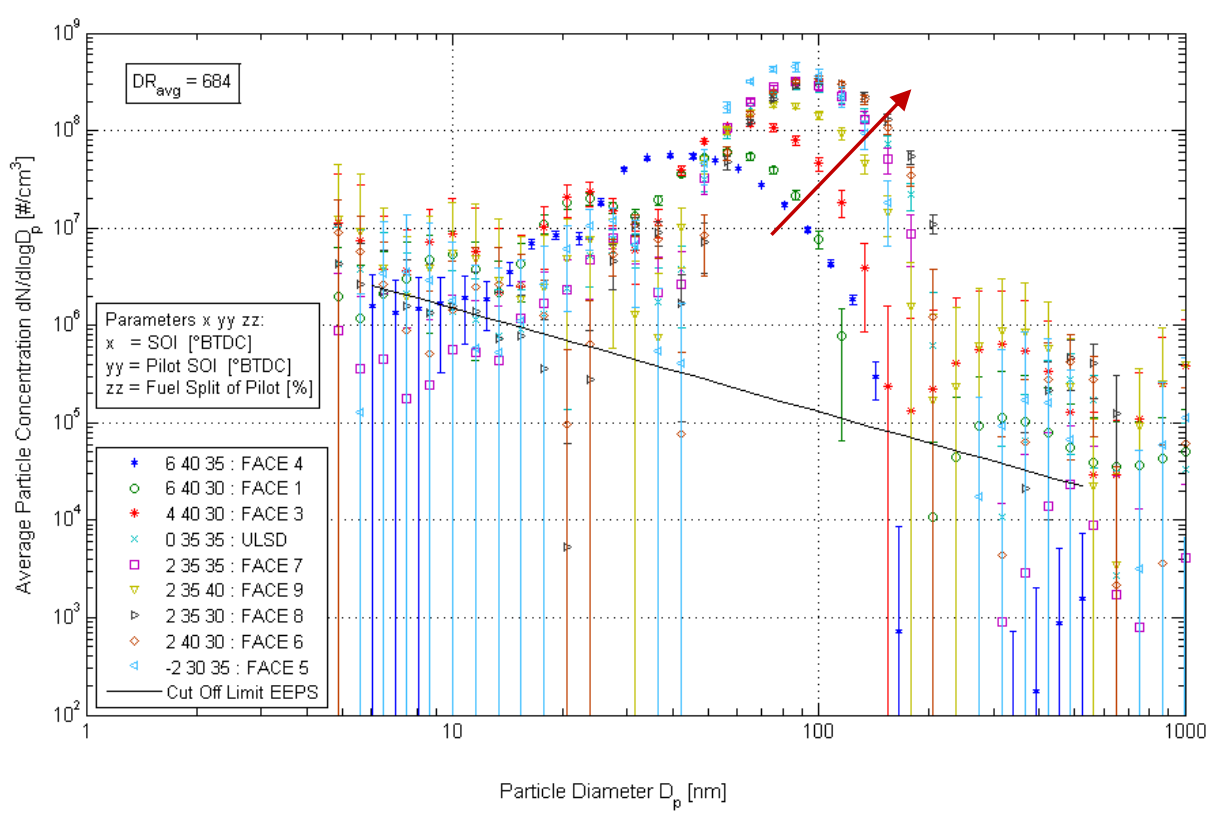

Figure 86 Particle Size Distribution for Optimal Split Injection Tests for Low $\mathrm{NO}_{\mathrm{x}}($ Error $=1 \sigma)-$ Filled Markers for EEPS ${ }^{\mathrm{TM}}$ 


\section{Optimal Split Injection Tests - Low Soot}

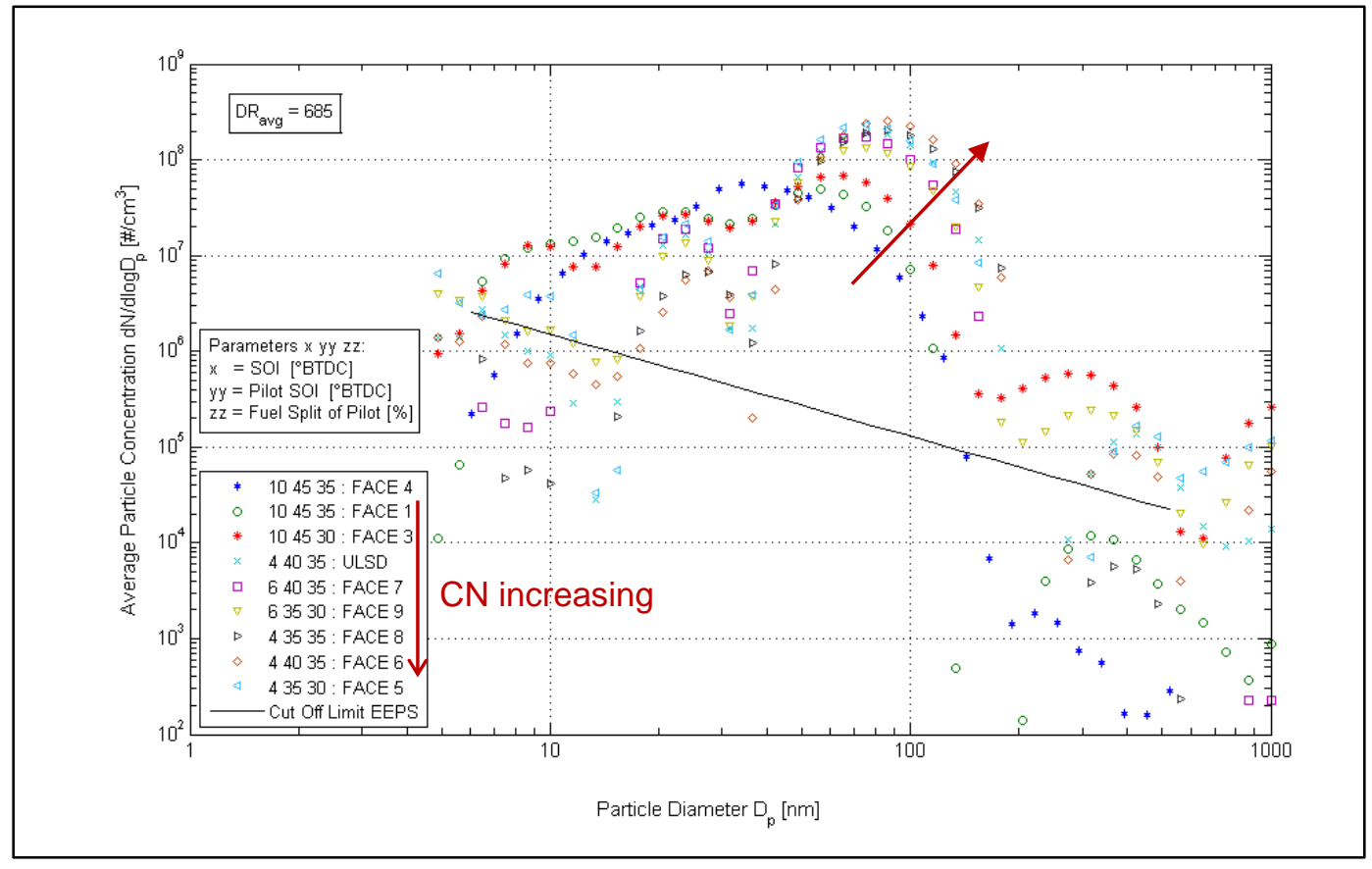

Figure 87 Particle Size Distribution for Optimal Split Injection Tests for Low Soot - Filled Markers for EEPS ${ }^{\mathrm{TM}}$

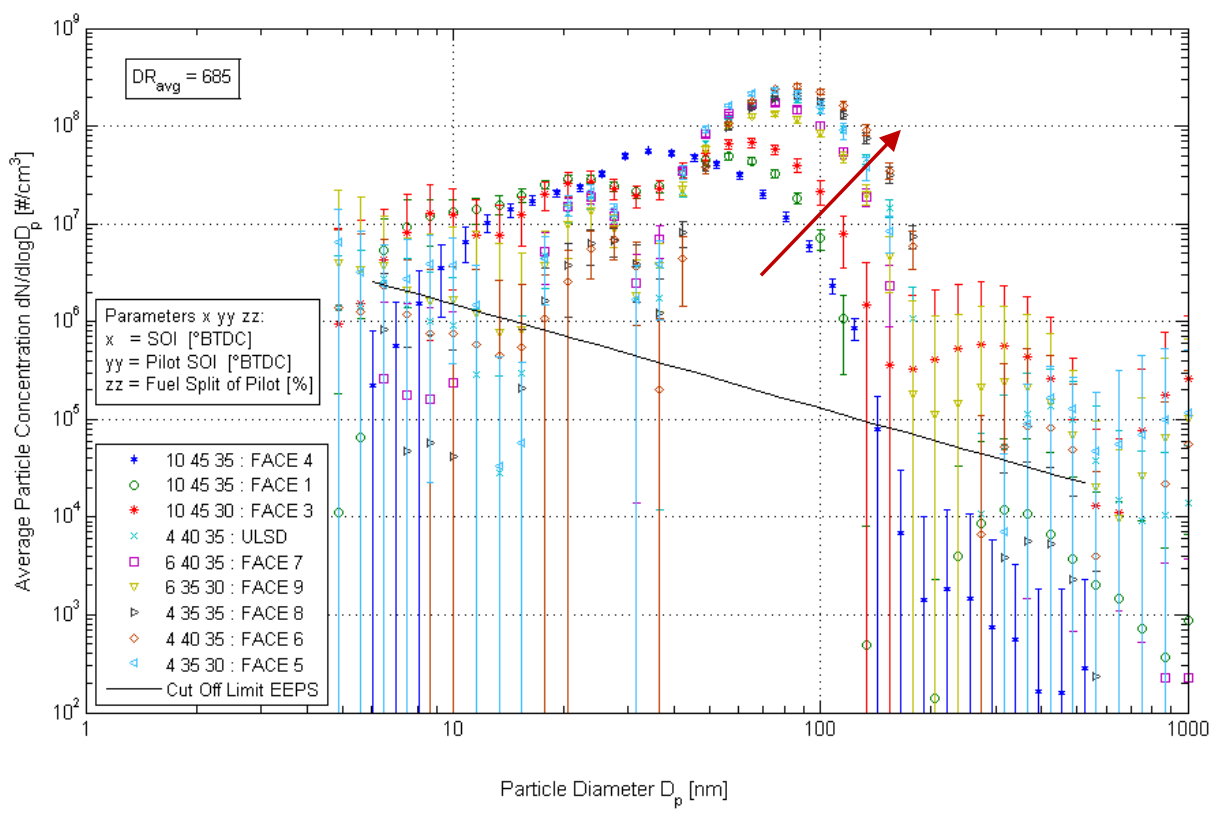

Figure 88 Particle Size Distribution for Optimal Split Injection Tests for Low Soot $($ Error $=1 \sigma)-$ Filled Markers for EEPS ${ }^{\mathrm{TM}}$ 


\section{Optimal Split Injection Tests - Highest BTE}

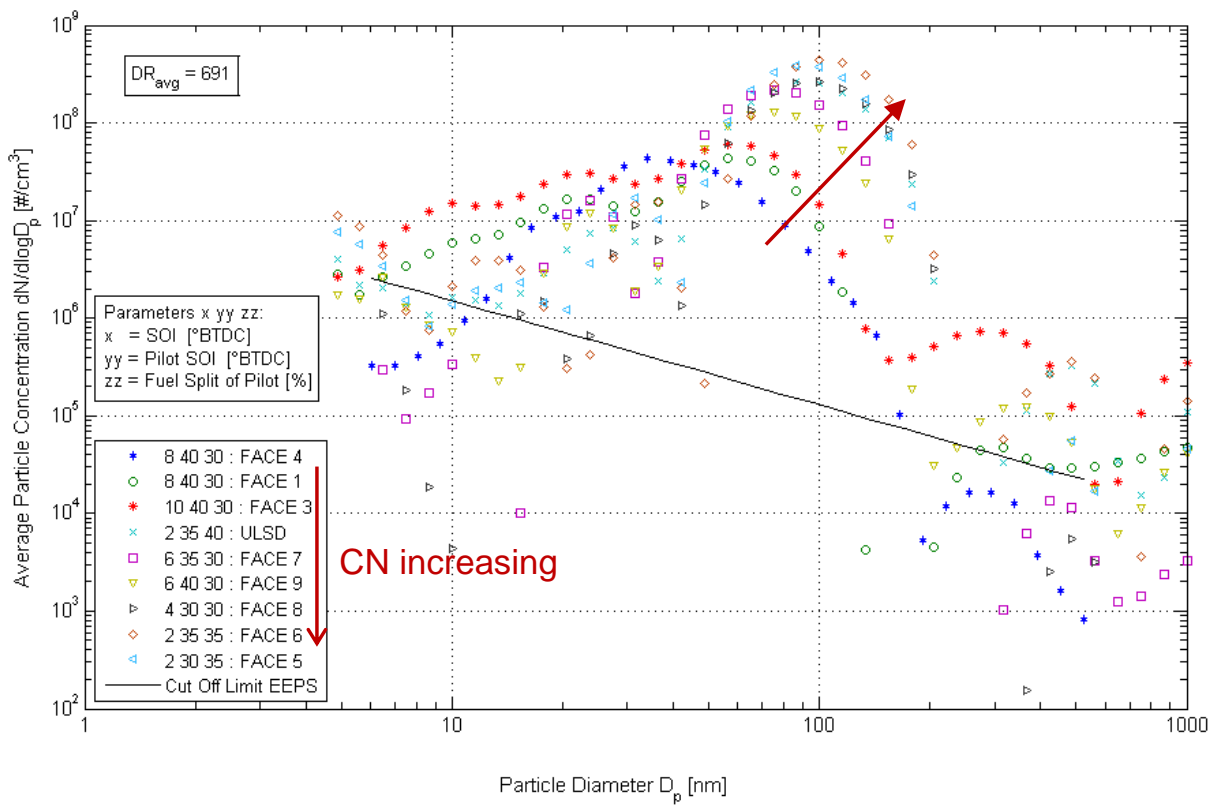

Figure 89 Particle Size Distribution for Optimal Split Injection Tests for Highest BTE - Filled Markers for EEPS ${ }^{\mathrm{TM}}$

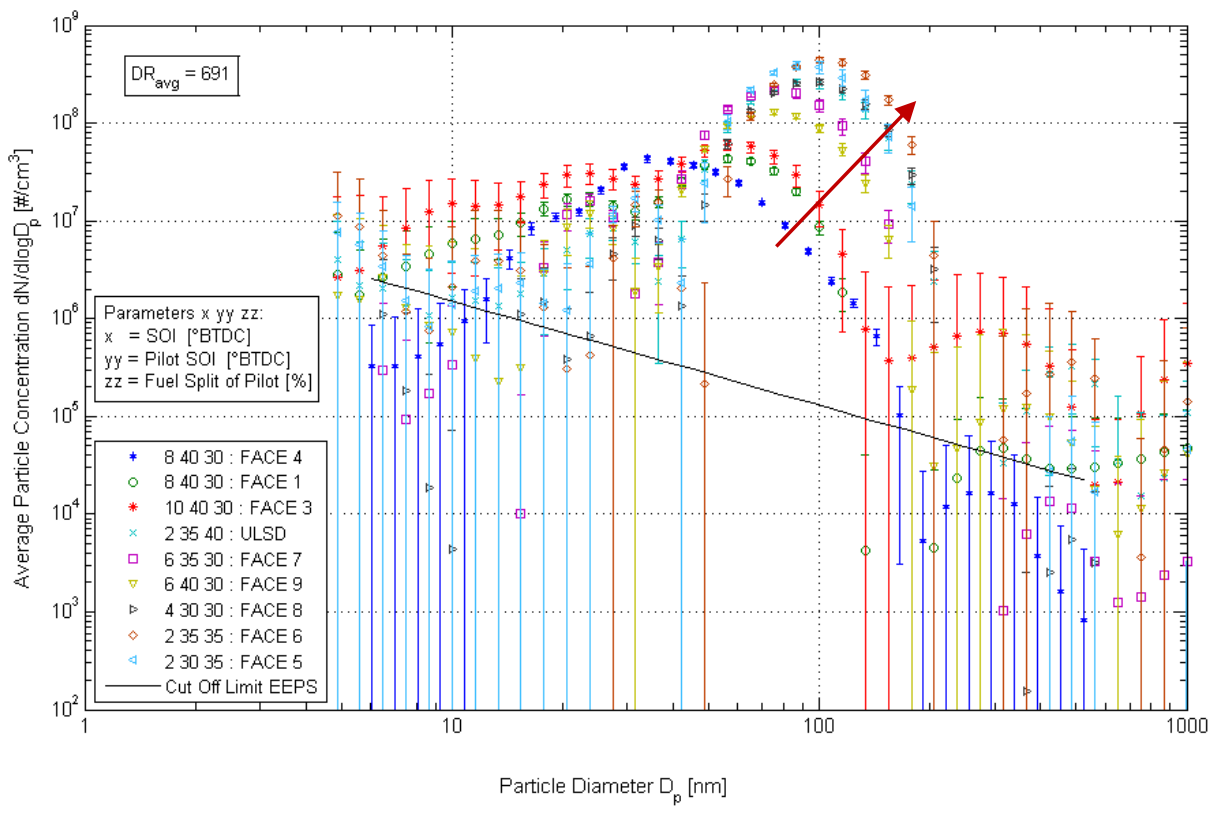

Figure 90 Particle Size Distribution for Optimal Split Injection Tests for Highest BTE $($ Error $=1 \sigma)-$ Filled Markers for EEPS ${ }^{\mathrm{TM}}$ 


\section{Optimal Single Injection Tests $-\mathrm{Low}_{\mathrm{NO}}$}

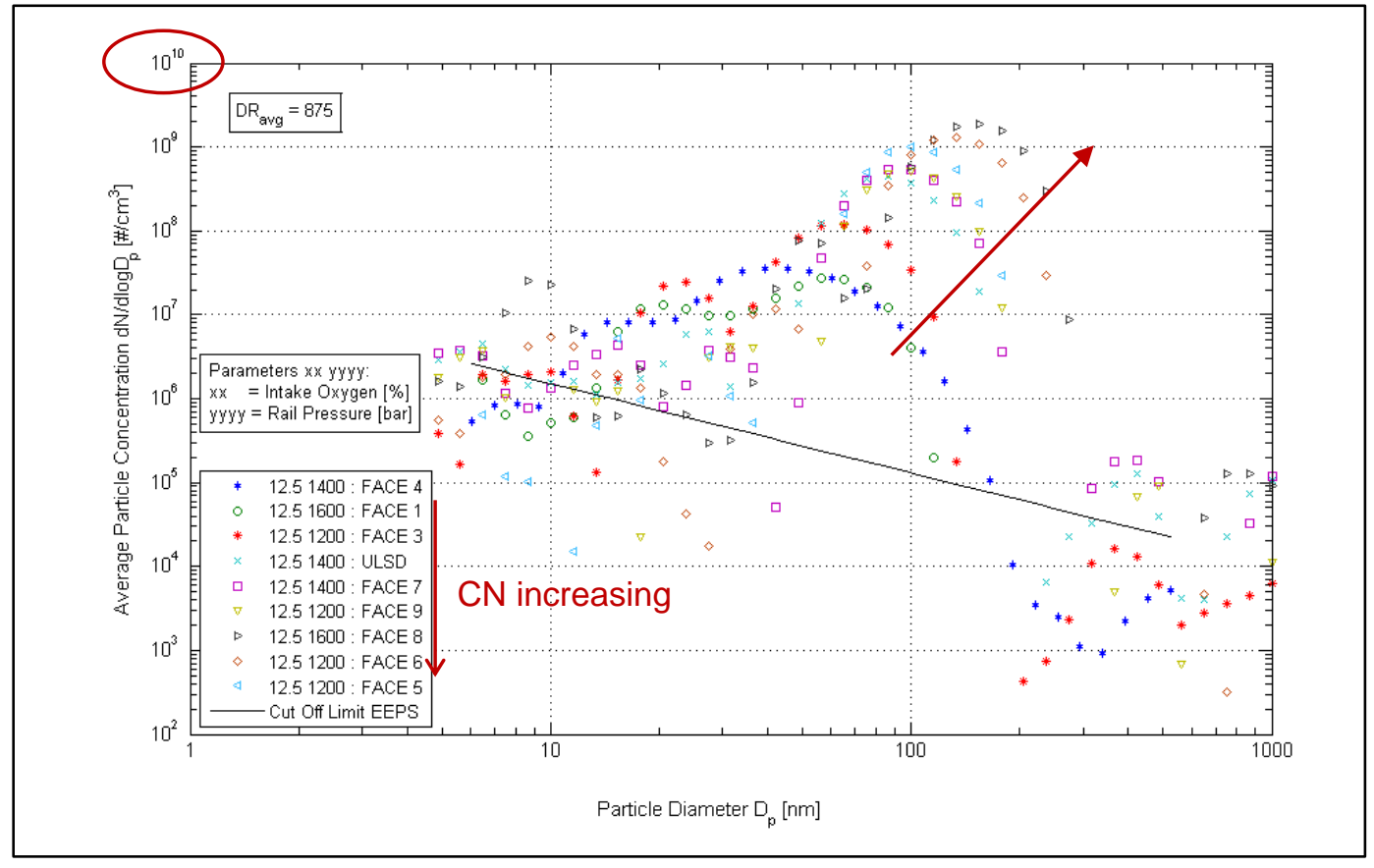

Figure 91 Particle Size Distribution for Optimal Single Injection Tests for Low $\mathrm{NO}_{\mathrm{x}}-$ Filled Markers for EEPS ${ }^{\mathrm{TM}}$

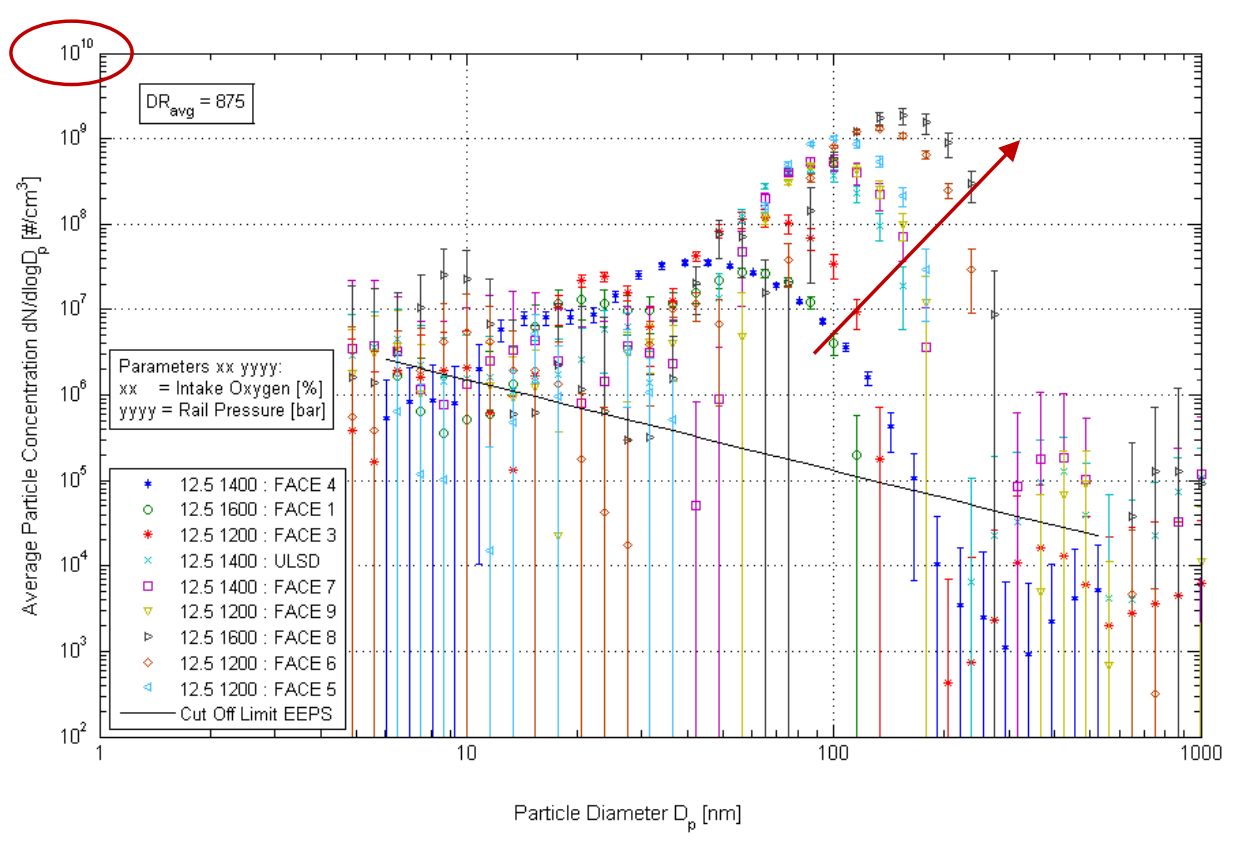

Figure 92 Particle Size Distribution for Optimal Single Injection Tests for Low $\mathrm{NO}_{\mathrm{x}}($ Error $=1 \sigma)-$ Filled Markers for EEPS ${ }^{\mathrm{TM}}$ 


\section{Optimal Single Injection Tests - Low Soot}

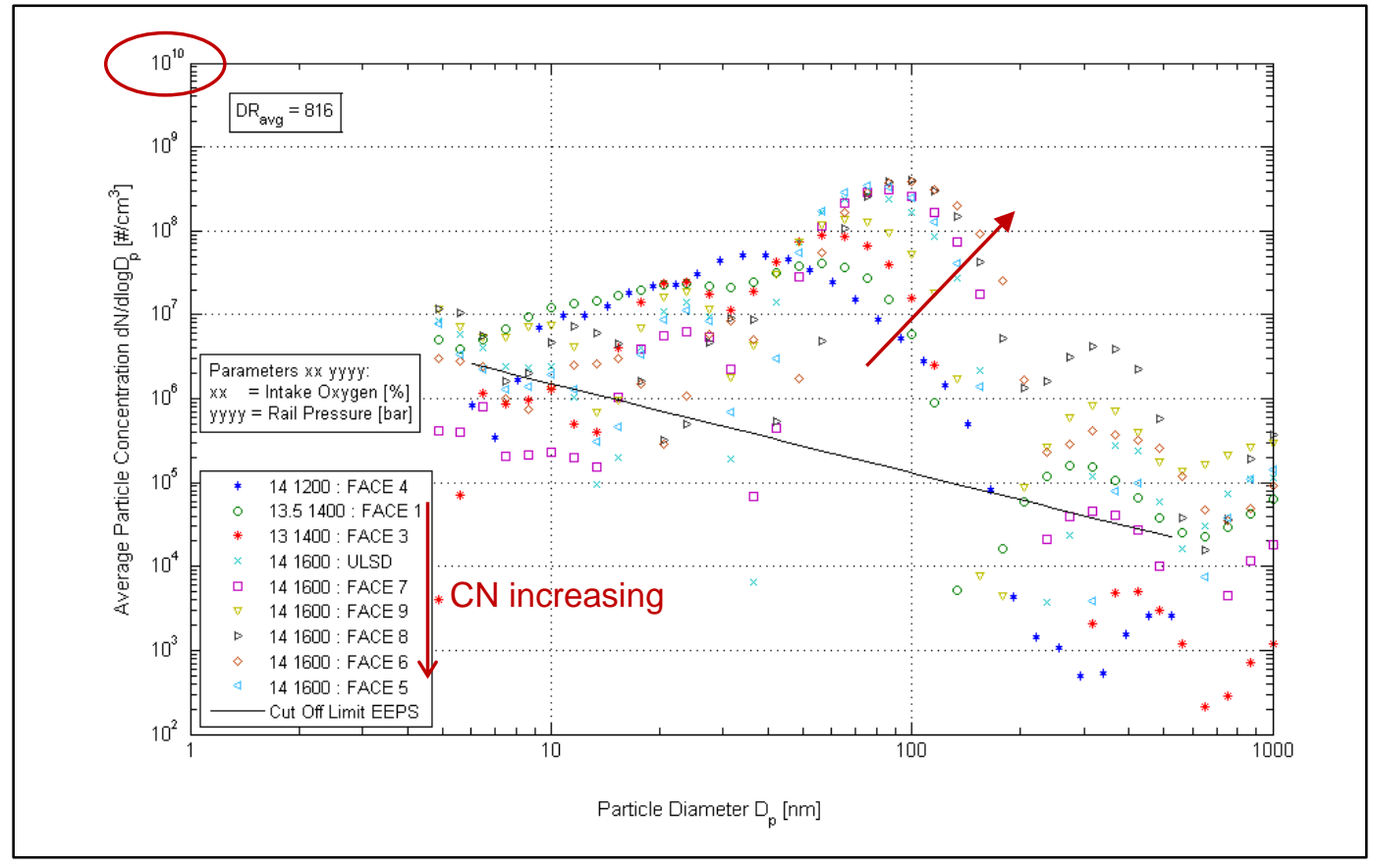

Figure 93 Particle Size Distribution for Optimal Single Injection Tests for Low Soot - Filled Markers for EEPS ${ }^{\mathrm{TM}}$

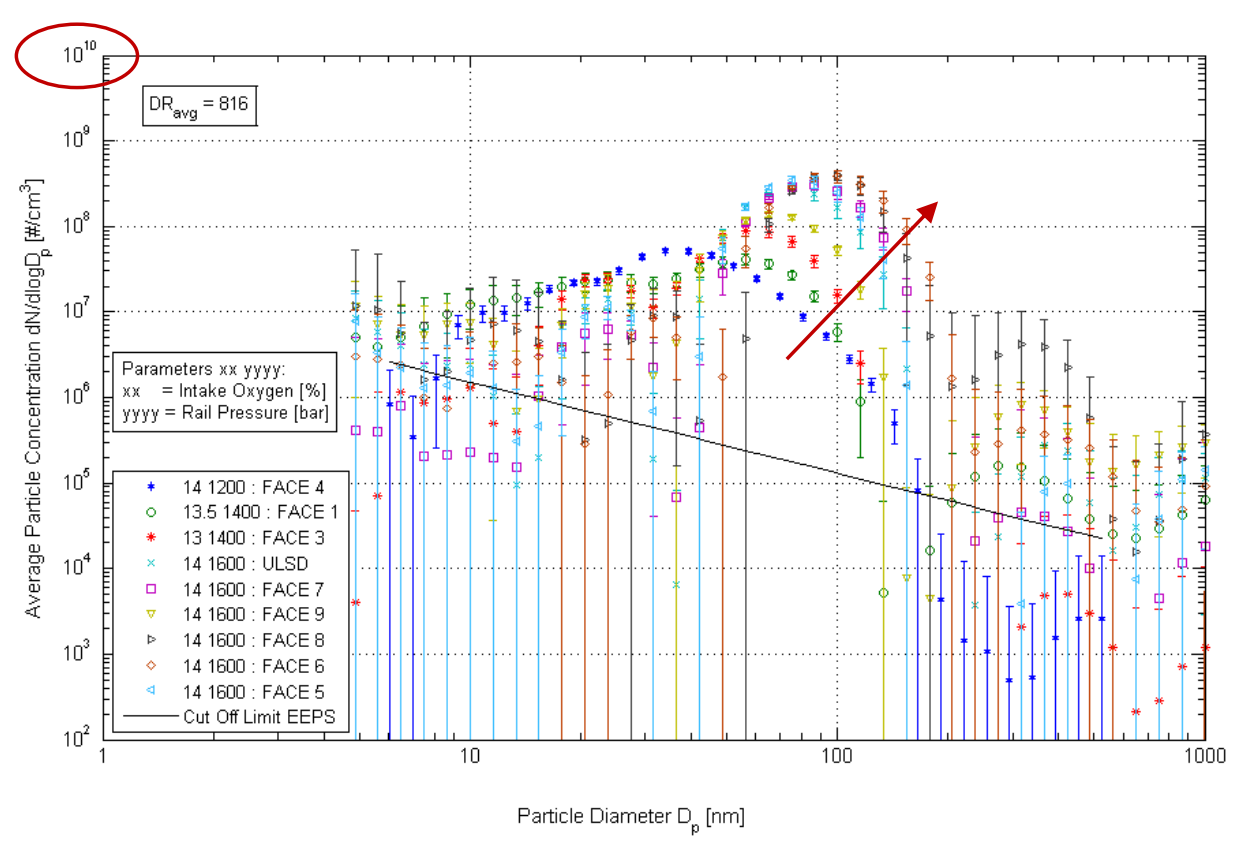

Figure 94 Particle Size Distribution for Optimal Single Injection Tests for Low Soot $($ Error $=1 \sigma)-$ Filled Markers for EEPS ${ }^{\mathrm{TM}}$ 


\section{Optimal Single Injection Tests - Highest BTE}

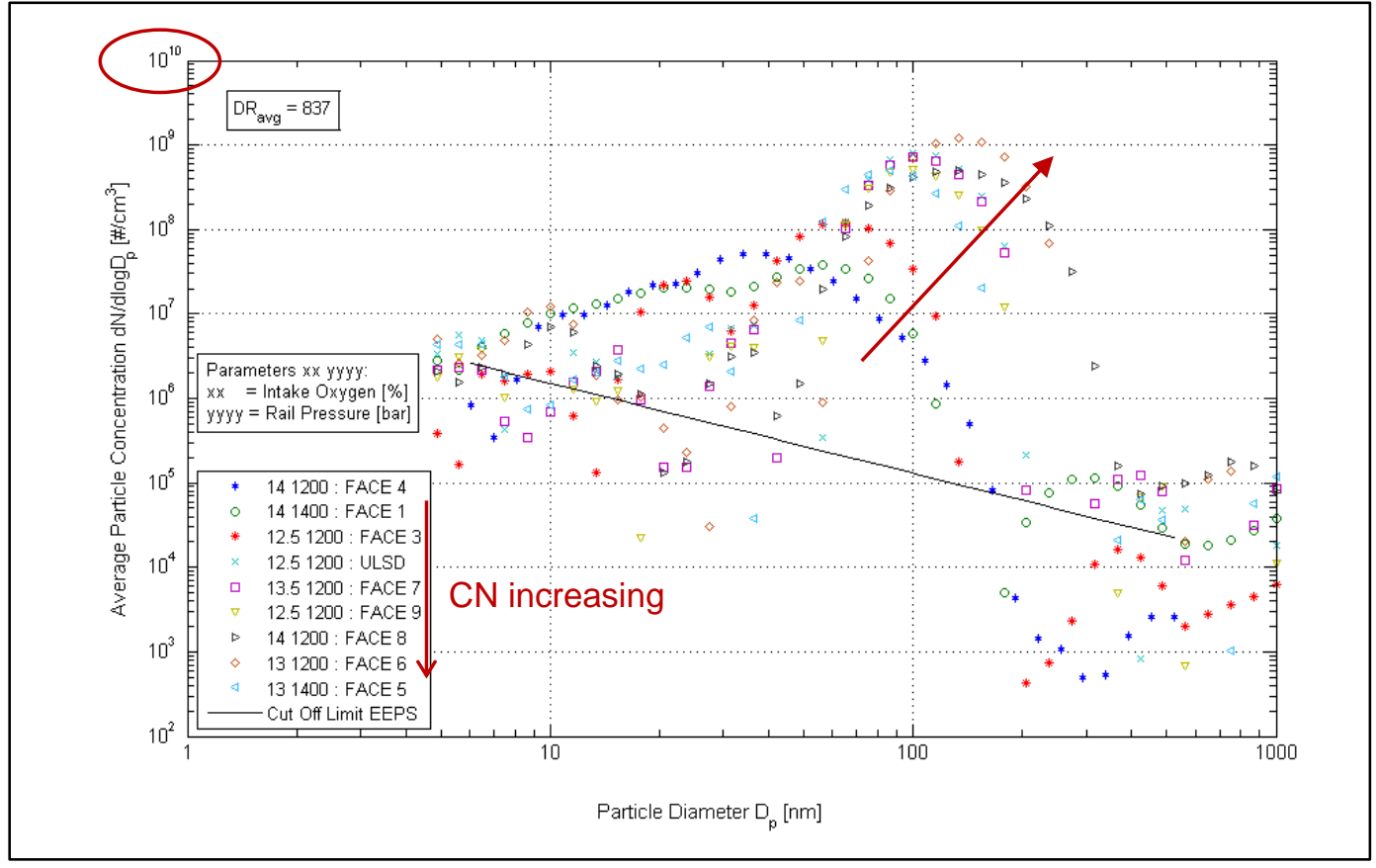

Figure 95 Particle Size Distribution for Optimal Single Injection Tests for Highest BTE - Filled Markers for EEPS ${ }^{\mathrm{TM}}$

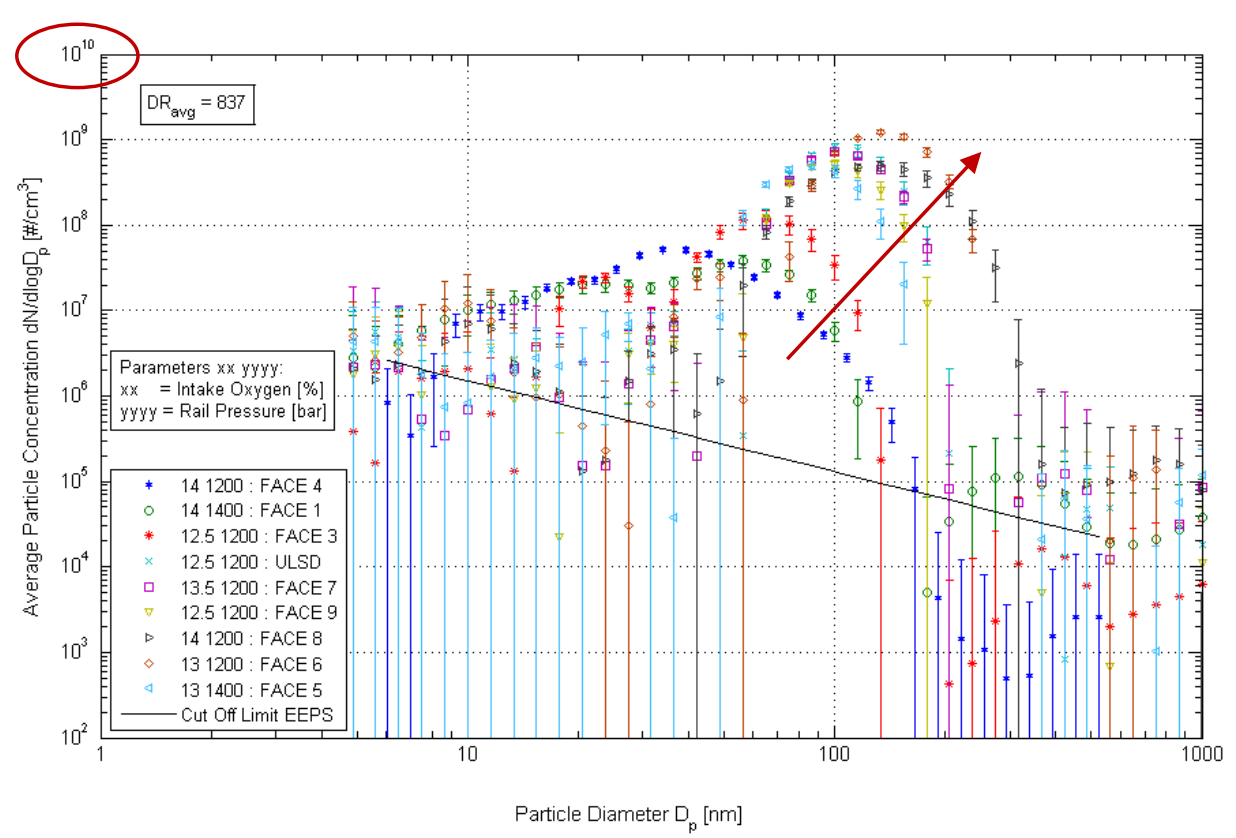

Figure 96 Particle Size Distribution for Optimal Single Injection Tests for Highest BTE $($ Error $=1 \sigma)-$ Filled Markers for EEPS ${ }^{\mathrm{TM}}$ 


\section{Low, Medium and High Cetane Fuel Comparison}

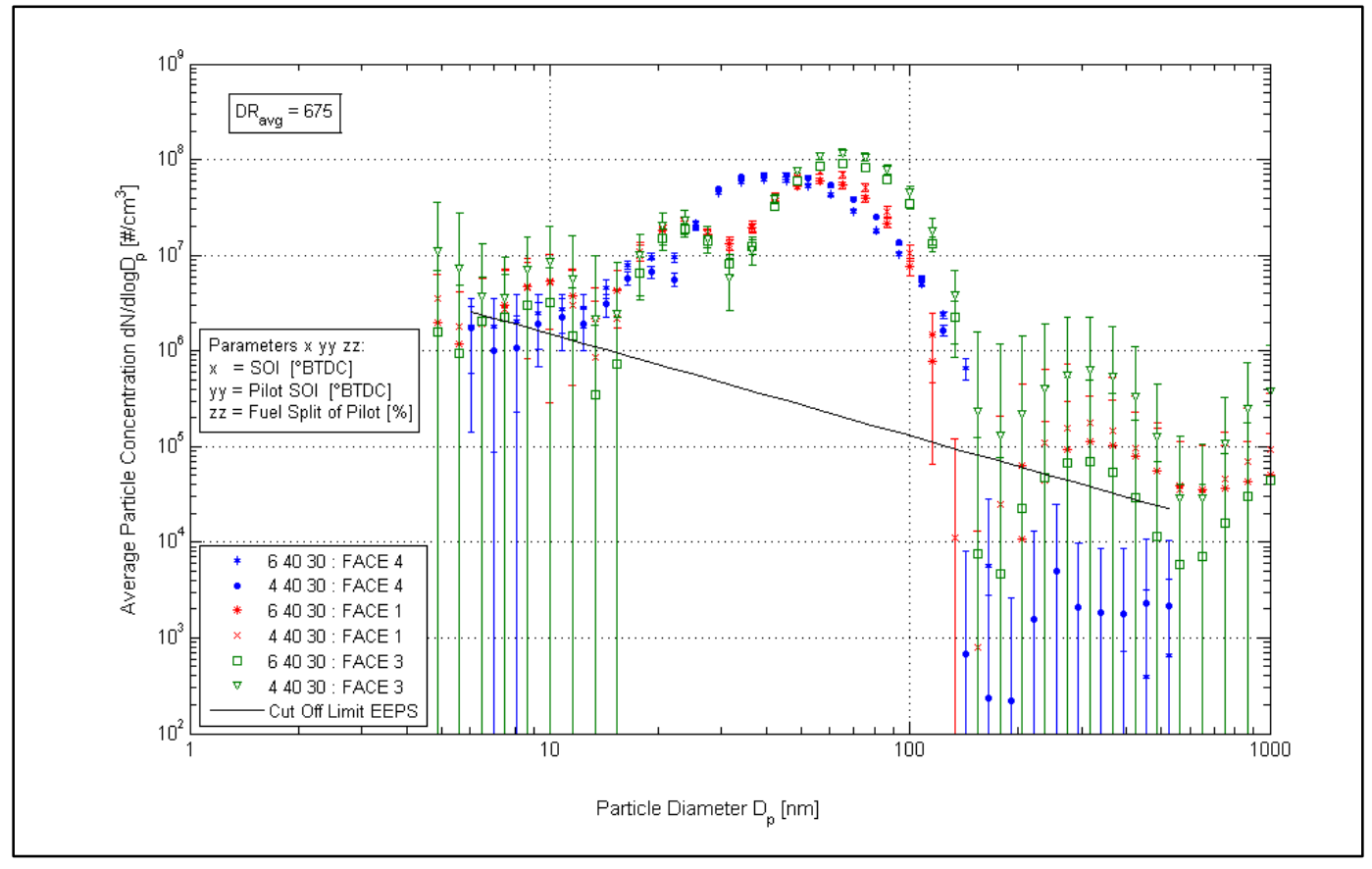

Figure 97 Particle Size Distribution for Low Cetane Fuels $($ Error $=1 \sigma)-$ Filled Markers for EEPS ${ }^{\mathrm{TM}}$

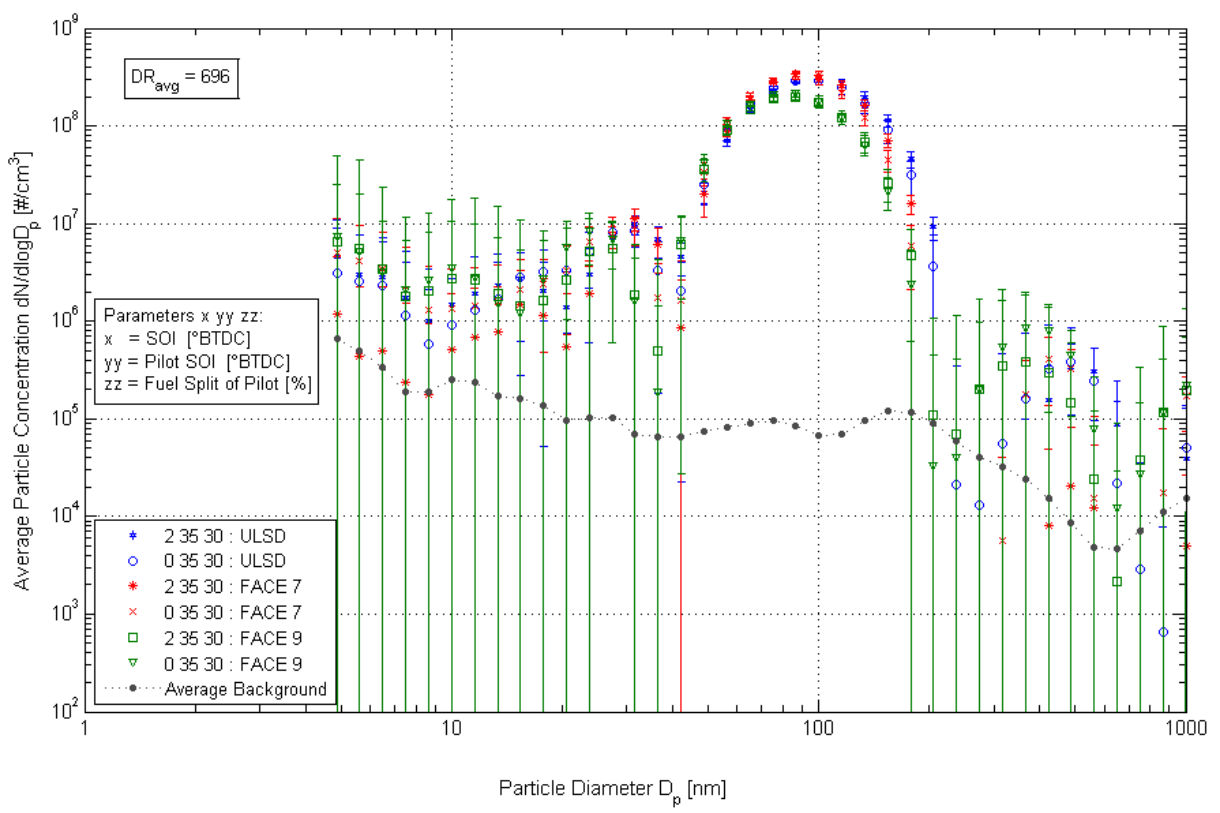

Figure 98 Particle Size Distribution for Medium Cetane Fuels $($ Error $=1 \sigma)$ 


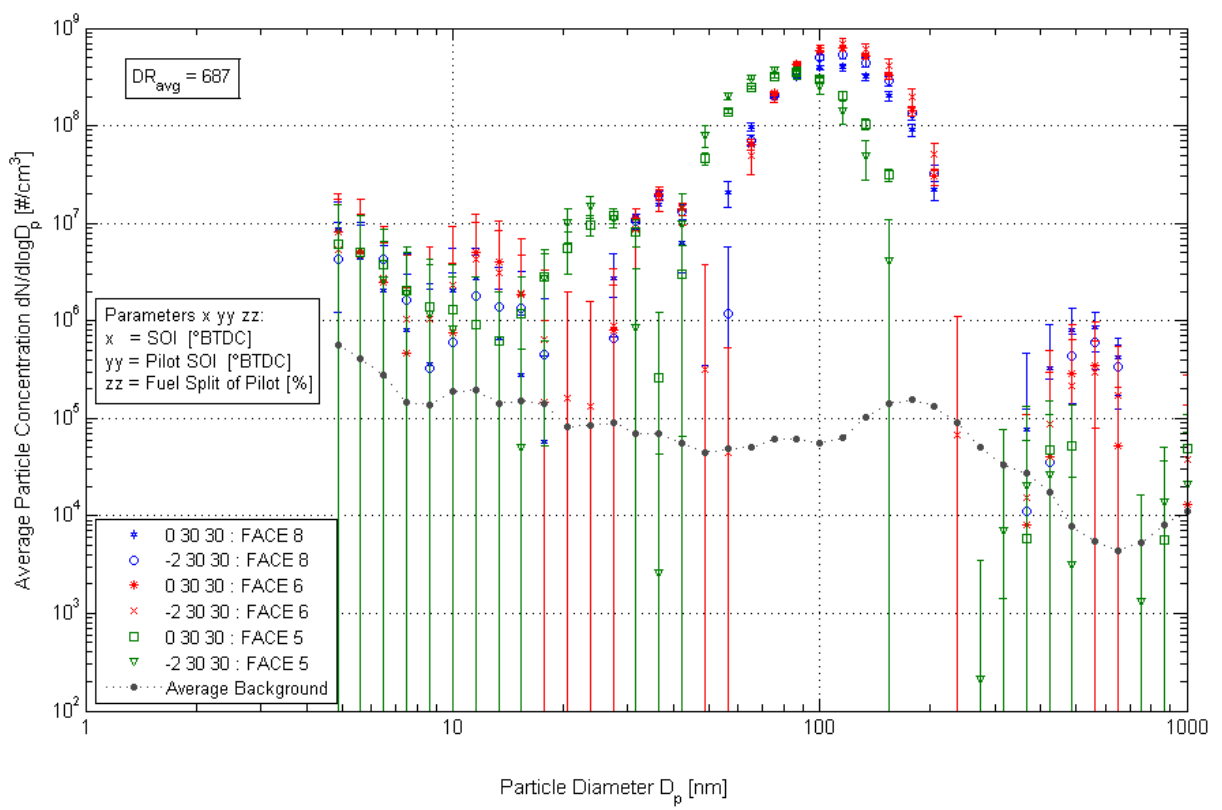

Figure 99 Particle Size Distribution for High Cetane Fuels $($ Error $=1 \sigma)$

Injection Timing Comparison

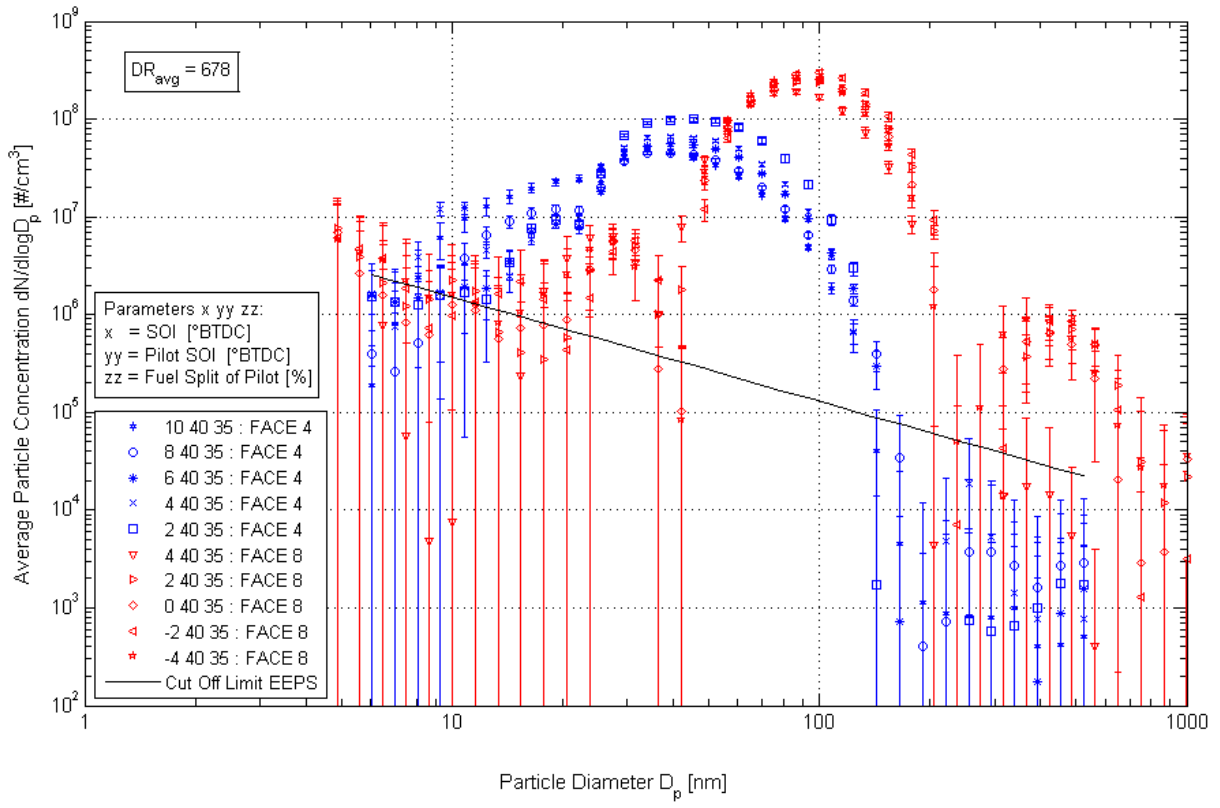

Figure 100 Particle Size Distribution for Low and High CN and Varying SOI Timing (Error $=1 \sigma)$ 


\section{Rail Pressure and Intake Oxygen Concentration during Single Injection}

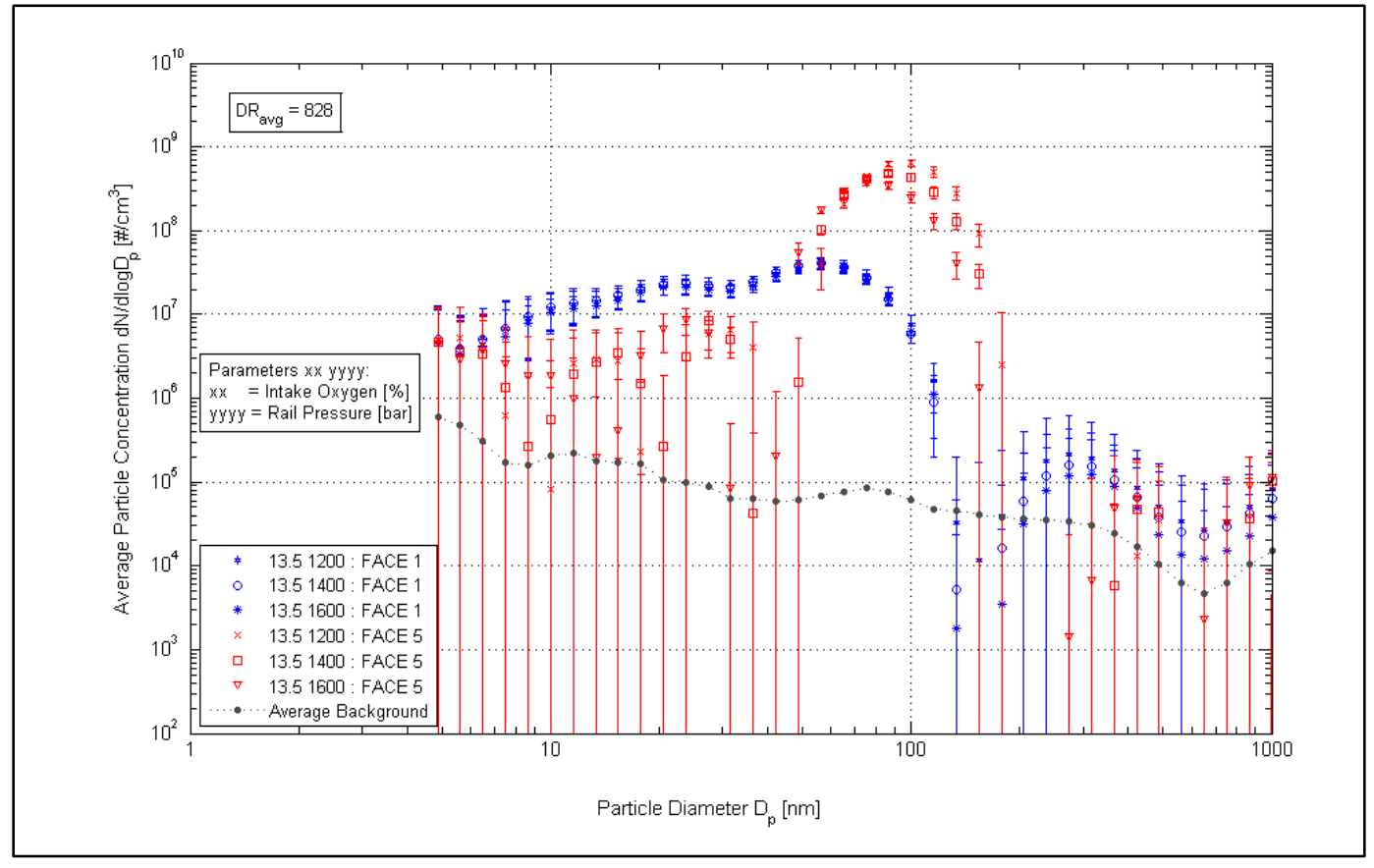

Figure 101 Particle Size Distribution for Low and High CN and Varying Rail Pressure (Error $=1 \sigma$ )

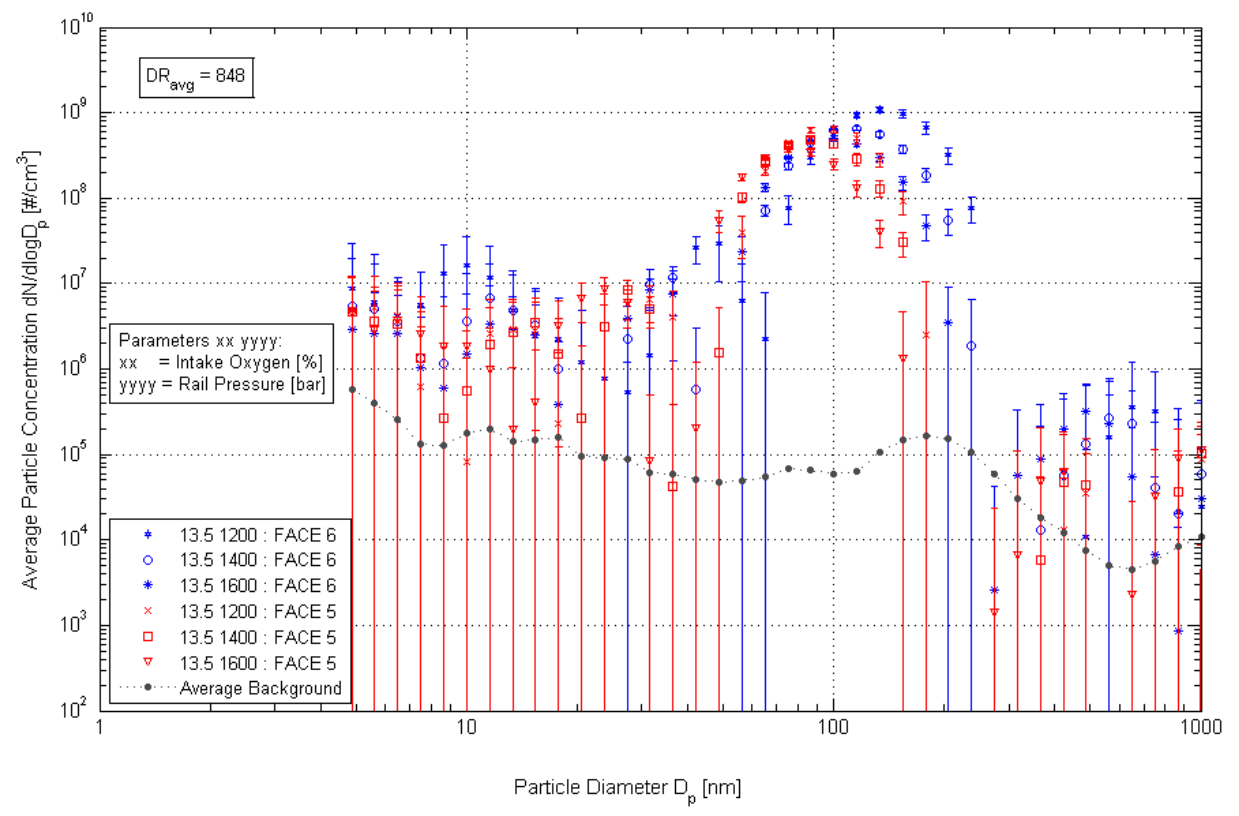

Figure 102 Particle Size Distribution for Low and High T90 and Varying Rail Pressure (Error $=1 \sigma$ ) 


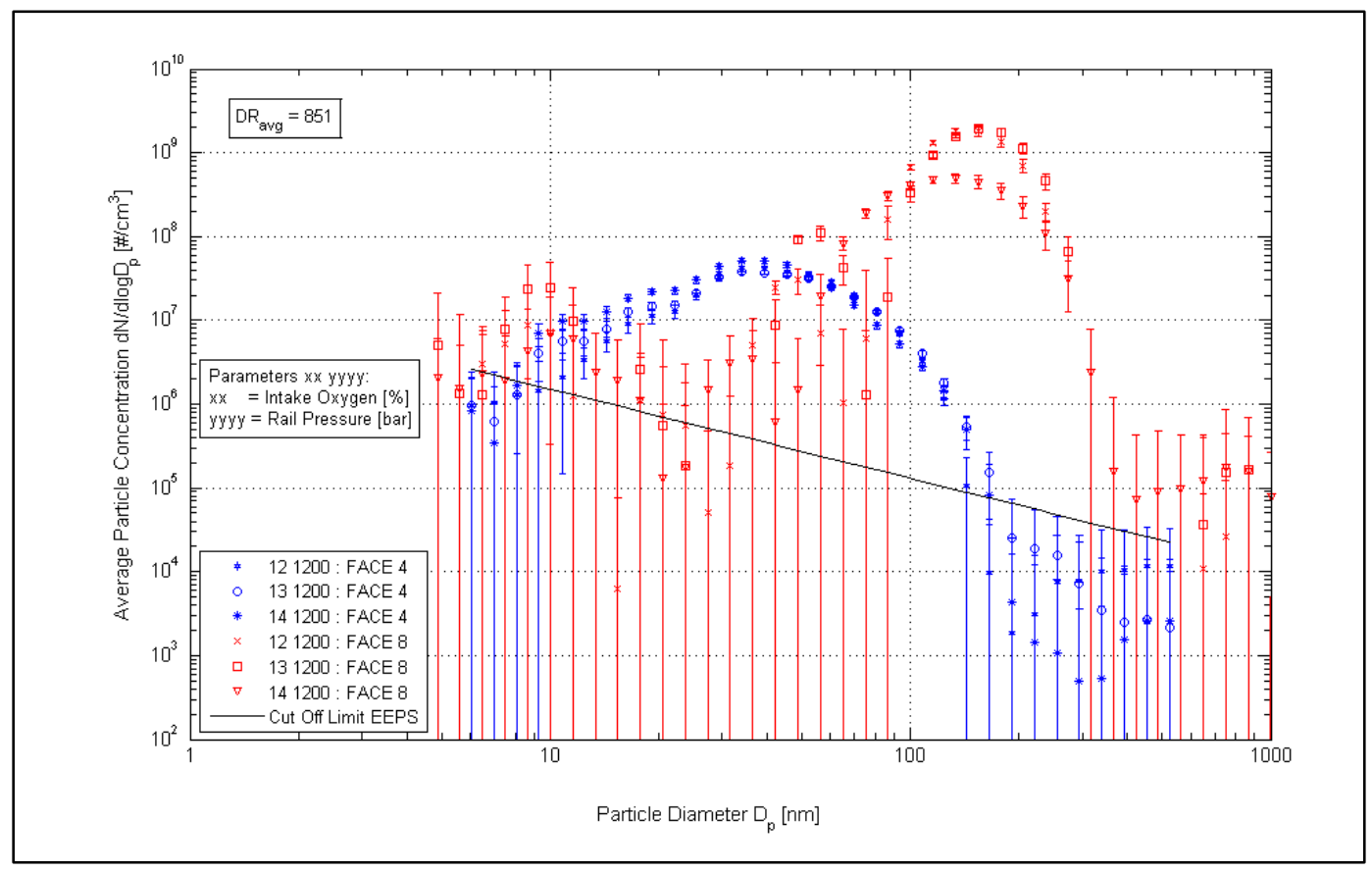

Figure 103 Particle Size Distribution for Low and High $\mathrm{CN}$ and Varying Intake- $\mathrm{O}_{2}($ Error $=1 \sigma)$ 